\title{
ABUSE LIABILITY OF CONTROLLED-RELEASE OXYCODONE FORMULATIONS
}

by

Bijan Rafat

A thesis submitted in conformity with the requirements

for the degree of Master of Science

Department of Pharmaceutical Sciences

University of Toronto

(C) Copyright by Bijan Rafat 2016 


\title{
ABUSE LIABILITY OF CONTROLLED-RLEASE OXYCODONE FORMULATIONS
}

\author{
Bijan Rafat \\ Master of Science \\ Department of Pharmaceutical Sciences \\ University of Toronto
}

2016

\begin{abstract}
Controlled-release opioid formulations may have differential abuse liability profiles related to rates of drug delivery. In this double-blind, placebo-controlled, randomized, crossover study, the abuse liability of a single 40mg intact oral dose of three controlled-release oxycodone formulations (Apo-oxycodone $\mathrm{CR} \AA$, OxyNEO $\AA$, and OxyContin ${ }^{\circledR}$ ) were compared by performing pharmacodynamic and pharmacokinetic analyses in 11 non-dependent recreational opioid users. OxyContin ${ }^{\circledR}$ was not available for 6 participants due to product expiry of discontinued product. Assessments included the primary outcomes of Drug High and Drug Liking ratings, and secondary measures of subjective effects, psychomotor performance, pupillometry and plasma oxycodone concentrations. The longer time to peak plasma concentrations of OxyNEO ${ }^{\circledR}$ compared to Apo-oxycodone $\mathrm{CR} \circledast$ and OxyContin $\AA$ was paralleled by a reduction in the early subjective effects of Drug High post-dose. Overall, the formulations produced comparable positive and negative subjective effects suggesting that they have similar abuse liability profiles when taken intact orally.
\end{abstract}




\section{Acknowledgments}

Throughout my career as a graduate student I have been very fortunate to be surrounded by people who have helped me in any way they could. I am forever grateful to all those people for making this dissertation possible and for their support and patience throughout my graduate experience.

My sincerest gratitude is extended to my supervisor, Dr. Beth Sproule. During this time, she provided me with a balanced academic environment in which I was able to pursue knowledge unreservedly on my own while always having her steadfast support and guidance. She has been amazingly kind and immensely patient with me during this process. She taught me how to question ideas and how to express my knowledge. Her passion for the field of addiction is strong and contagious; under her supervision I have developed a great appreciation and enthusiasm for the field. Further, I am grateful to her for introducing me to a network of caring people with great minds. I am also very grateful for her financial support.

My advisory committee members and the co-investigators in my project have helped me immeasurably. I wish to express my gratitude to Dr. Bruna Brands for her continuous support and motivation. She has helped me tremendously with understanding various aspects of clinical research while her sense of humor made the learning process enjoyable. Her words of wisdom and advice have always been received with great respect. I would also like to thank Dr. Winnie Seto for her guidance at the committee meetings and outside. In addition, I would like to thank Dr. Andrea Furlan for her unwavering support and insightful discussions. Further, I would like to express my gratitude to Dr. Andrew Smith and Keyghobad Farid Araki, for devoting so much

of their time to conduct medical assessments, attend the frequently scheduled study meetings and be on-call on study days.

I am deeply grateful to Josie, the research coordinator, who has been a great friend to me and who has always been there for me to sort out the technical details of my project. I am also very thankful to all the amazing friends I made at CAMH, Vlad, Sakina, Maria, Jill, and Greg, for their empathy and for being there at critical times. Outside of university, I am thankful to all my friends for all the laughs that were much needed at times. 
Last but not least, none of this would have been possible without the love, understanding and the support of my family. I dedicate this dissertation to my immediate family. I love you all. 


\section{Table of Contents}

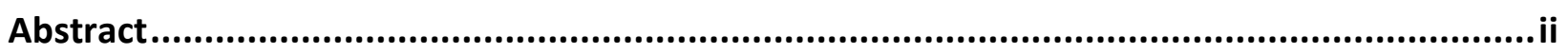

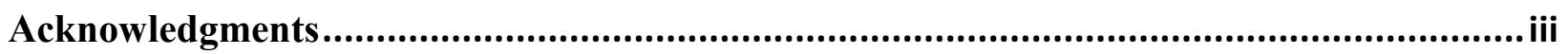

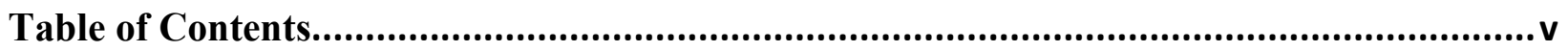

List of Tables

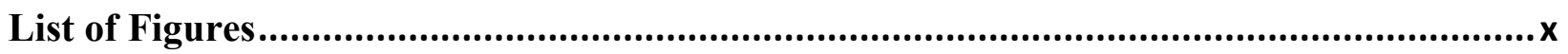

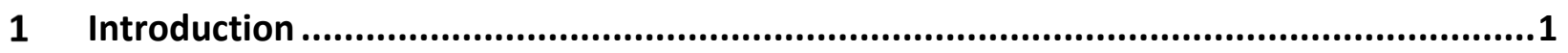

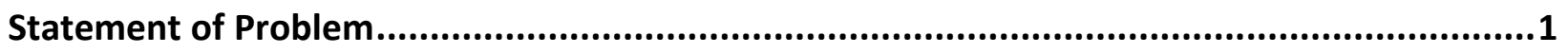

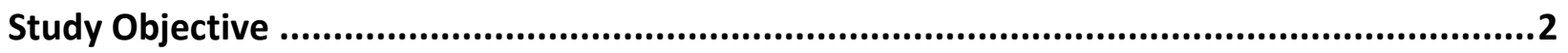

Statement of Research Hypothesis .....................................................................................

Background Information .....................................................................................................

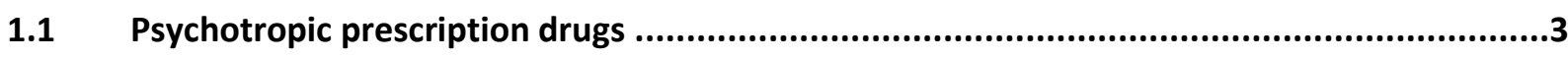

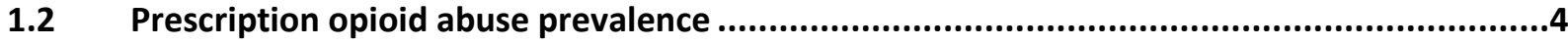

1.3 Definitions: substance abuse, addiction and physical dependence........................................6

$1.4 \quad$ Drug addiction and the reward pathway...........................................................................

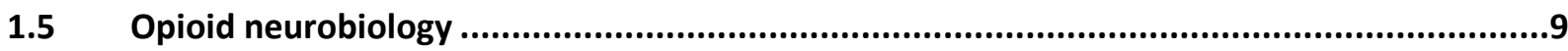

1.6 Prescription opioids - formulations, routes of administration and the associated harms ...10

$1.7 \quad$ Abuse liability of prescription drugs ..................................................................................12

1.8 The role of pharmacokinetics and routes of administration in abuse liability of prescription drugs 13

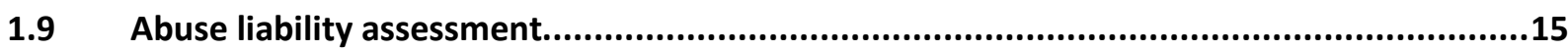

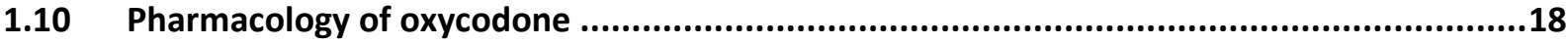

1.11 Controlled-release oxycodone formulations ...............................................................20

1.12 Abuse trends of controlled-release formulations before and after the introduction of the tamper resistant formulation .........................................................................................................22

1.13 Controlled-release oxycodone abuse liability studies .........................................................23

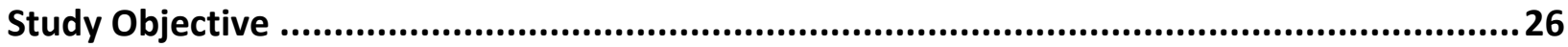


Statement of Research Hypothesis ..........................................................................................26

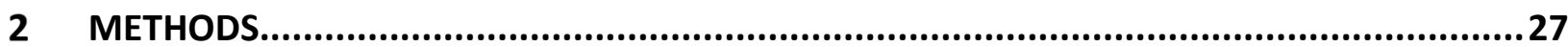

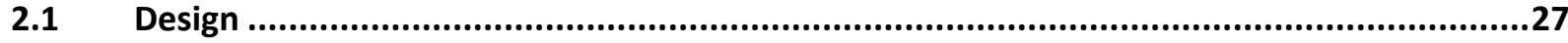

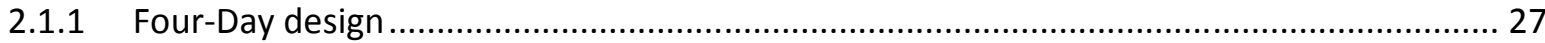

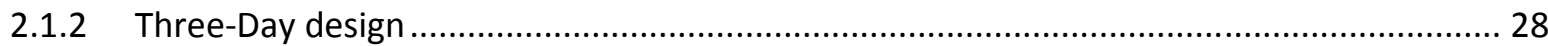

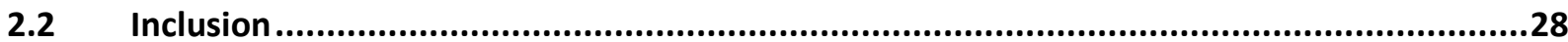

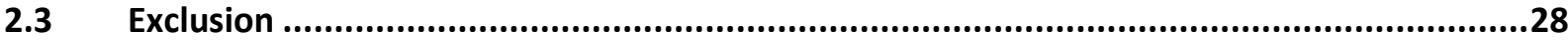

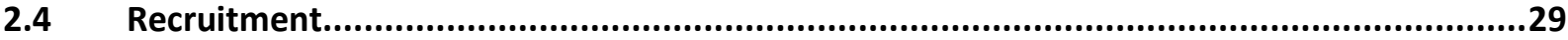

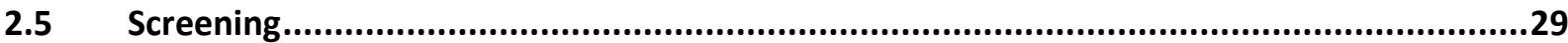

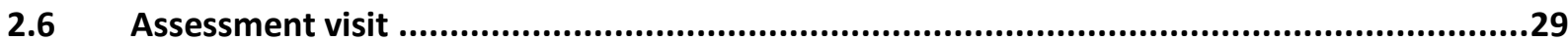

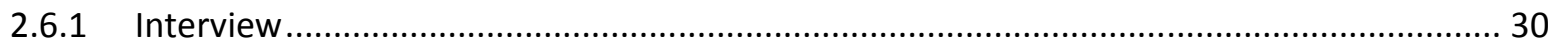

2.6.2 Medical and Neuropsychiatric assessment .................................................................. 30

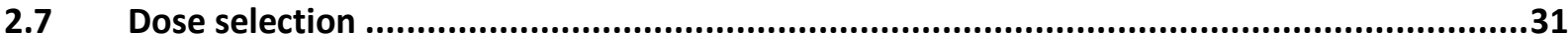

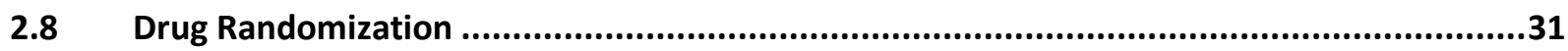

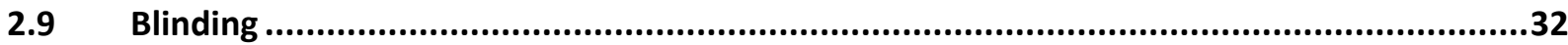

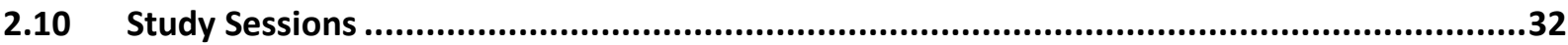

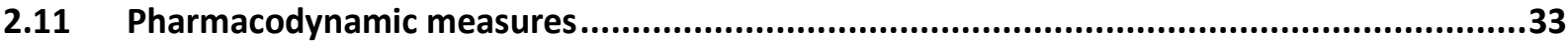

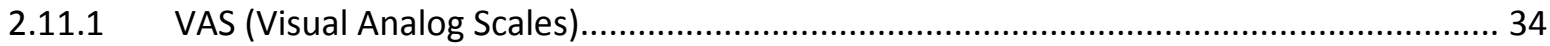

2.11.2 Addiction Research Center Inventory (ARCI) …......................................................... 34

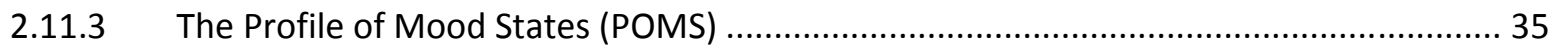

2.11.4 The Digit Symbol Substitution Test (DSST) ….......................................................... 35

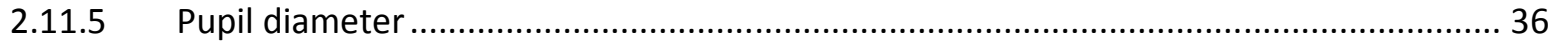

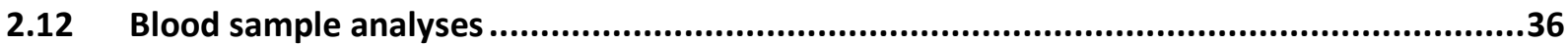

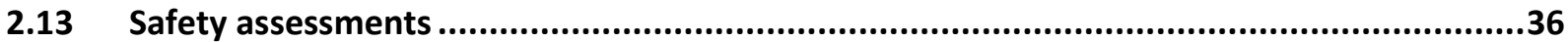

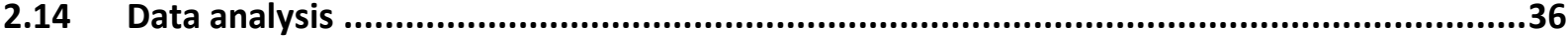

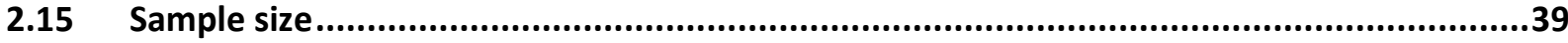

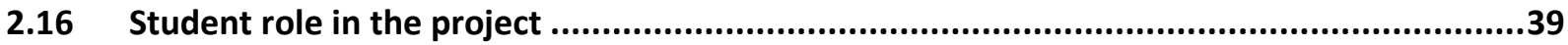

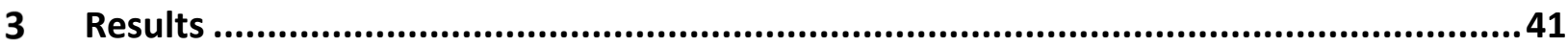

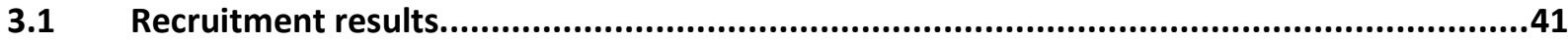

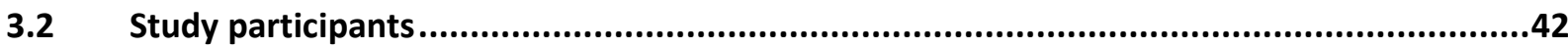

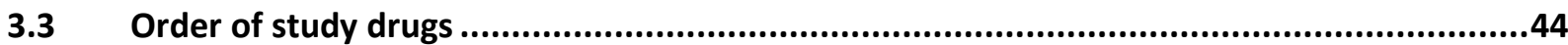

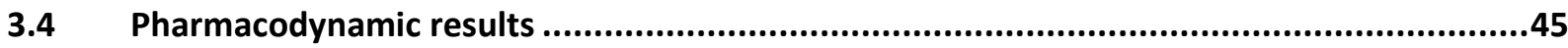




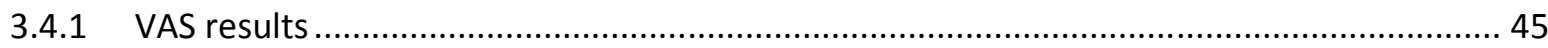

3.4.2 Addiction Research Centre Inventory (ARCI) results [peak (change from baseline to

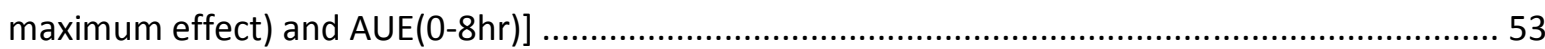

3.4.3 Profile of Mood States (POMS): [peak (change from baseline to maximum effect) and

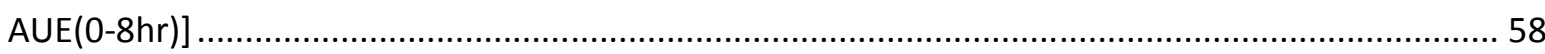

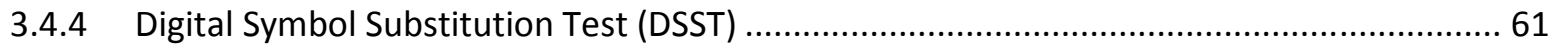

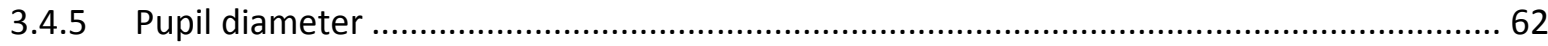

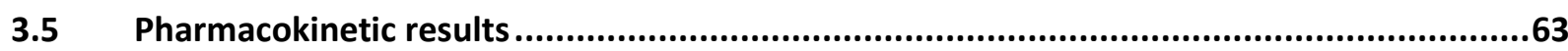

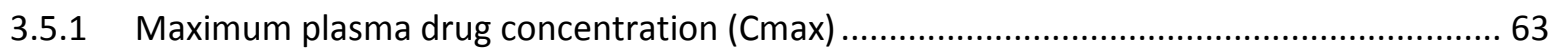

3.5.2 Time to reach maximum plasma drug concentration (Tmax) ….......................................6 63

3.5.3 Area under the plasma drug concentration curve (AUC) of oxycodone ........................... 64

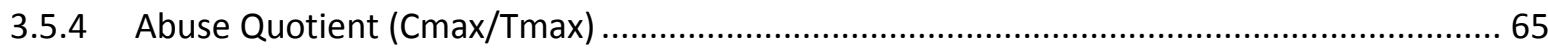

3.5.5 Plasma concentrations of oxycodone and its metabolites over time ................................6 66

3.5.6 Participants with low oxymorphone plasma concentrations ........................................... 68

3.6 Hysteresis in the oxycodone-plasma-concentration-Drug High relationship .......................70

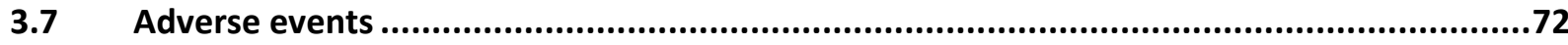

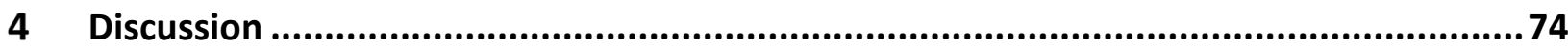

4.1 Analysis of the positive subjective effects and the pharmacokinetic results ......................74

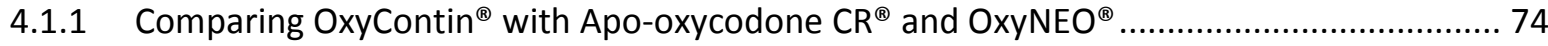

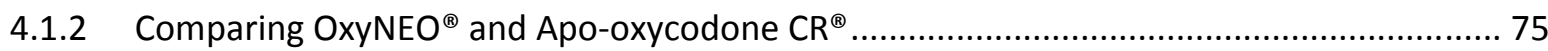

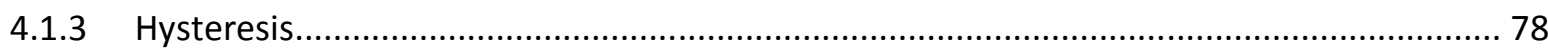

4.1.4 The inconsistent results of AUE for Drug Liking ......................................................... 79

4.1.5 Inconsistencies in the positive subjective effects amongst participants ........................... 79

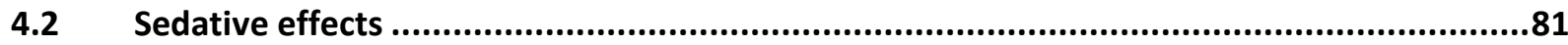

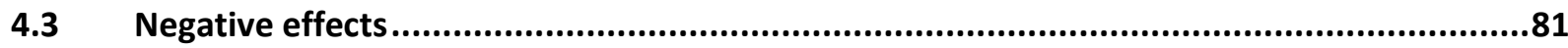

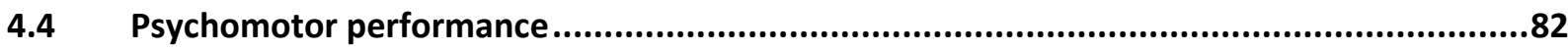

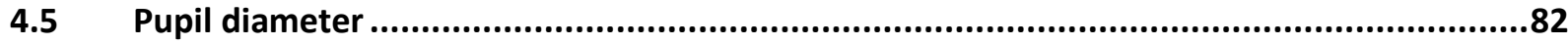

4.6 Plasma concentrations of oxycodone and its metabolites ..............................................83

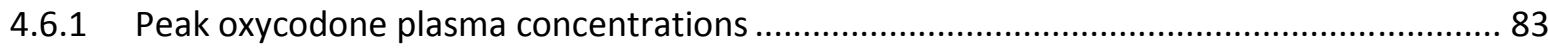

4.6.2 Plasma concentrations of oxycodone metabolites ...................................................... 83

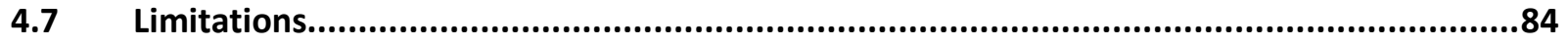

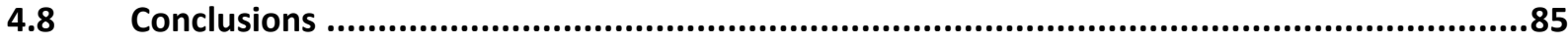

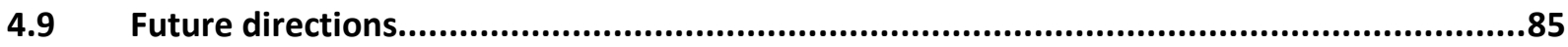




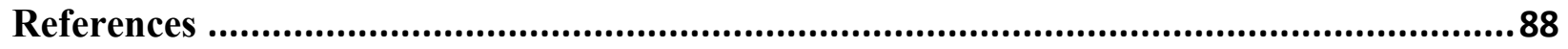

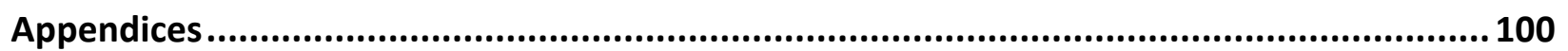




\section{List of Tables}

Table 1. Pharmacokinetic Parameters of controlled-release oxycodone formulations............... 21

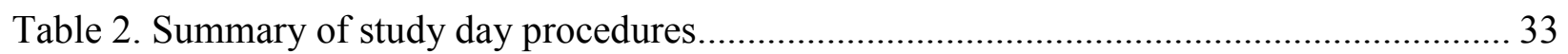

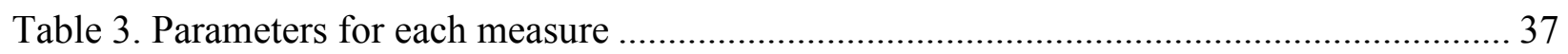

Table 4. Participant characteristics and drug use history................................................ 43

Table 5. Order of drug administration and the number of days between study days ................ 44

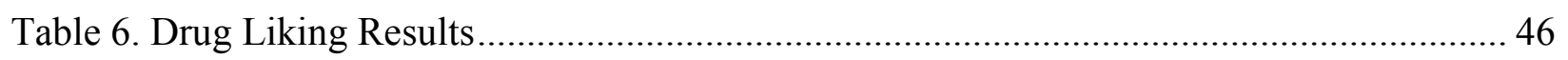

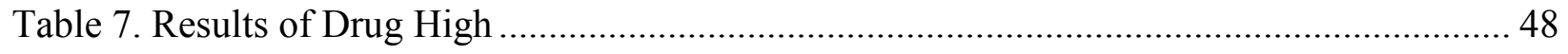

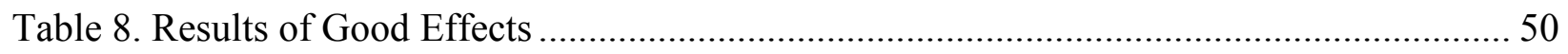

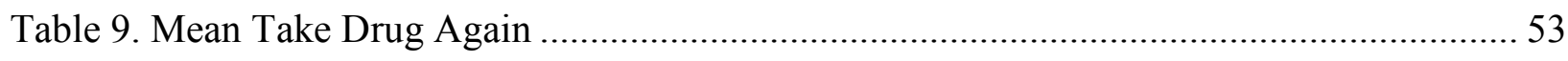

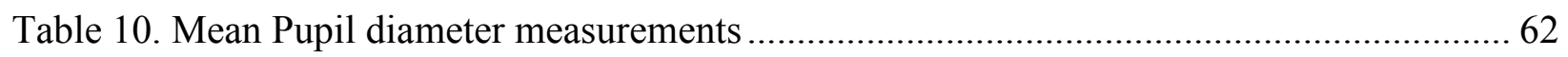

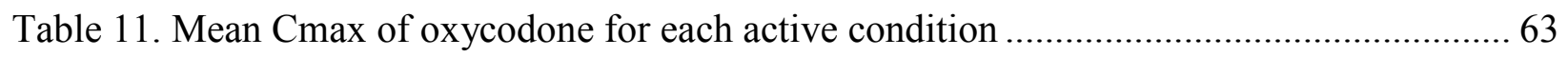

Table 12. Median and range of Tmax of oxycodone for each active condition ........................ 64

Table 13. Mean Abuse Quotient (oxycodone (Cmax/Tmax)) for each active condition............. 66

Table 14. Number of participants showing and/or reporting adverse events to the research nurse (participants reporting more than one instance of each adverse event were only counted once). 73 


\section{List of Figures}

Figure 1. Metabolism of oxycodone (Klimas et al., 2013)

Figure 2. Recruitment chart

Figure 3. Mean peak Drug Liking VAS score $(0=$ dislike intensely; $50=$ neither dislike or like; $100=$ like intensely) for each condition

Figure 4. Mean Drug Liking scores plotted over time for each condition. 46

Figure 5. Mean Drug Liking VAS AUE(0-2hr) (scale: 0-140) and AUE(0-8hr) (scale: 350-470)

Figure 6. Mean peak Drug High VAS scores ( $0=$ absolutely normal; 100 very high) 48

Figure 7. Mean Drug High scores plotted over time for each drug 49

Figure 8. Mean AUE(0-hr) of Drug High VAS

Figure 9. Mean peak of Good Effects (Unipolar VAS) 50

Figure 10. Mean Good Effects scores plotted over time for each condition 51

Figure 11. Mean AUE(0-hr) of Good Effects VAS ......................................................... 52

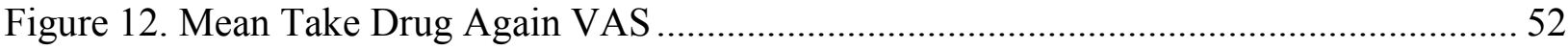

Figure 13. Mean change from baseline to peaks of the MBG subscale for each formulation...... 54

Figure 14. Mean change from baseline to peak of the ARCI subscales for each condition ......... 56

Figure 15. Mean change from baseline to peak for positive and negative composites scales of ARCI for each condition 57

Figure 16. Mean change from baseline to peak of the Fatigue subscale for each condition ........ 58

Figure 17. Mean change from baseline to peak of the Elation subscale for each condition......... 59 
Figure 18. Mean change from baseline to peak of the POMS subscales for each condition 59

Figure 19. Mean change from baseline to peak for POMS Positive and Negative composite scales for each condition

Figure 20. Mean change from baseline to peak for POMS Total Mood Disturbance (TMD) scale for each condition 61

Figure 21. Results of the Digital Symbol Substitution Test (DSST) variables for each condition

Figure 22. Mean pupil diameter response to each condition from 0 to 8 hours 62

Figure 23. Mean peak plasma concentration (Cmax) of oxycodone for each active condition.... 63

Figure 24. Mean oxycodone plasma concentrations for each condition plotted over time 64

Figure 25. Mean AUC of oxycodone for each condition from $0-1 \mathrm{hr}$ to $0-5 \mathrm{hr}$ 65

Figure 26. Mean abuse quotient for each condition with regards to oxycodone plasma concentrations 65

Figure 27. Mean plasma concentration of oxycodone and its metabolites from 0 to 6 hours for OxyContin ${ }^{\circledR}$

Figure 28. Mean plasma concentration of oxycodone and its metabolites from 0 to 6 hours for Apo-oxycodone $\mathrm{CR}^{\circledR}$

Figure 29. Mean plasma concentration of oxycodone and its metabolites from 0 to 6 hours for $\mathrm{OxyNEO}{ }^{\circledR}$

Figure 30. Participant 017-01 Mean plasma concentration of oxycodone and its metabolite concentrations from 0 to 6 hours for OxyContin ${ }^{\circledR}$ 68

Figure 31. Participant 017-01 Mean plasma concentration of oxycodone and its metabolite

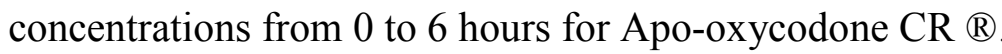


Figure 32. Participant 017-01 - Mean plasma concentration of oxycodone and its metabolite concentrations from 0 to 6 hours for OxyNEO ${ }$.

Figure 33. Participant 061-06 - Mean plasma concentration of oxycodone and its metabolite concentrations from 0 to 6 hours for $\mathrm{OxyNEO}{ }^{\circledR}$

Figure 34. Clockwise hysteresis of oxycodone plasma concentration versus Drug High for OxyContin ${ }^{\circledR}$......

Figure 35. Clockwise hysteresis of oxycodone plasma concentration versus Drug High for Apo-oxycodone $\mathrm{CR} \mathbb{R}$

Figure 36. Clockwise hysteresis of oxycodone plasma concentration versus Drug High for OxyNEO ${ }^{\circ}$ 


\section{Introduction}

\section{Statement of Problem}

Opioids play a major role in managing pain, however, many of them are prone to abuse because of their pleasurable subjective effects. Opioid use may lead to addiction with features of physical dependence, compulsive drug seeking, craving and use despite harmful consequences. Opioid use can also result in acquiring diseases and overdose deaths (White et al, 2005; CDC, 2013). Reports have indicated alarming rates of opioid abuse, toxicity and opioid-related overdose fatality (CDC, 2013).

Oxycodone is a semisynthetic potent opioid that provides relief for moderate to severe pain (Zacny \& Gutirrez, 2003). The original OxyContin®, a controlled-release oxycodone formulation, is known for being abused and having effects similar to heroin (Hays, 2004). An important pharmacological feature contributing to the abuse liability of OxyContin ${ }^{\circledR}$ has been suggested to be its biphasic absorption feature that allowed a rapid exposure to a significant proportion of the dose immediately followed by a more controlled-release of oxycodone when taken intact orally (Webster et al, 2012). Further, OxyContin ${ }^{\circledR}$ could readily be crushed to be snorted and dissolved to be injected for immediate release of the full dose for rapid effects (Comer et al, 2009). The speed of the onset of these subjective effects is associated with drug reinforcement (Sellers, Otton, \& Busto, 1991).

The high abuse rates of OxyContin ${ }^{\circledR}$ led to the introduction of a new controlled-release oxycodone formulation with tamper resistant properties, which replaced the original OxyContin ${ }^{\circledR}($ FDA, 2010). This formulation, known as OxyNEO $®$ in Canada, was introduced in the U.S. in 2010 and in Canada in 2012. OxyNEO ${ }^{\circledR}$ was associated with reduced crushability and dissolvability compared to the original OxyContin ${ }^{\circledR}$ that likely contributed to reducing abuse rates of controlled-release oxycodone formulations (Chilcoat et al., 2012; Cicero \& Ellis, 2015). The pharmacokinetic profile of OxyNEO ${ }^{\circledR}$ suggests that when taken intact orally, it will have a lower abuse liability compared to the original OxyContin ${ }^{\circledR}$ due to longer time to peak plasma concentrations. After the patent expiry of OxyContin ${ }^{\circledR}$ in 2012, generic formulations of OxyContin ${ }^{\circledR}$ were introduced in Canada but were not allowed in the U.S. Apo-Oxycodone CR ${ }^{\circledR}$ 
is a generic formulation and as with OxyContin ${ }^{\circledR}$, it has a biphasic absorption pattern and no tamper resistant properties (Health Canada, 2013, Apo-oxycodone CR $\mathbb{R}, 2012$ ).

As reviewed by Katz et al. (2011), swallowing intact tablets is a common route of abuse of OxyContin ${ }^{\circledR}$. The oral route is the initial route of administration associated with abuse of OxyContin ${ }^{\circledR}$ before progressing to other routes indicating that novice drug users prefer this route (Hays, 2004). Katz et al. (2011) also reported that the most number of deaths due to abuse or misuse of oxycodone formulations (including OxyContin $®$ ) occurred after ingestion. These results highlight the importance of oral administration in the context of abusing OxyContin ${ }$. Further, no published studies have been conducted to date to assess the relative abuse liability of oral intact OxyNEO ${ }^{\circledR}$ and Apo-oxycodone $\mathrm{CR} \circledast$.

\section{Study Objective}

The objective of this study was to assess the relative abuse liability of a single 40mg dose of 3 controlled-release oxycodone formulations (Apo-oxycodone $\mathrm{CR} \circledast$, OxyNEO ${ }^{\circledR}$, and the original OxyContin $($ ) in non-dependent recreational opioid users by performing pharmacodynamic and pharmacokinetic analyses.

Following expiry of the OxyContin ${ }^{\circledR}$ product April 30, 2014, the comparison was made between the remaining 2 products.

\section{Statement of Research Hypothesis}

If the pharmacokinetic Cmax and Tmax results of Apo-oxycodone $\mathrm{CR} \circledast$ was shown to be analogous to that of the original OxyContin ${ }^{\circledR}$, a comparable abuse liability would be anticipated. OxyNEO ${ }^{\circledR}$ is anticipated to have a relatively reduced abuse liability due to having a longer Tmax.

Following expiry of the OxyContin ${ }^{\circledR}$ product April 30, 2014, the hypothesis remains the same for the comparison of the 2 products. A lower abuse liability is anticipated for OxyNEO ${ }^{\circledR}$ compared to Apo-oxycodone $\mathrm{CR} \otimes$ due to its longer time to reach maximum concentrations. 


\section{Background Information}

\subsection{Psychotropic prescription drugs}

Psychotropic prescription drugs may pose risks of abuse and addiction in addition to having therapeutic benefits. Abuse of and addiction to these drugs are associated with increasing the dose, co-administering them with other drugs, changing the route of administration, and/or taking them for their intoxicating effects (Compton \& Volkow, 2006). These drugs act on the same neurotransmitter system and produce similar effects as their illicit drug counterparts (NIDA, 2014; Compton \& Volkow, 2006). Examples of psychotropic prescription drugs that are abused include oxycodone, an opioid that acts on the same system as heroin, methylphenidate, a stimulant that acts on the same system as cocaine, and dextromethorphan, which acts on the same receptors as PCP or ketamine (NIDA, 2014). In addition, the legitimacy of prescription drugs compared with illicit drugs may contribute to users' perception of the associated risks. A study of illicit drug users showed that the perceived risks associated with prescription opioids were diminished because "they came from the doctor" (Daniulaityte, Falck \& Carlson, 2012).

Surveys conducted by Health Canada have reported that the overall rate of psychotropic pharmaceutical drug (opioid pain relievers, stimulants, and sedatives) use among Canadians aged 15 years and older has remained unchanged (not statistically significantly different) from 20112012 -2013 (22-24\%) (CADUMS, 2012; CTADS, 2013). However, from 2011-2013, there was a statistically significant difference in the percentage of users that used them for the feeling they caused, to get high or for "other" reasons - these rates fluctuated from 2011(3.2\%) to $2012(6.3 \%)$ to $2013(2 \%)$. In 2013, $0.3 \%$ and $0.1 \%$ of the Canadian population were using opioid pain relievers and stimulants respectively for the purposes mentioned above. The number of persons using sedatives with those purposes was too few to be reported reliably in the years 2011-2013.

In 2014 , it was estimated that $2.5 \%$ of the U.S. population (equivalent to 6.5 million people) were using prescription drugs without being prescribed or only for the experience or feeling they caused (non-medically) (SAMHSA, 2013). This estimate has remained fairly steady from 20022014 (ranging from $2.4 \%$ to $2.9 \%$ ) although the 2014 estimate has been slightly lower than 2006, 2007, 2009, and 2010 ( $\mathrm{p}<0.05$, ranging from 2.7\% to 2.9\%) (SAMHSA, 2013). In 2013, 22,767 
deaths or about half of drug-overdose-related mortality were attributed to prescription drugs (CDC, 2013). Centers for Disease Control and Prevention (CDC) declared prescription opioidrelated overdose as an epidemic in the U.S. and a major contributor to these deaths (CDC, 2013).

Summary: Prescription drug abuse is prevalent and has contributed to half of drug-overdoserelated mortality in the U.S. Opioids have been known to be a major contributor to these deaths.

\subsection{Prescription opioid abuse prevalence}

Opioids are important therapeutic agents in the treatment of pain; however, their use has the potential to lead to maladaptive patterns of substance use. The opioid family includes drugs such as morphine, codeine, oxycodone, hydromorphone, fentanyl, and hydrocodone. Opioids pose major risk to individuals, in that without medical supervision even one single large dose can induce respiratory depression and cause death (OxyNEO $\left.{ }^{2}, 2013\right)$. Opioid abuse and addiction is harmful to both the user and to society (overdose mortality, infectious-disease transmission, crime) (Fischer \& Stover, 2012). It places an immense economic burden on society by generating direct costs (healthcare requirements and criminal-justice costs) and indirect costs (social security benefits due to unemployment and loss of productivity) (Fischer and Stover, 2012). North America consumes approximately $80 \%$ of the world's opioids [International Narcotics Control Board (INCB), 2013)]. Canada is the second-largest per capita consumer of prescription opioids exceeded only by the U.S. (INCB, 2013). Between 2005 and 2011, total prescription opioid dispensing increased across Canada and this increase was mostly attributed to non-codeine based opioids (Fischer, Jones, \& Rehm, 2014). The rate of increase of opioid dispensing has generally been paralleled by substantive levels of prescription opioid-related morbidity and mortality in Canada and in the US (Fischer \& Argento, 2012).

Epidemiological data regarding opioid related harms in Canada is limited. It was estimated that between 2009 and 2014, some 5000-10000 Canadians died prematurely as a result of prescription opioid-related overdose (Fischer, Gooch, Goldman, Kurdyak, \& Rehm, 2014). In Ontario, from 1991 to 2010 the rate of opioid-related deaths increased by $242 \%$ (Gomes et al., 2014). By 2010, approximately one of every eight deaths (12.1\%) among individuals aged 25-34 in Ontario was opioid-related (Gomes et al., 2014). The opioid related deaths in Ontario have continued to rise from 467 in 2010 to 577 in 2013 (Fischer, Jones, Murphy, Lalomiteanu, \& 
Rehm, 2015). The rise in fatalities from 2010 to 2013 has been attributed to prescription opioids other than oxycodone formulations (Fischer et al, 2015). In fact, during this period there was a decline in oxycodone related deaths (Fischer et al, 2014). Two factors that were attributed to this decline were the delisting of controlled-release oxycodone formulations from provincial drug formulary in 2012 and the intense media coverage of harms associated with OxyContin ${ }^{\circledR}$ from 2010 (Fischer et al, 2014). Despite the decline in oxycodone deaths in this period, $23 \%$ of these deaths in 2013 were related to oxycodone use (CAMH, 2015; Office of the Chief Coroner, 2014). In a 2006 cross-sectional study analyzing opioid prescribing and opioid-related mortality, it was shown that opioid related deaths in Ontario were associated with high frequency opioid prescribing physicians (Dhalla, Mamdani, Gomes, \& Juurlink, 2011). Physicians in the uppermost quintile of the frequency of prescribing opioids wrote the last opioid prescription before death for $62.7 \%$ of public drug plan beneficiaries whose deaths were opioid-related.

According to the Researched Abuse, Diversion, and Addiction- Related Surveillance (RADARS) System, which has gathered information from drug-diversion investigators, poison centers, substance-abuse treatment centers, and college students, in the U.S. from 2002 to 2010 there were large increases in rates of abuse and diversion of opioids (Dart et al., 2015). This increased rate flattened or decreased between 2011 and 2013 (Dart et al., 2015). The rate of opioid-related deaths followed a similar trend (Dart et al., 2015). Reported nonmedical use of opioids did not change significantly among college students (Dart et al., 2015). Of the 22,767 deaths relating to pharmaceutical overdose in 2013, 16,235 (71.3\%) involved opioids, and 6,973 (30.6\%) involved benzodiazepines (CDC, 2015). From 2004 to 2011, medical emergencies associated with pharmaceuticals increased from 0.5 million visits to 1.25 million visits (SAMHSA, 2012). In the same period, opioid related medical emergencies, which rose $183 \%$ or 315,000 more visits, were a major contributor to this increase. The number of oxycodone related medical emergencies were the highest amongst the opioid related medical emergencies with a $263 \%$ increase and over 100,000 more visits.

Summary: Although opioids have important therapeutic effects, they pose many risks to the individual including abuse, addiction, and overdose and burden the society with healthcare and criminal justice costs. Opioid consumption rates have generally paralleled opioid abuse rates. 
Both in the U.S. and in Canada, oxycodone containing products have been shown to be a major contributor to the prevalence of opioid-related harms.

\subsection{Definitions: substance abuse, addiction and physical dependence}

Jaffe (1975) has defined drug addiction as "a behavioral pattern of compulsive drug use, characterized by overwhelming involvement with the use of a drug, the securing of its supply, and a high tendency to relapse after withdrawal [abstinence]." A more recent definition of addiction by the National Institute on Drug abuse may be more exhaustive: "a chronic, relapsing brain disease that is characterized by compulsive drug seeking and use, despite harmful consequences. It is considered a brain disease because drugs change the brain; they change its structure and how it works. These brain changes can be long lasting and can lead to many harmful, often self-destructive, behaviors" (NIDA, 2014). Jaffe (1975) viewed the development of addiction as a behavioral pattern that progresses on a continuum starting from experimental use or circumstantial drug use to casual use, leading to intensive drug use followed by compulsive drug use and ultimately drug addiction. Compulsive use is the common component between the two definitions. Only a small portion of individuals (10-20\%) who use drugs shift from controlled use to compulsive use despite harmful consequences (Volkow, Wang, Fowler, \& Tomasi, 2012). The development of addiction in individuals is strongly influenced by genetic (50\% risk), developmental (higher risk in adolescence than adulthood) and environmental factors (access to drugs, stress) as well as the drug of choice (some drugs lead to addiction faster e.g., methamphetamine versus marijuana) (Volkow \& Li, 2005).

The Diagnostic and Statistical Manual (DSM) is the standard classification of mental disorders in the U.S. DSM has widespread impact on the diagnosis, treatment and investigation of such disorders (Hasin et al., 2013). In DSM-IV, 'dependence' captured the concept of addiction with the hallmark of impaired-control use (Wakefield, 2015). In DSM-5, substance abuse and substance dependence, which had a separate set of criteria in DSM-IV, are combined into a single disorder named Substance Use Disorder (Wakefield, 2015). DSM-5 defines Substance Use Disorder as a maladaptive pattern of substance use leading to clinically significant impairment or distress with presence of at least 2 out of 11 criteria (American Psychiatric Association, 2013). The criteria are clustered in four groups: impaired control, social impairment, risky use, and pharmacologic dependence (American Psychiatric Association, 
2013). The severity of the disorder is gauged based on the number of criteria with qualifiers of mild, moderate, and severe (American Psychiatric Association, 2013). The "recurrent substancerelated legal problems" has been removed from the previous version and "craving, or a strong desire or urge to use the substance" is the newly added criterion in DSM-5 (Wakefield, 2015).

According to DSM, physiological dependence occurs when symptoms of either tolerance or withdrawal are present (American Psychiatric Association, 2013). DSM defines tolerance as a need for markedly increased amounts of the substance to achieve intoxication or desired effect or the markedly diminished effect with continued use of the same amount of the substance. Withdrawal is defined as a manifestation of the characteristic withdrawal syndrome for the substance or use of the same (or a closely related) substance taken to relieve or avoid withdrawal symptoms (American Psychiatric Association, 2013). In DSM-5, physical dependence in terms of prescription drugs is distinguished from substance use disorder by noting that the tolerance and withdrawal criteria are not considered as criteria for those individuals taking the drug solely under medical supervision (American Psychiatric Association, 2013). Physical dependence can be a normal physiological adaptation to drug action, which may result from drug abuse as well as during a treatment such as treatment for pain (Vanyukov et al., 2012).

When pain patients are treated with opioids, physical dependence can occur but addiction only occurs in some patients (Portenoy \& Savage, 1997). Repeated use of opioids will usually but not always generate tolerance (Wise \& Koob, 2014). In this condition, the user will need to continually increase doses to maintain initial drug effectiveness and any abrupt abstinence can result in unpleasant withdrawal symptoms (Wise \& Koob, 2014). Maintenance of drug intake to avoid such symptoms has traditionally been known to be the reason behind opioid addiction (Wise \& Koob, 2014). However, this theory cannot explain the habit that initially established physical dependence nor can it provide reasons for the relapse of addicted individuals who have been detoxified (Wise \& Koob, 2014).

The definitions and criteria of 'substance abuse' involve the pattern of use (i.e. continued use) of substance despite the harmful consequences, the intention behind use (i.e. the experience or the feeling), and/or the way of obtaining the drug (only relevant to psychotropic prescription drugs). The DSM-IV-TR criteria for substance abuse did not involve the intention behind abuse but 
rather the continuation of use despite the consequences (i.e. failure to fulfill major work or home obligations). NIDA defines drug abuse as the inappropriate use of drugs (prescription or not) including repeated use to produce pleasure, alleviate stress, and/or alter or avoid reality. In the context of psychotropic prescription drugs, NIDA defines abuse as the use in ways other than prescribed or using someone else's prescription. The definition of psychotropic prescription drug abuse by the Canadian Tobacco, Alcohol, and Drug Survey (using for the experience, the feeling it causes, to get high or for "other" reasons) is in terms of the intention behind use (i.e. for the experience) (CTADS, 2013). A more comprehensive definition of prescription drug abuse is the "use that is associated with increased risk for harm, as characterized by obtaining the drugs from illegitimate sources, or risky patterns of use (excluding under-use) that deviate from accepted medical practice and/or scientific knowledge, or taking the drugs for purposes which are not therapeutic" (Health Canada, 2007). The components of this definition that was developed during a workshop, were meant to be incorporated into all of the subsequent national surveys. The fact that there are several ways of defining prescription drug abuse shows that there is a lack of consensus amongst the experts.

Summary: Drug addiction is a complex brain disorder that can lead to structural changes in the brain and behavioral changes associated with drug taking, and it is influenced by genetic and environmental factors. Physical dependence is a natural adaptation of the body to a drug with features of tolerance and withdrawal. There is no consensus regarding the definition of prescription drug abuse.

\subsection{Drug addiction and the reward pathway}

Drugs of abuse exert their initial reinforcing effects by activating the mesolimbic pathway, which includes dopamine-containing neurons. Dopaminergic neurons in the ventral tegmental area (VTA) (neurons that synthesize dopamine), a midbrain region, project to the nucleus accumbens (NAc) (Niehaus, Cruz-Bermudez, \& Kauer, 2009). The release of dopamine in the NAc is required for the rewarding effects of natural stimuli such as food and mating opportunities (Niehaus et al., 2009). Similarly, the reinforcing effects of drugs of abuse are associated with the large increases in the extracellular dopamine in the limbic regions (including the NAc) (Di Chiara and Imperato, 1988; Koob and Bloom, 1988; Volkow, Fowler, Baler, \& Telang, 2009). Two ventral striatal pathways, indirect and direct pathways, modulate reward and motivation 
(Volkow \& Morales, 2015). The surge of dopamine mediates reward directly by stimulation of the dopamine receptors (D1) in the direct pathway (Hikida et al., 2010; Kravitz et al., 2012). The stimulation of the dopamine receptors (D2) in the indirect pathway mediates reward by countering aversive responses via inhibition of this pathway. In addition to immediate responses to drug administration, neuroplastic changes occur upon chronic drug administration (Niehaus et al., 2009). These neuroplastic changes in the brain are manifested in addicted individuals' behaviors such as compulsive use. As reviewed by Everitt et al. (2008) and Volkow and Baler (2014), compulsive drug use may result as a consequence of downregulation of D2 receptors in the striatum upon chronic drug exposure. This downregulation leads to reductions in inhibition of the indirect pathway, which leads to reduced activity in prefrontal cortex. The reduced activity in prefrontal cortex is associated with compulsive behaviors as this area of the brain is involved in self-control (Volkow \& Folwer, 2000).

Summary: The neurobiology of drug abuse and addiction can be described in terms of temporary and structural changes (neuroplastic changes) in the brain. These include changes in the production of the dopamine and the upregulation and downregulation of dopamine receptors in the dopamine pathway.

\subsection{Opioid neurobiology}

The interaction of opioids with opioid receptors present in the central nervous system (CNS) and the peripheral nervous system leads to the various subjective effects including euphoria and analgesia. The opioid receptor subtypes include Mu, Delta, Kappa, and Opioid Receptor Like-1 (ORL-1), with ORL-1 being the least characterized one (Al-Hasani \& Bruchas, 2011). Opioid receptors are a group of inhibitory G-protein-coupled receptors and the binding of opioid receptor agonists activate the G-proteins, which leads to signaling cascades that ultimately result in subjective effects (Al-Hasani \& Bruchas, 2011). Mu receptors, which are an opioid receptor subtype, are predominantly found in the brainstem and medial thalamus (Reviewed in Trescot, Datta, Lee, \& Hansen, 2007). Their stimulation can result in supraspinal analgesia, respiratory depression, euphoria, sedation, decreased gastrointestinal motility, and physical dependence (Reviewed in Trescot et al., 2007). The kappa subtype is mainly present in the limbic and diencephalic regions, brainstem and spinal cord and are responsible for analgesia, sedation, dyspnea, psychomimetic effects, miosis, respiratory depression, euphoria, dysphoria, dyspnea 
(Reviewed in Trescot et al., 2007). The delta receptors, which are mainly located in the brain, are involved in producing analgesia while their other effects are not as well studied (Reviewed in Trescot et al., 2007).

When the opioid receptors located on the presynaptic terminals of the nociceptive C-fibers and A-delta fibers are activated by an opioid agonist, a signaling cascade is triggered that leads to the blockade of the release of pain neurotransmitters glutamate, substance P, and calcitonin generelated peptite from the nociceptive fibers, resulting in analgesia (McCleane \& Smith, 2007). When the opioid receptors on the GABAergic cells in the ventral tegmental area (VTA) are activated, the GABAergic interneurons selectively get hyperpolarized resulting in the disinhibition of the VTA dopaminergic neurons and increasing dopamine release in the nucleus accumbens and medial prefrontal cortex producing the rewarding effects (Dilts and Kalivas, 1989; Johnson and North, 1992; Svingos, Colago, \& Pickel, 1999; Di Chiara and Imperato, 1988).

Summary: The interaction of opioids with opioid receptors present in the central nervous system (CNS) and the peripheral nervous system leads to myriad of downstream effects including the known rewarding effects and analgesia.

\subsection{Prescription opioids - formulations, routes of administration and the associated harms}

Opioid pharmaceutical products are manufactured in different formulations. Each formulation has its own unique pharmacology which may influence the way they are abused i.e. route of administration (Kirsh, Peppin, \& Coleman, 2012). Immediate-release and controlled-release formulations products are known to be abused and because of their contrasting pharmacological characteristics, comparing them can demonstrate pharmacological factors contributing to abuse. Advantages of controlled-release opioid formulations over immediate-release formulations for therapeutic purposes include more convenient dosing and fewer peak-trough plasma concentration fluctuations, thus providing more stable drug plasma concentrations that may lead to a sustained and better pain control; and improved sleep without interruption (Wilsey, Fishman, Storment, \& Albanese, 2009). Controlled-release opioid formulations were originally thought to have a reduced abuse liability due to the slower onset of rewarding psychotropic effects 
compared to immediate-release formulations (Wilsey et al., 2009). However, availability of larger dose per tablet of the controlled-release formulations compared with the immediaterelease formulations may have increased the abuse liability of the former (Sloan \& Babul, 2006). In addition, users have found ways to achieve similar psychotropic effects from controlledrelease formulations to immediate-release formulations by tampering with them or increasing the dose (Sellers et al., 2013).

The controlled-release delivery mechanism of tablets can be destroyed via tampering. Tampering means crushing/chewing tablets (for oral or intranasal administration) or solubilizing them (for intravenous administration) in order to allow for a faster absorption and delivery of the drugs to the brain (Roset et al., 2001; Budman, Grimes, \& Butler, 2009). Faster delivery to the brain is associated with increased reinforcement and greater abuse liability of the drug (Farre \& Cami, 1991). For most drugs, including opioids, the ranking of routes of administration based on the speed of delivery to the brain from fastest to slowest are inhalation (i.e. smoking), intravenous, intranasal, and oral (Oldendorf, 1992). The oral route is associated with the slowest absorption because it will subject the drugs to first-pass hepatic metabolism before entering the systemic circulation. It is important to note that opioids are generally absorbed through all routes of administration (Budman et al., 2009). The most common routes of administration of opioids associated with abuse are the oral and the intranasal route (reviewed in Katz et al., 2011). The prevalence of the route of choice depends on the population being surveyed as it can vary with the experience of the user with opioids, the type of opioid used, whether the user is from an urban or a rural area, the source of the prescription opioid, and the age of the user (Young, Havens, \& Leukefeld, 2010; reviewed in Katz et al., 2011).

Tampering with opioid products prior to ingestion and administering them via routes other than the oral route may lead to acute toxicity from exposure to supratherapeutic doses which can in turn cause overdose and in some cases, death (Brushwood et al., 2012). However, oral administration has been associated with the most deaths, likely due to the prevalence of the oral route and due to the fact that it is the preferred route for novices (reviewed in Katz et al., 2011). The most dangerous route is the intravenous route because the number of deaths per use is higher than other routes likely due to the associated immediate absorption that can lead to overdose (reviewed in Katz et al., 2011). The non-oral routes have been associated with contracting 
diseases such as Acquired Immune Deficiency Syndrome (AIDS) and hepatitis C (White et al., 2005). It is likely that due to these communicable diseases and the desire to avoid "track marks" there is a higher prevalence of intranasal and oral administration of prescription opioids than injection (Comer et al., 2009).

Harms associated with opioids have led pharmaceutical companies to develop abuse-deterrent formulations: those with more than one active ingredient that act either as an agonist or antagonist to counter the euphoric effects of the opioid if injected; those that consist of an aversive agent limiting use of higher doses; pro-drug formulations that require chemical changes within the body before becoming active rendering injection routes less effective; and tamperresistant formulations that are resistant to crushing and dissolving because of the presence of physical barriers that make extraction of the active ingredient challenging (Raffa \& Pergolizzi, 2010).

Summary: Two important methods of abusing controlled-release opioids are increasing the dose and tampering with them before administration. Applying these methods may lead to toxicity, overdose and death. The reports of common routes of administration associated with abuse are the oral and the intranasal route. Preference for a route depends on the users' experience, environment, and the drug of choice.

\subsection{Abuse liability of prescription drugs}

The abuse liability of drugs is associated with the potential for harmful outcomes including addiction, overdose or toxicity (Schoedel \& Sellers, 2008). Raffa, Pergolizzi Jr, Muniz, Taylor, and Pergolizzi (2012) defined the abuse liability of a drug as the degree to which repeated use would occur due its positive subjective effects, reinforcing effects or negative effects. This definition encompasses the outcome measures used in abuse liability assessments in laboratories i.e. subjective effects, reinforcing effects, and negative effects. A drug that is shown to have an abuse liability based on these assessments may be abused in the real world (IMMPACT, 2015). Conversely, a drug that shows no sign of abuse in these assessments is very unlikely to be abused in the real world (IMMPACT, 2015). 
Each formulation of the same generic drug may have a distinct abuse liability depending on its mechanism of drug delivery and the ease of which it can be tampered with (Balster \& Walsh, 2013). The presence of an aversive agent in a formulation or the availability of a large dose in a controlled-release formulation can affect desirability and attractiveness of a drug (Carter and Griffiths, 2009; Fudala \& Johnson, 2006). The abuse potential of a drug may be influenced by factors other than its pharmacological properties (i.e. intrinsic abuse liability). Drug availability (i.e. internet can play an important role in increasing abuse of drugs by allowing access from online sources without a prescription) (Formen, 2003), ease of diversion and economic factors such as the price of a drug may affect its demand and in turn influence the price and the demand for an alternative drug (Carter and Griffiths, 2009). Cultural and social factors such as association of a drug with a particular activity (i.e. sex) may also influence the abuse of a drug (Inciardi et al., 2007).

Summary: Abuse liability of a drug is the degree to which its repeated use would occur depending on its positive and negative subjective effects and it is associated with addiction, overdose and toxicity. A drug's abuse potential can be influenced by its pharmacology, availability, price, demand as well as cultural and social factors.

\subsection{The role of pharmacokinetics and routes of administration in abuse liability of prescription drugs}

Understanding the subjective effects produced by drugs as a function of their pharmacokinetic profile can explain why users prefer certain formulations, routes of administrations and dosages. Rapid delivery of the drug into the brain allows for a rapid onset of subjective drug effects associated with drug reinforcement (Sellers, Otton, \& Busto, 1991). The speed of the onset of positive subjective effects has been generally understood to be associated with higher abuse liability of the drug. This is evident in behavioral patterns of drug abusers such as discovering various routes of administration or choosing the formulations that are absorbed faster (Sellers et al., 1991). The time to onset of effects depends on the release rate, the route of administration and the distribution kinetics at the site of action (Farre and Cami, 1991). However, after entering the plasma, the psychotropic drug needs to enter the brain to produce relevant subjective effects. To enter the brain, the active drug needs to cross the blood brain barrier (BBB) and factors such as molecular size, polarity and $\mathrm{pH}$ and more importantly lipophilicity affect early concentrations 
in the brain (Farre \& Cami, 1991). Crossing the BBB and reaching the site of action in the central nervous system (CNS) may introduce a lag between peripheral concentrations and central pharmacodynamic effects known as hysteresis (Lotsch, 2005).

Volkow and Swanson (2003) have demonstrated that dose and time to reach peak concentrations (Tmax) play an important role in the rate of rise in dopamine levels in the brain. Further, they showed that the rapid increase in the dopamine levels was significantly correlated with subjective effects of 'high'. Assuming that bioavailability does not change in response to dose, the absorption rate (rate of rise), Cmax (peak plasma drug concentration) and area under the drug plasma concentration curve (AUC) will increase with dose (Mansbach and Moore, 2005). Consequently, the pharmacokinetic parameters of Cmax and Tmax have been included in some abuse liability studies to evaluate their influence on subjective effects. The following studies examined the influence of Tmax, Cmax (or dose) and different routes of administration on positive subjective effects.

Mumford, Evans, Fleishaker, and Griffiths (1995) indicated that an immediate release formulation of alprazolam produced greater positive subjective effects than its controlled-release formulation of the same dose. In a methylphenidate study, it was shown that the positive subjective responses were more transient for the controlled-release formulation compared with the responses for immediate-release formulation of the same dose, which varied as function of dose and time (Kollins, Rush, Pazzaglia, \& Ali 1998). In the above studies, Tmax is likely to have influenced the ratings of positive subjective effects, as the doses were kept constant between the formulations. In order to account for the influence of Tmax without interference from Cmax, it may be necessary to examine studies that include comparators with similar Cmax and different Tmax. De Wit, Bodker, and Ambre (1992) investigated the onset of effects by comparing those of one high dose $(150 \mathrm{mg})$ of sodium pentobarbital administered once with several doses of low dose (180mg) sodium barbital administered every half an hour. Despite reaching similar peak plasma concentrations, the administration of one high dose of sodium pentobarbital produced increased positive subjective effects compared to when low doses were administered incrementally. De Wit, Dudish, and Ambre (1993) studied the abuse liability of diazepam by using a similar design as De Wit et al. (1992) and obtained comparable results. 
Dose-dependent increases in positive subjective effects have been shown in many drugs with various routes of administration including intranasal and oral methylphenidate and cocaine, intravenous morphine as well as oral controlled-release hydromorphone (Stoops, Lile, Fillmore, Glaser \& Rush, 2005 Kollins et al., 1998; Smith, Jones, \& Griffiths, 2001; Marsch, Bickel, \& Badger, 2001; Shram et al., 2010). Also, some studies have shown that increase in Cmax may override the influence of Tmax on positive subjective effects. In a study of hydromorphone formulations, a $64 \mathrm{mg}$ dose of controlled-release hydromorphone produced similar subjective effects as an 8mg dose of the immediate release formulation (Shram et al., 2010). In this study, the peak plasma concentrations were similar between these two comparators while the Tmax were much longer for the controlled-release formulation ( $1 \mathrm{hr}$ versus $24 \mathrm{hrs}$ ).

The effect of the pharmacokinetic profile of drugs on the immediacy of effects can also be evaluated by comparing various routes of administration. Singh, Jain, Ray, and Gupta (2001) demonstrated that intravenous diazepam had a higher abuse liability than oral diazepam as it produced more rapid and greater positive subjective effects. However, Reissig, Harrison, Carter, and Griffiths (2015) showed that inhaled alprazolam only modestly increased positive subjective effects compared with those effects produced by oral alprazolam even though the time of the onset of effects was much more rapid in the former route. These results indicate that although typically some routes are associated with faster absorption and faster onset of effects, there are other factors that influence the magnitude of the subjective effects when comparing routes i.e. the type of drug.

Summary: The delivery mechanism of a drug, dose and the associated route of administration can be expressed in the context of pharmacokinetics by parameters such as Cmax and Tmax, which are factors influencing the timing of the onset of effects and the intensity of the effects.

\subsection{Abuse liability assessment}

Assessments of a drug's abuse liability are performed in both human and non-human subjects. These tests provide necessary information for drug development, regulatory processes, and clinical practice (Carter \& Griffiths, 2009). Drug self-administration and drug discrimination are important assessment methods that have been used in both human and non-human subjects whereas studying the subjective effects in response to drugs can only be conducted in humans 
(Carter \& Griffiths, 2009). Self-administration of drugs is an operant response reinforced by the effects of the drug (Panlilio \& Goldberg, 2007). In these experiments, drugs of abuse, which serve as reinforcers, show increased self-administration when compared to saline or vehicle (Carter \& Griffiths, 2009). Drug discrimination methods provide information about the pharmacological action of a drug (Carter \& Griffiths, 2009). Their design is mostly focused on measuring a stimulus similarity between the test drug and a known standard drug (Preston, 1991). If the drugs share discriminative stimulus effects, it is likely that they have a similar pharmacological mechanism of action and similar reinforcing effects (Schuster \& Johanson, 1988). Methods using human subjects have limitations compared to non-human subjects such as the willingness of the volunteers to spend time, the cost associated with enrolling humans, ethical issues with regards to the drug being administered and the proper oversight required for human subjects (Carter \& Griffiths, 2009). Unlike using subjective effects measures, procedures of human drug self-administration and drug discrimination have not been used for regulatory purposes likely because these procedures are not as efficient, have not been validated to the same degree, and are not as easy to design and conduct (Carter \& Griffiths, 2010; Comer et al., 2012).

For the measures of subjective effects, the general assumption is that drugs of abuse induce changes in the users' subjective state and the users' self-reports on these changes can be used to predict the likelihood that the drug will be used excessively and non-medically (Fischman \& Foltin, 1991). Subjective effects are integral to abuse liability assessments given their association with the dopaminergic system and good concordance with the behavioral component of drug taking (Volkow \& Swanson, 2003; Comer et al., 2008). These studies are typically conducted by comparing the test drug to a drug in the same class with a known abuse liability as well as placebo (Comer et al., 2012). It is recommended that supratherapeutic doses be used as it increases the probability of detecting the effects (Comer et al., 2012; Schoedel \& Sellers, 2008). Further, the drugs are to be tested in non-dependent recreational abusers because they are familiar with the effects and are not expecting therapeutic benefits (Comer et al., 2012; Schoedel and Sellers, 2008).

Both positive and negative subjective effects are used in these assessments, as a drug that produces both positive and negative subjective effects is likely to have a lower abuse liability than a drug with only positive subjective effects (Comer et al., 2012). Visual Analogue Scale 
(VAS) measured ratings of drug liking, drug high and good effects have been recommended by the "Initiative on Methods, Measurement, and Pain Assessment in Clinical Trials"(IMMPACT) group to be core primary outcome measures in opioid analgesic abuse liability assessment studies (Comer et al., 2012). This group has also indicated that Drug liking is a very sensitive and reliable measure of the likelihood of abuse of a drug; most abuse liability assessment experts agree that the subjective rating of drug liking is probably the single most informative outcome measure (Carter \& Griffiths, 2009; Griffiths, Bigelow \& Ator, 2003; McColl and Sellers, 2006). The global evaluations such as VAS measures of "take drug again" and "overall drug liking" are used after drug effects have mostly or completely dissipated (Griffith et al., 2003; Harris et al., 2013). These retrospective measures have the advantage of assessing the overall drug experience, or what is remembered from the experience under relatively or completely sober conditions; thus they may provide valuable information about the likelihood of re-administration of the drug under such conditions (Griffith et al., 2013). A recent study that aimed to evaluate the association between subjective effects of opioids and real world data showed significant associations between reduction in "overall drug liking" and reduced real-world nonmedical use of different opioids formulations, healthcare utilization, and costs (White et al., 2015).

The Addiction Research Centre Inventory (ARCI) is another questionnaire that has been used in abuse liability studies to assess subjective effects. The ARCI was developed in 1958 by studying individuals who were addicted to opioids under various-drug and no-drug conditions (Haertzen, Hill \& Belleville, 1958; Haertzen, Hill \& Belleville, 1963). It includes subscales which have been empirically derived and are sensitive to various drug classes i.e. Morphine Benzedrine Group scale (MBG) to detect opioid and amphetamine effects (Haertzen et al., 1963). The Profile of Mood States (McNair, 1971) is a commonly used mood scale that assesses momentary mood states. It is known to be sensitive to stimulants and sedatives in light drug users or nondrug users (Foltin \& Fischman, 1991, De wit \& Griffiths, 1991). Unlike ARCI, it does not have a scale that can be used to predict the likeability of a future self-administration of a substance (Fischman \& Foltin, 1991).

Other supplementary measures used in abuse liability studies of opioids include pupil diameter, and cognitive and psychomotor performance (Comer et al., 2012). Respiration rate and oxygen saturation are normally measured as part of the safety assessment. Pupil diameter serves as a 
sensitive objective endpoint that confirms opioid-related physiological effects as opioids cause pupil constriction (Bigelow, 1991; Comer et al., 2012). It has also been used as a pharmacodynamic measure of opioids to compare potency. The pattern of pupillary response has not been shown to be consistently associated with analgesic potency and subjective response and it is generally used as a secondary endpoint in abuse liability studies (Babalonis, Lofwall, Nuzzo, \& Walsh, 2014; Schoedel et al., 2010; Comer et al., 2013, Shram et al., 2015, Shram et al., 2014;

Setnik et al., 2012). Evaluating cognitive and psychomotor performance are secondary measures that can provide information about drugs' adverse effects associated with psychomotor speed, coordination and memory (Carter \& Griffiths, 2009).

Summary: Abuse liability assessments include those applied in animals and humans. A more practical and efficient assessment method in humans is the evaluation of self-reported subjective effects such as positive and negative effects. VAS Drug Liking and Drug High are recommended primary outcome measures in abuse liability assessments.

\subsection{Pharmacology of oxycodone}

Oxycodone (6-deoxy-7,8- dihydro-14-hydroxy-3-O-methyl-6-oxomorphine) is a potent, semisynthetic, opioid agonist that provides effective relief for moderate-to-severe pain and has been in clinical use since 1915 (Falk, 1917; Zacny \& Gutirrez, 2003). Oxycodone has agonist activity on the mu, kappa, and delta receptors (Ordonez, Gallego, \& Baron, 2007). Evidence suggests that the analgesic activity of oxycodone is primarily mediated by the kappa receptors and/or mu receptors (Lorenzini, Daali, Dayer, \& Desemeules, 2012; Klimas, Witticke, Fallah, \& Mikus, 2013; Ross and Smith, 1997; Staahl et al., 2008).

Biotransformation of oxycodone occurs in the liver (Lamberg, Hei et al., 2009). Oxycodone is metabolized to noroxycodone by Cytochrome P450 3A4 (CYP34A) mediated N-demethylation, to oxymorphone by Cytochrome P450 2D6 (CYP2D6) O-demethylation, and to oxycodol by reduction (Lalovic et al., 2006; Lemberg, Heiskanen, Kontinen, \& Kalso, 2009). The metabolite noroxycodone is subsequently metabolized to noroxymorphone by CYP2D6 mediated Odemethylation and to noroxycodol by reduction (Lalovic et al., 2006; Lemberg et al., 2009). The metabolite oxymorphone is further metabolized to noroxymorphone by CYP3A/CYP2D6 mediated N-demethylation and to oxymorphol by reduction (Lalovic et al., 2006; Lemberg et al., 
2006). Oxycodone, as a parent compound has been shown to be the major contributor to the central opioid effects such as pupil constriction and subjective effects (Lalovic et al., 2006; Kaiko et al., 1995). This notion is further substantiated by experimental results that have shown that oxycodone metabolites cannot cross the BBB to the same extent (all metabolites), are present at a lower concentrations in the circulation (noroxymorphone, oxymorphone, oxymorphone and alpha- and beta-oxycodol), and/or have a lower binding affinity for mu receptors compared to the parent compound (noroxoycodone, beta-noroxycodol) (Lalovic et al., 2006; Klimas et al., 2013).

Figure 1. Metabolism of oxycodone (Klimas et al., 2013)

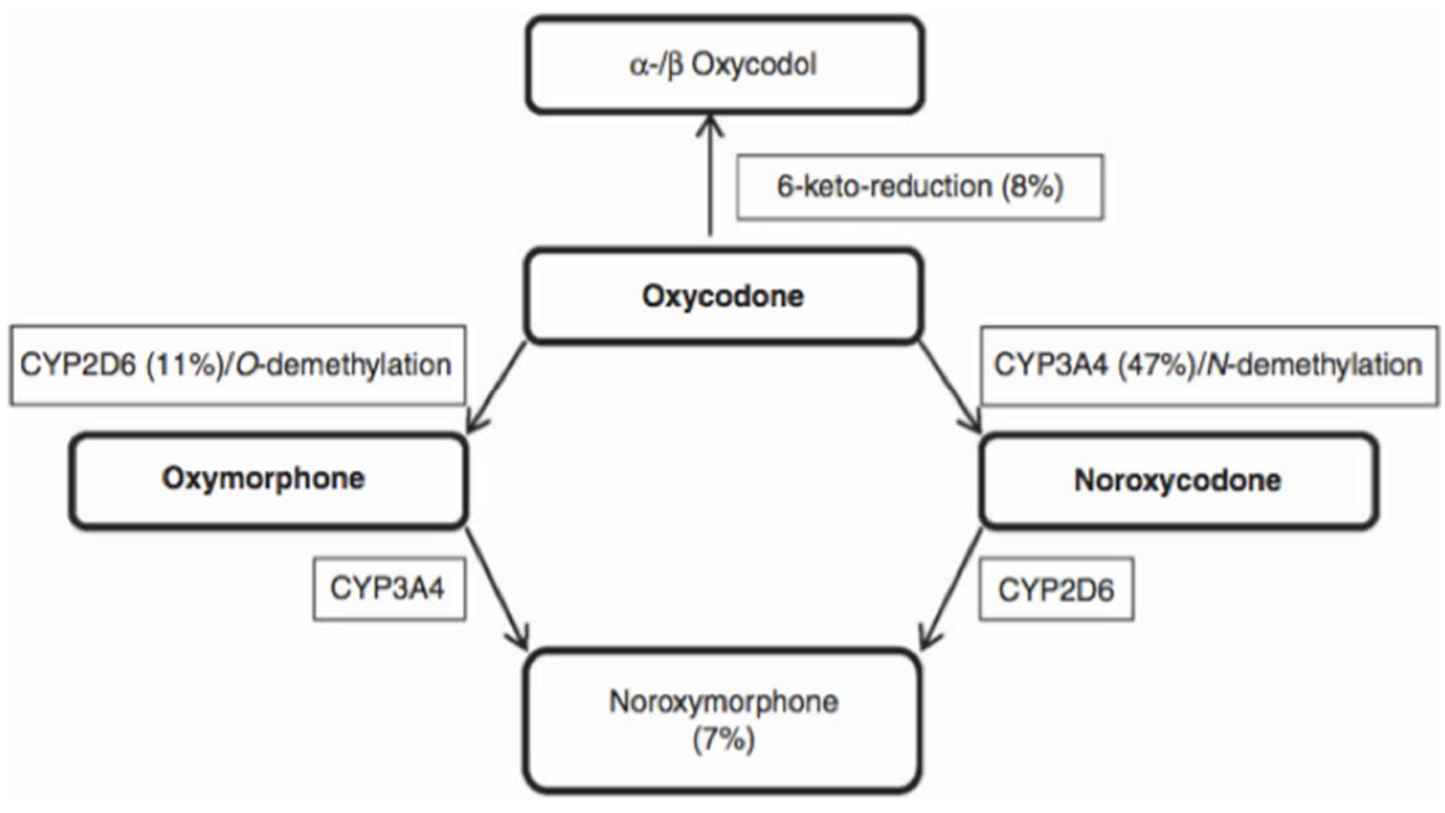

Oxycodone is a weak base with liposolubility and serum protein binding similar to those of morphine (38-48\%) (Leow, Watt, Williams, \& Cramond, 1992; Coluzzi \& Mattia, 2005). Oxycodone is well absorbed when orally administered and has a higher bioavailability than morphine. In humans, $50 \%$ to $87 \%$ of an oral dose of oxycodone reaches the central compartment compared to a parenteral dose (Poyhia et al., 1992). Oxycodone's increased bioavailability compared to morphine can be explained by its 3- methoxy substituent (group $\mathrm{CH} 3$ at position 3), which prevents it from undergoing complete glucuronidation (only about $3 \%$ is 
glucoronidated) unlike morphine that does undergo this metabolic pathway (Yee et al., 2012; Poyhia et al., 1992).

Summary: Oxycodone's analgesia has been attributed to its activity on mu and kappa receptors. Evidence suggests that oxycodone, as the parent compound, is mainly responsible for its pharmacodynamic effects compared to its metabolites. It is well absorbed orally and has higher bioavailability than morphine.

\subsection{Controlled-release oxycodone formulations}

Oxycodone first became available in fixed combination with acetaminophen, acetylsalicylic acid, or nonsteroidal anti-inflammatory drugs (NSAIDs) (Colluzi and Mattia, 2005). For decades it was classified as a "weak" opioid for mild and moderate pain with comparable indications to codeine (Colluzi and Mattia, 2005). In 1996, oxycodone in an immediate-release formulation became available as a single-entity product (Zacny and Guertez, 2003). Controlled-release oxycodone (OxyContin ${ }^{\circledR}$ ) was introduced in 1996 in Canada and in the United States (FDA, 2008; Lexchin and Kohler, 2011). Because of the escalations in the abuse rates of oxycodone, in 2010 and 2012 the abuse deterrent controlled-release formulations were introduced in the US and in Canada, respectively (Butler et al., 2012; Fletcher \& Tsuyuki, 2013), and the first abuse deterrent immediate release formulation was introduced in the US in 2011 (FDA, 2011). These new formulations feature tamper resistant properties such as forming a gel when mixed with water to make intravenous administration difficult and resistance to crushing to make intranasal administration difficult.

OxyContin ${ }^{\circledR}$ is a controlled-release form of oxycodone hydrochloride, which was designed to provide delivery of oxycodone over a 12-hour period (Griffin \& Miller, 2011). The original formulation of OxyContin ${ }^{\circledR}$ was available in higher doses than other oxycodone formulations, had a biphasic absorption pattern that could lead to an initial immediate-release of more than $30 \%$ of the oxycodone dose, and the full dose could be accessed via tampering with the tablets (Mandema, Kaiko, Oshlack, Reder, \& Stanski, 1996; Setnik, Roland, Cleveland, \& Webster, 2011). These pharmacological features contributed to the enhancement of its euphoric effects and its abuse (Setnik, et al., 2011). OxyContin ${ }^{\circledR}$ could be readily tampered with and 
administration of the tampered form could lead to a rapid release and absorption that could result in a fatal overdose (Health Canada, 2011).

In Canada, after the patent expiration of OxyContin ${ }^{\circledR}$ in November 2012, generic formulations of this formulation were introduced into the market whereas they were banned in the U.S. (Health Canada, 2013). Apo-Oxycodone CR ${ }^{\circledR}$ was one of the generic formulations introduced. This formulation is not tamper-resistant and has biphasic absorption, and thus, it could potentially present the same problems as the original formulation (Apo-oxycodone $C R \circledast, 2012$ ).

The tamper-resistant reformulation of oxycodone is bioequivalent to the original formulation and replaced the original formulation (OxyNEO $\left.{ }^{\circledR}, 2013\right)$. The reformulation was introduced in Canada under the trade name OxyNEO ${ }^{\circledR}$ and in the US under OxyContin ${ }^{\circledR}$ (same name as the original formulation) (Fletcher \& Tsuyuki, 2013). Evidence from a combination of drug monographs and literature suggest that oxycodone plasma concentrations, after the oral intact administration of $\mathrm{OxyNEO}{ }^{\circledR}$, may take a longer time to reach peak plasma concentrations (Tmax) compared to Apo-oxycodone $\mathrm{CR} \AA$ and OxyContin ${ }^{\circledR}$, while the latter two formulations appear to have similar Tmax (See Table 1) (Apo-oxycodone CR®, 2012; OxyNEhO®, 2014; Purdue study, 2012; Webster et al., 2012).

Table 1. Pharmacokinetic Parameters of controlled-release oxycodone formulations

\begin{tabular}{|l|c|c|}
\hline & Tmax (hours) & Cmax (ng/ml) \\
\hline OxyContin ${ }^{\circledR} 40 \mathrm{mg}^{*}$ & Median: 2.5 (range: 0.75-5) & $40.5 \pm 10.7 \mathrm{SD}$ \\
\hline Apo-oxycodone CR ${ }^{\circledR} 40 \mathrm{mg}^{* *}$ & Median: 3 (range: 1-6) & $45(\mathrm{CV} \% 24.5)$ \\
\hline OxyNEO® 40mg* & Median: 4.5 (range: 3-8) & $42.6 \pm 11.7 \mathrm{SD}$ \\
\hline
\end{tabular}

*Purdue study (2012)

**Apo-oxycodone CR ${ }^{\circledR}$ (2012)

Summary: The original OxyContin ${ }^{\circledR}$ and Apo-oxycodone CR ${ }^{\circledR}$ (generic version of OxyContin $($ ) have a biphasic absorption, are not tamper resistant, and have a numerically similar Tmax. Such properties have been attributed to OxyContin ${ }^{\circledR}$ abuse and can present the 
same problems for generic formulations. OxyNEO® is a reformulated tamper resistant controlled-release oxycodone formulation that has tamper resistant properties and has a numerically longer Tmax compared to the other two formulations.

\subsection{Abuse trends of controlled-release formulations before and after the introduction of the tamper resistant formulation}

In the studies investigating abuse of the original OxyContin ${ }^{\circledR}$ prior to the arrival of the reformulated tamper resistant product, it was shown that the preferred routes were predominantly oral and intranasal and in one study it was reported that the abusers preferred ingesting intact tablet versus chewed (Carise et al., 2007; Hays, Kirsh, \& Passik, 2003; Katz, Fernandez, Chang, Benoit, \& Butler, 2008). A study of 579 OxyContin addicted individuals showed that users tended to begin with the oral route and progress to snorting and injecting (Hays, 2004).

Studies have indicated reduced abuse and diversion rates of controlled-release oxycodone after the introduction of the reformulated OxyContin ${ }^{\circledR}$ (Chilcoat et al., 2012; Iwanicki et al., 2015; Butler et al., 2012; Cicero \& Ellis, 2015). Evidence suggests that after the introduction of the reformulated OxyContin ${ }^{\circledR}$, the reduction in abuse via the oral route may not have been as much impacted as abuse via the intranasal route and in some cases users have even transitioned from other routes to the oral route (Havens et al., 2014; Butler et al., 2012; Cicero and Ellis, 2015; Brown et al., 2012). The tamper resistant properties of reformulated OxyContin ${ }^{\circledR}$ have led to the discovery of new tampering recipes, which may explain why this formulation is still being abused via tampering (McNaughton et al., 2014). Unfortunately, most of these studies did not indicate whether the tablets are tampered with prior to ingestion or swallowed intact. Although the new formulation appears to have contributed to reduced tampering and abuse rates of controlled-release oxycodone, some studies suggest that the introduction of the tamper resistant formulation has led many users to transition to other opioids including the more harmful illicit opioids such as heroin (Cicero et al., 2012; Cassidy et al., 2014; Coplan et al., 2013; Cicero and Ellis, 2015). However, it is important to note that a study by Dart et al. (2015) indicated that the trend in heroin use started before the introduction of the reformulated OxyContin ${ }^{\circledR}$.

The introduction of the reformulated OxyContin ${ }^{\circledR}$ forced some chronic pain patients (those who were using the original OxyContin ${ }^{\circledR}$ ) to switch to either the reformulated product or to other 
prescription opioids (Michna, Kirson, Shei, Burnbaum, \& Ben-Joseph, 2014). According to studies by (Michna et al., 2014) and Argoff, Stanos, Wieman, (2013), many chronic pain patients prefer the original OxyContin ${ }^{\circledR}$ to the reformulated OxyContin ${ }^{\circledR}$. In the Argoff et al. (2013) study, it was reported that a common objection of the patients after being switched to the reformulated OxyContin ${ }^{\circledR}$ was that they cannot feel it working. The authors suggested that this may have meant that they are experiencing less positive subjective effects due to the less rapid initial absorption and that the objection may not have been due to reduced analgesic efficacy. In the Michna et al. (2014) study, it was shown that the rates of diagnosed opioid abuse were higher amongst patients that avoided switching to the reformulated OxyContin ${ }^{\circledR}$ after its introduction compared to those that did make the switch.

Summary: Oral route of administration (both intact and non-intact) has been reported to be a common route and the initial route of abuse of controlled-release oxycodone. Most studies that have surveyed routes of administration associated with abuse have not distinguished between oral intact and oral crushed/chewed routes of administration. The introduction of the reformulated OxyContin ${ }^{\circledR}$ may have had more impact on the reduction of abuse via non-oral routes versus oral routes, and has generally been correlated with increase in abuse of other opioids. Some chronic pain patients prefer the original OxyContin ${ }^{\circledR}$ to the reformulated OxyContin ${ }^{\circledR}$. One possible reason for this is that they want to continue experiencing the positive subjective effects associated with the original formulation.

\subsection{Controlled-release oxycodone abuse liability studies}

There are five published studies that compare the abuse liability of controlled-release oxycodone formulations to one another or to other oxycodone formulations. To assess the relative abuse liability of these formulations, Webster et al. (2012), Setnik et al. (2012) Harris et al. (2013), and Morton et al. (2014) included positive subjective effects as their primary outcome measures whereas Perrino et al. (2013) only looked at the pharmacokinetic parameters and adverse reactions.

Webster et al. (2012) compared the abuse liability of four different oral oxycodone formulations: intact and crushed $40 \mathrm{mg}$ original OxyContin ${ }^{\circledR}$, intact $80 \mathrm{mg}$ original OxyContin ${ }^{\circledR}$, and intact $40 \mathrm{mg}$ immediate release formulation in recreational opioid users. They showed that crushing or 
increasing (in this case doubling) the dose of OxyContin ${ }^{\circledR}$ increased the associated positive subjective effects to match those of the immediate release formulation. This was also reported in another study (Setnik et al., 2012) in recreational opioid users, in which crushed 40mg OxyContin ${ }^{\circledR}$ produced similar positive subjective ratings to $20 \mathrm{mg}$ of the intact immediaterelease formulation. In the Webster et al. (2012) study, Cmax and fluctuation of AUC in the first hour following drug administration were shown to be associated with the positive subjective effects across treatments. The authors attributed the abuse liability of the formulations to be a function of both time and plasma drug concentrations and not just the concentration parameter alone. In two other unpublished studies of intranasal and oral oxycodone formulations, the contribution of plasma concentration and time to peak was highlighted by showing a correlation between positive subjective effects and the suggested pharmacokinetic parameter of abuse quotient (Cmax/Tmax) (Webster et al., 2009; Shram et al., 2011). The abuse quotient increases as Cmax increases and as Tmax decreases hence it complies with the notion that increased dose and a more rapid increase in plasma drug concentrations is associated with an increase in the ratings of positive subjective effects.

Interestingly, crushing may not always increase positive subjective effects. In a study conducted by Morton et al. (2014) in recreational opioid users, crushing a new controlled-release oxycodone formulation (Xartemis XR, a tamper resistant formulation that contains immediaterelease (IR) and controlled-release (CR) layer that utilize a biphasic mechanism) delayed the onset of effects compared to its intact version. As well, crushing an oxycodone IR formulation (Percocet) was associated with lower positive subjective effects at certain time points compared to its intact version. In the case of Xartemis XR, the authors explained that its two layers (IR and CR layer) mixed into one monophasic "ER debris" after crushing, which resulted in the delayed effects. In the case of Percocet, the authors hypothesized that the formulation's crushed encapsulation may have attenuated the associated effects. They also explained that the fact that the participants were not administering the drugs in their usual conditions (i.e. using their own paraphernalia and using their own method of crushing) was a limitation. The authors did not attribute any of the effects to acetaminophen (an active ingredient in Xatermis and Percocet). In this study, increasing dose was associated with increased positive subjective effects with both Percocet and Xartemis XR (15mg oxycodone compared with 30mg oxycodone in each formulation). 
The only two published studies that have compared the abuse liability of the original OxyContin ${ }^{\circledR}$ and the reformulated OxyContin ${ }^{\circledR}$ are intranasal studies (Perrino et al., 2013; Harris et al., 2013). In these studies, the participants [with a history of opioid abuse/misuse in Perrino et al. (2013) and nonmedical use of opioids in Harris et al. (2013)], were asked to snort crushed tablets. Together, the studies showed that the original OxyContin ${ }^{\circledR}$ produced relatively greater positive subjective effects, less negative effects (less nasal discomfort) and had a greater abuse quotient (a shorter Tmax and a greater Cmax) compared to the reformulated product. Thus, the original formulation was associated with a greater abuse liability compared to the reformulated OxyContin ${ }^{\circledR}$.

Summary: Controlled-release formulations have been known to be crushed in order to increase the speed of delivery of the drug and thereby the speed of the onset of effects. Hence, it is not surprising that across these abuse liability studies of controlled-release oxycodone formulations, the crushed product was compared with intact products in the oral studies and expectedly, in the intranasal studies, different crushed products were compared with one another. Crushing (apart from the Xartemis XR study) and increasing the dose were associated with increased abuse liability. The reformulated OxyContin ${ }^{\circledR}$ was associated with a reduced abuse liability in the intranasal studies compared to the original formulation.

Gaps: Only two of these studies (Webster et al., 2012 and Perrino et al., 2013) included pharmacokinetic analysis and positive subjective effects combined. Including pharmacokinetic analysis in abuse liability studies has utility because of its objective nature and the recognized associations between pharmacokinetic data and the positive subjective effects. Assessing the abuse liability of these drugs in non-healthy participants (i.e. chronic pain patients) or in healthy non-drug abusers was not investigated. The comparisons made in these studies did not cover all the relevant routes of administration. For example, none of the studies compared the abuse liability of the original OxyContin ${ }^{\circledR}$ with reformulated OxyContin ${ }^{\circledR}$ administered intact orally. In addition, the studies did not assess the abuse liability of generic controlled-release oxycodone formulations, which are available in the Canadian and not in the U.S. market (e.g. Apooxycodone $C R \circledR$ is a generic formulation that has been available since Nov, 2012). 


\section{Study Objective}

The objective of this study was to assess the relative abuse liability of a single $40 \mathrm{mg}$ dose of 3 controlled-release oxycodone formulations (Apo-oxycodone $\mathrm{CR} \AA$, OxyNEO ${ }$, and the original OxyContin ${ }^{\circledR}$ ) in non-dependent recreational opioid users by performing pharmacodynamic and pharmacokinetic analyses.

Following expiry of the OxyContin ${ }^{\circledR}$ product April 30, 2014, the comparison was made between the remaining 2 products.

\section{Statement of Research Hypothesis}

If the pharmacokinetic Cmax and Tmax results of Apo-oxycodone $\mathrm{CR}{ }^{\circledR}$ was shown to be analogous to that of the original OxyContin ${ }^{\circledR}$, a comparable abuse liability would be anticipated. OxyNEO ${ }^{\circledR}$ is anticipated to have a relatively reduced abuse liability due to having a longer Tmax.

Following expiry of the OxyContin ${ }^{\circledR}$ product April 30, 2014, the hypothesis remains the same for the comparison of the 2 products. A lower abuse liability is anticipated for OxyNEO® compared to Apo-oxycodone $\mathrm{CR} \circledast$ due to its longer time to reach maximum concentrations. 


\section{METHODS}

\subsection{Design}

This was a single-center, single-dose, double-blind, placebo-controlled, randomized, crossover, abuse liability study of three controlled-release oxycodone formulations (OxyContin ${ }^{\circledR}$, OxyNEO ${ }^{\circledR}$, Apo-oxycodone () ) conducted in healthy participants who were non-dependent recreational opioid users. The study consisted of two different designs that took place sequentially due to the expiration of OxyContin: the first design included 4 study days and was implemented from Feb 2014 to April 2014. A second study design was required following the expiry of OxyContin ${ }^{\circledR}$ product on April 30, 2014. This design included 3 study days with the remainder of formulations and took place from May 2014 to November 2014. On each study day the participants were assessed for both pharmacodynamics (subjective effects, psychomotor speed and pupil diameter) and pharmacokinetic outcomes (Cmax, Tmax, AUC, and abuse quotient (Cmax/Tmax)). The primary outcome measures were the VAS rating of Drug Liking and Drug High. According to product monographs, the half-life of the formulations used in this study range between 5.1 to $7.1 \mathrm{hrs}$. This indicates that they should be eliminated from the body in 5.5 to 35.5 hours. The study days were at least 48 hours apart to ensure no carry over effects. The study aimed to have a maximum of 21 days of separation between study days in order to limit impact of changes in subjective experiences.

\subsubsection{Four-Day design}

The first design included 4 study days during which each subject was administered one tablet of either 40mg OxyContin ${ }^{\circledR}, 40 \mathrm{mg}$ OxyNEO ${ }^{\circledR}, 40 \mathrm{mg}$ Apo-Oxycodone $\mathrm{CR} \circledast$ or placebo on each day. The first 2 study days were dedicated to a drug discrimination phase. On these days either placebo or OxyContin ${ }^{\circledR}$ was administered in a randomized double-blind fashion. Participants who could distinguish OxyContin ${ }^{\circledR}$ from placebo on selected pharmacodynamic measures (e.g., $=$ or $>25$-point difference on the visual analog scale for Drug Liking relative to placebo), proceeded to the subsequent two study days. On study days 3 and 4, Apo-oxycodone CR $®$ and OxyNEO ${ }^{\circledR}$ was administered in a randomized double-blind fashion. 


\subsubsection{Three-Day design}

The second design included 3 study days during which each participant was administered either one tablet of $40 \mathrm{mg}$ OxyNEO ${ }^{\circledR}, 40 \mathrm{mg}$ Apo-oxycodone $\mathrm{CR} \circledast$ or placebo per day in a random order and in a double-blind fashion. The discrimination phase was removed as a result of removal of OxyContin ${ }^{\circledR}$ (positive control) from the study due to its expiry.

\subsection{Inclusion}

1) Healthy male and female participants 18 to 50 years of age

2) Willing and capable to give written informed consent

3) Have used opioids recreationally to achieve a "high" on at least five occasions in the 12 months before screening and at least once in the 90 days before screening according to self-report

4) Willing to use a medically acceptable form of birth control and have a negative pregnancy test for women of childbearing potential

5) Passed medical assessment, which included physical examination, assessment of medical history, vital signs, blood work, and urine toxicology screen

6) Willing to abstain from alcohol 12 hours before and during the study days

\subsection{Exclusion}

1) Current or past Axis I psychiatric illness (including current drug dependence or past opioid dependence, except nicotine dependence).

2) Current hepatic disease or renal failure

3) Pregnancy or lactation in women

4) Current medication that is known to interact with opioids

5) Known contraindications or hypersensitivity to opioids 


\section{6) Current opioid therapy}

7) Chronic pain disorder requiring regular medication

The study was approved by Research Ethics Board (REB) at the Centre for Addiction and Mental Health (CAMH). The approval letter is attached to appendix I. A Clinical Trial Application (CTA) was submitted to Health Canada as required for all clinical trials using medications outside of their approved indications. In response, Health Canada issued a 'No Objection Letter', attached in appendix II.

\subsection{Recruitment}

Participants were recruited by advertisement. The advertisement was posted around CAMH buildings (Queen St. site and the Russell St. site) as well as on the CAMH website, University of Toronto (campus and newspaper), Ryerson University (campus and newspaper), Ontario College of Art and Academy of Design (campus), and George Brown College (campus and newspaper). The advertisement was also posted on the Kijiji website, Craigslist website, NOW magazine (online and print), Backpage website, and Daily Xtra website.

\subsection{Screening}

Those interested called CAMH and were screened over the phone. The content of the screening questions included the callers' drug use history and demographics. Once they passed the screening, they came in for an assessment to confirm those responses and were further assessed. A copy of the telephone screening form is attached in appendix III.

\subsection{Assessment visit}

On this visit the participants were informed about the study details and underwent the informed consent process (Appendix IV). Those consenting to participate were then assessed to determine their eligibility for the study. The assessment included an interview, and a medical and a psychiatric exam conducted by either the Qualified Investigator or the other physician coinvestigator. After the medical and neuropsychiatric exam the participants were guided to the CAMH laboratory to provide urine and blood samples for further assessment of health and verification of self-reported drug history. Based on the lab results and completed assessment 
forms, the participants were either deemed eligible or ineligible confirmed by the Qualified Investigator.

\subsubsection{Interview}

The interview consisted of demographic questions such as age, marital status, employment status and highest level of education completed. The drug history questions focused on opioid use (dose, name, method of administration and the frequency of use) to gather information and to identify participants who could tolerate the oxycodone dose. Participants were also asked to provide details about their history and current use of non-opioid substances i.e. nicotine, alcohol, etc. The responses were recorded in an assessment form, which is attached in appendix V.

\subsubsection{Medical and Neuropsychiatric assessment}

This part of the assessment took place in order to include only healthy non-dependent participants in the study. The physician conducted a medical history and examination, which included:

1) Vital signs: the participants' blood pressure, temperature and heart rate were measured and recorded.

2) Review of body systems: a checklist was used to systematically review major organ systems functions.

3) Current and past conditions: participants were asked about their history of health conditions.

4) Current medications and allergies: participants were asked to name the medications they were currently taking to assess for potential interactions with opioids and to ensure there was no current opioid therapy. They were also asked to report any allergies.

5) Urine sample collection: the CAMH Clinical Laboratory performed full drug toxicology analysis. The lab results were used to verify participant responses to the drug history questionnaire about recent drug use. 
6) Blood sample: tests for pregnancy (for women), liver function tests, renal function, and hematology were performed.

7) Mini International Neuropsychiatric Interview (MINI) (Seehan, 1998; Pinninti, Madison, Mussler, \& Rissmiller, 2003): participants' mental health was assessed through the administration of the MINI to rule out psychiatric and substance use disorders. Participants with current or past Axis I psychiatric illness (including current drug dependence or past opioid dependence, except nicotine dependence) were excluded based on the clinical judgment of the physician. The MINI is a brief structured interview used to identify the symptoms of psychiatric disorders, including alcohol and substance abuse/dependence. The criteria for these subscales have been validated on both the DSMIV and the International Classification of Diseases. The MINI has high patient acceptability and high reliability even when used by non-clinicians. MINI has been shown to be easily incorporated into clinical interviews with good acceptance by patients.

\subsection{Dose selection}

The 40mg dose was selected based on two previous abuse liability studies in which OxyContin ${ }^{\circledR}$ was used as a positive control (Webster et al., 2012; Setnik et al., 2011). The intact OxyContin ${ }^{\circledR}$ $40 \mathrm{mg}$ oral dose produced robust positive subjective effects compared to placebo in recreational users of opioids. Furthermore, no serious adverse events were reported. The same dose was chosen for the other two controlled-release formulations of oxycodone (Apo-oxycodone $\mathrm{CR} \circledR$ and $\mathrm{OxyNEO}{ }^{\circledR}$ ) for an objective comparison of the formulations.

\subsection{Drug Randomization}

In the four-day design, the order of drug administration for the drug discrimination phase (placebo or OxyContin ${ }^{\circledR}$ ) was assigned in a random order. Separately, the order of drug administration for the second phase (OxyNEO ${ }^{\circledR}$ or Apo-oxycodone $\mathrm{CR} \circledast$ ) was also assigned in a random manner. The randomization codes for each phase were developed using a random number table in blocks of four. In the three-day design, participants were randomized to receive placebo ${ }^{\circledR}$, OxyNEO ${ }^{\circledR}$ and Apo-oxycodone $\mathrm{CR} \circledast$ in blocks of six. The randomization was not balanced in the study because the participants who did not attend when scheduled may or may 
not have completed the study subsequently and this disrupted the plan for replacing the participant dropouts.

\subsection{Blinding}

Drug administration was done in a blinded manner using identical looking study capsules for the oxycodone products and placebo. The oxycodone tablets were over-encapsulated, and the placebos prepared, using gelatin capsules and lactose filler by the CAMH Pharmacy Research Medication Management Service to ensure matching capsules were administered for all conditions. Participants were blinded to the order of all drug administrations. In the four-day design, the investigators knew that on each of the first two days (drug discrimination phase) either OxyContin ${ }^{\circledR}$ or placebo was administered in a random order. The investigators were also aware that on each of the $3^{\text {rd }}$ and the $4^{\text {th }}$ study days the participants received either OxyNEO ${ }^{\circ}$ or Apo-oxycodone $\mathrm{CR} \AA$ in a random order. In the three-day design, (two active drugs and placebo), the patients and investigators were blinded to the order of the 3 conditions.

\subsection{Study Sessions}

Each study day followed the same methodology with the only difference in the study medication administered. Participants were asked to abstain from caffeine, alcohol and nicotine for 12 hours, abstain from other drugs from a few days before, and to fast for 8 hours before arriving the morning of the study days. Upon arrival, participants were asked to provide a urine sample for toxicology screening and to submit to an alcohol breathalyzer test. A research nurse trained for the study, drew blood over the course of the study day using an intravenous catheter. Baseline blood draws for pharmacokinetic analysis, pharmacodynamic measures (subjective tests, pupillometery and psychomotor tests) and safety measures (vital signs, sedation and recording observations i.e. adverse events) were taken before study drug administration. Following drug administration participants were allowed to have water after one hour and normal fluid intake could resume after two hours. Likewise, after two hours they were offered a small snack. Blood draws (for pharmacokinetic analysis), pharmacodynamic tests and safety measures were repeated in cycles throughout the day following drug administration at 1, 1.5, 2, 2.5, 3, 3.5, 4, 4.5, 5, and 6 hours. The cycles could be conducted up to 15 minutes following the scheduled time for those cycles scheduled 30 minutes apart; and 30 minutes following the $5^{\text {th }}$ and $6^{\text {th }}$ hour cycles. Outside 
of this window the cycle was not to be conducted and the next cycle would have resumed at the scheduled time, if applicable. A light lunch was offered as a high fat meal may influence the pharmacokinetic results. Benziger et al. (1995) showed that Tmax was greater for 40mg OxyContin ${ }^{\circledR}$ after a high-fat meal compared to fasted conditions. After the $6^{\text {th }}$ hour cycle the catheter was removed. The participants were administered the last pharmacodynamic and safety measures at the $8^{\text {th }}$ hour. The participants were then assessed by the research nurse for the ability to safely leave. Participants were sent home via a taxi and advised to not drive and remain at home that evening to allow the medication to fully wear off. Due to delay in arrival of taxi, two participants took public transit home on one occasion each. Participants were followed up by a phone call to ensure they had safely arrived home.

Table 2. Summary of study day procedures

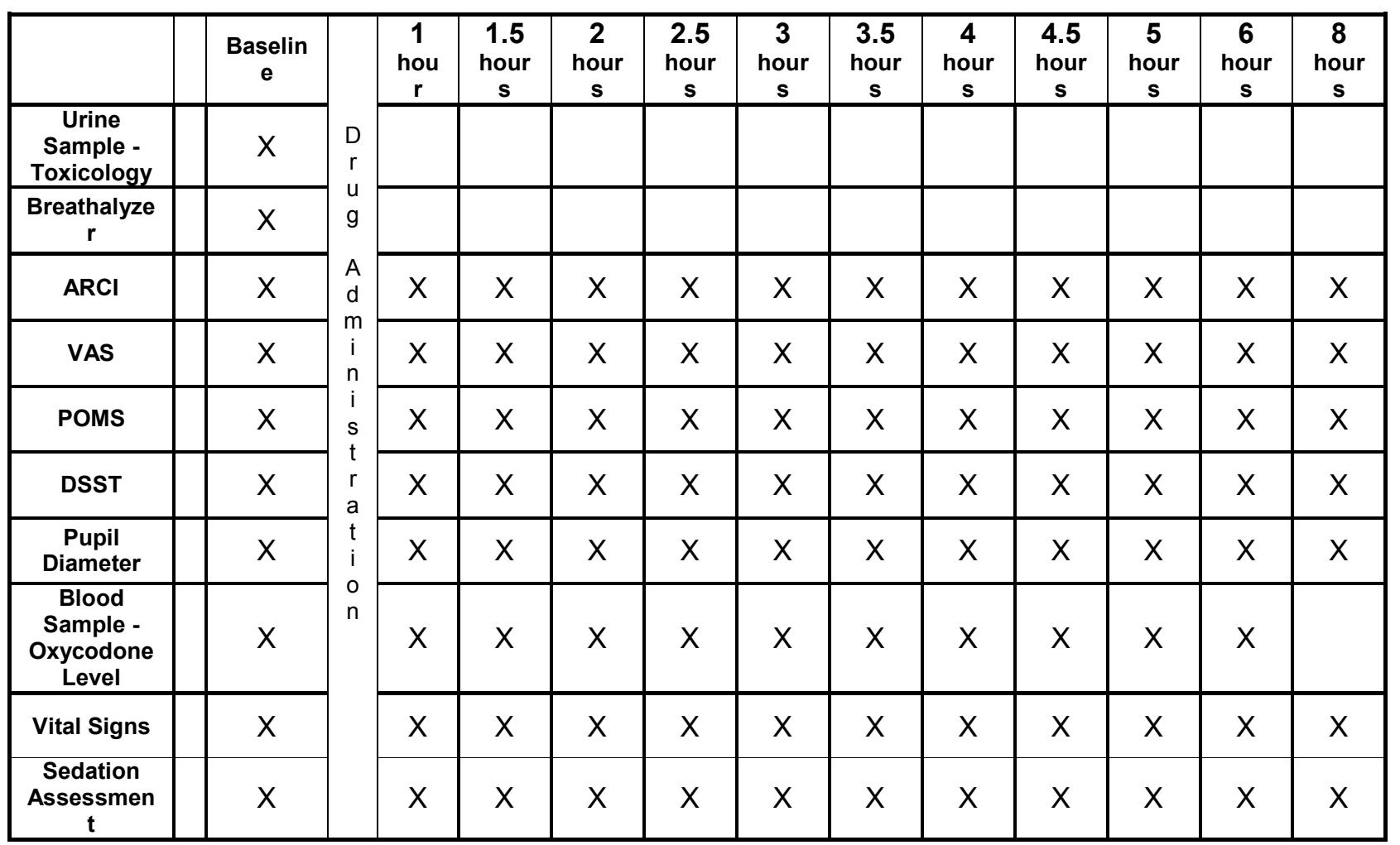

\subsection{Pharmacodynamic measures}

The pharmacodynamic measures were computerized. 


\subsubsection{VAS (Visual Analog Scales)}

These scales are often used in assessment of momentary changes in subjective effects. The bipoloar measure of Drug Liking is considered a reliable and a valid measure of abuse liability (Bigelow, 1991; Griffiths et al., 2003; Comer et al., 2008). For this measure, the anchor on the left reads "dislike intensely"(score $=0$ ), the anchor in the center reads "neither dislike or like" (score $=50$ ), and the anchor on the right reads "like intensely" (score=100). The unipolar measure of Drug High is anchored at the ends by 'absolutely normal' and 'very high'. Comer et al. (2008) showed that there is generally good concordance between the positive subjective effects (Good Effects, Drug High, and Drug Liking) and reinforcing effects (self-administration of drugs in humans). The measures that used the unipolar scale were: Drug High, Drug Effects, Good Effects, Bad Effects, Feel Sick, Nausea, Sleepy, and Dizzy. Drug liking and Take Drug Again used bipolar VAS, which have anchors at each end of the scale and in the center. For the global 'Take Drug Again', which was only administered once at the end of each study day (at the $8^{\text {th }}$ hour), the anchor on the left read "definitely not"(score $=0$ ), the anchor in the center read "neutral" (score=50), and the anchor on the right read "definitely so" (score=100). Participants were instructed to rate how they feel along a continuum by making a mark along the line.

\subsubsection{Addiction Research Center Inventory (ARCI)}

(Cole et al., 1982; Haertzen et al., 1963; Martin et al., 1971)

The ARCI scale was developed by the Addiction Research Centre. It is a scale used for evaluating the effects of different psychotropic drug classes. The version of ARCI used in this study consists of a 76-item true/false questions, which is a combination of the 49-item ARCI short form and the 66item ARCI-Cole. AMPH and BG, Benzedrine Group scales are both indices of amphetamine-like effects. The pentobarbital, chlorpromazine, alcohol group scale (PCAG) is a measure of sedation; the morphine-benzedrine group scale (MBG) is a measure of euphoria; the lysergic acid diethylamide group scale (LSD) estimates dysphoric and psychotomimetic changes. Other subscales include: Stimulation-Euphoria, Sedation-Motor, Sedation-Mental, Unpleasantness-Physical, Stimulation-Motor, Stimulation-Mental and Abuse Potential. The ARCI positive composite scale is composed of the Stimulation-Euphoria, the Abuse potential, the AMPH, the MBG, and the BG subscales. The ARCI negative composite scale is composed of the Sedation-Motor, Sedation-Mental, Unpleasantness-Physical, 
Unpleasantness-Dysphoria, PCAG, and the LSD subscales. The subscales are composed of different scoring ranges and are adjusted to a percentage form to calculate composite scores.

\title{
2.11.3 The Profile of Mood States (POMS)
}

\author{
(McNair, 1971; Johanson \& Uhlenhuth, 1982)
}

This is an adjective checklist that is used to detect changes in mood. Participants indicate how they feel with respect to a series of 72 adjectives using a five-point scale including 'not at all', 'a little', 'moderately', 'quite a bit' and 'extremely'. The adjectives contained in the instrument yield eight different mood subscales including: Anxiety-Tension, Depression-Dejection, AngerHostility, Vigor, Fatigue, Confusion, Friendliness and Elation. A number of composite scale scores can be derived from the eight mood scales. POMS negative effects are a combination of the Tension, Anger, Depression Fatigue and Confusion scales while a positive effects score is calculated by subtracting the Depression score from the Elation score. Similarly, an Arousal score is determined by adding together the Tension and Vigor scales and subtracting Fatigue and Confusion. Finally, a Total Mood Disturbance (TMD) score can be obtained by summing the Tension-Anxiety, Depression-Dejection, Anger, Fatigue, and Confusion scales and subtracting the Vigor - or more simply, subtracting Vigor from negative effects composite score. The TMD can be used as a single global estimate of a clinical state.

\subsubsection{The Digit Symbol Substitution Test (DSST)}

(McLeod, Griffiths, Bigelow \& Yingling, 1982)

The DSST is a computerized psychomotor test that requires participants to replicate a pattern on a blank numbered template. There are ten different symbols made up of different combinations of blank and filled squares. These ten symbols are randomly paired with the numbers from 0 to 9. The participant is randomly given a number between 0 to 9 that is associated with one specific symbol from the legend. The participant is able to see the legend at all times. Participants make symbol for digit substitutions as quickly as possible within 90 seconds. The number of correct substitutions is used as a measure of psychomotor function. The DSST has been used in many previous studies as a sensitive measure of psychomotor response, recognition of sensory information and visual-motor coordination. 


\subsubsection{Pupil diameter}

At each cycle the pupil diameter was measured using a custom-made camera (pupillometer) that uses an infrared light source to acquire an image of the pupil. The image of the participants' pupils along with the diameter measurement of their pupils were captured, calculated and stored in a computer that was linked to the pupillometer.

\subsection{Blood sample analyses}

Plasma oxycodone and metabolites (noroxycodone, oxymorphone and noroxymorphone) analyses were conducted at the R\&D Laboratories of Gamma-Dynacare using a validated liquid chromatography/mass spectrometry procedure. The limit of detection (LOQ) was set at $0.1 \mathrm{ng} / \mathrm{ml}$ such that concentrations lower than $0.1 \mathrm{ng} / \mathrm{ml}$ were not quantified.

\subsection{Safety assessments}

There were three registered nurses associated with the study who were responsible for the safety assessments. Each study day was monitored by one registered nurse. At each cycle, heart rate, blood pressure, oxygen saturation, respiratory rate, and skin temperature were measured and recorded using a Criticare Scholar® II Vital Signs Monitor manufactured by Criticare Systems Inc. Also, a global assessment of sedation was conducted by observation using a Likert scale of 1 to 5. Any clinical observations such as adverse events were recorded. The adverse events were logged in an adverse events form and were subsequently inspected and signed by the qualified investigator.

\subsection{Data analysis}

Participants from the four-day design and three-day design were included in the analysis. From the four-day design, data from the discrimination phase (first 2 study days) was analyzed to demonstrate eligibility of participants included in the second phase. The data from the threeday design $\left(\mathrm{OxyNEO}{ }^{\circledR}\right.$, Apo-oxycodone $\mathrm{CR}{ }^{\circledR}$ and Placebo) was analyzed with the data from the four-day design $\left(\mathrm{OxyNEO}{ }^{\circledR}\right.$, Apo-oxycodone $\mathrm{CR} \circledast$ and Placebo) using linear mixed model.

Different parameters were used in the statistical tests depending on the pharmacodynamic measure. The mean scores of each parameter for all the participants on each study day were used 
to compare the drug effects. TEmax (time to maximum subjective effects) and AUE analysis for different time intervals were used only for the VAS positive subjective measures to capture the effects in the immediate period post-drug administration (ascending portion of the effect curve) due to the association of the early effects with the reinforcing effects of the drugs (Carter \& Griffiths, 2009).

Table 3. Parameters for each measure

\begin{tabular}{|l|c|c|c|c|c|c|}
\hline \multicolumn{1}{|c|}{ Measure } & Peak* & $\begin{array}{c}\text { Maximum } \\
\text { change } \\
\text { from } \\
\text { baseline** }\end{array}$ & $\begin{array}{c}\text { AUE at } \\
\mathbf{1 , 1 . 5 ,} \\
\mathbf{2 , 2 . 5 ,} \\
\mathbf{3 , 3 . 5 , 4} \\
\mathbf{h r * * *}\end{array}$ & $\begin{array}{c}\text { AUE at 8 } \\
\text { hr*** }^{* * *}\end{array}$ & $\begin{array}{c}\text { Average } \\
\text { daily } \\
\text { score^ }\end{array}$ & $\begin{array}{c}\text { Time to } \\
\text { peak effect } \\
\text { (TEmax) }\end{array}$ \\
\hline $\begin{array}{l}\text { Primary outcome } \\
\text { measures: } \\
\begin{array}{l}\text { VAS drug liking and } \\
\text { drug high }\end{array}\end{array}$ & $\mathrm{X}$ & $\mathrm{X}$ & $\mathrm{X}$ & $\mathrm{X}$ \\
\hline VAS good effects & $\mathrm{X}$ & & $\mathrm{X}$ & $\mathrm{X}$ & & $\mathrm{X}$ \\
\hline $\begin{array}{l}\text { VAS drug effects, bad } \\
\text { effects, feel sick, } \\
\text { nausea, sleepy and } \\
\text { dizzy }\end{array}$ & $\mathrm{X}$ & & & & & \\
\hline ARCI and POMS & & $\mathrm{X}$ & & $\mathrm{X}$ & & \\
\hline DSST & $\mathrm{X}$ & $\mathrm{X}$ & & & $\mathrm{X}$ & \\
\hline Pupil diameter & $\mathrm{X}$ & & & & \\
\hline
\end{tabular}

*Peak (maximum score) for each study day was computed using Excel. For the measure of pupil diameter, the trough values were used.

** Maximum change from baseline was calculated in order to evaluate the change to peak effects from pre-treatment due to the variation in baseline ratings between and within participants.

*** Area under the effect curve (AUE) was calculated using the trapezoidal method.

$\wedge$ Average daily score was calculated by taking the average of all the scores throughout each study day.

$\sim$ TEmax was only analyzed for the positive subjective effects measured by VAS as the onset of effects is a parameter associated with the reinforcing effects of the drugs of abuse

For the pharmacokinetic analyses, descriptive statistics for plasma concentrations of oxycodone were calculated using non-compartmental methods. Cmax and Tmax were determined from the observed concentration-time profiles. The area under the concentration-time curve (AUC) was approximated using the linear trapezoidal method. The Cmax/Tmax ratio (abuse quotient) served as an index of the average rate of increase in drug concentration from dosing to Tmax (Perrino et al., 2013). 
Graphs were used to track the time course of drug effects and of drug plasma concentrations. For all the graphs, arithmetic means were used to calculate the data at each time point. The plasma concentrations of oxycodone and its metabolites (norooxycodone, oxymorphone, noroxymorphone) were plotted against time for each formulations and for selected participants to demonstrate individual variability. Graphs of Drug High versus oxycodone concentrations over time were included to look for the presence of hysteresis. Oxycodone plasma concentrations over time for all the formulations were plotted in one graph to supplement the AUC data. The graph of pupil diameter against time was included to demonstrate opioid effects.

All analyses were carried out using SPSS v20 for Windows. Statistical tests were two sided, with alpha level of 0.05. To compare means, a Mixed Effect Model was used. This model can be used with repeated measures data, which refers to data from participants measured repeatedly under different conditions (Littell, Pendergast, \& Natarajan, 2000). The term "mixed model" refers to the model's ability to accommodate fixed effects and random effects (Littell et al., 2000). Mixed Effect Models can address lack of independence present in longitudinal data. Another advantage of this model is that it can handle missing values by using the maximum likelihood estimation, which uses all available information to compute the value of the parameter that is mostly likely to have resulted (West, Welch, \& Galecki, 2006).

Subjects were considered random effects (random intercept model). This model assumes the data is independent between subjects while it accommodates dependence in the data within subject, across time. All the other predictors were considered fixed effects. Treatment (drug) was the main categorical predictor with 4 levels (Placebo, OxyContin, OxyNEO®, and Apo-oxycodone $\mathrm{CR}($ ). Sex, age and weight (in $\mathrm{kg}$ ) were used as covariates in all analyses. Bonferroni adjustment for multiple comparison was applied to all pair-wise comparisons involving the 4 treatments.

For the pharmacodynamic analysis, the dependent variable were the subjective effects and pupil diameter; Time effect was controlled through the variable period, which was defined as the number of days since the start of the study. When the dependent variable was pupil diameter period was not controlled for due to the fact that no period effect was anticipated for the objective measurements. An identical model specification was used in the pharmacokinetic 
analysis, which also did not include period as a control. Cmax, AUC and abuse quotient were the dependent variables in this case.

Further, the differences amongst the comparators in the median time to peak subjective effects (TEmax) and the median time to peak plasma drug concentrations (Tmax) were examined by looking at the differences in time to peak and not by performing statistical analysis. Amongst the abuse liability studies of controlled-release oxycodone formulations, Webster et al. (2012), Setnik et al. (2011); and Morton et al. (2014) used statistical analysis to compare the means of time to peak (Tmax and TEmax) whereas Harris et al. (2013) and Perrino et al. (2013), compared the medians arithmetically. However, it must be noted that there are some pharmacokinetic studies that have used non-parametric tests such as Wilcox signed rank test and Wilcox rank sum test to compare Tmax medians in other oxycodone formulations (Luikas et al., 2011; Lofwall et al., 2012).

\subsection{Sample size}

Sample size was calculated based on the outcome of maximum drug liking (100mm VAS). There was no previous data published providing estimated means and variance for different controlledrelease oxycodone formulations, however, assumptions were based on a related study. ${ }^{6} \mathrm{~A}$ mean and a standard deviation of $60 \pm 30$ for one formulation and $45 \pm 30$ for another formulation which represents a one-half standard deviation difference (effect size $=0.5$ ) with a Pearson correlation coefficient of $\mathrm{r}=0.85$ in a paired, crossover fashion, using a two-sided alpha 0.05 , a sample size of 11 would provide $80 \%$ power. Therefore, we targeted 12 participants to complete all 4 study days. This is consistent with the sample size recommendations (10-14 participants) recommended for these types of studies (Griffiths, Bigelow, \& Ator, 2003). In order to achieve this we anticipated needing to recruit approximately 25 participants to account for dropouts and those not 'passing' the first discrimination phase.

\subsection{Student role in the project}

- Helped in writing protocol

- Helped in completing Toronto Academic Health Sciences Network (TAHSN) form to submit to CAMH REB 
- Screened, interviewed and consented all potential participants

- Scheduled assessment sessions and study days for participants by coordinating with the clinicians associated with the study

- Coordinated with the CAMH pharmacy to obtain the study medications

- Conducted the breathalyzer test at the beginning of each study day

- Administered all pharmacodynamic tests

- $\quad$ Provided meal, snack and water for the participants

- Centrifuged blood at most study cycles

- Coordinated the taxi for the participants upon completion of each study day

- Ensured all study supplies are restocked

- Helped pack specimen according to TDG guidelines and sent them to lab for analysis

- Organized data collected and performed statistical analysis on data 


\section{Results}

\subsection{Recruitment results}

Recruitment strategies employed from Feb 2014 until December 2014 resulted in 101 calls.

From the 101 calls, 14 persons met the eligibility criteria of which 11 persons were able to participate in the study. The other 87 persons were either ineligible, could not be reached, or did not attend assessment (Fig. 1.).

Figure 2. Recruitment chart

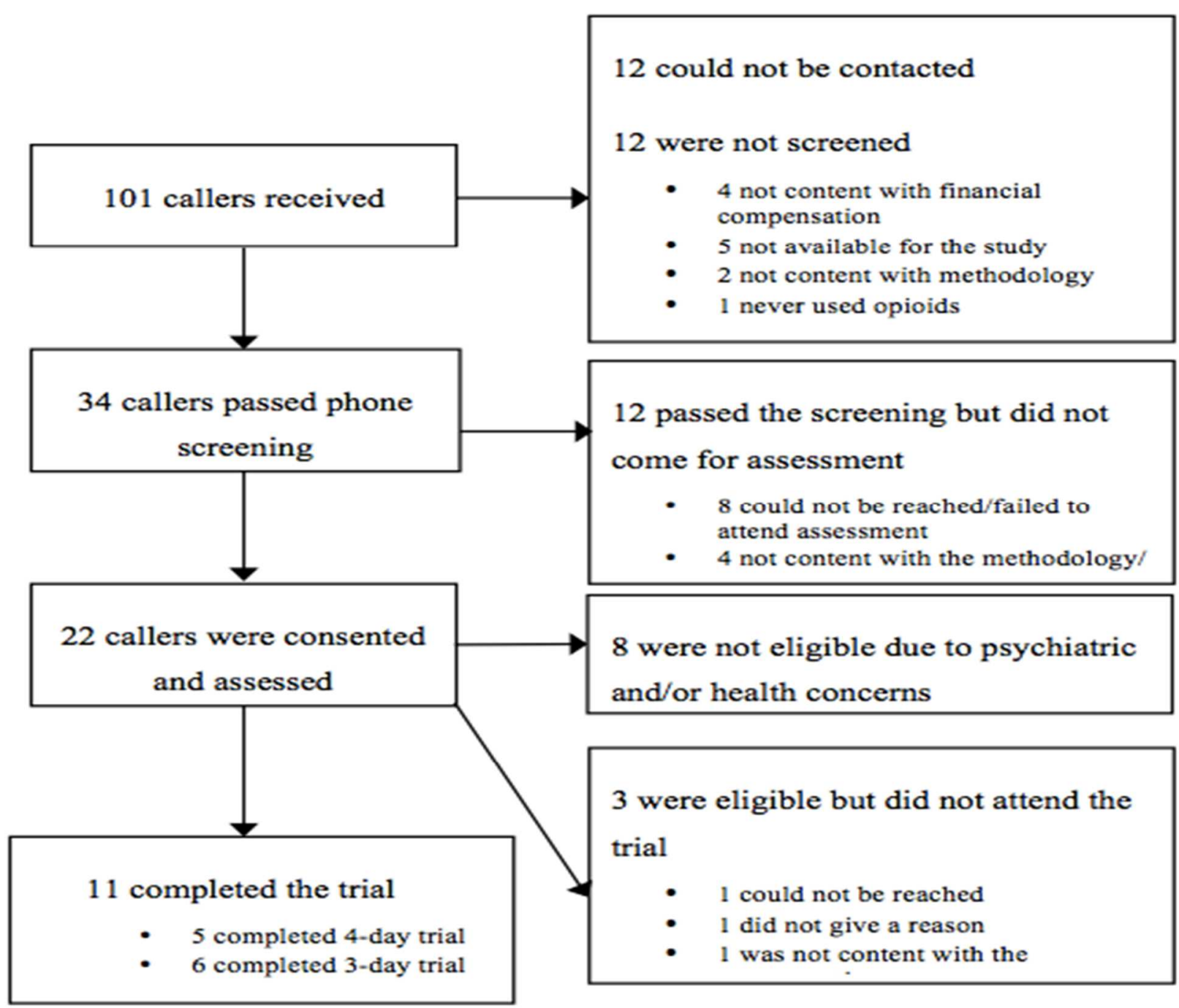




\subsection{Study participants}

Of the 11 participants 5 completed the four-day design and 6 completed the three-day design. There were 8 male and 3 female participants. The average age and the average weight of the participants were $38.3 \pm 7.9$ and $85.4 \pm 17 \mathrm{~kg}$ respectively (refer to Table 1).

The participants' drug use profile is shown in Table 1. All the participants had current opioid use and were absent of opioid dependence confirmed by psychiatric interview (Mini International of Neuropsychiatric Interview.) One participant (073-07) preferred the intravenous administration of heroin whereas the rest of the participants preferred the oral or intranasal administration of prescription opioids. 
Table 4. Participant characteristics and drug use history

\begin{tabular}{|c|c|c|c|c|c|c|c|c|c|}
\hline $\begin{array}{l}\text { Participant } \\
\text { code }\end{array}$ & Age & $\begin{array}{l}\text { Weight } \\
(\mathrm{Kg})\end{array}$ & Gender & $\begin{array}{l}\text { Usual dose of the } \\
\text { preferred opioid } \\
\text { formulation \& opioid use } \\
\text { frequency }\end{array}$ & $\begin{array}{l}\text { Preferred } \\
\text { route of } \\
\text { administration }\end{array}$ & $\begin{array}{l}\text { Nicotine } \\
\text { use } \\
\text { frequency }\end{array}$ & $\begin{array}{l}\text { Alcohol } \\
\text { drinking } \\
\text { frequency }\end{array}$ & $\begin{array}{l}\text { Cannabis } \\
\text { use frequency }\end{array}$ & $\begin{array}{l}\text { Other drugs } \\
\text { (frequency: } \\
2 \leq \text { month) }\end{array}$ \\
\hline 011-02 & 39 & 94 & Male & $\begin{array}{c}\text { N/A mg oxycodone CR } \\
(1-2 / \text { week })\end{array}$ & Oral (intact) & Past use & 2drinks/day & $3(1$ gram $) /$ week & $\begin{array}{l}\text { Cocaine, } \\
\text { Hallucinogens }\end{array}$ \\
\hline 017-01 & 48 & 113 & Male & $\begin{array}{c}\text { 80mg oxycodone CR } \\
(1-2 / \text { week })\end{array}$ & Intranasal & Never used & Never drank & Never used & $\begin{array}{l}\text { No current use } \\
\text { of other drugs }\end{array}$ \\
\hline 023-03 & 36 & 92 & Male & $\begin{array}{c}\text { 80mg oxycodone CR } \\
(1-2 / \text { week })\end{array}$ & Intranasal & $\begin{array}{l}\text { 10cigaretttes } \\
\text { /day }\end{array}$ & 3drinks/month & 3gram/day & $\begin{array}{l}\text { Cocaine, } \\
\text { Amphetamine, } \\
\text { Sedatives }\end{array}$ \\
\hline 004-04 & 46 & 71 & Male & $\begin{array}{c}\text { 80mg oxycodone CR } \\
(1-2 / \text { month })\end{array}$ & Intranasal & Past use & 3 drinks/month & Never used & $\begin{array}{l}\text { No current use } \\
\text { of other drugs }\end{array}$ \\
\hline 031-05 & 39 & 111 & Male & $\begin{array}{c}\text { 10mg oxycodone IR or } \\
\text { 40mg oxycodone CR } \\
(>1 / \text { month })\end{array}$ & Intranasal & Past use & $<1$ drink/month & 1gram/day & Cocaine \\
\hline 061-06 & 44 & 67 & Female & $\begin{array}{l}\text { N/A mg oxycodone IR } \\
\text { (1-2/month) }\end{array}$ & Intranasal & $1-2 /$ month & 6drinks/month & Never used & Cocaine \\
\hline 073-07 & 25 & 63 & Male & $\begin{array}{c}\text { heroin } / 0.03 \mathrm{~g} \\
(2 / \text { month })\end{array}$ & Intravenous & $\begin{array}{l}\text { E-cigarette } \\
\text { daily }\end{array}$ & 3 drinks/month & $1(0.5$ gram $) /$ week & $\begin{array}{l}\text { No current use } \\
\text { of other drugs }\end{array}$ \\
\hline 078-08 & 49 & 90 & Male & $\begin{array}{c}\text { 10mg oxycodone IR } \\
(1-2 / \text { week })\end{array}$ & Intranasal & Past use & $<1$ drink/month & $<1 /$ month & $\begin{array}{l}\text { No current use } \\
\text { of other drugs }\end{array}$ \\
\hline 084-09 & 31 & 86 & Male & $\begin{array}{c}\text { 80mg oxycodone CR } \\
(1-2 / \text { week })\end{array}$ & Oral (intact) & Past use & 4drinks/month & Never used & $\begin{array}{l}\text { No current use } \\
\text { of other drugs }\end{array}$ \\
\hline 085-10 & 33 & 83 & Female & $\begin{array}{c}\text { 40mg oxycodone CR } \\
(1-2 / \text { month })\end{array}$ & Oral (intact) & Past use & $<1$ drink/month & Never used & $\begin{array}{l}\text { No current use } \\
\text { of other drugs }\end{array}$ \\
\hline 095-11 & 31 & 69 & Female & $\begin{array}{c}\text { 10mg oxycodone } \\
\text { (formulation: N/A) } \\
(1-2 / \text { month })\end{array}$ & Oral (crushed) & Past use & $\begin{array}{l}\text { 8drinks } \\
\text { (one session)/month }\end{array}$ & Never used & $\begin{array}{l}\text { No current use } \\
\text { of other drugs }\end{array}$ \\
\hline
\end{tabular}




\subsection{Order of study drugs}

Table 5. Order of drug administration and the number of days between study days

\begin{tabular}{|c|c|c|c|c|}
\hline $\begin{array}{l}\text { Participan } \\
\text { t code }\end{array}$ & $\begin{array}{l}\text { Drug received } \\
\text { on Day1 }\end{array}$ & $\begin{array}{l}\text { Drug received on } \\
\text { Day2 (\#days after } \\
\text { Day1) }\end{array}$ & $\begin{array}{l}\text { Drug received on } \\
\text { Day3 (\#days after } \\
\text { Day2) }\end{array}$ & $\begin{array}{l}\text { Drug received on } \\
\text { Day4 (\#days } \\
\text { after day3) }\end{array}$ \\
\hline 011-02 & OxyContin $\AA$ & Placebo $(31)^{*}$ & OxyNEO® (7) & $\begin{array}{l}\text { Apo-Oxycodone } \\
\text { CR® (3) }\end{array}$ \\
\hline 017-01 & Placebo & OxyContin $®(5)$ & $\begin{array}{l}\text { Apo-Oxycodone } \\
\text { CR® (18) }\end{array}$ & OxyNEO® (5) \\
\hline 023-03 & OxyContin $\AA$ & Placebo (7) & $\begin{array}{l}\text { Apo-Oxycodone } \\
\text { CR® (14) }\end{array}$ & OxyNEO® (8) \\
\hline 004-04 & OxyContin $\AA$ & Placebo (9) & OxyNEO (28)* & $\begin{array}{l}\text { Apo-Oxycodone } \\
\text { CR® (2) }\end{array}$ \\
\hline $031-05$ & OxyContin ${ }^{\circledR}$ & Placebo (14) & $\begin{array}{l}\text { Apo-Oxycodone } \\
\text { CR® }(6)\end{array}$ & OxyNEO® (3) \\
\hline $061-06$ & $\begin{array}{l}\text { Apo-oxycodone } \\
\text { CR® }\end{array}$ & OxyNEO® $(25)^{*}$ & Placebo (18) & \\
\hline 073-07 & Placebo & OxyNEO® (13) & $\begin{array}{l}\text { Apo-oxycodone } \\
\text { CR® }(29)^{*}\end{array}$ & \\
\hline 078-08 & 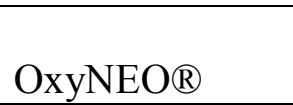 & $\begin{array}{l}\text { Apo-oxycodone } \\
\text { CR® (12) }\end{array}$ & Placebo (7) & \\
\hline 084-09 & Placebo & $\begin{array}{l}\text { Apo-oxycodone } \\
\text { CR® (16) }\end{array}$ & OxyNEO® (12) & \\
\hline $085-10$ & 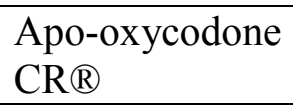 & OxyNEO® (12) & Placebo (4) & \\
\hline 095-11 & Placebo & $\begin{array}{l}\text { Apo-oxycodone } \\
\mathrm{CR}(2)\end{array}$ & OxyNEO® (6) & \\
\hline
\end{tabular}

The number of days of separation between the study days varied from two days to thirty-one amongst the participants. Four participants had passed the 21-day limit that was set originally to restrict impact of changes of subjective experience $(*)$. These were reported as protocol deviations. In these participants, no noticeable differences were observed in the positive subjective effects between the two separated study days. To control for this variation, the number of days between the study days was included as a covariate in the data analysis. 


\subsection{Pharmacodynamic results}

\subsubsection{VAS results}

3.4.1.1 Primary outcome: Drug Liking peak and time to peak

The mean peak Drug Liking for Apo-oxycodone $\mathrm{CR} \circledast$ and OxyNEO ${ }^{\circledR}$ were significantly higher than for placebo ( $\mathrm{p}=0.003$ and $\mathrm{p}=0.012$, respectively). There were no significant differences between OxyContin ${ }^{\circledR}$ and placebo. Further, there were no significant differences amongst the active drugs in this measure. The median time to peak effects (TEmax) was similar amongst the active drugs and the placebo.

Figure 3. Mean peak Drug Liking VAS score $(0=$ dislike intensely; $50=$ neither dislike or like; $\mathbf{1 0 0}=$ like intensely) for each condition

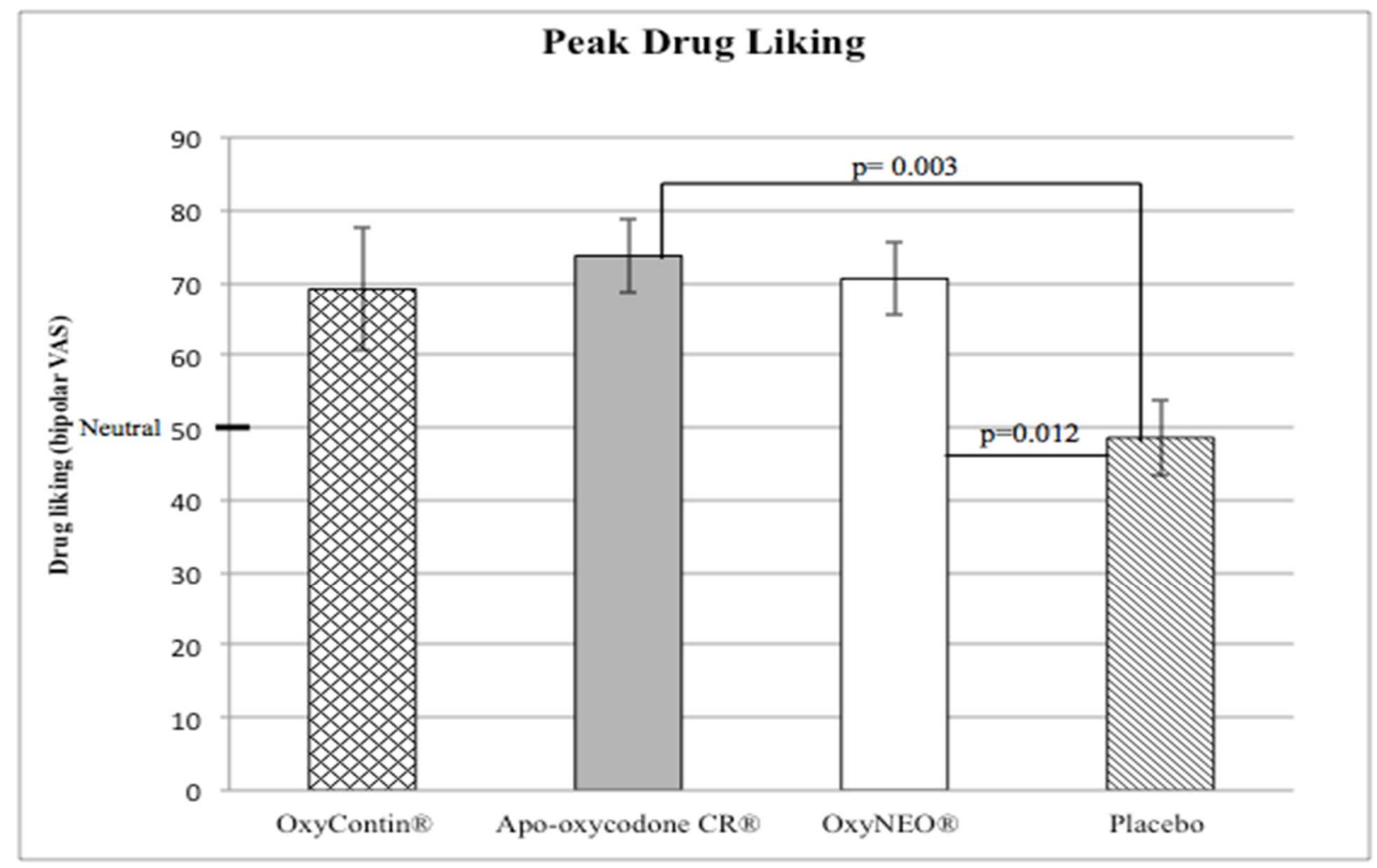


Table 6. Drug Liking Results

\begin{tabular}{|l|l|l|}
\hline Drug & $\begin{array}{l}\text { Mean peak (Std. } \\
\text { Error) }\end{array}$ & $\begin{array}{l}\text { Median time to peak (range) } \\
\text { (hr) }\end{array}$ \\
\hline OxyContin $\AA(\mathrm{N}=5)$ & $69.16(8.53)$ & $2(1-8)$ \\
\hline Apo-oxycodone $\mathrm{CR} \AA(\mathrm{N}=11)$ & $73.74(5.09)$ & $\begin{array}{l}2.5(1.5-8) \\
(\mathrm{n}=10)^{*}\end{array}$ \\
\hline OxyNEO $(\mathrm{N}=11)$ & $70.60(5.14)$ & $\begin{array}{l}2(1-3.5) \\
(\mathrm{n}=9)^{* *}\end{array}$ \\
\hline Placebo $(\mathrm{N}=11)$ & $48.6(5.22)$ & $\begin{array}{l}2(1.5-4) \\
(\mathrm{n}=3) * * *\end{array}$ \\
\hline
\end{tabular}

*1 participant did not report increased effects from baseline

**2 participants did not report increased effects from baseline

$* * * 8$ participants did not report increased effects from baseline

\subsubsection{Primary outcome: Drug Liking (AUE)}

There were no significant differences in the mean AUE of Drug Liking at any of the time intervals amongst comparators. The means used in figure 4 were calculated arithmetically while the means use in Figure 5 bar chart were adjusted.

Figure 4. Mean Drug Liking scores plotted over time for each condition

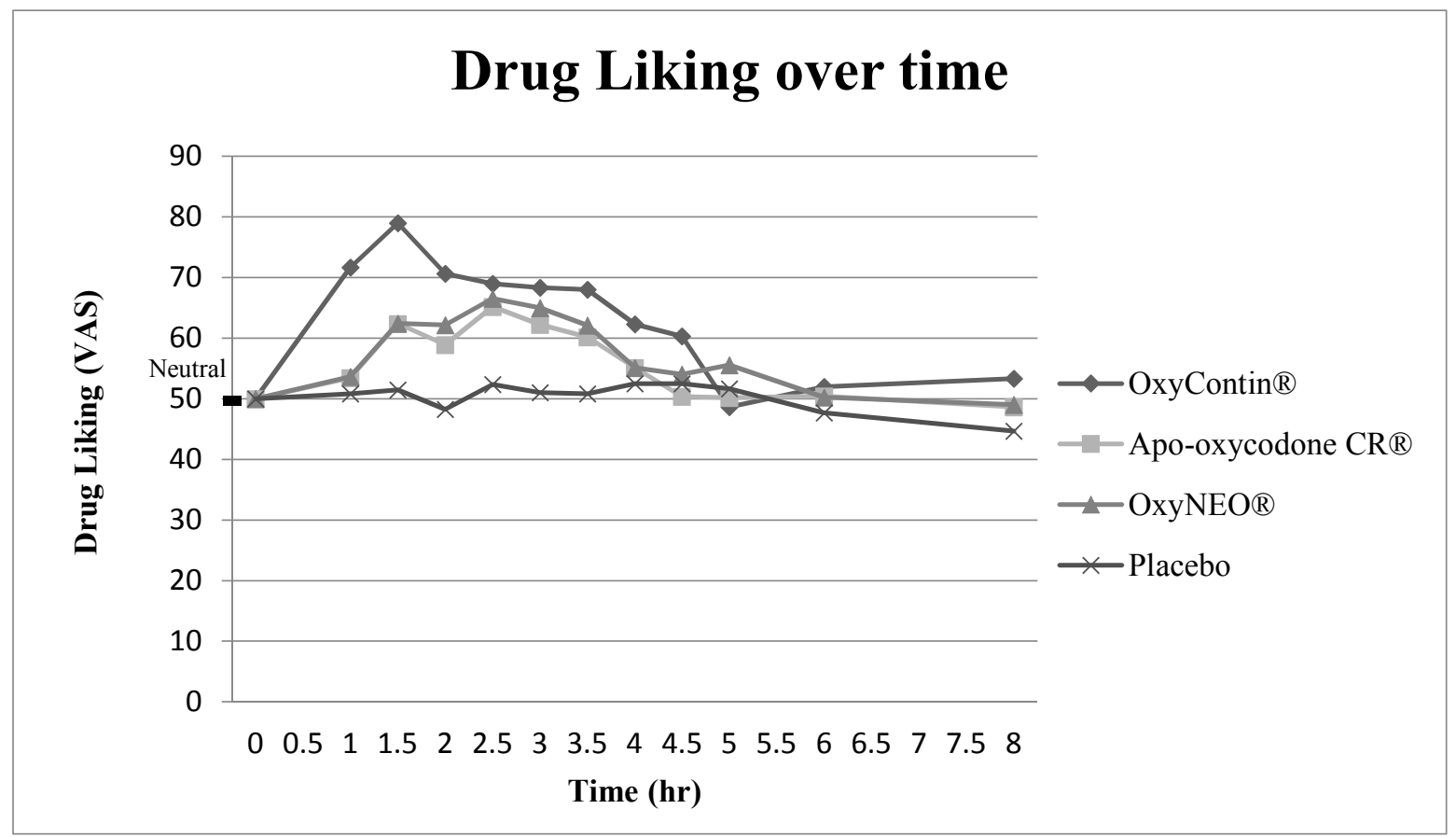


Figure 5. Mean Drug Liking VAS AUE(0-2hr) (scale: 0-140) and AUE(0-8hr) (scale: 350470)

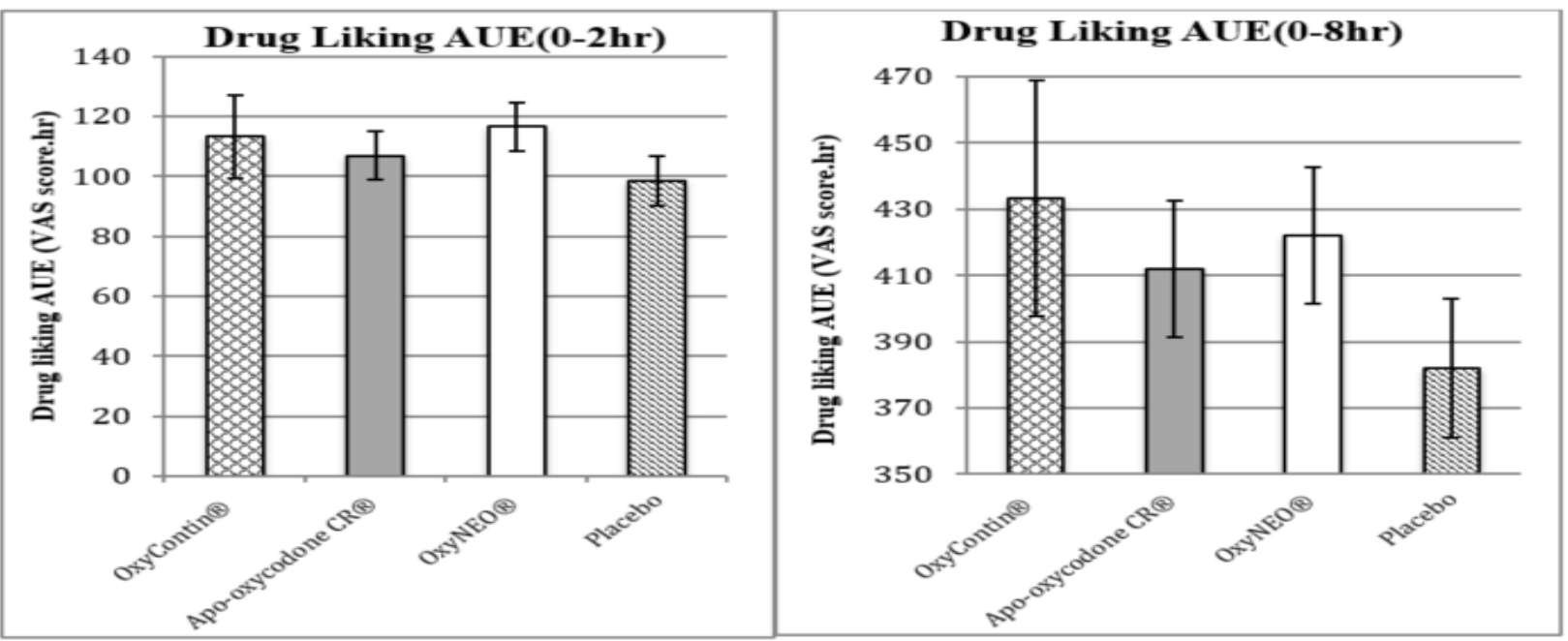

*Differences in the mean AUE of Drug Liking amongst the comparators were not statistically significant

\subsubsection{Primary outcome: Drug High (peak and time to peak)}

The mean peak Drug High for Apo-oxycodone $C R \AA$, OxyNEO ${ }$, and OxyContin ${ }^{\circledR}$ were significantly higher than for placebo $(\mathrm{p}<0.001, \mathrm{p}<0.001$, and $\mathrm{p}=0.007$, respectively). There were no significant differences in the mean peak Drug High scores and time to peak effect (TEmax) amongst the active drugs (figure $7 \&$ table 6 ). 


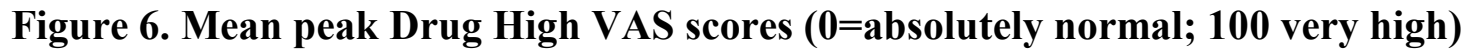

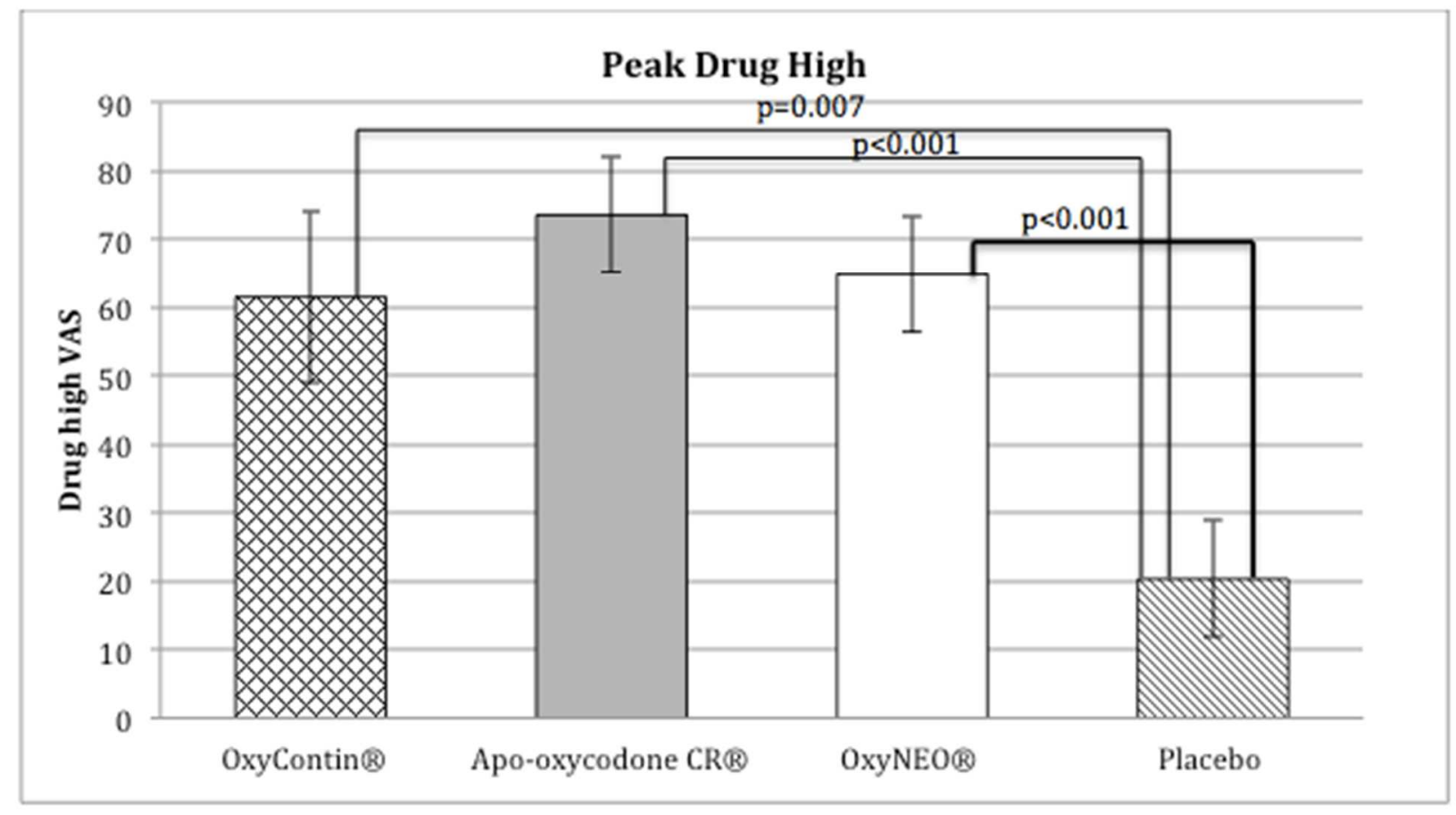

Table 7. Results of Drug High

\begin{tabular}{|l|l|l|}
\hline Drug & $\begin{array}{l}\text { Mean peak (std. } \\
\text { Error) }\end{array}$ & $\begin{array}{l}\text { Median time to peak } \\
\text { (range)(hr) }\end{array}$ \\
\hline OxyContin $®(\mathrm{~N}=5)$ & $61.64(12.60)$ & $2(1.5-4)$ \\
\hline Apo-oxycodone CR@ $(\mathrm{N}=11)$ & $73.58(8.41)$ & $2(1-3.5)$ \\
\hline OxyNEO@ $(\mathrm{N}=11)$ & $64.85(8.46)$ & $\begin{array}{l}3(1.5-3) \\
(\mathrm{n}=10)^{*}\end{array}$ \\
\hline Placebo $(\mathrm{N}=11)$ & $20.23(8.55)$ & $\begin{array}{l}2.5(1.5-3) \\
(\mathrm{n}=7)^{* *}\end{array}$ \\
\hline
\end{tabular}

*1 participant did not report increased effects from baseline

**4 participants did not report increased effects from baseline

\subsubsection{Primary outcome: Drug High (AUE)}

The active drugs were significantly higher than placebo for all the AUEs of Drug High between and including $2.5 \mathrm{hrs}$ to $8 \mathrm{hrs}(\mathrm{p}<0.05)$. For the intervals below $2.5 \mathrm{hrs}$, only Apo-oxycodone $\mathrm{CR} \AA$ produced significantly greater AUE than placebo [AUE(0-1hr), AUE(0-1.5hr), AUE(0-2hr) $(\mathrm{p}=0.038, \mathrm{p}=0.001$, and $\mathrm{p}=0.001$, respectively) $]$. Apo-oxycodone $\mathrm{CR}{ }^{\circledR}$ was significantly greater 
than $O x y N E O{ }^{\circledR}$ for $\operatorname{AUE}(0-1.5 \mathrm{hr}), \operatorname{AUE}(0-2 \mathrm{hr})$ and $\operatorname{AUE}(0-2.5 \mathrm{hr})(\mathrm{p}=0.001, \mathrm{p}=0.017$, and $\mathrm{p}=0.047$, respectively). There were no significant differences amongst the comparators for the mean AUE in the rest of the intervals. The mean effects used in figure 7 were calculated arithmetically while the means use in Figure 8 bar chart were adjusted.

Figure 7. Mean Drug High scores plotted over time for each drug

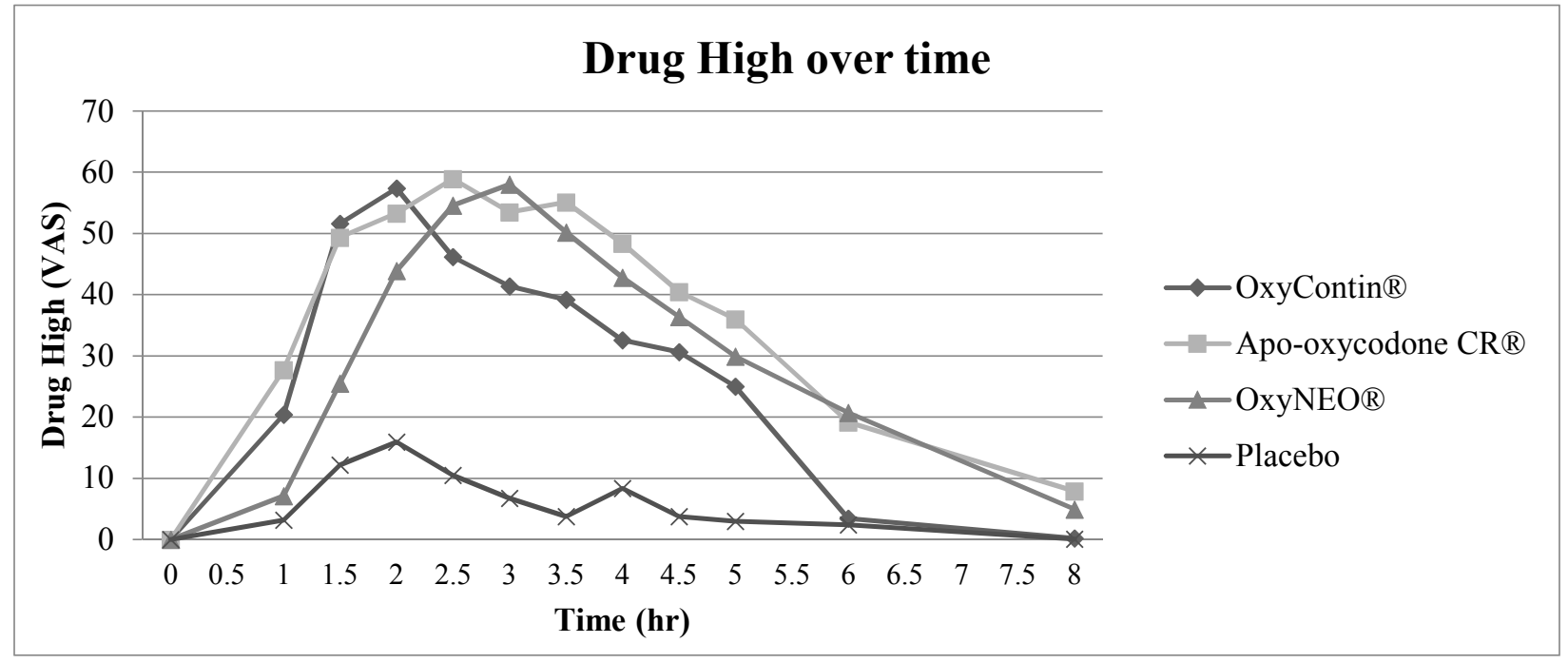

Figure 8. Mean AUE(0-hr) of Drug High VAS

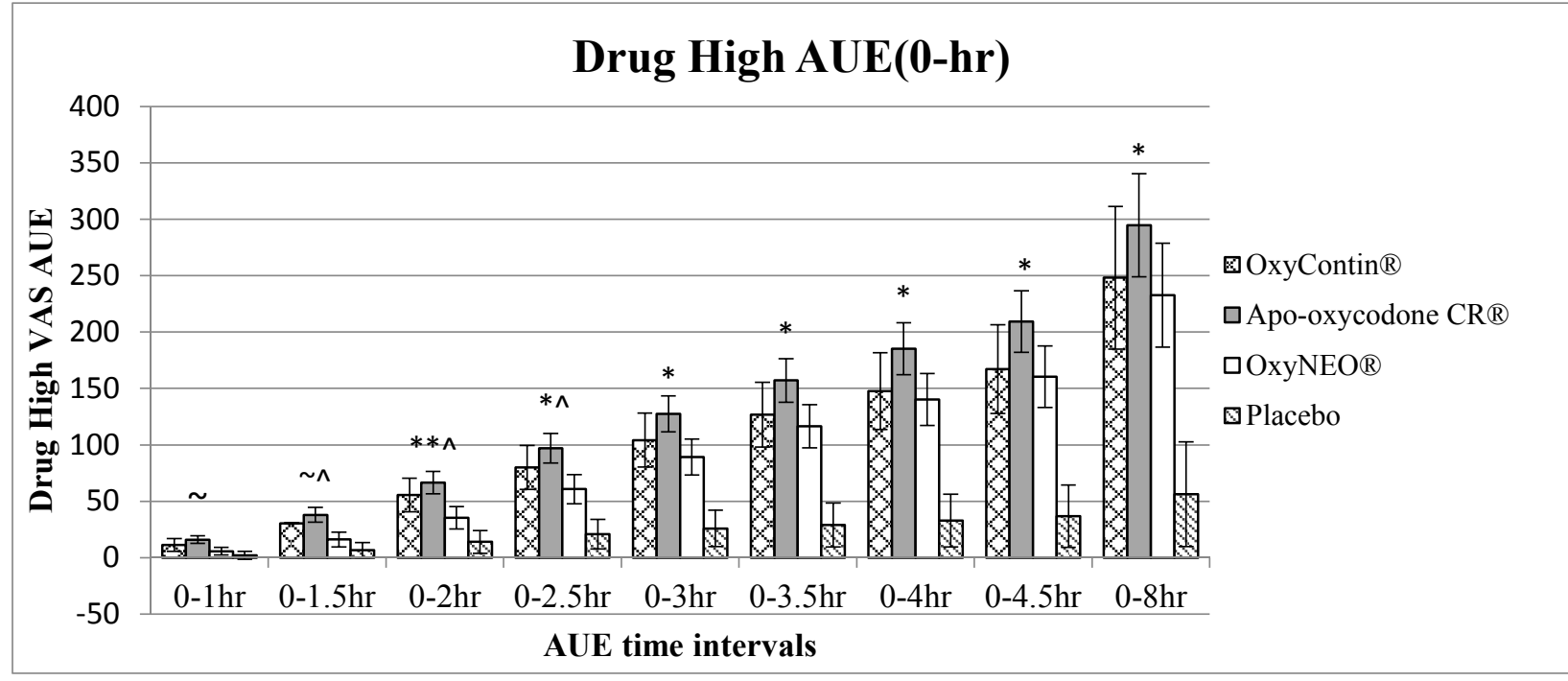

* All active drugs vs placebo $(\mathrm{p}<0.05)$

**Apo-oxycodone $\mathrm{CR} \AA$ and OxyContin ${ }^{\circledR}$ vs placebo $(\mathrm{p}<0.05)$

$\sim$ Apo-oxycodone $\mathrm{CR} \AA$ vs placebo

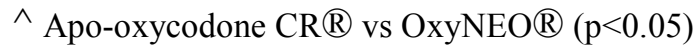




\subsubsection{Good Effects (peak and time to peak)}

OxyContin ${ }^{\circledR}$, Apo-oxycodone $\mathrm{CR} \AA$, and OxyNEO ${ }^{\circledR}$ were significantly greater than placebo in the mean peak Good Effects ( $\mathrm{p}=0.029, \mathrm{p}=0.001, \mathrm{p}=0.001$ ). No significant differences were found amongst the active drug in the mean peak and time to peak effects (TEmax).

Figure 9. Mean peak of Good Effects (Unipolar VAS)

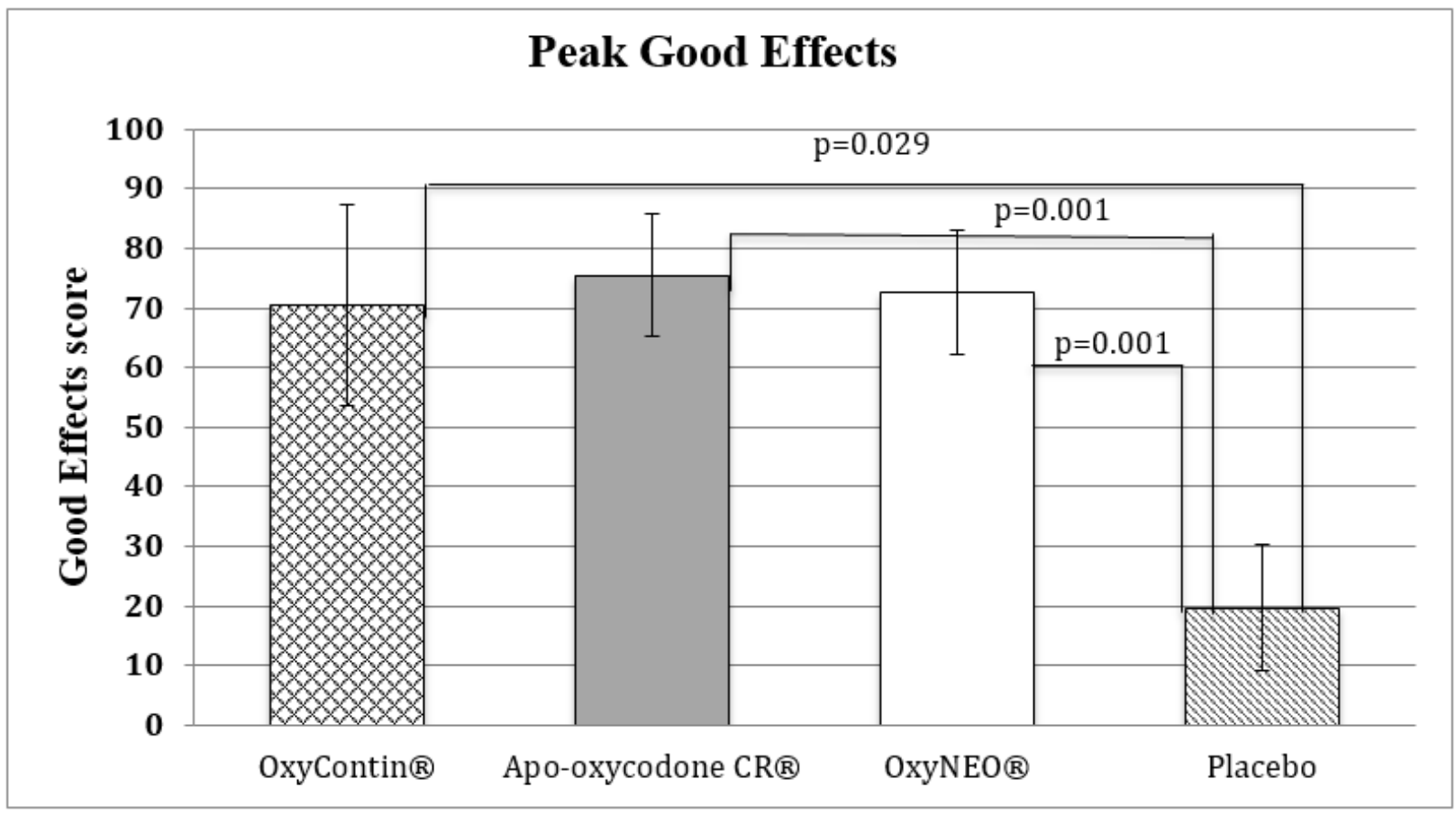

Table 8. Results of Good Effects

\begin{tabular}{|l|l|l|}
\hline Drug & Mean peak (Std. Error) & $\begin{array}{l}\text { Median time (range) } \\
\text { hr) }\end{array}$ \\
\hline OxyContin ${ }^{\circledR}(\mathrm{N}=5)$ & $70.472(17.00)$ & $2(1-2.5)$ \\
\hline Apo-oxycodone CR $(\mathrm{N}=11)$ & $75.483(10.35)$ & $2.5(1-4.5)$ \\
\hline OxyNEO $(\mathrm{N}=11)$ & $72.668(10.44)$ & $\begin{array}{l}2.25(1.5-3) \\
(\mathrm{n}=10)^{*}\end{array}$ \\
\hline Placebo $(\mathrm{N}=11)$ & $19.664(10.59)$ & $\begin{array}{l}1.5(1.5-2) \\
(\mathrm{n}=6)^{* *}\end{array}$ \\
\hline
\end{tabular}

*1 participant did not report increased effects from baseline

**5 participants did not report increased effects from baseline 


\subsubsection{Good Effects (AUE)}

The active drugs were significantly higher than placebo for the mean of the AUEs of Good Effects between and including $\operatorname{AUE}(0-3 \mathrm{hr})$ to $\operatorname{AUE}(0-4.5 \mathrm{hr})(\mathrm{p}<0.05)$. Apo-oxycodone $\mathrm{CR} \mathbb{R}$ and $\mathrm{OxyNEO}{ }^{\circledR}$ were significantly higher than placebo for $\operatorname{AUE}(0-8 \mathrm{hr})(\mathrm{p}=0.001$ and $\mathrm{p}=0.002$, respectively). Apo-oxycodone $\mathrm{CR} \otimes$ was significantly higher than placebo for $\mathrm{AUE}(0-2.5 \mathrm{hr})$ $(p=0.019)$. There were no significant differences amongst other comparators amongst the measured AUEs. The mean effects used in figure 10 were calculated arithmetically while the means use in Figure 11 bar chart were adjusted.

Figure 10. Mean Good Effects scores plotted over time for each condition

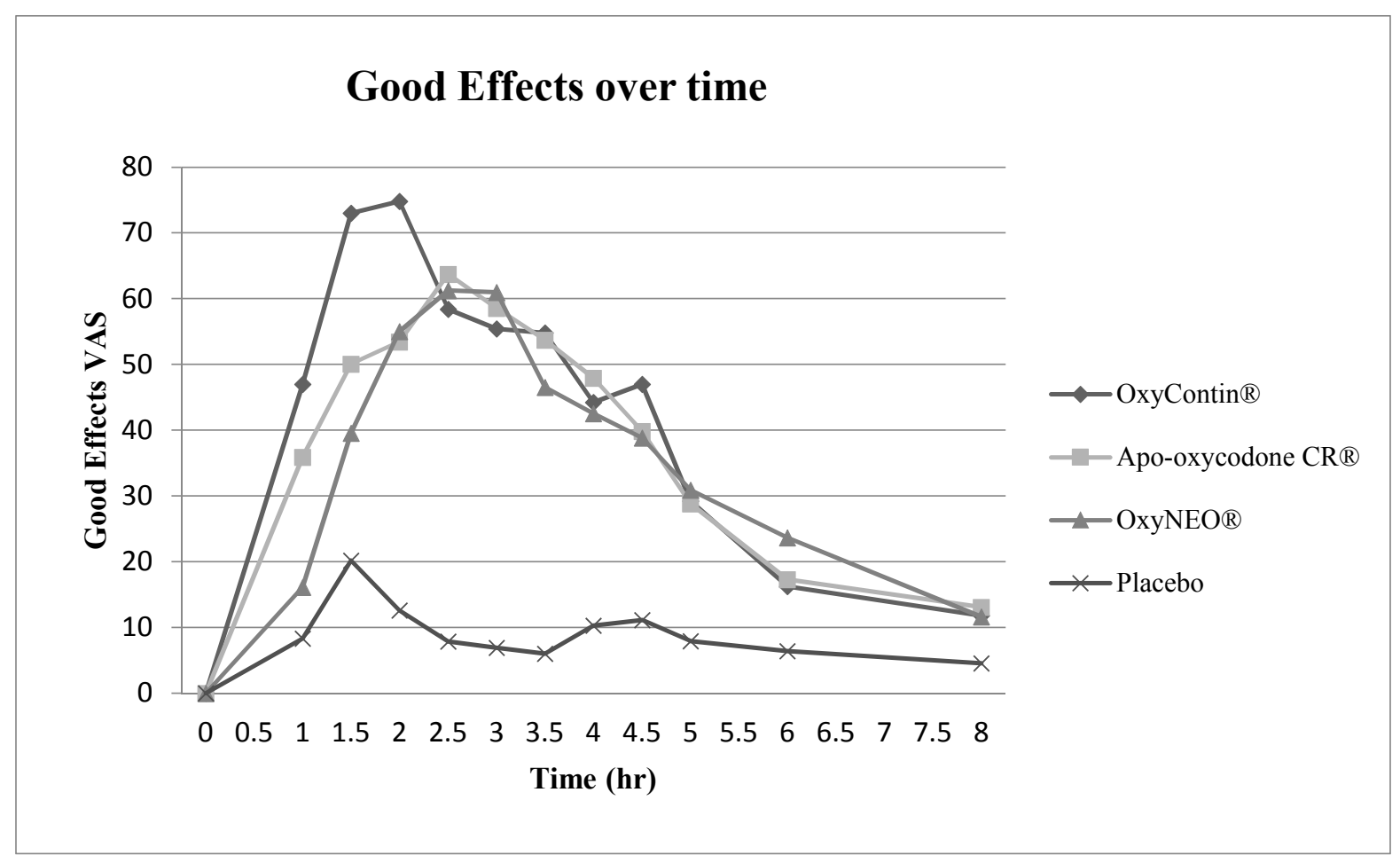


Figure 11. Mean AUE(0-hr) of Good Effects VAS

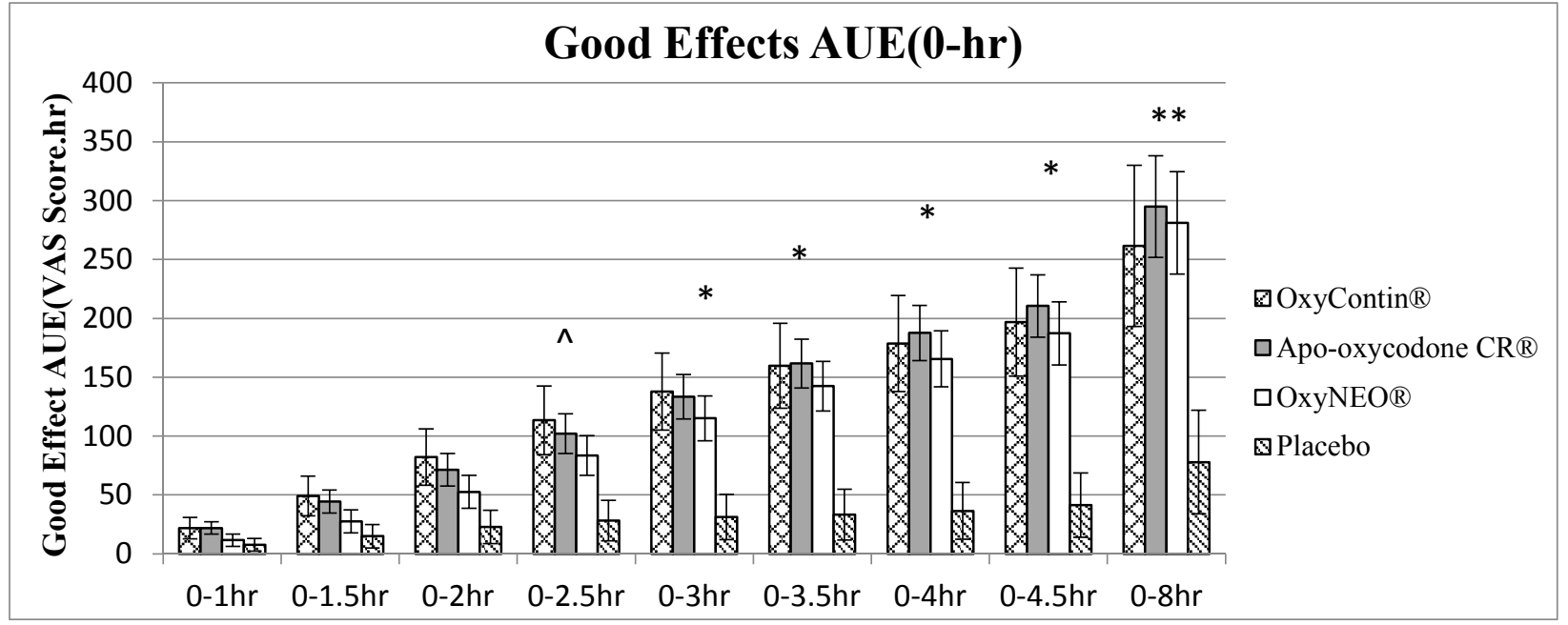

* All active drugs vs placebo $(\mathrm{p}<0.05)$

**Apo-oxycodone $\mathrm{CR} \AA$ and OxyNEO $\AA$ vs placebo $(\mathrm{p}<0.005)$

$\wedge$ Apo-oxycodone $\mathrm{CR} \AA$ vs placebo $(\mathrm{p}=0.019)$

\subsubsection{Take Drug Again}

OxyNEO ${ }^{\circledR}$ and Apo-oxycodone $\mathrm{CR} 囚$ were not significantly different from placebo for the mean score of Take Drug Again ( $\mathrm{p}=0.10$ and $\mathrm{p}=0.061$, respectively). This measure was used for the last six participants in the three-day design.

\section{Figure 12. Mean Take Drug Again VAS}

$(0=$ definitely not; $50=$ neutral; $100=$ definitely so $)$ for each drug

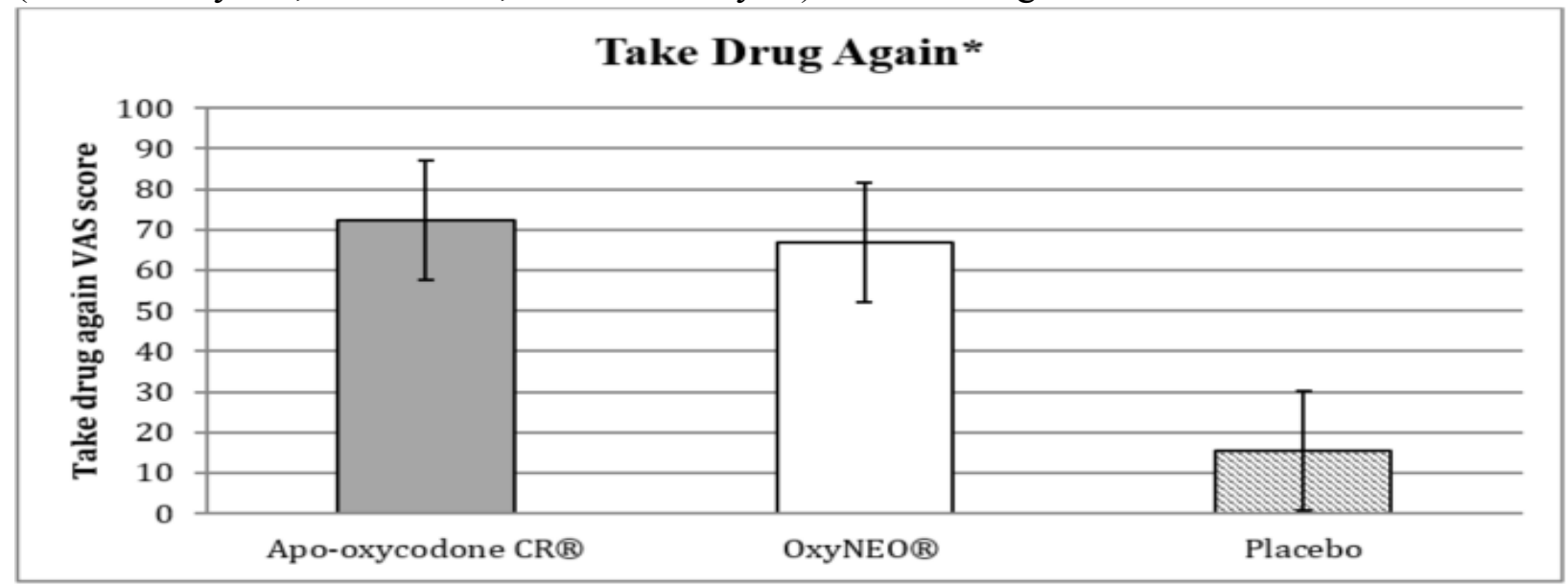

*The differences amongst the comparators were not statistically significant. 
Table 9. Mean Take Drug Again

\begin{tabular}{|l|l|}
\hline Drug & Mean Take Drug Again (Std. Error) \\
\hline Apo-oxycodone $\mathrm{CR} \otimes(\mathrm{N}=6)$ & $72.3(14.70)$ \\
\hline OxyNEO $(\mathrm{N}=6)$ & $66.84(14.75)$ \\
\hline Placebo & $15.53(14.77)$ \\
\hline
\end{tabular}

\subsubsection{Other VAS measures}

The active drugs were significantly higher than placebo for the mean and AUE(0-8hr) of Drug Effects $(p<0.05)$. There were no significant differences amongst the active drugs for the mean peak and AUE $(0-8 \mathrm{hr})$. There were no significant differences amongst the comparators for the mean peak and AUE(0-8hr) of Bad Effects, Feel Sick, Nausea, Sleepy, and Dizzy.

3.4.2 Addiction Research Centre Inventory (ARCI) results [peak (change from baseline to maximum effect) and $\operatorname{AUE}(0-8 \mathrm{hr})]$

\subsubsection{ARCI-Morphine-Benzedrine Group (MBG) subscale}

The MBG subscale measures euphoria. Apo-oxycodone $\mathrm{CR} \circledast$ and $\mathrm{OxyNEO}{ }^{\circledR}$ were significantly greater than placebo for the mean peak of MBG subscale ( $\mathrm{p}=0.007$ and $\mathrm{p}=0.015$, respectively) while OxyContin ${ }^{\circledR}$ was not significantly different from placebo. There were no significant differences amongst the active drugs in this measure. There were no significant differences for the mean AUE(0-8hr) of MBG amongst the active drugs and the placebo. 
Figure 13. Mean change from baseline to peaks of the MBG subscale for each formulation

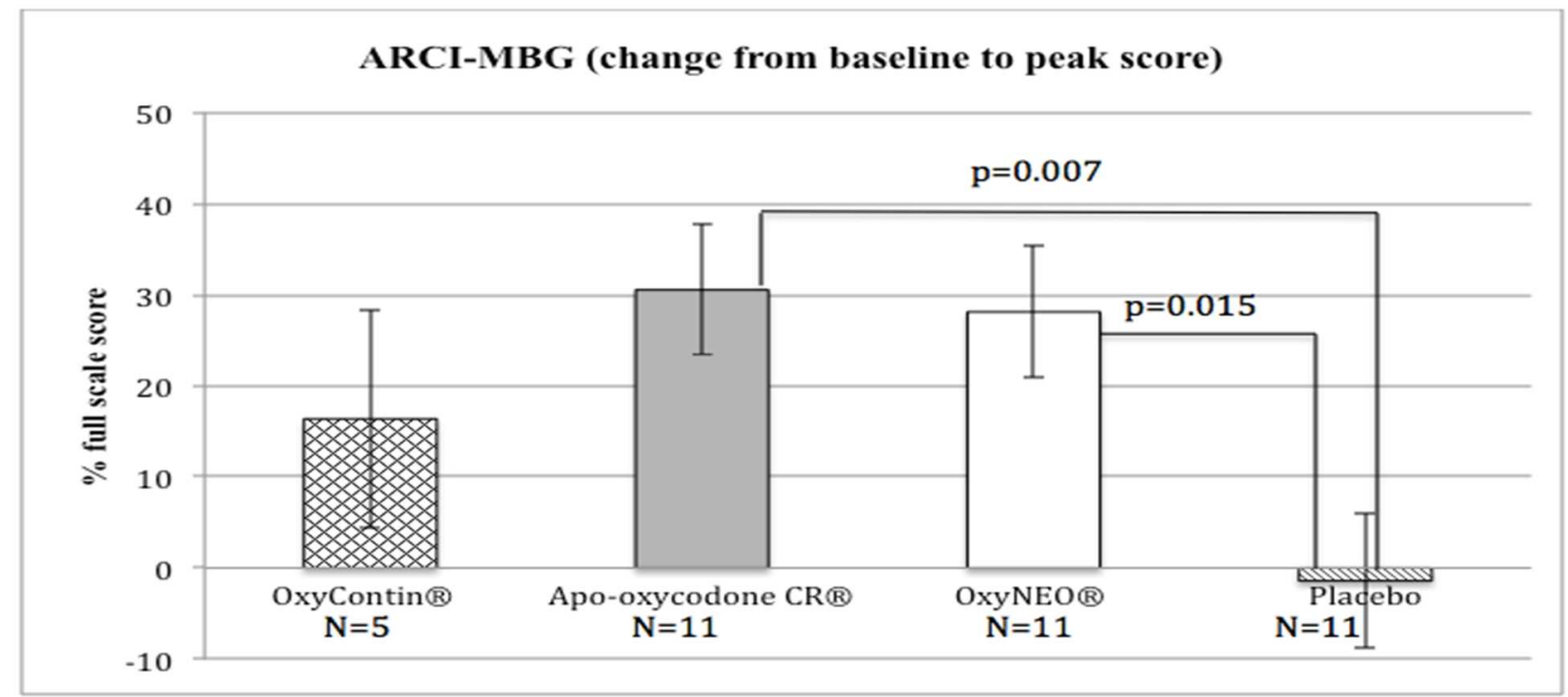

\subsubsection{ARCI sedation subscales}

For the mean peak and AUE(0-8hr) subscale of Pentobarbital-Chlorpromazine-Alcohol Group (PCAG), no significant differences were detected amongst the drugs. For the mean peak ARCI/Cole subscale of Sedation Mental, Apo-oxycodone CR ${ }^{\circledR}$ was significantly greater than placebo $(\mathrm{p}=0.021)$; similar results were obtained for the mean AUE(0-8hr) of Sedation Mental.

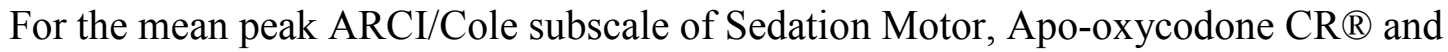
OxyNEO ${ }^{\circledR}$ were significantly greater than placebo $(\mathrm{p}=0.001$ and $\mathrm{p}=0.002$, respectively); similar results were obtained for the mean $\operatorname{AUE}(0-8 \mathrm{hr})$ of Sedation Motor. Other than the differences mentioned, there were no significant differences amongst the comparators for these subscales. The peak effects are depicted in figure 10.

\subsubsection{ARCI: Negative effects' subscales}

For the mean peak ARCI subscale of Lysergic Diethylamide (LSD), Apo-oxycodone CR $\mathbb{R}$ produced significantly greater effects compared to those of placebo $(p=0.002)$; for the mean $\mathrm{AUE}(0-8 \mathrm{hr})$ of LSD, Apo-oxycodone $\mathrm{CR} \AA$ and $\mathrm{OxyNEO}{ }^{\circledR}$ produced significantly greater effects compared to placebo $(\mathrm{p}<0.05)$. For the mean peak ARCI/Cole subscale of Unpleasant Physical, Apo-oxycodone $\mathrm{CR} \AA$ and OxyNEO ${ }^{\circledR}$ produced significantly greater effects than those of placebo ( $\mathrm{p}=0.001$ and $\mathrm{p}=0.003$, respectively). For this subscale, Apo-oxycodone $\mathrm{CR} \circledast$ and 
OxyNEO ${ }^{\circledR}$ also produced greater effects compared to those of OxyContin ${ }^{\circledR}(\mathrm{p}=0.012$ and $\mathrm{p}=0.020)$; Similar results were obtained for the mean AUE(0-8hr) of Unpleasant Physical. For the mean peak ARCI/Cole subscale of Unpleasant Dysphoria, Apo-oxycodone CR ${ }^{\circledR}$ produced greater effects compared to placebo $(\mathrm{p}=0.004)$; similar results were obtained for the mean AUE(0-8hr) of Unpleasant Dysphoria. Other than the differences mentioned, there were no significant differences amongst the comparators for these subscales. The peak effects are depicted in figure 10.

\subsubsection{ARCI: Stimulant and other euphoric effects' subscales}

For the mean peak ARCI subscale of Amphetamine Group (AMPH), OxyNEO® produced greater effects compared to placebo $(p=0.019)$; there were no significant differences amongst the comparators for the mean $\mathrm{AUE}(0-8 \mathrm{hr})$ of $\mathrm{AMPH}$. There were no significant differences for the mean peak and AUE(0-8hr) of Benzedrine Group subscale amongst the comparators. For the mean peak ARCI/Cole subscale of Stimulation Motor, Apo-oxycodone CR ${ }^{\circledR}$ and OxyNEO $®$ produced significantly greater effects than those of placebo $(p=0.038$ and $p=0.022$, respectively); For the mean $\operatorname{AUE}(0-8 \mathrm{hr})$ of this subscale, there were no significant differences amongst the comparators. For the mean peak ARCI/Cole subscale of Stimulation Euphoria, Apo-oxycodone $\mathrm{CR} \AA$ and $\mathrm{OxyNEO}{ }^{\circledR}$ produced significantly greater effects than those of placebo $(\mathrm{p}=0.001$ and $\mathrm{p}=0.002$, respectively); similar results were obtained for the mean $\operatorname{AUE}(0-8 \mathrm{hr})$ of this subscale. The peak effects are depicted in figure 10.

\subsubsection{ARCI-Abuse Potential subscale}

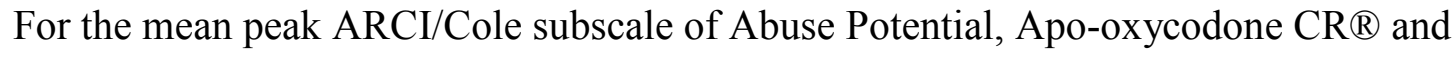
OxyContin ${ }^{\circledR}$ produced greater effects compared to placebo $(\mathrm{p}=0.185$ and $\mathrm{p}=0.57$, respectively) and OxyNEO ${ }^{\circledR}$ produced significantly greater effects compared to those of placebo $(\mathrm{p}<0.5)$. There were no significant differences amongst the active drugs and the placebo for the mean AUE(0-8hr) of this subscale. The peak effects are depicted in figure 10. 
Figure 14. Mean change from baseline to peak of the ARCI subscales for each condition

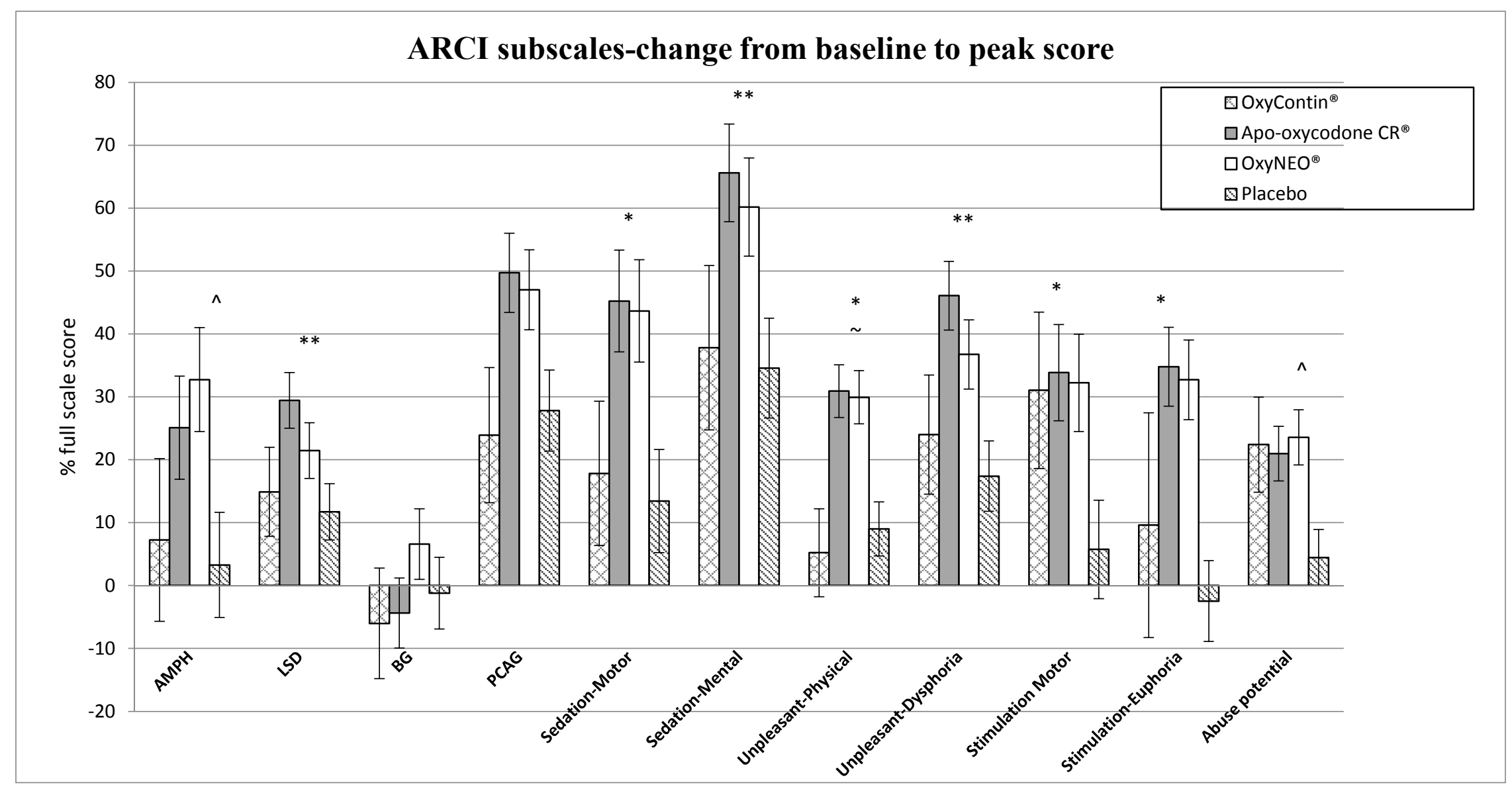

*Apo-oxycodone CR $\AA$ and OxyNEO $\circledR$ vs placebo $(\mathrm{p}<0.05)$

$* *$ Apo-oxycodone $\mathrm{CR} \otimes$ vs placebo $(\mathrm{p}<0.05)$

$\wedge$ OxyNEO ${ }^{\circledR}$ vs placebo $(\mathrm{p}<0.05)$

$\sim$ OxyNEO ${ }^{\circledR}$ and Apo-oxycodone $C R \AA$ vs OxyContin ${ }^{\circledR}(p<0.05)$ 


\subsubsection{ARCI-positive and negative composite scales}

Apo-oxycodone $\mathrm{CR}{ }^{\circledR}$ and $\mathrm{OxyNEO}{ }^{\circledR}$ were significantly greater than placebo in the mean ARCI positive composite scale $(\mathrm{p}<0.001)$. There were no significant differences amongst the active drugs for this measure. Apo-oxycodone $\mathrm{CR} \AA$ and OxyNEO ${ }^{\circledR}$ were significantly greater than placebo in the mean ARCI negative composite scale $(p<0.005)$. There were no significant differences amongst the active drugs for this measure.

Figure 15. Mean change from baseline to peak for positive and negative composites scales of ARCI for each condition

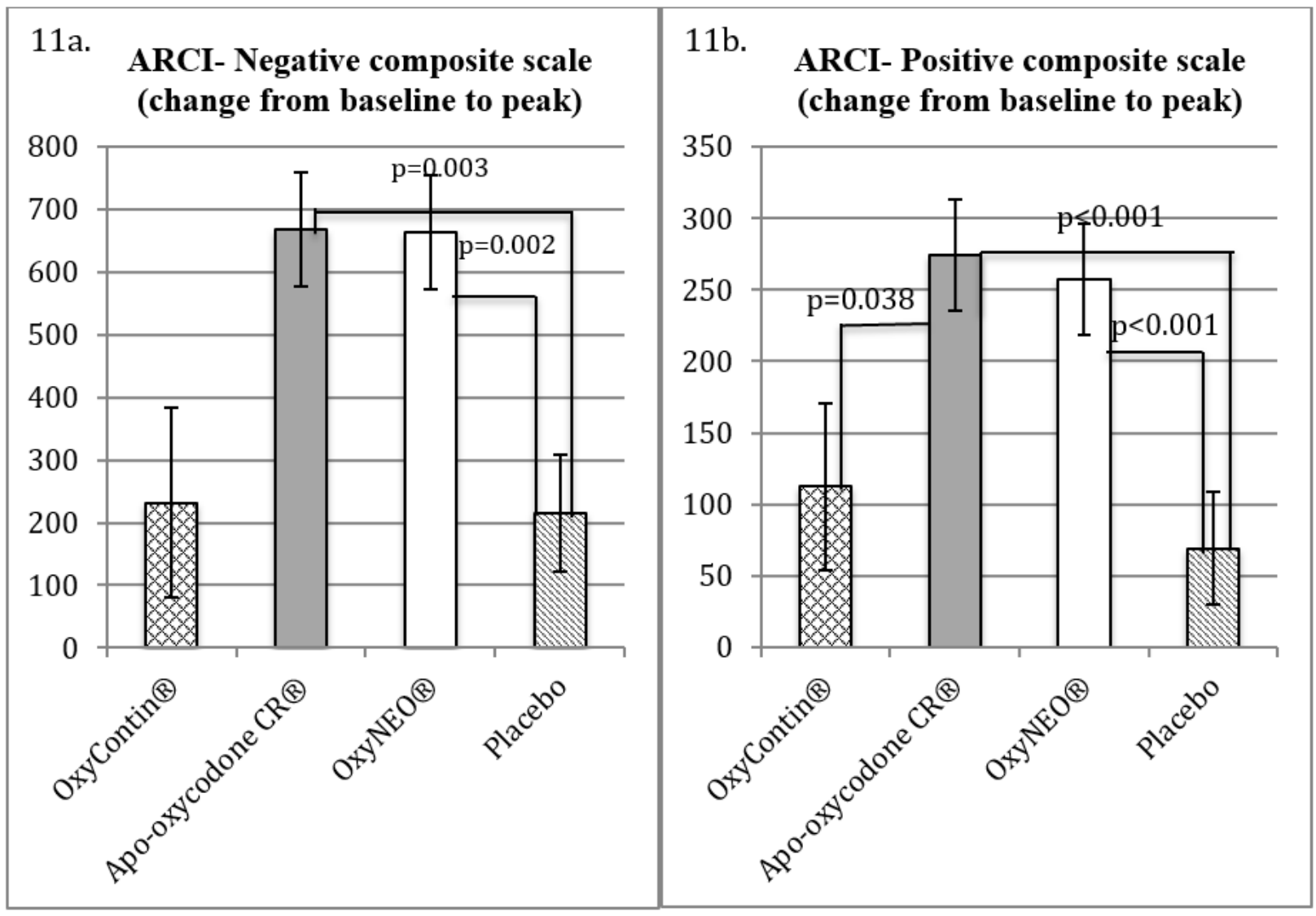


3.4.3 Profile of Mood States (POMS): [peak (change from baseline to maximum effect) and AUE(0-8hr)]

\subsubsection{POMS subscales}

The mean peak effects of Fatigue for Apo-oxycodone $\mathrm{CR} 囚$ and OxyNEO ${ }^{\circledR}$ were significantly greater than those for placebo $(p<0.05)$. There were no significant differences amongst the active drugs for this subscale. No significant differences were found for the mean $\operatorname{AUE}(0-8 \mathrm{hr})$ of Fatigue amongst the comparators.

For the mean peak of Confusion, the effects of Apo-oxycodone CR® were significantly greater than those of placebo and OxyContin ${ }^{\circledR}(p<0.05)$. There were no significant differences amongst the other comparators for this measure; for the mean $\operatorname{AUE}(0-8 \mathrm{hr})$ of Confusion, Apo-oxycodone $\mathrm{CR} \AA$ was significantly greater than placebo $(\mathrm{p}<0.05)$. There were no significant differences amongst the active drugs and the placebo for the mean peak and AUE $(0-8 \mathrm{hr})$ of TensionAnxiety, Anger-Hostility, Depression-Dejection, Friendliness, Vigor, Elation, and arousal.

Figure 16. Mean change from baseline to peak of the Fatigue subscale for each condition

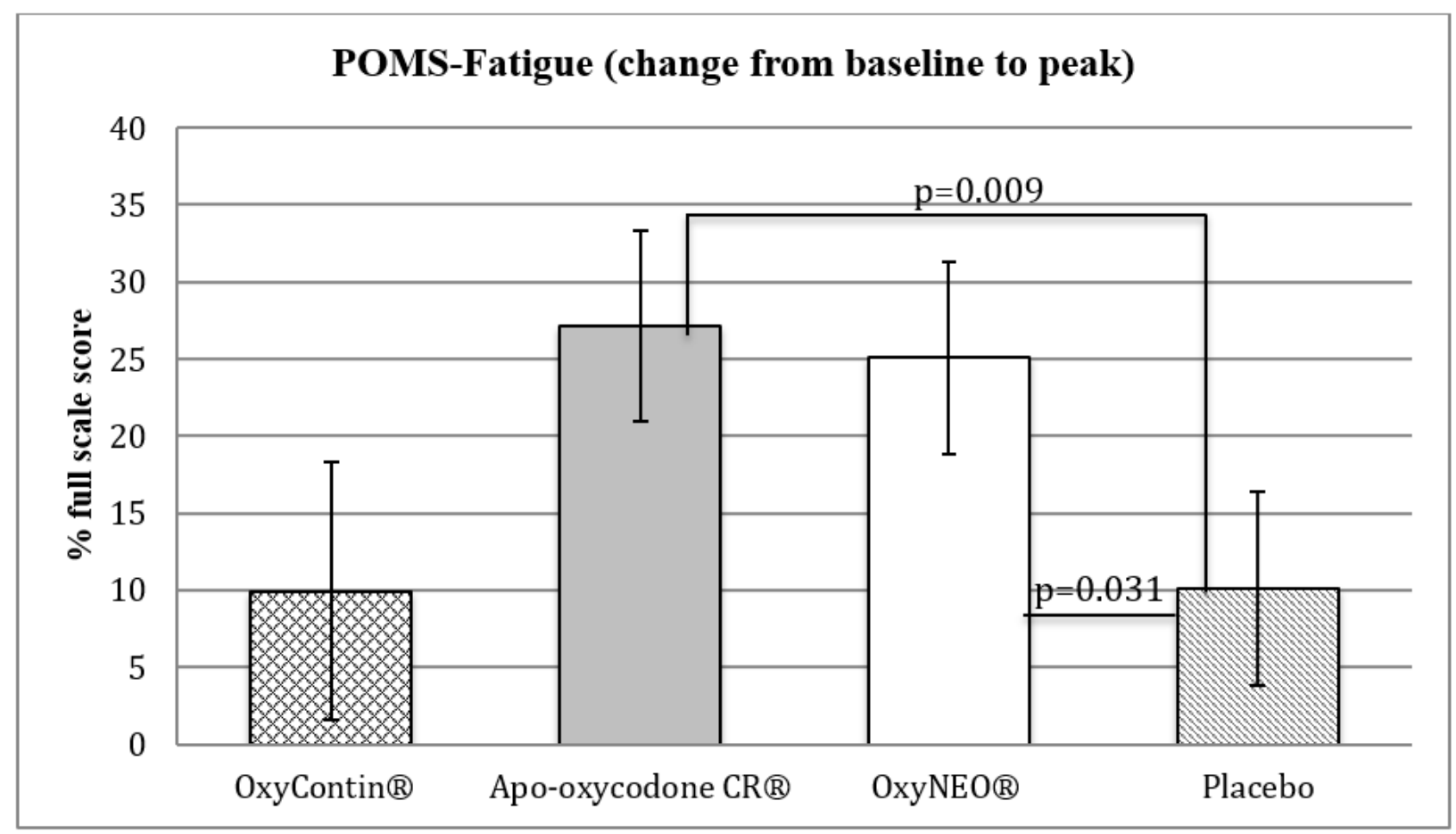


Figure 17. Mean change from baseline to peak of the Elation subscale for each condition

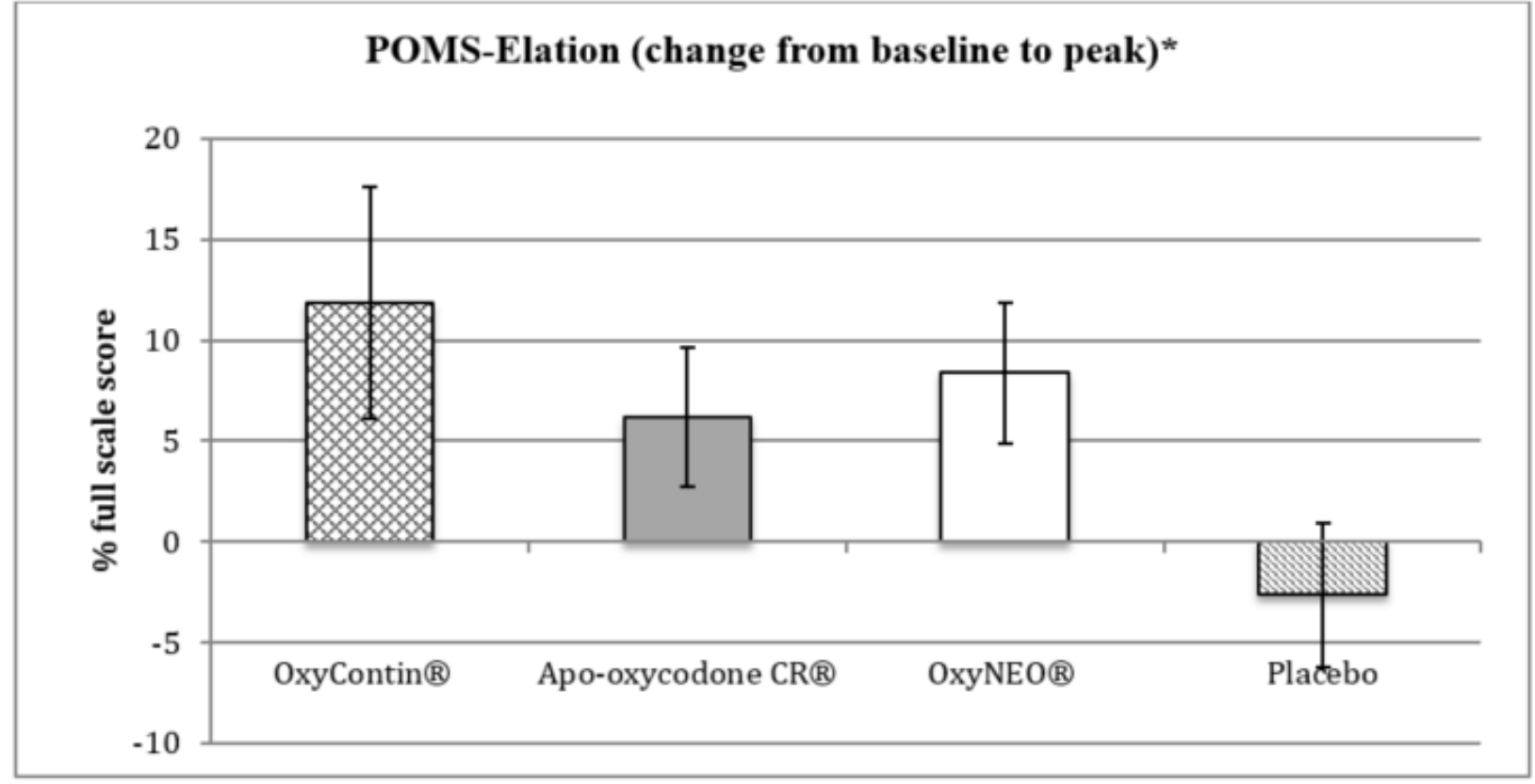

*The differences amongst the comparators were not statistically significant.

Figure 18. Mean change from baseline to peak of the POMS subscales for each condition

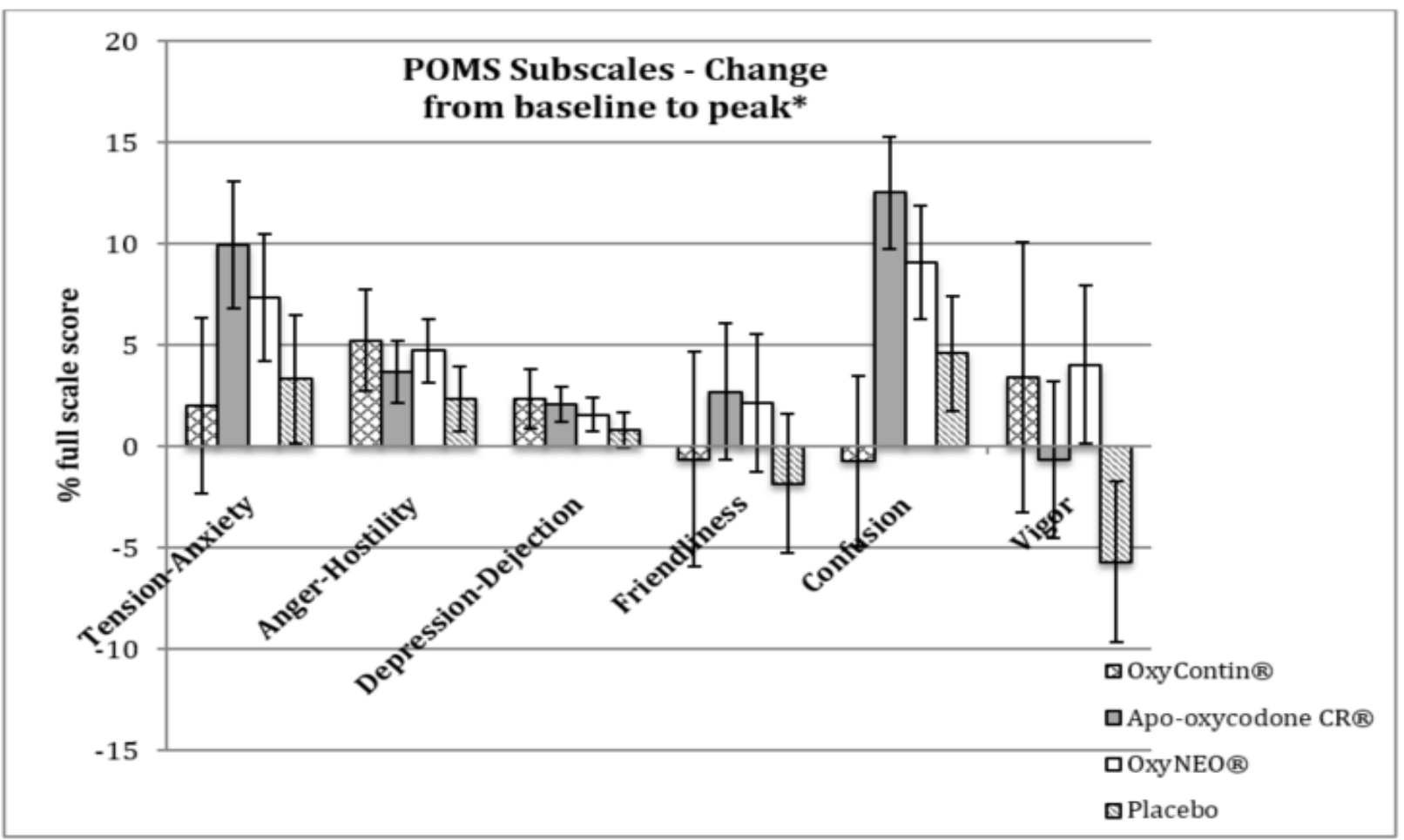

*The differences amongst the comparators were not statistically significant. 
3.4.3.2 POMS positive and negative composite scale and Total Mood Disturbance scale (TMD) [peak (change from baseline to maximum effect) and AUE(0-8hr)]

There were no significant differences in POMS positive composite score amongst the drugs. For the mean negative composite scale, Apo-oxycodone $\mathrm{CR} \circledast$ produced significantly greater effects than placebo $(\mathrm{p}<0.05)$ and $\mathrm{OxyNEO}{ }^{\circledR}$ was associated with increased effects compared to placebo although the differences were not significant $(\mathrm{p}=0.097)$. There were no significant differences amongst the other comparators for this measure. For the derived measure of peak Total Mood Disturbance scale (TMD), there were no significant differences amongst the drugs.

Figure 19. Mean change from baseline to peak for POMS Positive and Negative composite scales for each condition

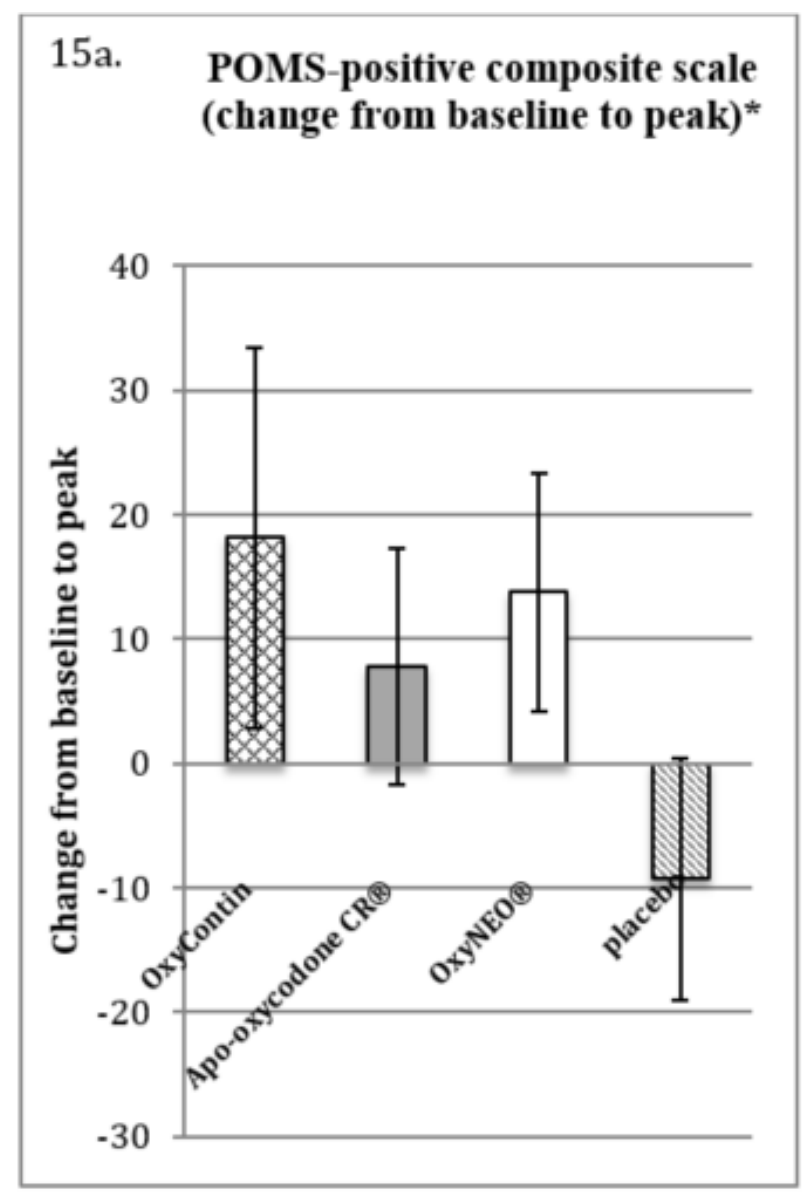

\section{5b. POMS-negative composite scale (change from baseline to peak)}

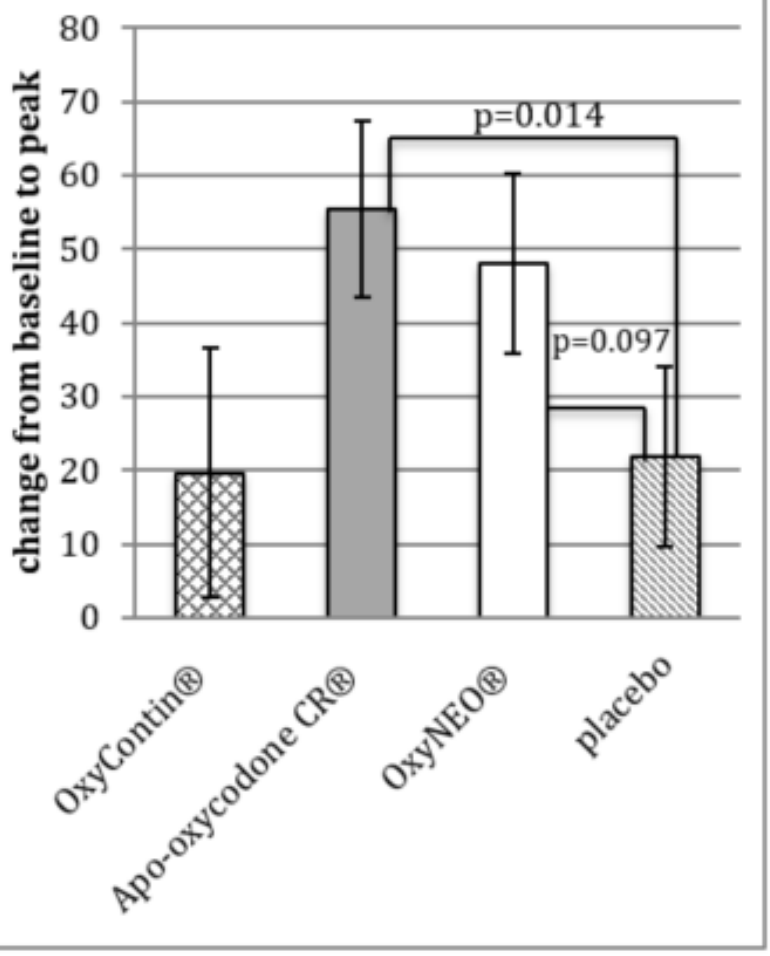

*The differences amongst the comparators were not statistically significant. 
Figure 20. Mean change from baseline to peak for POMS Total Mood Disturbance (TMD) scale for each condition

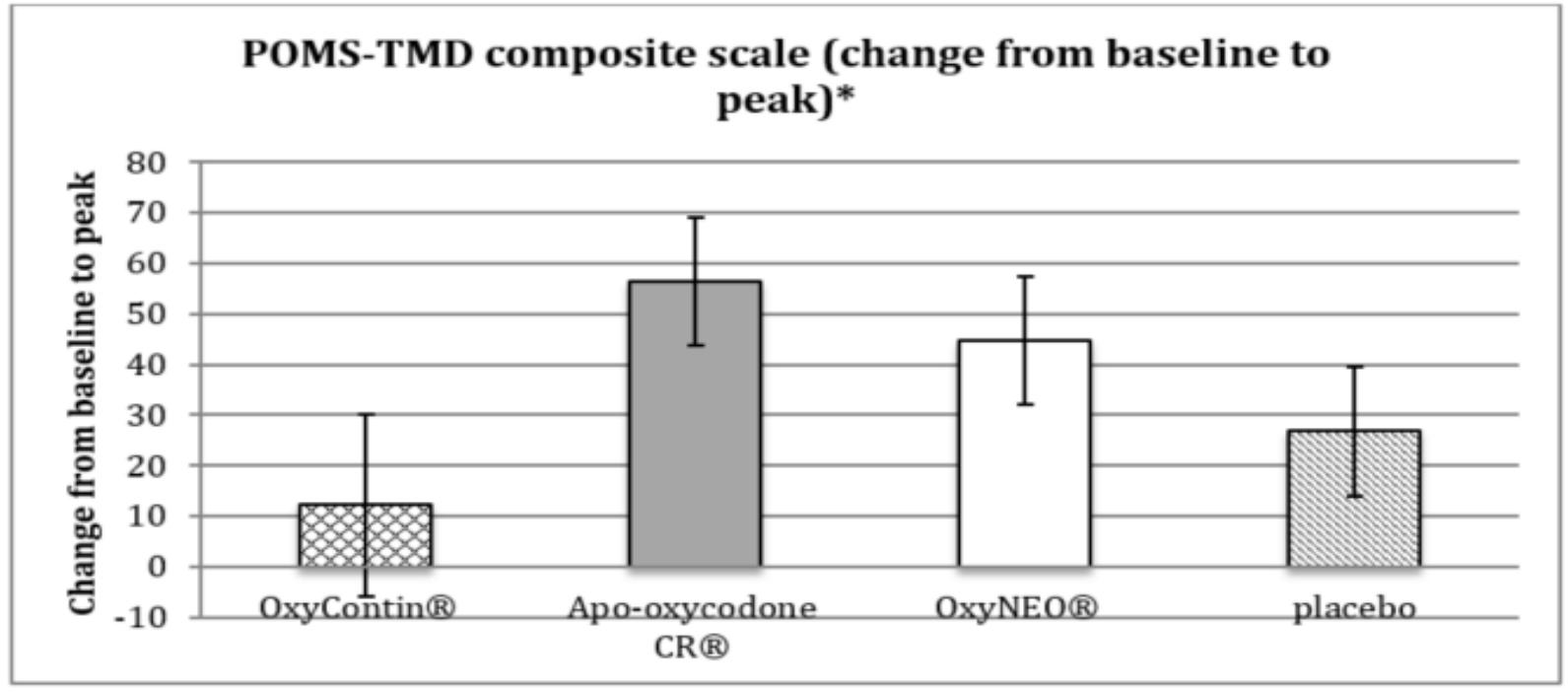

*The differences amongst the comparators were not statistically significant.

\subsubsection{Digital Symbol Substitution Test (DSST)}

There were no significant differences amongst the active drugs or between the active drugs and placebo for the mean peak number of correct trials and for the mean number of completed trials of DSST.

Figure 21. Results of the Digital Symbol Substitution Test (DSST) variables for each condition
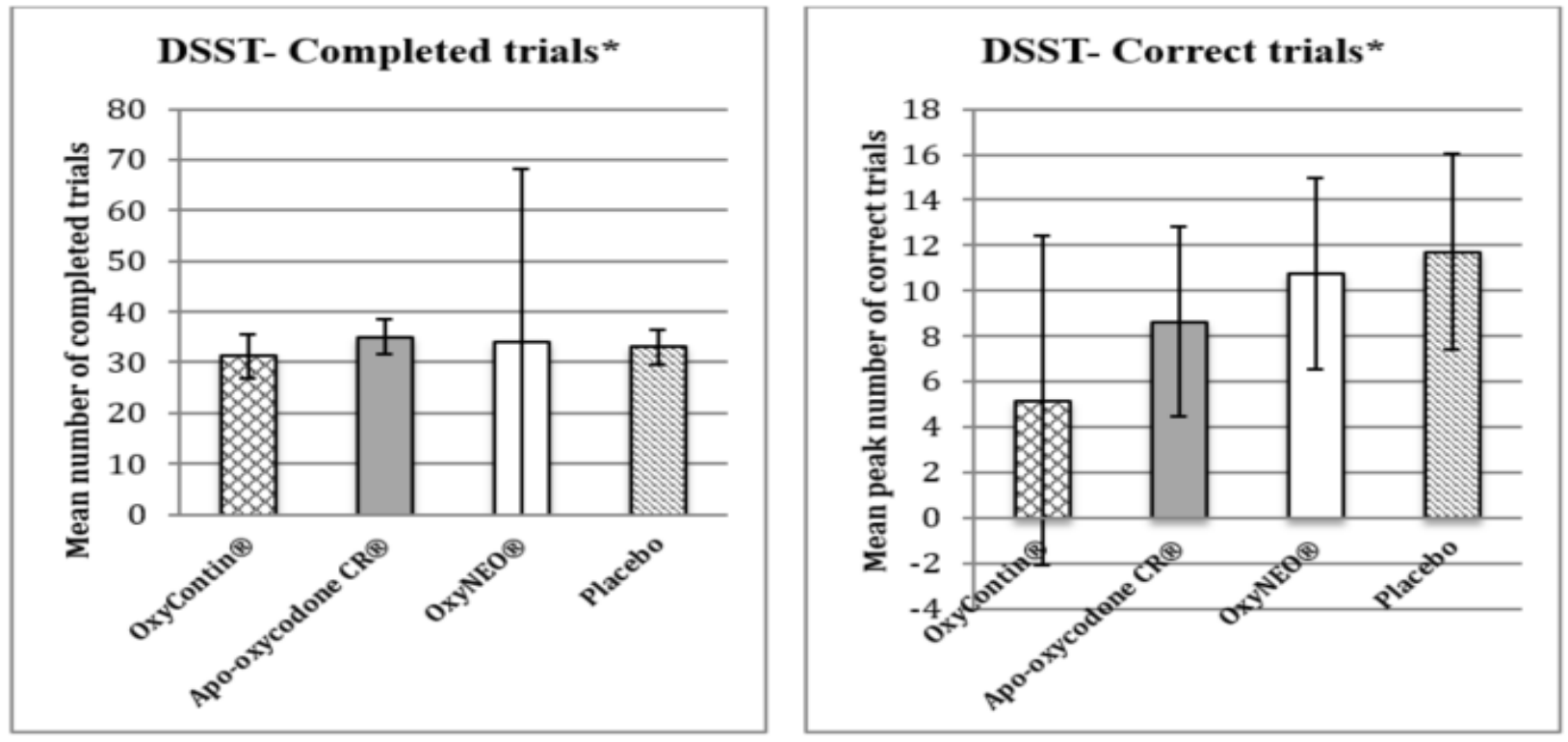
*The differences amongst the comparators were not statistically significant.

\subsubsection{Pupil diameter}

The active drugs produced significantly decreased mean trough pupillary responses compared to those of placebo $(p=0.001)$. There were no significant differences amongst the active drug in the mean trough measure of pupil diameter.

Table 10. Mean Pupil diameter measurements

\begin{tabular}{|l|c|}
\hline \multicolumn{1}{|c|}{ Drug } & $\begin{array}{l}\text { Mean diameter (Std. Error) } \\
(\mathbf{m m})\end{array}$ \\
\hline OxyContin $\AA(\mathrm{N}=5)$ & $2.2(0.24)$ \\
\hline Apo-oxycodone $\mathrm{CR} \AA(\mathrm{N}=11)$ & $2.1(0.18)$ \\
\hline OxyNEO $(\mathrm{N}=11)$ & $2.3(0.18)$ \\
\hline Placebo $(\mathrm{N}=11)$ & $3.4(0.18)$ \\
\hline
\end{tabular}

Figure 22. Mean pupil diameter response to each condition from 0 to 8 hours

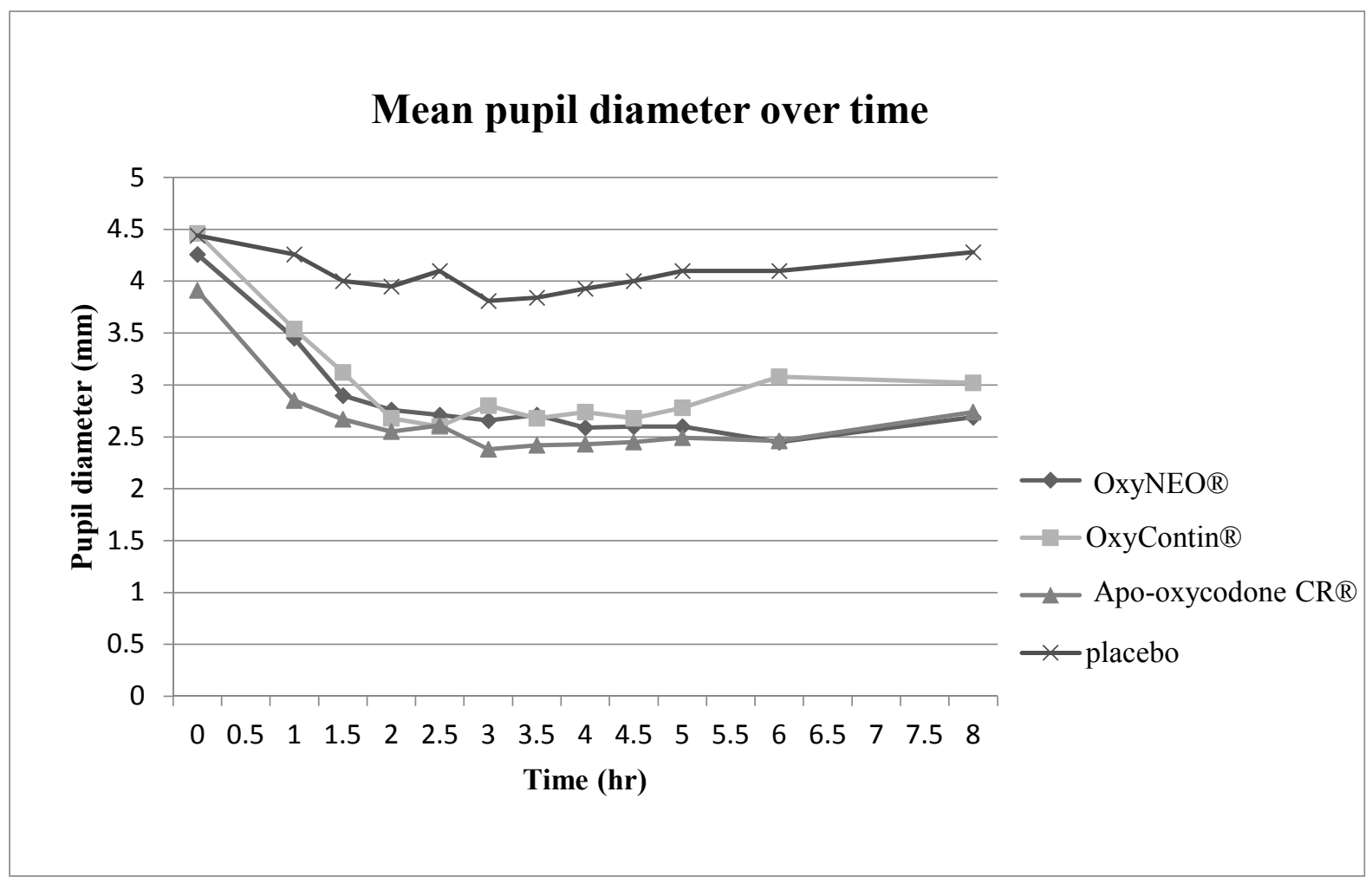




\subsection{Pharmacokinetic results}

\subsubsection{Maximum plasma drug concentration (Cmax)}

There were no significant differences amongst the active drug in the measure of Cmax (ng/mL).

Figure 23. Mean peak plasma concentration (Cmax) of oxycodone for each active condition

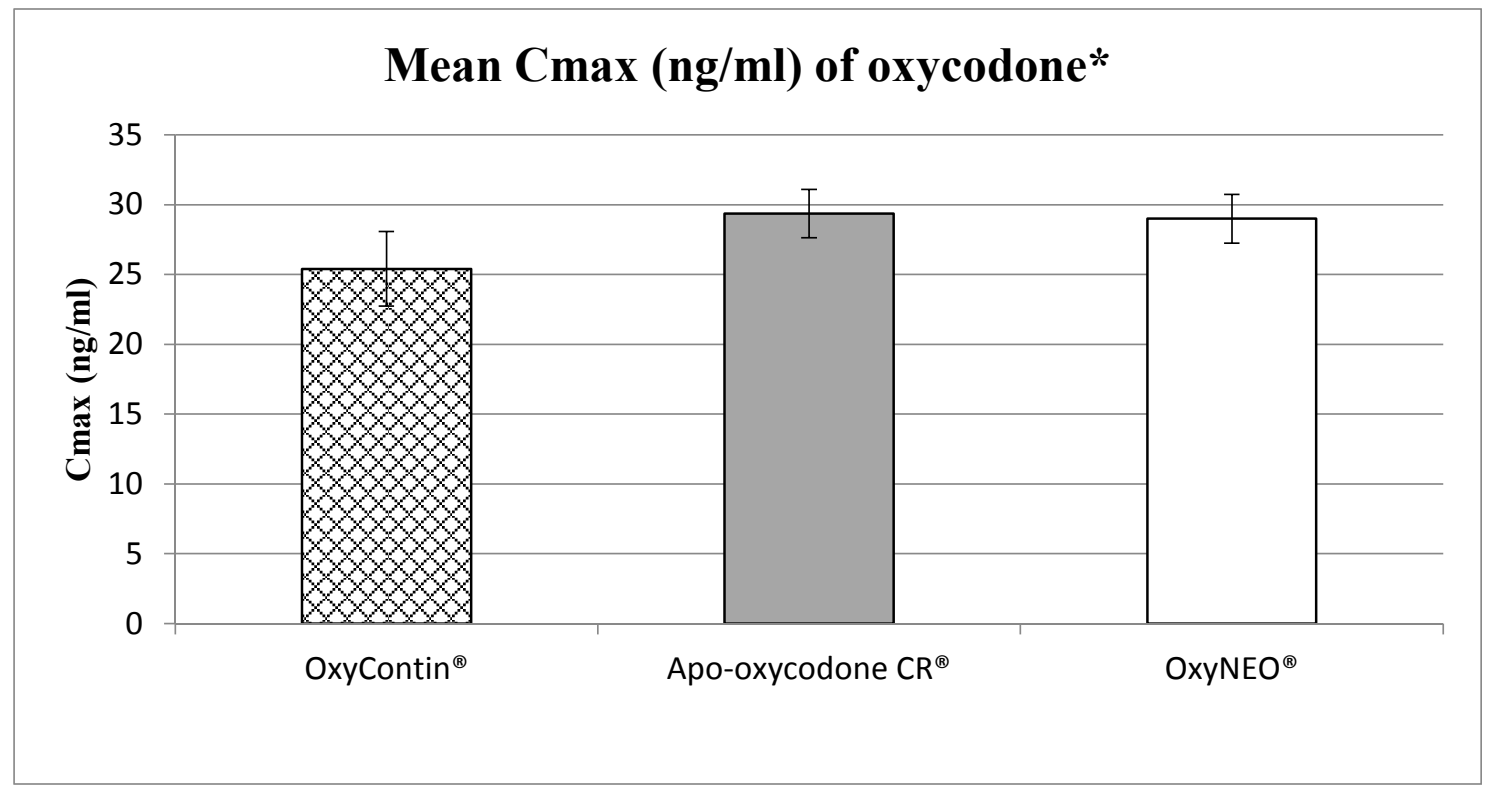

*The differences amongst the comparators were not statistically significant.

Table 11. Mean Cmax of oxycodone for each active condition

\begin{tabular}{|l|l|}
\hline Active drug & $\begin{array}{l}\text { Mean Cmax of the Active } \\
\text { Formulations (std. error) }\end{array}$ \\
\hline OxyContin $\AA$ & $25.4(2.67)$ \\
\hline Apo-oxycodone CR ${ }$ & $29.4(1.74)$ \\
\hline OxyNEO $\circledR$ & $29.1(1.73)$ \\
\hline
\end{tabular}

3.5.2 Time to reach maximum plasma drug concentration (Tmax)

As depicted in Table 12. The median time to peak oxycodone concentrations (Tmax) for Apooxycodone $\mathrm{CR} \bowtie$ and OxyContin ${ }^{\circledR}$ were similar while they were 2-2.5 hours shorter than the Tmax for OxyNEOR. 
Table 12. Median and range of Tmax of oxycodone for each active condition

\begin{tabular}{|l|l|}
\hline Active drug & Median Tmax of the Active Drugs (range) (hr) \\
\hline OxyContin ${ }^{\circledR}$ & $2.5(1.5-3.5)$ \\
\hline OxyNEO ${ }^{\circledR}$ & $5(1.5-6)$ \\
\hline Apo-oxycodone CR ${ }^{\circledR}$ & $3(1-6)$ \\
\hline
\end{tabular}

3.5.3 Area under the plasma drug concentration curve (AUC) of oxycodone There were no significant differences amongst the drugs in the drug exposure using the mean pharmacokinetic parameter of $\mathrm{AUC}(0-1 \mathrm{hr}), \mathrm{AUC}(0-2 \mathrm{hr}), \mathrm{AUC}(0-3 \mathrm{hr}), \mathrm{AUC}(0-4 \mathrm{hr})$, and AUC $(0-5 \mathrm{hr})$. The mean plasma concentrations used in figure 24 were calculated arithmetically while the means use in Figure 25 bar chart were adjusted.

Figure 24. Mean oxycodone plasma concentrations for each condition plotted over time

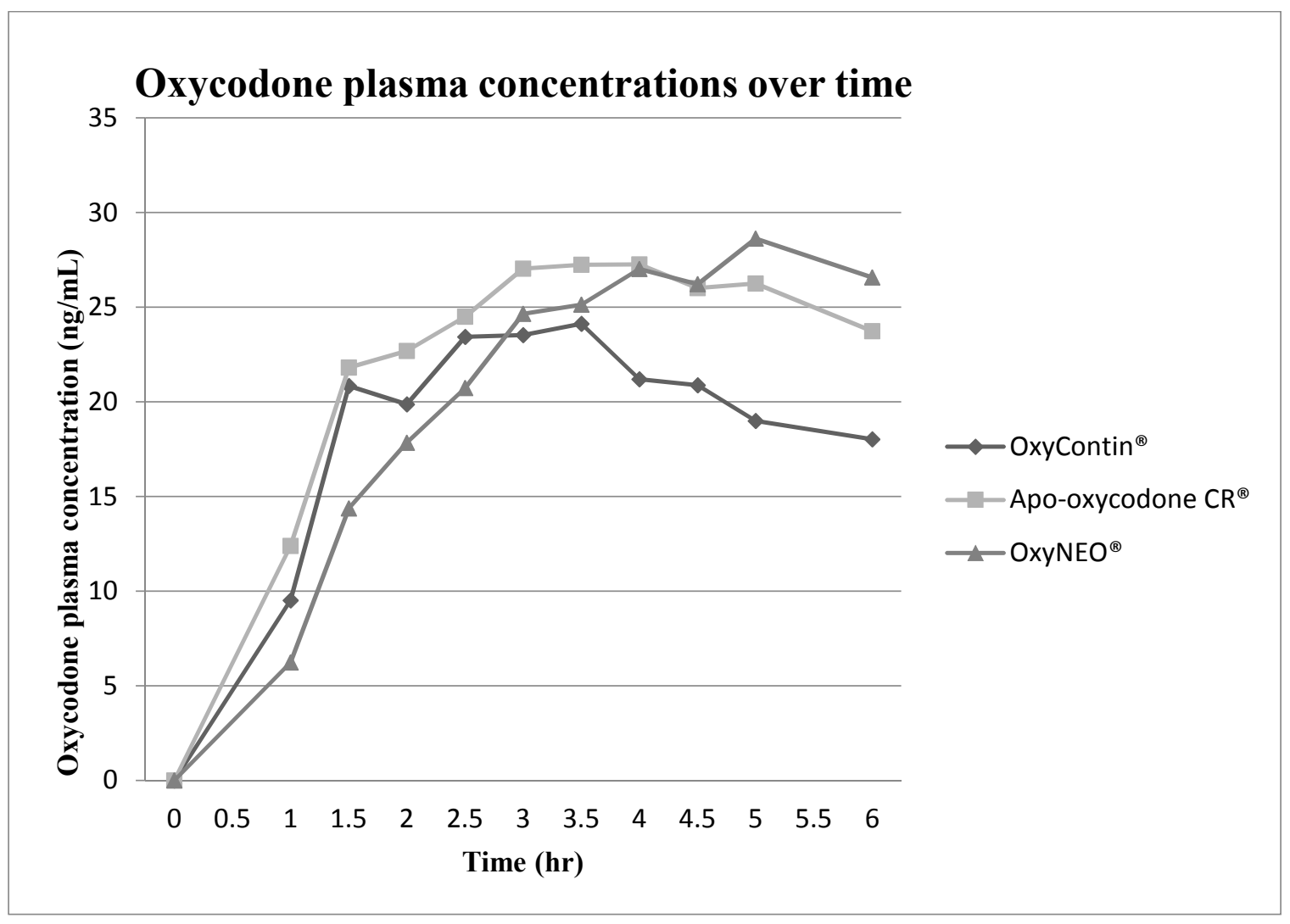


Figure 25. Mean AUC of oxycodone for each condition from 0-1 hr to 0-5 hr

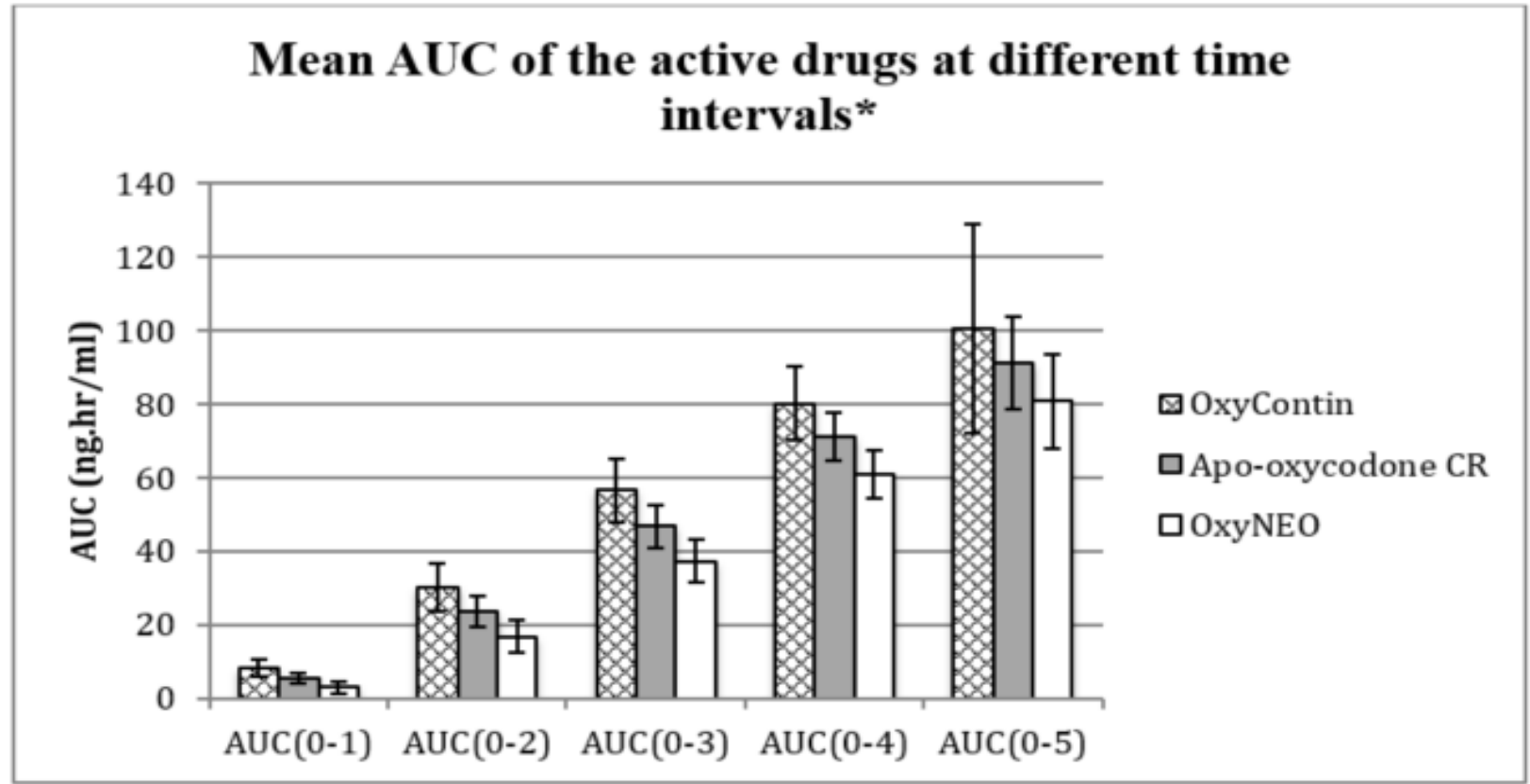

*The differences amongst the comparators were not statistically significant.

\subsubsection{Abuse Quotient (Cmax/Tmax)}

There were no significant differences amongst Apo-oxycodone $C R \AA$ and OxyContin $\AA$ and OxyNEO ${ }^{\circledR}$ for the measure of abuse quotient of oxycodone plasma concentrations.

Figure 26. Mean abuse quotient for each condition with regards to oxycodone plasma concentrations

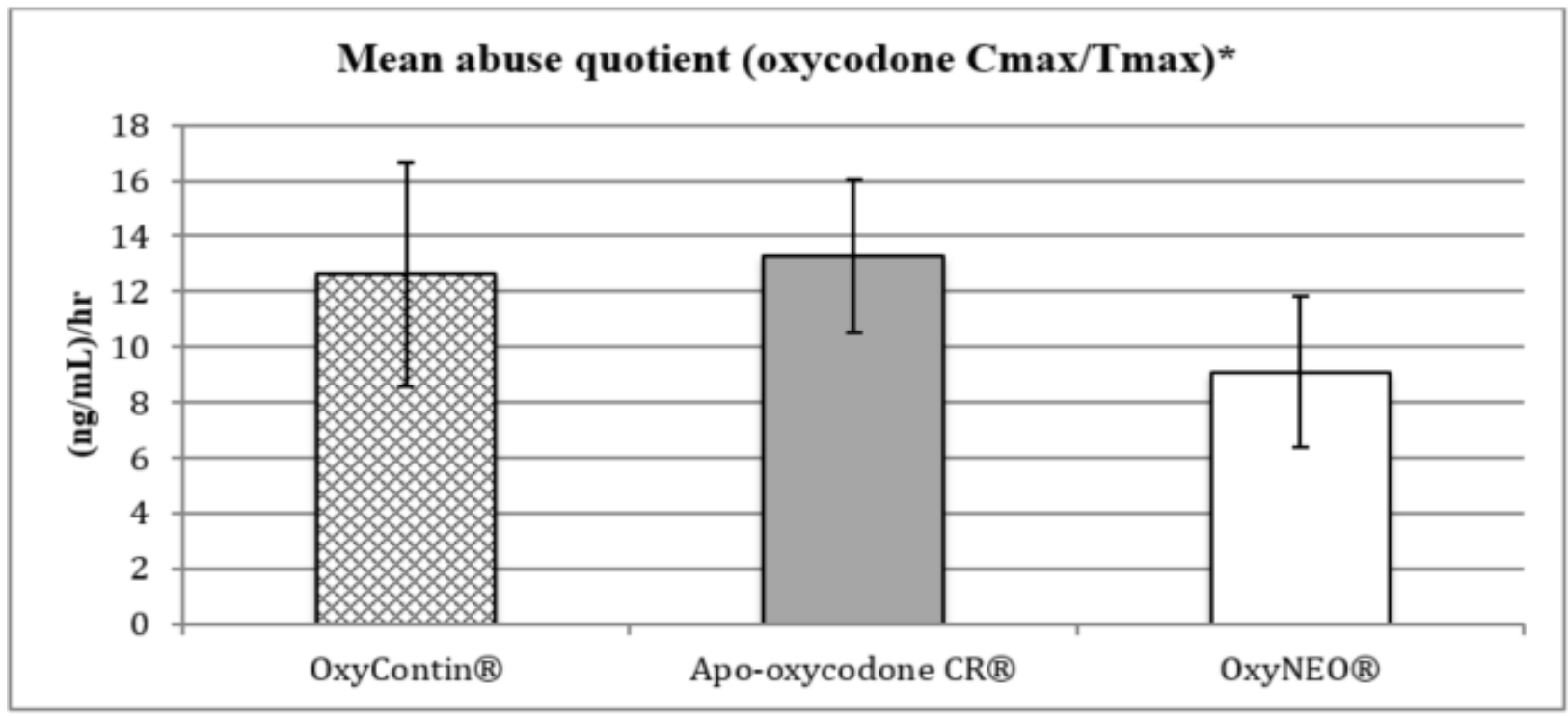

*The differences amongst the comparators were not statistically significant. 
Table 13. Mean Abuse Quotient (oxycodone (Cmax/Tmax)) for each active condition

\begin{tabular}{|l|r|}
\hline Drug & Abuse quotient ((ng/mL)/hr) \\
\hline OxyContin $\AA$ & $12.6(4.04)$ \\
\hline Apo-oxycodone CR $\AA$ & $13.3(2.74)$ \\
\hline OxyNEO $\AA$ & $9.1(2.74)$ \\
\hline
\end{tabular}

\subsubsection{Plasma concentrations of oxycodone and its metabolites over time}

The arithmetic means of plasma concentrations of oxycodone and those of oxycodone metabolites of the study drugs are depicted over time in figures 22,23 , and 24 . The left vertical axis is the concentration scale for oxycodone and noroxycodone, and the right vertical axis represents the concentration scale for oxymorphone and noroxymorphone.

Figure 27. Mean plasma concentration of oxycodone and its metabolites from 0 to 6 hours for OxyContin ${ }^{\circledR}$

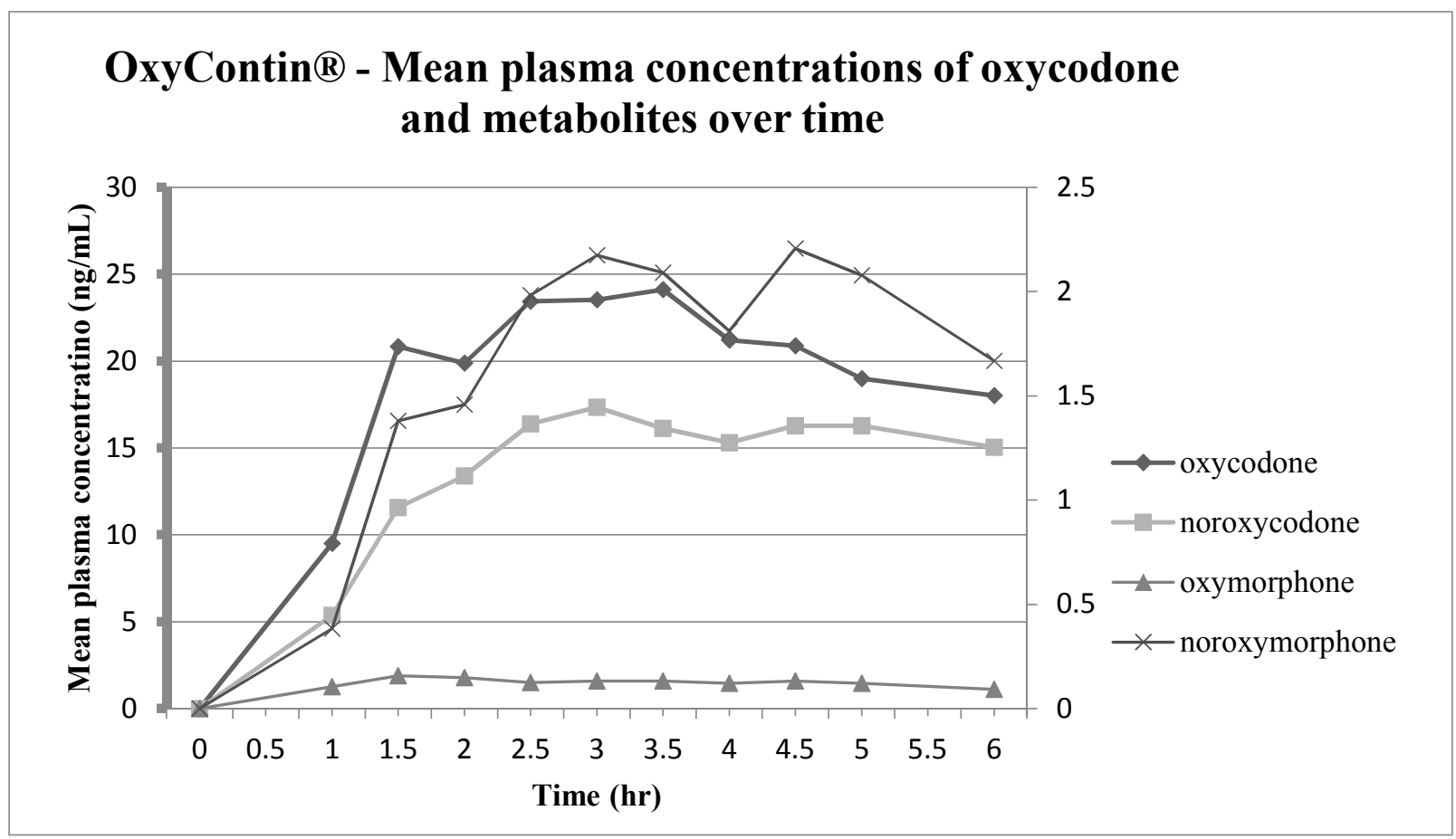


Figure 28. Mean plasma concentration of oxycodone and its metabolites from 0 to 6 hours for Apo-oxycodone $\mathbf{C R}^{\circledR}$

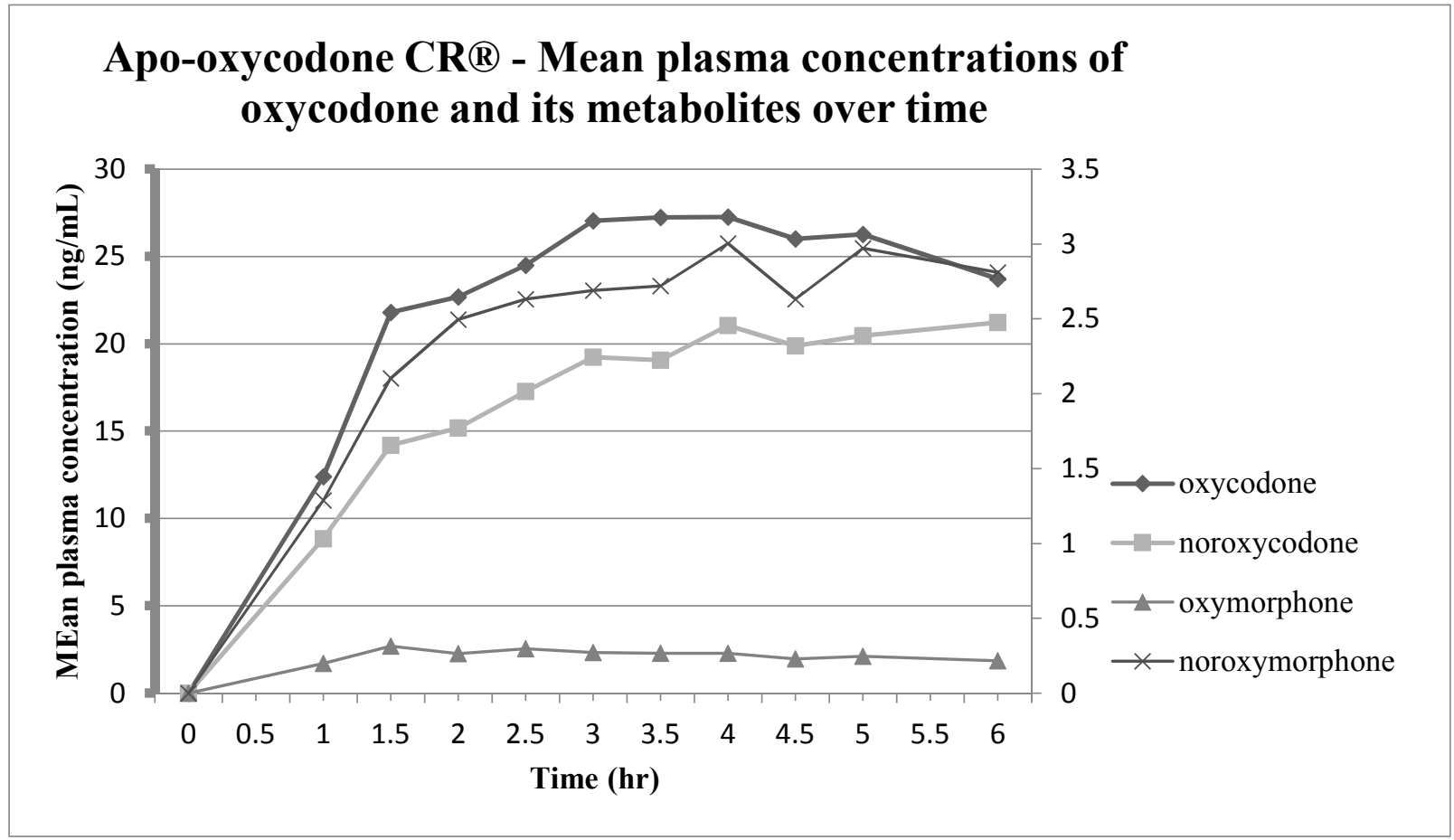

Figure 29. Mean plasma concentration of oxycodone and its metabolites from 0 to 6 hours for OxyNEO ${ }^{\circledR}$

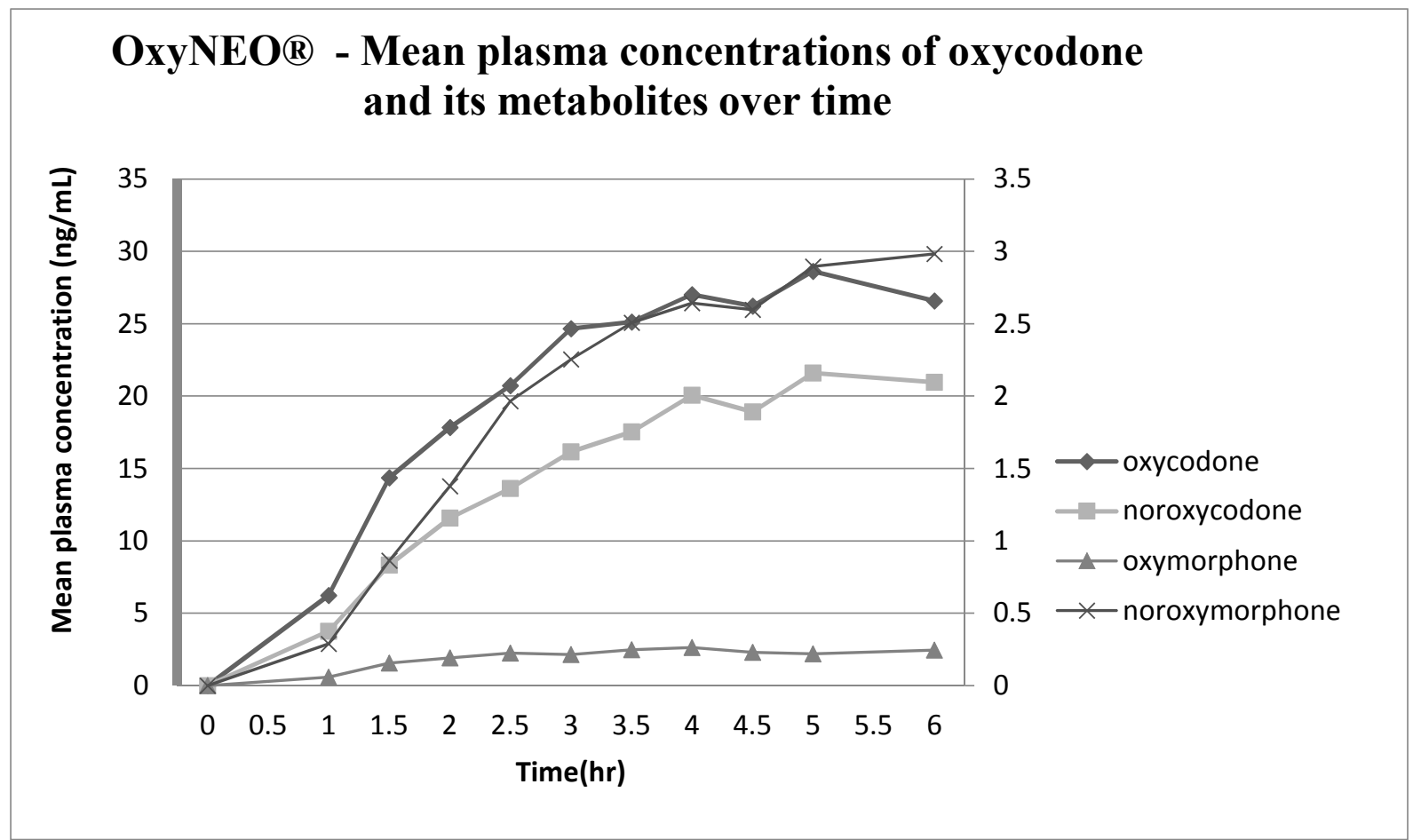




\subsubsection{Participants with low oxymorphone plasma concentrations}

Relatively low levels (concentrations of less than $0.1 \mathrm{ng} / \mathrm{ml}$ ) of oxymorphone were observed in three participants in response to all the administered active drugs. In these participants there was a delay in the initial increase in noroxymorphone concentration such that the concentration of noroxymorphone at the 1-hour point (or longer) are below $0.1 \mathrm{ng} / \mathrm{ml}$. Figures 25, 26, and 27 show the plasma concentration over time graphs for one of these participants (017-01) for which oxymorphone concentration was consistently lower than $0.1 \mathrm{ng} / \mathrm{ml}$ at all the time points. Figure 29 depicts the plasma concentration over time graph of a participant (061-06) for which oxymorphone concentration was higher than $0.1 \mathrm{ng} / \mathrm{ml}$ at all the measured time points. For this participant the concentration of noroxymorphone were consistently over $0.1 \mathrm{ng} / \mathrm{ml}$ at all time points. The left vertical axis is the concentration scale for oxycodone and noroxycodone, and the right vertical axis represents the concentration scale for oxymorphone and noroxymorphone.

Figure 30. Participant 017-01 Mean plasma concentration of oxycodone and its metabolite concentrations from 0 to 6 hours for OxyContin ${ }^{\circledR}$

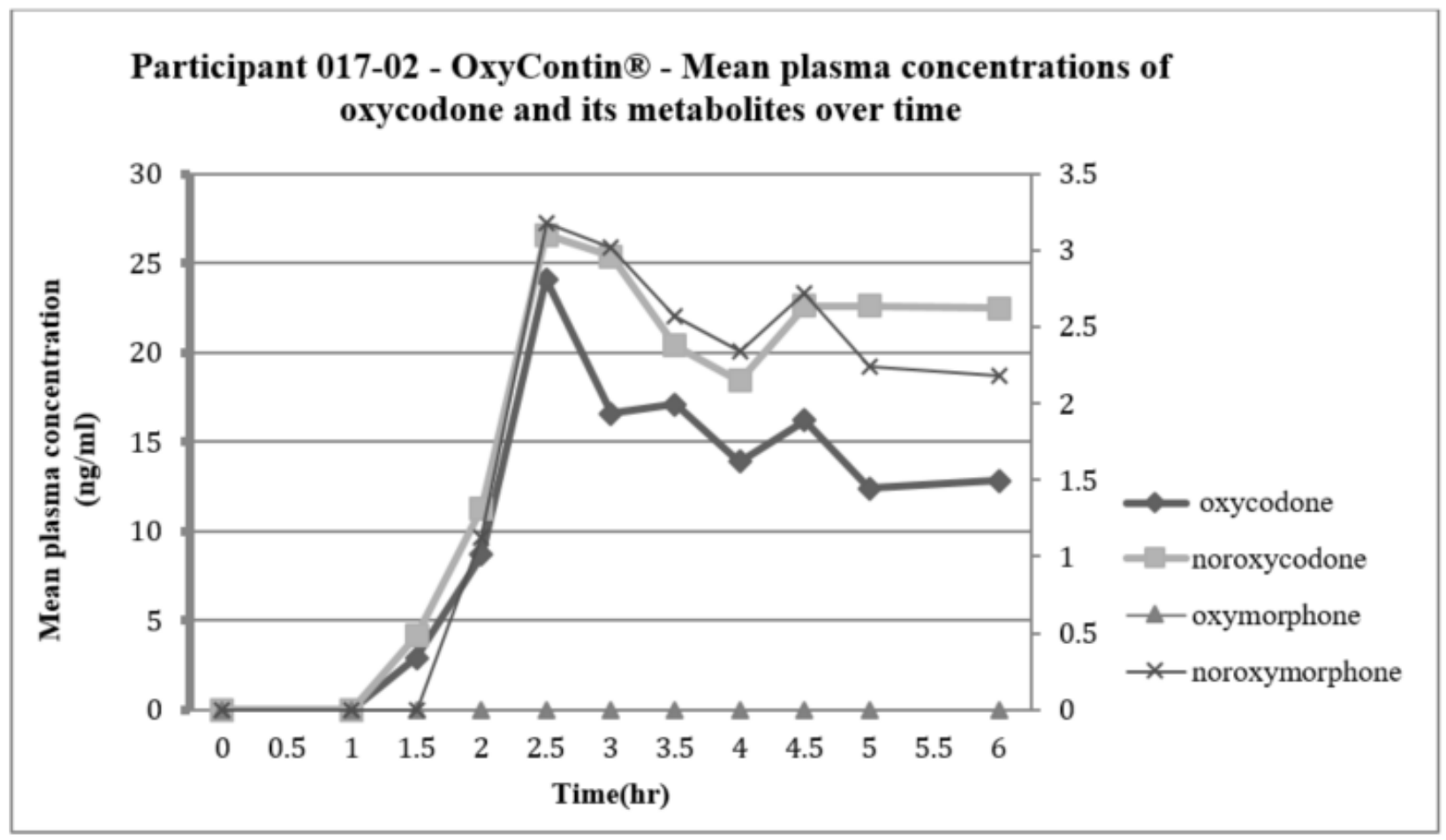


Figure 31. Participant 017-01 Mean plasma concentration of oxycodone and its metabolite concentrations from 0 to 6 hours for Apo-oxycodone CR ${ }^{\circledR}$

Apo-oxycodone CRß - Mean plasma concentrations of oxycodone and its metabolites over time

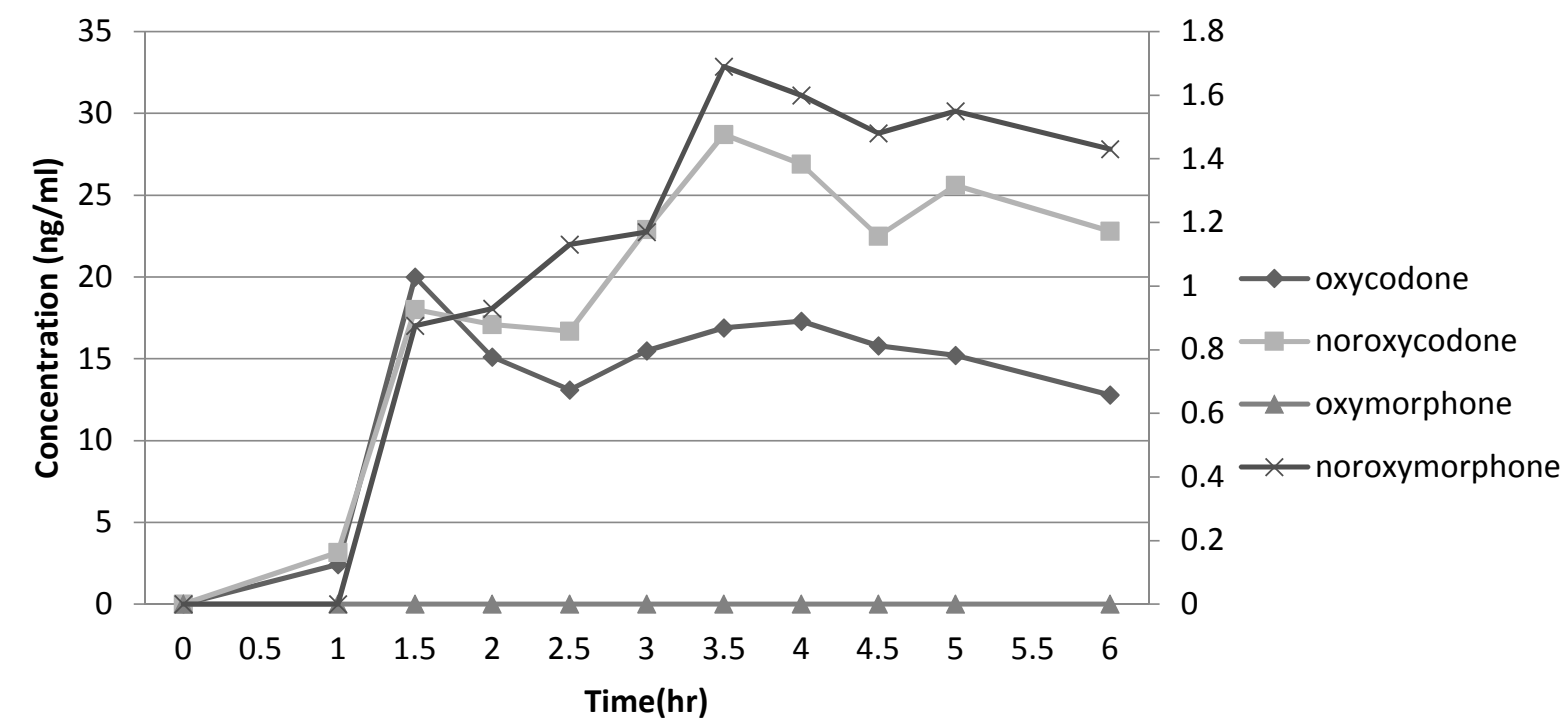

Figure 32. Participant 017-01 - Mean plasma concentration of oxycodone and its metabolite concentrations from 0 to 6 hours for OxyNEO®

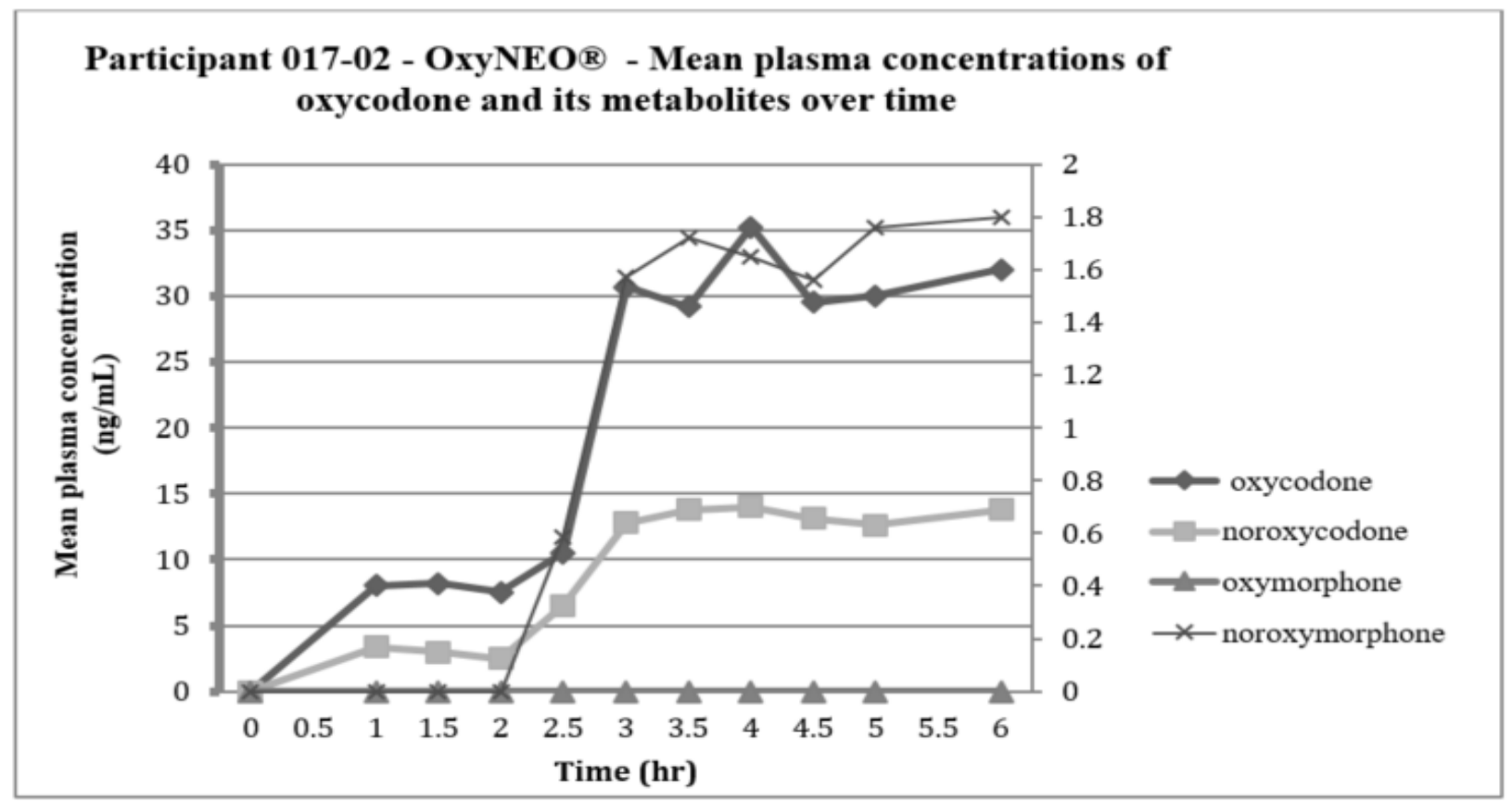


Figure 33. Participant 061-06 - Mean plasma concentration of oxycodone and its metabolite concentrations from 0 to 6 hours for OxyNEO®

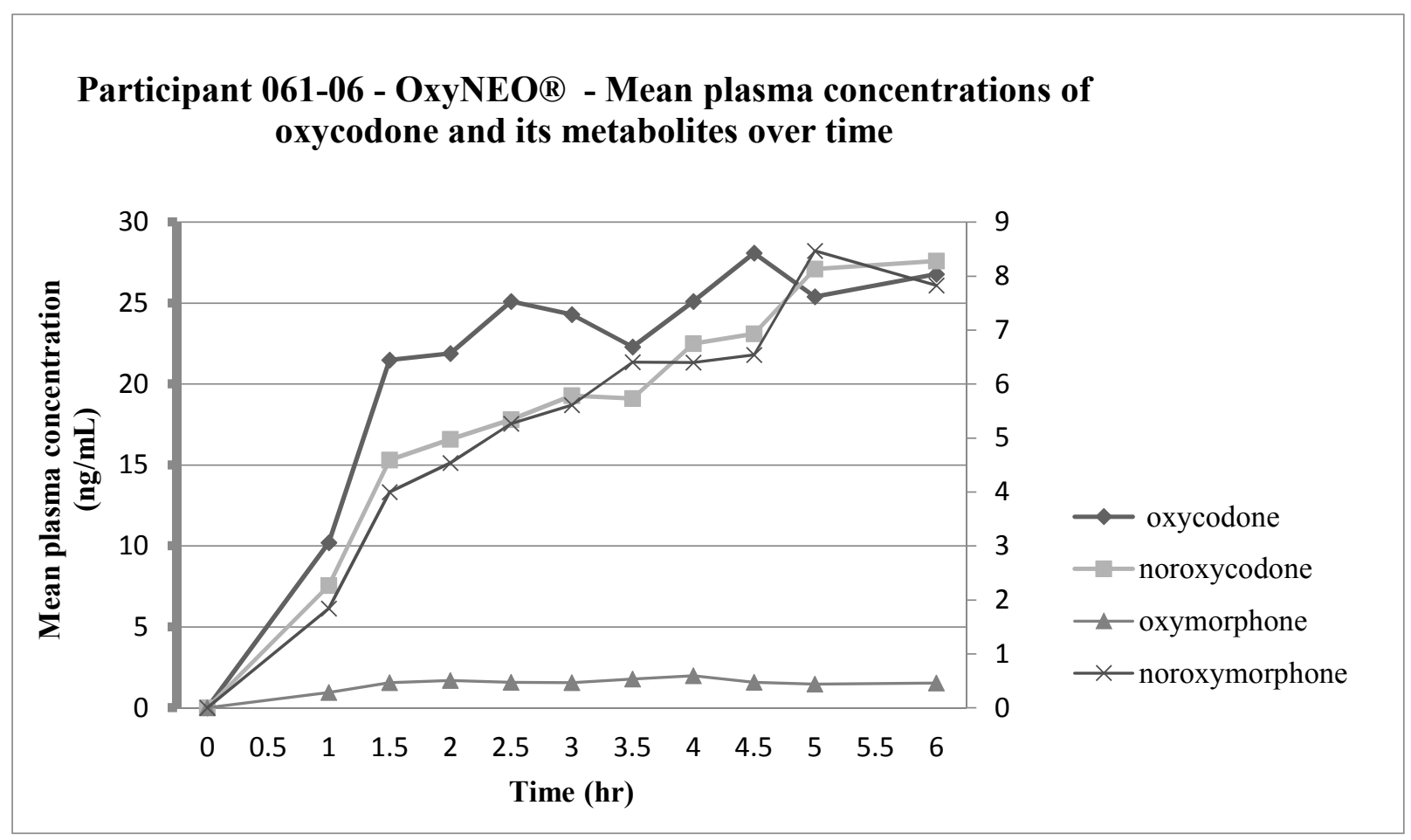

\subsection{Hysteresis in the oxycodone-plasma-concentration-Drug High relationship}

In the following graphs (Figure 29, 30, and 31) the oxycodone plasma concentration versus Drug High measured in the first 6 hours post drug intake for each active drug form a clockwise hysteresis pattern. There is almost a linear relationship between oxycodone plasma concentration and Drug High in the early time intervals (up to $1.5 \mathrm{hr}$ for OxyContin $\AA$; up to $2.5 \mathrm{hr}$ for Apooxycodone $\mathrm{CR} \AA$; up to $3 \mathrm{hr}$ for $\mathrm{OxyNEO}(\mathbb{R})$. After some time, the effects start diminishing at a noticeably faster rate than oxycodone plasma concentrations. 
Figure 34. Clockwise hysteresis of oxycodone plasma concentration versus Drug High for OxyContin ${ }^{\circledR}$

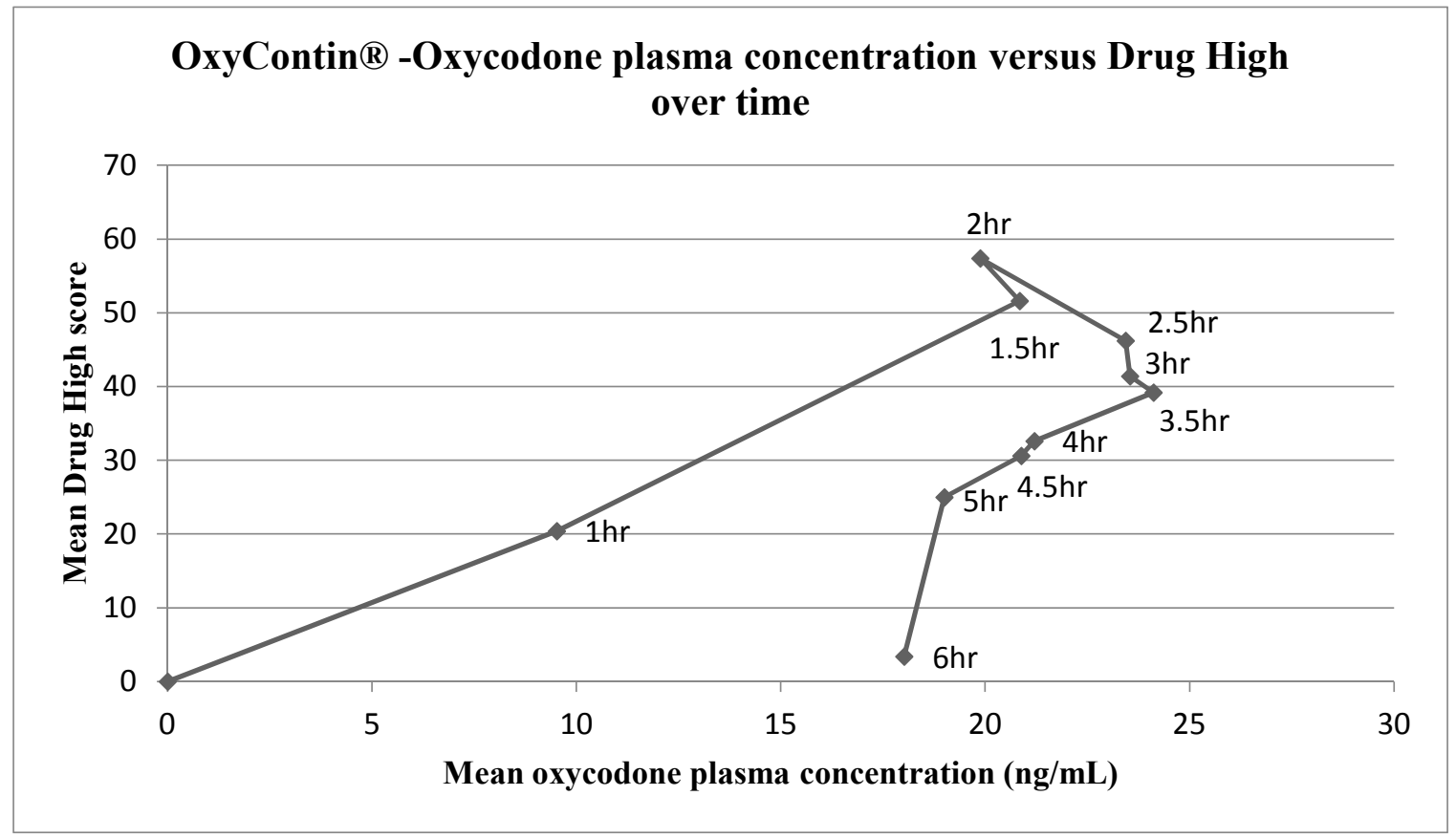

Figure 35. Clockwise hysteresis of oxycodone plasma concentration versus Drug High for Apo-oxycodone $\mathrm{CR}{ }^{\circledR}$

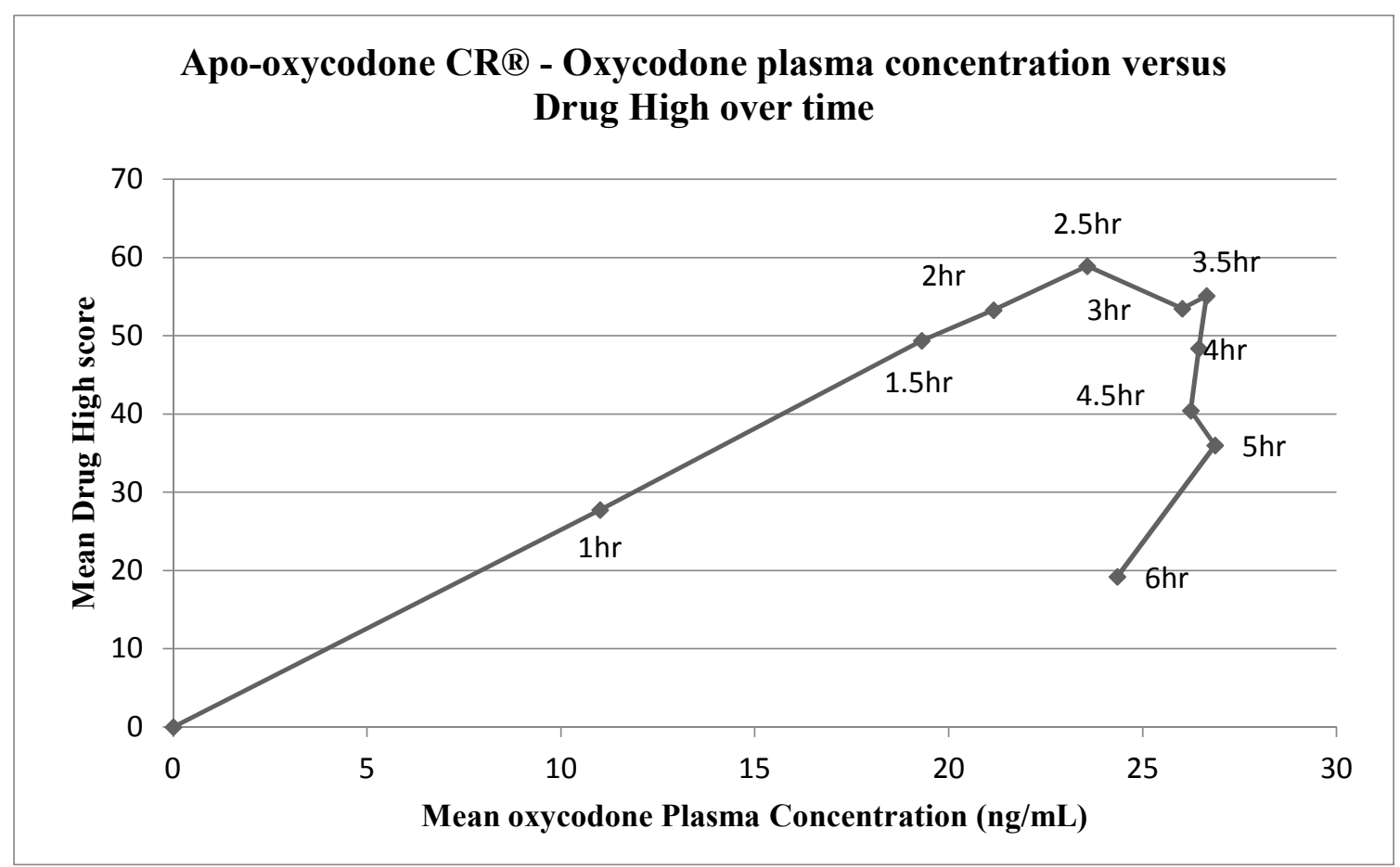


Figure 36. Clockwise hysteresis of oxycodone plasma concentration versus Drug High for OxyNEO®

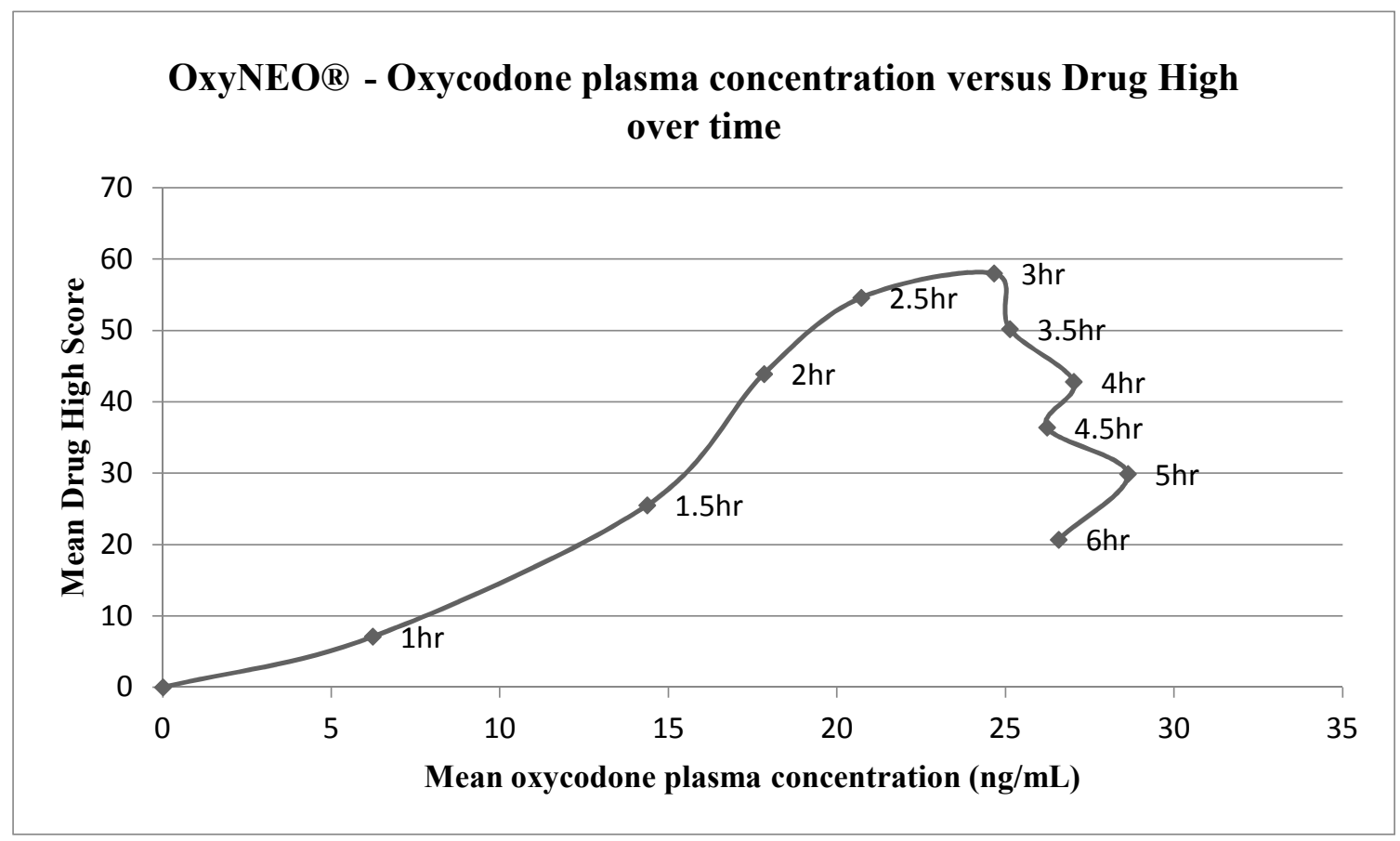

\subsection{Adverse events}

There were no serious adverse events during the study. All adverse events were mild, monitored by the nurse, and resolved by the end of study day. This sedation scale (1-5) started being used after the first study day of the first subject (011-02) on which day he had received OxyContin ${ }^{\circledR}$. The note on that study day indicated that the participant was sedated but the level of sedation was not assessed. There were no sedative effects reported by the nurse on the subsequent participants that received OxyContin ${ }^{\circledR}$. Amongst the participants, the highest sedation level recorded for Apo-oxycodone $\mathrm{CR}{ }^{\circledR}$ was 5, for OxyNEO ${ }^{\circledR}$ was 2, and for placebo was 4. 
Table 14. Number of participants showing and/or reporting adverse events to the research nurse (participants reporting more than one instance of each adverse event were only counted once)

\begin{tabular}{|l|c|c|c|c|c|c|c|}
\hline Drug & Vomiting & Nausea & Itchiness & $\begin{array}{l}\text { Stomach } \\
\text { Cramps }\end{array}$ & $\begin{array}{l}\text { Dry } \\
\text { mouth }\end{array}$ & Sedation & $\begin{array}{l}\text { Other } \\
\text { events }\end{array}$ \\
\hline OxyContin $®$ & 1 & & 1 & & & 1 & \\
\hline Apo-oxycodone CR $®$ & 2 & 2 & 3 & 1 & & 3 & \\
\hline OxyNEO $®$ & 1 & 2 & 4 & & 1 & 2 & \\
\hline Placebo & & & & & & 2 & $1^{*}$ \\
\hline
\end{tabular}

* Participant 095-11 experienced chest pain, blurry vision and headache on the placebo day. Due to the seriousness of the symptoms, the symptoms for this participant were reported to the Qualified Investigator throughout the day. The symptoms dissipated by the end of the study day and did not reappear after the participant arrived home. 


\section{Discussion}

This is the first study to compare the abuse liability of intact tablets of different controlledrelease oxycodone formulations by conducting pharmacokinetic and pharmacodynamics analysis. The comparison allowed for a specific evaluation of the impact of pharmacokinetics on positive subjective effects. The main findings of this study were 1) the three drugs (40mg OxyContin $\AA$, 40mg Apo-oxycodone $C R \AA$, and 40mg OxyNEO () ) have a similar abuse liability as no significant differences were detected amongst them for the majority of the positive subjective effects 2) The pharmacokinetic results were similar amongst the drugs and were generally consistent with the subjective effects 3 ) The time to reach peak oxycodone concentrations (Tmax) for OxyNEO ${ }^{\circ}$ was noticeably longer compared to the other two drugs and the influence of this was detected in a reduced feeling of high within the first 2.5 hours of drug intake 4) The negative effects recorded as part of the study safety assessments and those evaluated by the study measures of VAS, POMS and ARCI were comparable amongst the drugs.

\subsection{Analysis of the positive subjective effects and the pharmacokinetic results}

In this study, evaluating the abuse liability of the drugs was predominantly based on the positive subjective effects and how these effects were influenced by the pharmacokinetic results. Thus according to the hypothesis, $\mathrm{OxyNEO}{ }^{\circledR}$, due to delayed peak plasma concentrations, was expected to be associated with reduced positive subjective effects compared to Apo-oxycodone $\mathrm{CR} \AA$ and OxyContin ${ }^{\circledR}$, while the latter two drugs were expected to produce comparable reports of positive subjective effects due having a similar peak and time to peak plasma concentrations.

\subsubsection{Comparing OxyContin ${ }^{\circledR}$ with Apo-oxycodone $\mathrm{CR} \AA$ and OxyNEO ${ }^{\circledR}$}

Consistent with the hypothesis, OxyContin ${ }^{\circledR}$ and Apo-oxycodone $\mathrm{CR} \AA$, which were demonstrated to have similar pharmacokinetic results, were also comparable in both peak and temporal parameters (area under the effect curve and time to peak effects) of positive subjective effects. The similarities in pharmacokinetic results (peak plasma concentrations and the time to peak) of the two drugs were agreeable with data reported in the product monograph of Apooxycodone $C R \circledast$ (Apo-oxycodone $C R \AA, 2012$ ). The similarities in the positive subjective effects indicate that the two drugs have a similar abuse liability when administered intact orally. 
OxyContin ${ }^{\circledR}$ and OxyNEO ${ }^{\circledR}$ produced similar peak positive subjective effects. The scores for Drug High and Good Effects in the early time intervals after dosing (measured by area under the effect curve) were higher for OxyContin ${ }^{\circledR}$, although the differences were not statistically significant. These differences were consistent with a delay in the peak plasma concentration of OxyNEO ${ }^{\circledR}(\operatorname{Tmax}=5$ hours $)$ versus OxyContin ${ }^{\circledR}(\operatorname{Tmax}=2.5$ hours $)$. Evidently, inconsistent with the hypothesis, the delay in peak plasma concentrations did not have a meaningful impact on the positive subjective effects. The similarity in these effects confirms that OxyContin ${ }^{\circledR}$ and OxyNEO® have a similar abuse liability when administered intact orally.

The results of OxyContin ${ }^{\circledR}$ were associated with greater variability and hence, decreased precision due to the smaller sample (5 out of 11 participants received OxyContin $®$ ). In our study, OxyContin ${ }^{\circledR}$ demonstrated prominent responses of Drug Liking, Drug High, and Good Effects versus placebo, although the differences were significant only in the latter two effects. In abuse liability assessments of opioids the positive control is expected to produce statistically significantly greater positive subjective effects than placebo in order to establish validity (McColl and Sellers, 2006; Griffiths, Bigelow \& Ator, 2003). The pharmacokinetic and pharmacodynamic results from the participants who received Apo-oxycodone CR ${ }^{\circledR}$ were comparable to OxyContin ${ }^{\circledR}$ but with less variability resulting in more consistent distinctions from placebo. Therefore, Apo-oxycodone $\mathrm{CR} \AA$ was a more appropriate drug for $\mathrm{OxyNEO} \AA$ to be compared against.

\subsubsection{Comparing OxyNEO ${ }^{\circledR}$ and Apo-oxycodone $\mathrm{CR} \circledR$}

The peak positive subjective effects (Drug High, Drug Liking, Good Effects, ARCI-Morphine Benzedrine Group, ARCI-Stimulation-Euphoria and ARCI-Stimulation-Motor) were comparable between Apo-oxycodone $\mathrm{CR} \AA$ and $\mathrm{OxyNEO} \AA$ and were significantly different from placebo. Inconsistent with the hypothesis, these results suggest that Apo-oxycodone $\mathrm{CR} \AA$ and $\mathrm{OxyNEO} \AA$ have a similar abuse liability when swallowed intact despite the delayed peak drug plasma concentrations of OxyNEO® [Tmax: 5 hours $\left(\mathrm{OxyNEO}{ }^{\circledR}\right)$ versus 3 hours (Apo-oxycodone $\left.\left.\mathrm{CR}{ }^{\circledR}\right)\right]$. The influence of this delay, which is indicative of slower initial drug absorption, was observed in a delay in the onset of the subjective effect of Drug High. The effects of drug high associated with OxyNEO ${ }^{\circ}$ were significantly reduced compared to Apo-oxycodone $\mathrm{CR} \AA$ in the first 2.5 hours after dosing as measured by the area under the effect curve [AUE (0-2.5hr)]. This 
pattern was also observed in the measure of Good Effects, although the reduction in this effect was not statistically significant. Consistent with these results, the peak Drug High effects associated with $\mathrm{OxyNEO}{ }^{\circledR}$ were delayed compared to the timing of the peak effects for Apooxycodone $C R \AA$ (TEmax: 3 versus 2 hours, respectively). The similar patterns observed amongst different subjective effects support this finding.

The pharmacokinetic results of Cmax, AUC and abuse quotient (Cmax/Tmax) were comparable between the drugs, while the Tmax was noticeably longer for OxyNEO®. A shorter Tmax is associated with a greater Cmax in oxycodone formulations reflecting a more rapid absorption as evidenced by the pharmacokinetic profile of immediate release oxycodone versus that of controlled-release oxycodone (Benziger et al., 1997; Webster et al., 2012). In this study the differences were demonstrated in Tmax without influencing Cmax nor influencing peak subjective effects. This may imply that the lack of difference in the peak effects in our study is due to having similar Cmax across the drugs and that the influence of Cmax is as important if not more important than Tmax on peak effects in cases which Tmax occurs a few hours after dosing.

Only two studies (Webster et al., 2012; Harris et al., 2013) have previously investigated the abuse liability of controlled-release oxycodone formulations by performing pharmacokinetic analysis and assessing positive subjective effects. Consistent with our study, in the Webster et al. (2012) study, no differences in peak subjective effects were observed amongst the formulations when Cmax was similar and Tmax results varied across the treatments [the Tmax for $80 \mathrm{mg}$ OxyContin ${ }^{\circledR}(2.8 \mathrm{hr})$ was approximately 1 hour prolonged compared with $40 \mathrm{mg}$ Immediate Release Oxycodone (Tmax:1.6hr) and 40mg crushed OxyContin® (Tmax: 1.7hr)]. In the Webster et al. (2012) study, differences in peak subjective effects appeared to be more positively linked with changes in peak plasma concentrations and drug exposure in the first hour measured by AUC (0-1hr). Further, consistent with our study, the subjective effects that were produced in the early time intervals measured by the area under the effect curve were likely to have been influenced by delays in peak plasma concentrations (Longer Tmax for 80mg OxyContin ${ }^{\circledR}$ was associated with a significantly reduced AUE(0-1hr) of Drug Liking and High compared to those of 40mg Immediate Release Oxycodone).

Another association that may be worth examining is the possibility of the diminishing influence of Tmax on subjective effects after a certain time point. In our study for example, the difference 


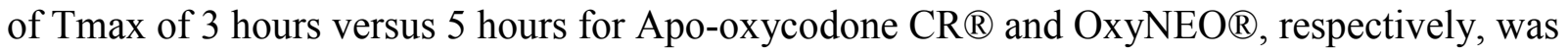
not manifested in the peak subjective effects. In the Webster et al (2012), the influence of Tmax on peak effects even within earlier hours post-dose (1.6hours versus 2.8hours) was not meaningful with the Cmax held constant. However, it must be noted that because a different method for calculating Tmax was used in the Webster et al. (2012) study, the comparison of the Tmax values must be examined with caution. The Webster et al. (2012) calculated the least squares mean of Tmax whereas in this study the median of Tmax was calculated.

In the Harris et al. (2013) study, the influence of Tmax could not be accounted for because when the Tmax was different between the comparators, so was the Cmax. Further, unlike this study, the route investigated in the Harris et al. (2013) study was intranasal. Despite these discrepancies, in the Harris et al. (2013) study, both Cmax and Tmax combined exerted their influence on the subjective effects, which is why the measure of abuse quotient (Cmax/Tmax) was attributed to the change in the effects. In our study, the abuse quotient was relatively lower for OxyNEO ${ }^{\circledR}$ due to having a longer Tmax, although no statistically significant differences were detected.

The evidence based on the two studies and our study suggests that both peak plasma concentrations and time to peak plasma concentrations have an impact on positive subjective effects. More specifically, delayed peak plasma concentrations were associated with significantly lower effects in the early time intervals measured by AUE, and increase in peak plasma concentrations was associated with greater peak subjective effects. Measures of peak effects and AUE provide different information about drug effects such as the magnitude of effects and the temporal pattern of effects, respectively (Jasinski, Henningfield, \& Johnson, 1984). In particular, the AUE in the early intervals post-dose can provide information about the onset of drug effects, which has been known to be a critical aspect in a drug's abuse liability (Webster et al., 2012; Raffa, Pergolizzi, Muniz, Taylor Jr, \& Pergolizzi, 2012; Sellers et al., 2013).

The lack of differences in the overall subjective effects especially in the peak effects despite the differences in the Tmax can be supported theoretically by how it relates to the dopamine levels in the brain. Volkow and Swanson (2003) showed that equivalent increases in the dopamine levels for intravenous methylphenidate and oral methylphenidate only induced a drug high in the former route of administration. They also showed that the intensity of Drug High is significantly 
correlated to the rate of increase in dopamine levels in the early time intervals and not correlated in later time intervals (in the first $5 \mathrm{~min}$ versus in the first hour). Therefore, it can be inferred that the reason we did not see an overall difference in the positive subjective effects, was the low or lack of correlation between the rate of increase in dopamine levels with these effects in the later time intervals. Although oxycodone and methylphenidate belong in a different class of drugs, this comparison may still be relevant as the reinforcing effects of all drugs of abuse have been shown to be directly associated with the large and fast increases in dopamine (Volkow, Fowler, Wang, \& Swanson, 2004).

\subsubsection{Hysteresis}

The results for Apo-oxycodone $\mathrm{CR} \AA$ and $\mathrm{OxyNEO} \AA$ showed that there was a clockwise hysteresis between oxycodone plasma concentration and the subjective effect of Drug High. The increase in the Drug High in the first 2.5-3 hours post-dose and the rate of oxycodone plasma concentrations were similar, and from 3.5-6 hours post dose, there was a noticeable decline in Drug High while the oxycodone plasma concentrations remained almost unchanged. A study by Benziger et al. (1997) of 20mg OxyContin ${ }^{\circledR}$ showed that there was minimal to no hysteresis between the VAS Drug Effect and plasma concentrations during a 12-hour assessment. Although, it must be noted that this study was conducted in healthy non-drug-abusers and that the effect measured was not Drug High. Thus, more studies need to be carried out to confirm our results. Louizos, Yanez, Forrest \& Davies (2014) who have reviewed studies that included analysis of hysteresis, have suggested that hysteresis can occur as a consequence of a number of different pharmacokinetic and pharmacodynamics mechanisms. One mechanism that can account for the occurrence of clockwise hysteresis (common amongst preclinical studies of opioids), is the development of acute drug tolerance, which implies that the decreases in the effects are as a result of receptor desensitization (Louizos et al., 2014). Amongst other mechanisms, clockwise hysteresis was suggested to occur as a result of re-distribution of the drug out of brain to other fatty tissues such that the peripheral plasma concentrations may not reflect brain concentrations (Louizos et al., 2014). Although our analysis showed that it is likely that hysteresis had occurred, to explore the mechanism behind it, conducting other types of analysis is necessary such as finding the drug concentration at the effect site. 


\subsubsection{The inconsistent results of AUE for Drug Liking}

The AUE for Drug Liking was inconsistent with the rest of the results such that no significant differences were observed between the active drugs and the placebo in any of the intervals. This incongruity may be explained by the balanced effect-nature of the bipolar scale of Drug Liking versus the unipolar scales of Good Effects and Drug High, in that it measures both liking (score of 50-100) and disliking (score of 0-50). Because of its scale-type and the particular subjective effect it measures, Drug Liking may be relatively more sensitive to the negative effects of the drugs. This information may be relevant to our study as the participants felt the negative effects on most active drug days (23/27 days) based on the responses to VAS of Dizzy, Nausea, Bad effects and Feel Sick although they varied in magnitude, onset and duration. From the four studies examining the positive subjective effects of controlled-release oxycodone, Morton et al. (2014) and Harris et al. (2013) included the bipolar Drug Liking measure in their study and only Morton et al. (2014) reported the analysis of AUE for this measure which showed significantly different results for the active drugs compared to placebo. In Morton et al. (2014) study, the negative effects associated with opioids were not evaluated for participants by using a scale and only the number and type of adverse events were reported, which could not be effectively examined as two or more adverse events may have occurred in the same participant. Overall, the fact that the AUE for Drug Liking did not produce meaningful results may be because of the mitigating influence of the negative effects of the active drugs. Further, the discrepancy between peak Drug Liking and AUE of Drug Liking results may be due to the difference in their purpose and how they are calculated (Maximum effects occurring at one time point versus cumulative effects over different time intervals with the incorporation of time in the calculation, respectively).

\subsubsection{Inconsistencies in the positive subjective effects amongst participants}

The pattern of positive subjective responses over time on drug days for some participants differed from the rest. The rating of Drug Liking for two participants (085-10 and 095-11), who received OxyNEO ${ }^{\circledR}$ and Apo-oxycodone $\mathrm{CR} \AA$, respectively, never increased and only decreased after dosing. This immediate decline observed one hour after drug intake in the liking effects was explained by the fact that the participants were feeling the negative effects associated with the drug (the responses for the measure of Bad Effects increased considerably, before or at the same time as the decrease in Drug Liking). Consequently, the participants' response to the measure of 
Take Drug Again, which was administered at the end of the day, was "definitely not". The results for these participants to the other active drug (OxyNEO ${ }^{\circledR}$ or Apo-oxycodone $\mathrm{CR} \AA$; they did not receive OxyContin ${ }^{\circledR}$ ) were consistent with the rest of sample.

One participant (073-07) had noticeably minimal increases on the VAS positive subjective measures on both OxyNEO ${ }^{\circledR}$ and Apo-oxycodone $\mathrm{CR} \AA$, which appeared to be comparable to the participants' responses on the placebo day (he did not receive OxyContin ${ }^{\circledR}$ ). The drug use profile of this participant was different from the rest of the sample in that he preferred injecting heroin as opposed to the oral or intranasal administration of prescription opioids. This difference in drug use preference may have caused the user to rate the effects of oral controlled-release oxycodone formulations relative to the effects of heroin. Fraser and Isbell (1960) showed that "non-tolerant addicts" who were given propoxyphene (a narcotic pain reliever), described the drug effects based on their experience with other drugs such as heroin. If the participant rated the effects relative to heroin, it may be expected to see such disparities in the effects compared to the rest of the participants, as the pharmacokinetics associated with intravenous administration of opioids and the pharmacology of heroin differ from those of orally administered controlledrelease oxycodone.

Another unusual result was associated with participant 031-05 on the day he received OxyNEO ${ }^{\circledR}$. This participant did not report any effects using the VAS except for Sleepiness, which was also the only effect he had reported on the VAS on the placebo day. His responses after taking OxyContin ${ }^{\circledR}$ and Apo-oxycodone $\mathrm{CR}{ }^{\circledR}$ however, did show increased effects. The inconsistency in response to the different drugs may be explained by examining the pharmacokinetic results in this participant. On the OxyNEO ${ }^{\circledR}$ day, his oxycodone plasma concentrations were very low for a relatively long period after dosing and reached peak at 5 hours (he was the only participant that had lower than $20 \mathrm{ng} / \mathrm{ml}$ plasma concentrations until the $4^{\text {th }}$ hour after dosing). On the other two active drug days his plasma levels reached peak $>20 \mathrm{ng} / \mathrm{ml}$ by the second hour post-dose which was paralleled by the early increases in the subjective effects. This example further highlights the influence of pharmacokinetics on the positive subjective effects and the extent of variability in participants. 


\subsection{Sedative effects}

Sedation is a major side effect of opioids (Young-MChaugan \& Miaskowski, 2001). The safety assessment of opioid-induced sedation is important because sedation can signal respiratory depression, which is a life-threatening adverse event of opioids (Passero, 2009). The active drugs all produced greater sedative effects compared to the placebo but in some measures, the effects were not significant compared to placebo and there were no significant differences amongst the drugs. The lack of significant difference between OxyContin $®$ and placebo in sedative effects, as it was also evident in the evaluation of positive subjective effects, was attributed to the lower number of participants that received OxyContin ${ }^{\circledR}$. Apo-oxycodone $C R \AA$ and OxyNEO $\AA$ were significantly greater than placebo for the mean peak and AUE(0-8hr) of ARCI-Sedation-Motor and mean peak of POMS-Fatigue. For other measures of sedation, (mean peak VAS of Sleepiness, PCAG and Sedation Mental and Pentobarbital Chlorpromazine Alcohol Group (PCAG)), Apo-oxycodone $\mathrm{CR} \AA$ and OxyNEO ${ }^{\circledR}$ produced greater effects than placebo although the differences were not significant. The fact that the results were not consistent amongst the measures may be due to the sample size and/or that the measures captured different aspects of sedation. For example, the developers of the ARCI scale had shown that the sample would need to be large for PCAG effects associated with opioids to become evident (Haertzen, 1966). The sedative effects were not analyzed/reported in the abuse liability studies of controlled-release oxycodone formulations. In two abuse liability studies of oral immediate release oxycodone and intravenous oxycodone (Stoops et al., 2010; Walsh et al., 2008) in recreational opioid users, which included the administration of the PCAG measure, the study by Stoops et al. (2010) did not report significant differences in sedation between placebo and oxycodone while significance between these conditions was reported by Walsh et al. (2008). In both of these studies, expectedly, oxycodone produced increased positive subjective effects. Therefore, the influence of sedative effects on the abuse liability of oxycodone is not clear in these studies; however, from a safety standpoint, sedation is considered a negative effect, as it is an indicator of respiratory depression associated with opioids.

\subsection{Negative effects}

Some of the acute and common side effects or the negative effects of opioids include sedation, dizziness, nausea and vomiting (Benyamin et al., 2008). These effects may offset positive 
subjective effects and result in reduced abuse liability (Brady, Lydiard, \& Brady, 2003; Schoedel et al., 2011). In this study the negative subjective effects were comparable amongst the drugs. The reports of adverse events by the participants to the research nurse and the negative effects assessed by the VAS measures, which include the common acute negative effects and the ARCI subscales that include unpleasant subjective/physical feelings were comparable amongst the active drugs and were greater than placebo. In many cases, the type of adverse event tended to be similar for each participant on different active drug days. For example, the participant(s) that felt itchiness on the OxyNEO ${ }^{\circledR}$ day, were likely to feel itchiness on the other active drug days. The similarity in the negative effects amongst the drugs further supports that the drugs had a similar abuse liability.

\subsection{Psychomotor performance}

The Digital Symbol Substitution Test, which is a psychomotor performance test that can evaluate psychomotor impairment induced by drugs, was the only measure of psychomotor performance administered in this study. The results for the active drugs, which included measurements of the number of completed trials and number of correct trials, were not significantly different from placebo and from one another. These results are consistent with three studies of intranasal and intravenous oxycodone (Comer et al., 2009; Lofwall et al., 2012; Stoops et al., 2010) that were conducted in opioid users (the studies of controlled-release oxycodone did not administer DSST). In these studies, there were no significant differences between the opioids and placebo on the measure of DSST $(p<0.05)$. These results indicate that the DSST does not capture psychomotor impairment associated with oxycodone in recreational opioid users. In a study of recreational opioid users, controlled-release oxycodone produced increased effects of psychomotor impairment compared with controlled-release oxymorphone using the Divided Attention Test (Schoedel et al., 2010). Further, as opioids produce sedative effects they are also known to impair psychomotor skills (Schoedel et al., 2010).

\subsection{Pupil diameter}

Pupil constriction is a known effect of opioids' central action (Ghodse et al., 1999). The measure of pupil diameter is an objective pharmacodynamic measure used to validate opioid abuse liability studies and to evaluate opioid potency (Setnik et al., 2011; Schoedel et al., 2011). In this study, there were no significant differences detected amongst the drugs in the associated trough 
pupil diameter and the active drugs were significantly greater than placebo for this measure $(\mathrm{p}=0.001)$. Contrary to subjective effects, the pupillary responses in this study provided objective physiological evidence of the opioid effects and demonstrate the validity of the study.

\subsection{Plasma concentrations of oxycodone and its metabolites}

\subsubsection{Peak oxycodone plasma concentrations}

The mean Cmax for the formulations in this study was $13-16 \mathrm{ng} / \mathrm{mL}$ lower than previous reports of Cmax for these formulations (Apo-oxycodone $C R \circledast$, 2012; Purdue, 2012). This disparity may suggest that the average activity of the drug metabolizing enzymes in our sample population was high compared to those in previous reports. In an exploratory study of immediate-release oxycodone it was shown that Cmax for oxycodone incrementally increased from ultra metabolizers to extensive metabolizers to poor metabolizers though the differences were not significant (Samer et al, 2010). The lack of significance in the results was attributed to the small sample size. In another study of immediate release oxycodone, the inhibition of the enzymes responsible for the metabolism of oxycodone (CYP2D6 and CYP3A4) led to a 1.8-fold increase in Cmax (Grunlond, 2010). Combined, these studies suggest that differences in the activity of these enzymes can influence the Cmax and that there is inter-individual variability in the activity of these enzymes. Thus, it is likely that the high activity of drug metabolizing enzymes were responsible for the relatively low mean Cmax. To confirm this association, genotypic tests for the enzymes and/or calculation of the ratio between oxycodone and metabolite concentrations would be helpful. Although the overall subjective effects may have been influenced by this difference, it is unlikely that the relative abuse liability of the drugs were affected due to the crossover design of the study.

\subsubsection{Plasma concentrations of oxycodone metabolites}

The variation in plasma concentration-time curves of oxycodone metabolites amongst participants may have indicated some inter-individual variability in levels of drug-metabolism enzymes that catalyze oxycodone oxidation. The fact that three participants had consistently low concentrations of oxymorphone $(<0.1 \mathrm{ng} / \mathrm{mL})$ in their plasma in response to all the active drugs suggests reduced CYP2D6 activity (likely due to a specific CYP2D6 genotype). This is because CYP2D6 is the enzyme responsible for catalyzing the formation of oxymorphone from 
oxycodone (Lalovic et al, 2006). Based on the assumption the activity of CYP2D6 was low in these participants and knowing that CYP2D6 also plays a major role in catalyzing the formation of noroxymorphone, the concentrations of noroxymorphone were expected to be low for these three participants compared to the other participants (Lalovic et al, 2006). Indeed, the data showed that the early-post-dose concentrations of noroxymorphone were low $(<0.1 \mathrm{ng} / \mathrm{ml})$ in these participants; however, because the results were evaluated by visual examination of the numbers and graphs and that the low concentrations were only observed in the early time intervals and not later, it was not possible to attribute the changes in the metabolite concentrations to levels of CYP2D6 with certainty. Further, no patterns were detected between pharmacodynamic effects and the metabolites concentrations.

It must be emphasized that studies have generally attributed the pharmacodynamic effects of oxyocodone primarily to itself and not to its metabolites (Keiko et al, 1996; Lalovic et al., 2006). Further, oxycodone is mainly metabolized to noroxycodone by CYP3A4 (74\%) and thus its concentration is relatively less affected by changes in CYP2D6 (Gronlund et al., 2010; Lemberg et al., 2009). However, no oxycodone studies were found that investigated the influence of genotypes and metabolites on abuse liability-related effects.

\subsection{Limitations}

There are several limitations to this study. The expiry and the discontinuation of OxyContin ${ }^{\circledR}$ approximately two months after start of the study recruitment and not being able to obtain more of this drug, resulted in three limitations. Firstly, only the first five participants received the four treatments (four-day design: OxyContin $\AA$, Apo-oxycodone $\mathrm{CR} \AA$, OxyNEO ${ }^{\circledR}$, and placebo) while the subsequent 6 participants received three treatments (three-day design: Apo-oxycodone $\mathrm{CR} \AA$, OxyNEO ${ }^{\circledR}$, and placebo), which led to an imbalance in the study sequence. This and the disruption in the plan for replacing participant dropouts made it not feasible to account for order effects. Secondly, due to the a lower number of participants who received OxyContin ${ }^{\circledR}(\mathrm{N}=5)$, most of the results after taking OxyContin ${ }^{\circledR}$ were associated with increased variability compared to the results for Apo-oxycodone $\mathrm{CR} \AA$ and $O x y N E O \AA$, which led to some of the results for OxyContin ${ }^{\circledR}$ to be not significantly different from placebo unlike the other two drugs. For the positive subjective effects, the values amongst the three drugs were similar while the result of OxyContin ${ }^{\circledR}$ for Drug Liking was not significantly different from placebo. Thirdly, the drug 
discrimination phase was only applied in the first five participants who were included in the fourday design. As the subsequent six participants did not go through this phase, there was a potential for participants to not be able to reliably detect the opioid effects; However, apart from one participant who had a preference for IV heroin, the results for the other participants appeared to be generally consistent with the first five participants and therefore, this was not considered to be an important limitation for this study.

The study only used a single dose of each formulation and it is generally recommended to include a range of doses of the test drugs and the control drug. This is to demonstrate orderly dose-effect relationship of the test compound (Griffiths et al., 2003). However, as the 40mg dose was already shown to produce robust positive subjective effects in this population and as the study drugs have already been approved, it was not necessary to explore the dose-effect relationship for the purposes of this study.

\subsection{Conclusions}

In the current study, intact single doses of OxyContin ${ }^{\circledR}$, Apo-oxycodone $\mathrm{CR} \circledast$ and OxyNEO ${ }^{\circledR}$ produced comparable positive and negative subjective effects and thus appear to have a similar abuse liability. The delay in the peak plasma concentrations of OxyNEO ${ }^{\circledR}$ was not sufficient to influence the magnitude of the peak positive subjective effects and only seemed to have an impact on the early post-dose effects of Drug High. The findings of this study are relevant, as the oral intact route has been recognized for being a common and a harmful route of administration associated with the abuse of controlled-release oxycodone formulations.

\subsection{Future directions}

Prescription opioid abuse and addiction is a serious problem. Abuse liability studies play an important role in understanding why some of these drugs are abused more than others.

The onset of peak positive subjective effects and the magnitude of these effects are both important variables in abuse liability studies. Future studies should consider quantifying the influence of latency in peak positive subjective effects in relation to the magnitude of the peak effects and to time to peak plasma concentrations. This information may contribute to the understanding of why some oral formulations are abused more than others. 
In our study there was a participant that did not report any positive or negative subjective effects

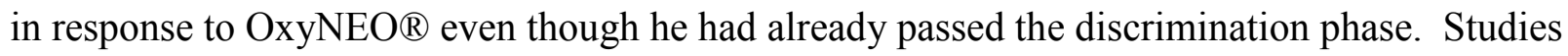
may be able to avoid this by using only at least two positive subjective effects in the discrimination phase, a greater score difference between placebo day and active drug day for qualification, and only qualify the participants who can detect the early effects (depending on the formulation being tested) for the purpose of choosing participants that can more reliably detect opioid effects.

Another factor that has been known to affect the subjective experience of drug users is their drug use history (the list of drugs they have abused and other related features). For example, an orally administered drug in a user that has a history of intravenous use may not produce the same effects as it would in a drug user who has previously only administered drugs orally. Future studies may benefit from examining the influences of 'drug use history' features such as the frequency of drug use, how current the drugs were used, the type of drugs used, dosage and the route of administration on the subjective effects. This knowledge may inform investigators of how restrictive their inclusion/exclusion criteria should be with regards to the participants' drug use history.

Comparing the abuse liability of the formulations used in this study may be beneficial in other populations such as healthy non-drug-abusers or chronic pain patients. Conducting abuse liability assessments in populations such as chronic pain patients is more complex because they typically are not known to report euphoria (Wasan et al., 2009). However, some of these patients display aberrant drug-related behaviors after taking medically prescribed drugs for pain such as selfadministration of non-prescribed opioid or illegal drugs (Wasan et al., 2009). An abuse liability study of opioids by Wilsey, Fishman, Li, Stortment, and Albanese (2009) in chronic pain patients showed that there were no statistically differences in the ratings of positive subjective effects between the hydrocodone, morphine and placebo and in most of the measures, the ratings were greater for placebo. In another study of chronic non-malignant pain patients that were maintained on buprenorphine/naloxone, oxycodone produced an overall greater ratings of positive subjective effects (Good Effects and Drug High but not Drug Liking) compared to placebo (Jones, Sullivan, Manubay, Vosburg, \& Comer, 2011). However, according to the authors, the effects were less robust than previously reported effects in recreational users without pain and that oxycodone failed to serve as a reinforcer. Thus, the typical abuse liability 
assessment design may not be effective in this population. In order to design an effective study to assess abuse liability of drugs in chronic pain patients, it may be necessary to further explore the reasons (i.e. subjective effects other than the ones used in the current abuse liability assessments) that may influence their tendency to abuse/misuse opioids. For example, a study by Wasan et al. (2009) showed that craving is more prevalent in chronic pain patients that have a history of aberrant drug behaviors versus the chronic pain patients that have no history of these behaviors. Further, exploring the influence of participant characteristics such as history of aberrant drug behaviors, the type, severity, and duration of their pain, and drug use history on their rating of subjective effects may help with recruiting more responsive and potentially more suitable participants. Lastly, as these patients are experiencing pain and/or are dependent on pain medication, they may be reluctant to participate in such studies or when they do participate, their responses may be biased. That is, they may fear that their physicians will be informed about their responses or that they are contributing to studies which may prevent them from getting their medication in the future. Conducting surveys in this population to obtain more information about their potential biases and reluctance to attend in such studies may help with the effectiveness of the design of abuse liability assessments in chronic pain patients.

Although the results of our study demonstrated that the three formulations have similar abuse liability profiles, epidemiologic and surveillance studies conducted in real-world settings are necessary to confirm these findings. 


\section{References}

Al-Hasani, R., \& Bruchas, M. R. (2011). Molecular mechanisms of opioid receptor-dependent signaling and behavior, Anesthesiology, 115, 1363-1381.

American Psychiatric Association. (2000). Diagnostic and statistical manual of mental disorders (4th ed., text rev.). Washington, DC: Author.

American Psychiatric Association. (2013). Diagnostic and statistical manual of mental disorders (5th ed.). Arlington, VA: American Psychiatric Publishing.

Apo-oxycodone CR Monograph. (2012). Retrieved 2013

Balster, R. L., \& Walsh, S. L. (2013). Abuse liability Evaluation. In Encylopedia of Psychopharmacology (pp. 1-6). Berlin: Springer-Verlag.

Benyamin, R., Trescot, A. M., Datta, S., Buenaventura, R., Adlaka, R., Sehgal, N., et al. (2008). Opioid complications and side effects. Pain Physician, 11(Suppl. 2), S105-S120.

Benziger, D. P., Kaiko, R. F., Miotto, J. B., Fitzmartin, R. D., Reder, R. F., \& Chasin, M. (1995). Differential effects of food on the bioavailability of controlled-relese oxycodone tablets and immediate-release oxycodone solution. Journal of Pharmaceutical Sciences , 85, 407-410.

Benziger, D. P., Miotto, J., Grandy, R. P., Thomas, G. B., \& Swanton, R. E. (1997). A pharmacokinetic/pharmacodynamic study of controlled-release oxycodone. Journal of Pain and Symptom Management, 13, 75-82.

Bigelow, G. E. (1991). Human drug abuse liability assessment: opioids and analgesics. British Journal of Addiction, 86, 1615-1628.

Bostrom, E., Hammarlund-Udenaes, M., \& Simonsson, U. S. (2008). Blood-brain barrier transport helps to explain discrepancies in in vivo potency between oxycodone and morphine. Anesthesiology, 108, 495-505.

Bostrom, E., Simonsson, U. S., \& Hammarlund-Udenaes, M. (2006). In vivo blood-brain barrier transport of oxycodone in the rat: indications for active influx and implications for pharmacokinetics/pharmacodynamics. Drug Metabolism and Disposition, 34, 1624-1631.

Brady, K. T., Lydiard, R. B., \& Brady, J. V. (2003). Assessing abuse liability in clinical trials. Drug and Alcohol Dependence, 70(2 Suppl), S87-S95. 
Brown, K. R., Severtson, S. G., \& Dart, R. C. (2012). A look at the differences in rates of abuse via unintended routes before and after reformulation intervention. North American Congress of Clinical Toxicology. Las Vegas: Radars.

Brushwood, D. B., Rich, B. A., Webster, L., Coleman, J. J., Passik, S. D., \& Brennan, M. J. (2012). Balance and the adoption of abuse-deterrent opioid formulations in pain management practice. Pharmacy Review, 1, 1-16.

Butler, S. F., Cassidy, T. A., Chilcoat, H., Black, R. A., Landau, C., Budman, S. H., et al. (2012). Abuse rates and routes of administration of reformulated extended-release oxycodone: initial findings from a sentinel surveillance sample of individuals assessed for substance abuse treatment. The Journal of Pain, 14, 351-358.

CAMH. (2015). Restrictions on prescribing oxycodone followed by increases in other strong opioid use and opioid-related deaths in Ontario, CAMH research shows. Retrieved from Centre for Addiction and Mental Health: http://www.camh.ca/en/hospital/about_camh/newsroom/news_releases_media_advisories _and_backgrounders/current_year/Pages/Restrictions-on-prescribing-oxycodone.aspx Canadian Alcohol and Drug Use Monitoring Survey. (2012). Retrieved 2015, from Health Canada: http://www.hc-sc.gc.ca/hc-ps/drugs-drogues/stat/_2012/summary-sommaireeng.php

Canadian Tobacco, Alcohol and Drugs Survey. (2013). Retrieved 2015, from Government of Canada: http://healthycanadians.gc.ca/science-research-sciences-recherches/datadonnees/ctads-ectad/summary-sommaire-2013-eng.php

Carter, L. P., \& Griffiths, R. R. (2009). Principles of laboratory assessment of drug abuse liability and implications for clinical development. Drug and Alcohol Dependence, 105(Suppl.1), S14-S25.

Centers for Disease and Control and Prevention. (2013). Injury Prevention \& Control: Prescription Drug Overdose. Retrieved 2015, from CDC: http://www.cdc.gov/drugoverdose/data/overdose.html

Chilcoat, H., Bucher, B. B., Coplan, P., Dart, R. C., Davis, J., Green, J. L., et al. (2012). Changes in diversion rates following the intruduction of a reformulated extended release oxycodone product. American Academy of Physical Medicine and Rehabilitation Annual Meeting. Atlanta: Radar Systems. 
Cicero, T. J., \& Ellis, M. S. (2015). Abuse-deterrent formulations and the prescription opioid abuse epidemic in the United States: lessons learned from OxyContin. Journal of American Medical Association, 72, 424-30.

Cicero, T. J., Ellis, M. S., \& Surratt, H. L. (2012). Effect of abuse-deterrent formulation of OxyContin. New England Journal of Medicine, 367, 187-189.

Cole, J. O., Orzack, M. H., Beak, B., Bird, M., \& Bar-tal, Y. (1982). Assessment liability of buspirone in recreational sedative users. Journal of Clinical Psychiatry, 43, 69-75.

Coluzzi, F., \& Mattia , C. (2005). Oxycodone. Pharmacological profile and clinical data in chronic pain management. Minerva Anestesiol, 71, 451-460.

Comer, S. D., Ashworth, J. B., Foltin, R. W., Johanson, C. E., Zacny, J. P., \& Walsh, S. L. (2008). The role of human drug self-administration procedures in the development of medications. Drug and Alcohol Dependence, 96, 1-15.

Comer, S. D., Zacny, J.P., Dworkin, R. H., Turk, D. C., Bigelow, G. E., Foltin, R. W., et al. (2012). Outcome measures for opioid abuse liability laboratory assessment studies in humans: IMMPACT recommendations. Pain, 153, 2315-2324.

Compton, W. M., \& Volkow, N. D. (2014). Major increases in opioid analgesic abuse in the United States: concerns and strategies. Drug and Alcohol Dependence, 81, 103-107.

Coplan, P. M., Kale, H., Sandstorm, L., Landau, C., \& Chilcoat, H. D. (2013). Changes in oxycodone and heroin exposures in the National Poison Data System after introduction of extended-release oxycodone with abuse-deterrent characteristics. Pharmacoepidemiology and Drug Safety, 22, 1274-1282.

Curtis, G. B., Johnson, G. H., Tayler, C. R., O'Callaghan, B. R., \& Lacouture, P. G. (1999). Relative potency of controlled-release oxycodone and controlled-release morphine in a postoperative pain model. European Journal of Clinical Pharmacology, 55, 425-429.

DasMahapatra, P., Black, R. A., Wieman, M. S., \& Butler, S. F. (2014). Changes in prevalence of prescription opioid abuse after introduction of an abuse-deterrent opioid formulation. Pain Medicine, 15, 440-451.

Everitt, B. J., Belin, D., Economidou, D., Pelloux, Y., Dalley, J. W., \& Robbins, T. W. (2008). Neural mechanisms underlying the vulnerability to develop compulsive drug-seeking habits and addiction. Philosophical Transactions of The Royal British Society, 363, 312531-35. 
Falk, E. (1917). Eukodal, ein neues nakotikum. Munchner Medizinische Wochenschrift, 12, 381384.

Farre, M., \& Cami, J. (1991). Pharmacokinetic considerations in abuse liability evolution. British Journal of Addiction, 86, 1601-1606.

FDA. (2010). News and Events. Retrieved from U.S. Food and Drug Administration: http://www.fda.gov/NewsEvents/Newsroom/PressAnnouncements/ucm207480.htm

Fischer, B., Jones, W., Murphy, Y., Lalomiteanu, A., \& Rehm, J. (2015). Recent developments in prescription opioid-related dispensing and harm indicators in Ontario, Canada. Pain Physician, 18, E659:E662.

Fletcher, J., \& Tsuyuki, R. (2013). Don't tamper with oxycodone. Canadian Medical Association Journal, 185, 107.

Foltin, R. W., \& Fischman, M. W. (1991). Assessment of abuse liability of stimulant drugs in humans: a methodological survey. Drug and Alcohol Dependence, 28, 48.

Forman, R. F. (2003). Availability of opioids on the internet. Journal of American Medical Association, 290, 889.

Fraser, H. F., \& Isbell, H. (1960). Pharmacology and addiction liability of dl- and dpropoxyphene. Bull. Narcotics, 12, 9-14.

Fudala, P. J., \& Johnson, R. E. (2006). Development of opioid formulations with limited diversion and abuse potential. Drug and Alcohol Dependence, 83(Suppl. 1), S40-S47.

Ghodse, H., Greaves, J. L., \& Lynch, D. (1999). Evaluation of the opioid addiction test in an outpatient drug dependency unit. British journal of Psychiatry, 175, 158-161.

Gomes, T., Mamdani, M. M., Dhalla, I. A., Cornish, S., Paterson, J. M., \& Juurlink, D. N. (2014). The burden of premature opioid-related mortality. Addiction, 109, 1482-1488.

Griffiths, R. R., Bigelow, G. E., \& Ator, N. A. (2003). Principles of initial experimental drug abuse liability assessment in humans. Drug and Alcohol Dependence, 70(Suppl. 3), S41S54.

Gronlund, J., Saari, T. I., Hagelberg, N. M., Neuvonen, P. J., Olkkola, K. T., \& Laine, K. (2010). Exposure to oral oxycodone is increased by concomitant inhibition of CYP2D6 and 3A4 pathways, but not by inhibition of CYP2D6 alone. British Journal of Clinical Pharmacology, 70, 78-87.

Haertzen, C. A. (1966). Development of scales based on patterns of drug effects, using the Addiction Research Center Inventory (ARCI). Psychological Reports, 18, 163-194. 
Haertzen, C. A., Hill, H. E., \& Belleville, R. E. (1963). Development of the addiction research centre (ARCI): selection of items that are sensitive to the effects of various drugs. Psychopharmacologia, 4, 155-166.

Harris, S. C., J, P., Smith I, Shram, M. J., Colucci, S. V., Bartlett, C., et al. (2013). Abuse potential, pharmacokinetics, pharmacodynamics, and safety of intranasally administered crushed oxycodone $\mathrm{HCl}$ abuse-deterrent controlled-release tablets in recreational opioid users. The Journal of Clinical Pharmacology, 54, 468-478.

Hasin, D. S., O'Brien, C. P., Auriacombe, M., Borges, G., Bucholz, K., Budney, A., et al. (2013). DSM-5 criteria for substance use disorders: recommendations and rationale. American Journal of Psychiatry, 170, 834-851.

Havensa, J. R., Leukefelda, C. G., DeVeaugh-Geissb, A. M., Copland, P., \& Chilcoat, H. D. (2014). The impact of a reformulation of extended-release oxycodone designed to deter abuse in a sample of prescription opioid abusers. Drug and Alcohol Dependence, 139, 917.

Hays, L., Kirsh, K. L., \& Passik, S. D. (2003). Seeking drug treatment for OxyContin abuse: a chart review of consecutive admissions to a substance abuse treatment facility in Kentucky. Journal of National Comprehensive Cancer Network, 1, 423-428.

Hikida, T., Kimua, K., Wada, N., Funabiki, K., \& Nakanishi, S. (2009). Distinct roles of synaptic transmission in direct and indirect striatal pathways to reward and aversive behavior. Neuron, 63, 40-47.

Hill, H. E., Haertzen, C. A., \& Belleville, R. E. (1958). The Addiction Research Center Inventory (ARCI) Test Booklet. Lexington, Kentucky: NIMH Addiction Research Center.

Griffin, H., \& Miller, B. L. (2011). OxyContin and a regulation deficiency of the pharmaceutical industry: rethinking state-corporate crime. Critical Criminology, 19, 213.

Iwanicki, J. L., Severtson, S. G., Green, J. L., Besharat, A. C., \& Dart, R. C. (2015). Abuse deterrent reformulation of controlled-release oxycodone is associated with persistently declining rates of abuse and diversion by both oral and non-oral routes. Pain Week. Las Vegas: Radars Systems.

Jasinski, D. R., Johnson, R. E., \& Henningfield, J. E. (1984). Abuse liability assessment in human subjects. Trends in Pharmacological Science, 16, 196-200.

Johanson, C. E., \& Uhlenhuth, E. H. (1982). Drug preferences in humans. Federation Proceedings, 42, 228-233. 
Jones, J. D., Sullivan, M. A., Manubay, J., Vosburg, S. K., \& Comer, S. D. (2011). The subjective, reinforcing, analgesic effects of oxycodone in patients with chronic, nonmalignant pain who are maintained on sublingual buprenorphine/naloxone. Neuropsychopharmacology, 36, 411-422.

Katz, N., Dart, R. C., Bailey, E., Trudeau, J., Osgood, E., \& Paillard, F. (2011). Tampering with prescription opioids: nature and extent of the problem, health consequences, and solutions. The American Journal of Drug and Alcohol Abuse, 37, 205-217.

Katz, N., Fernandez, K., Chang, A., Benoit, C., \& Butler, S. F. (2008). Internet-based survey of nonmedical prescription opioid use in the United States. Clinical Journal of Pain, 24, 528-535.

Kaiko, R. F., Benziger, D. P., Fitzmartin, R. D., Burke, B. E., Reder, R. F., \& Goldenheim P. D. (1996). Pharmacokinetic-pharmacodynamic relationships of controlled-release oxycodone. Clinical Pharmacology and Therapeutics, 59, 52-61.

Klimas, R., Witticke, D., Fallah, S. E., \& Mikus, G. (2013). Contribution of oxycodone and its metabolites to the overall analgesic effect after oxycodone administration. Expert Opinion on Drug Metabolism and Toxicology, 9, 517-528.

Kravitz, A. V., Tye, L. D., \& Kreitzer, A. C. (2012). Distinct roles for direct and indirect pathway striatal neurons in reinforcement. Nature Neuroscience, 15, 816-818.

Lalovic, B., Kharasch, E., Hoffer, C., Risler, L., Lieu-Chen, L., \& Shen, D. D. (2006).

Pharmacokinetics and pharmacodynamics of oral oxycodone in healthy human subjects: role of circulating active metabolites. Clinical Pharmacology and Therapeutics, 79, 461479.

Lemberg, K. K., Heikanen, T. E., Kotinen, V. K., \& Kalso, E. A. (2009). Pharmacology of oxycodone: does it explain why oxycodone has become a bestselling strong opioid? Scandinavian Journal of Pain, 1(Suppl. 1), S18-S23.

Leow, K. P., Smith, M. T., Watt, J. A., Williams, B. E., \& Cramond, T. (1992). Comparative oxycodone pharmacokinetics in humans after intravenous, oral, and rectal administration. Therapeutic Drug Monitoring, 14, 479-484.

Lexchin, J., \& Kohler, J. C. (2011). The danger of imperfect regulation: OxyContin use in the United States and Canada. International Journal of Risk and Safety in Medicine, 23, 233240. 
Lofwall, M. R., Nuzzoc, P. A., \& Walsh, S. L. (2012). Effects of cold pressor pain on the abuse liability of intranasal oxycodone in male and female prescription opioid users. Drug and Alcohol Dependence, 123, 229-238.

Lorenzini, K. I., Daali, Y., Dayer , P., \& Desmeules, J. (2012). Pharmacokineticpharmacodynamic modelling of opioids in healthy human volunteers. Basic and Clinical Pharmacology and Toxicology, 110, 219-226.

Louizos, C., Yanez, J. A., Forrest, M. L., \& Davis, N. M. (2014). Understanding the hysteresis loop conundrum in pharmacokinetic/pharmacodynamic relationships. Journal of Pharmacy and Pharmaceutical Sciences, 17, 34-91.

Luikas, A., Hagelberg, N. M., Kuusniemi, K., Neuvanen, P. J., \& Olkkola, K. T. (2012). Inhibition of cytochrome P450 3A by clarithromycin uniformly affects the pharmacokinetics and pharmacodynamics of young and elderly volunteers. Journal of Clinical Psychopharmacology, 31, 302-308.

Mandema, J. W., Kaiko, R. F., Oshlack, B., Reder, R. F., \& Stanski, D. R. (1996). Characterization and validation of a pharmacokinetic model for controlled-release oxycodone. British Journal of Clinical Pharmacology, 42, 747-756.

Martin, W. R., Sloan, J. W., Sapira, J. D., \& Jasinski, D. R. (1971). Physiologic, subjective and behavioral effects of amphetamine, methamphetamine, ephedrine, phenmetrazine and methylphenidate in man. Clinical Pharmacology and Therapeutics, 12, 245-258.

McColl, S., \& Sellers, E. M. (2006). Research design strategies to evaluate the impact of formulations on abuse liability. Drug and Alcohol Dependence, 83(Suppl. 1), S52-S62.

McLeod, D. R., Griffiths, K. R., Bigelow, G. E., \& Yingling, J. (1982). An automated version of the digit-symbol substitution test (DSST). Behavior Methods Research Instruments and Computers, 5, 4463-4466.

McNair, D. M. (1971). Profile of Mood States. Educational and Industrial Testing Service, San Diego.

McNaughton, E. C., Coplan, P. M., Black, R. A., Weber, S. E., Chilcoat, H. D., \& Butler, S. F. (2014). Monitoring of internet forums to evaluate reactions to the introduction of reformulated OxyContin to deter abuse. Journal of Medical Internet Research, 16, e119.

Morton, T., Kostenbader, K., Montgomery, J., Devarakonda, K., Barrett, T., \& Webster, L. (2014). Comparison of subjective effects of extended-release versus immediate-release 
oxycodone/acetaminophen tablets in healthy nondependent recreational users of prescription opioids: a randomized trial. Postgraduate Medicine, 126, 20-32.

National Institute on Drug Abuse. (2014). The Science of Drug Abuse and Addiction: The Basics. Retrieved 2015, from NIDA: https://www.drugabuse.gov/publications/mediaguide/science-drug-abuse-addiction-basics

National Survey on Drug Use and Health: Summary of National Findings. (2012). Retrieved 2015, from Substance Abuse and Mental Health Services Administration: http://www.samhsa.gov/data/sites/default/files/NSDUHresults2012/NSDUHresults2012.p df

National Survey on Drug Use and Health: Summary of National Findings. (2013). Retrieved 2015, from Substance Abuse and Mental Health Services Administration: http://www.samhsa.gov/data/sites/default/files/NSDUHresultsPDFWHTML2013/Web/N SDUHresults2013.pdf

Niehaus, J. L., Cruz-Bermudez, N. D., \& Kauer, J. A. (2009). Plasticity of addiction: a mesolimbic dopamine short-circuit? American Journal of Addiction, 18, 259-271.

Office of the Chief Coroner. (2014). Number of Opioid Related Deaths by Drug 20022013. Ontario: Office of the Chief Coroner.

Ontario Public Drug Programs Division. (2012). RE: Important notice regarding change in funding status of oxycodone controlled-release tablet- (discontinuation of OxyContin and introduction of OxyNEO).

OxyNEO® Monograph. (2014). Retrieved August 2014, from http://www.purdue.ca/files/OxyNEO\%20pm\%20EN.pdf

Perrino, P., Colucci, S. V., Apseloff, G., \& Harris, S. C. (2013). Pharmacokinetics, tolerability, and safety of intranasal administration of reformulated OxyContin tablets compared with original OxyContin tablets in healthy adults. Clinical Drug Investigation, 33, 441-449.

Pinninti, N. R., Madison, H., Musser, E., \& Rissmiller, D. (2003). MINI International Neuropsychiatric Schedule: clinical utility and patient acceptance. European Psychiatry, 18, 361-364.

Pokrovnichka, A. (2008). History of OxyContin: labeling and risk management program. FDA. Portenoy, R. K., \& Savage, S. R. (1997). Clinical realities and economic considerations: special therapeutic issues in intrathecal therapy-tolerance and addiction. Journal of Pain and Symptom Management, 14(Suppl. 3), S27-S35. 
Poyhia, R., Seppala, T., Olkkola, K. T., \& Kalso, E. (1992). The pharmacokinetics and metabolism of oxycodone after intramuscular and oral administration to healthy subjects. British Journal of Clinical Pharmacology, 33, 617-621.

Preston, K. L. (1991). Drug discrimination methods in human drug abuse liability evaluation. British Journal of Addiction, 86, 1587-1594.

Purdue Pharma. (2012). Abuse Liability Clinical Study Reports. Center for Drug Evaluation and Research.

Raffa, R. B., Pergolizzi Jr, J. V., Muniz, E., Tayler Jr, R., \& Pergolizzi, J. (2012). Designing opioids that deter abuse. Pain Research and Treatment, 2012, 1-10.

Raffa, R. B. \& Pergolizzi Jr, J. V. (2010). Opioid formulations designed to resist/deter abuse. Drugs, 70, 1657-75.

Reissig, C. J., Harrison, J. A., Carter, L. P., \& Griffiths, R. R. (2015). Inhaled vs. oral alprazolam: subjective, behavioral and cognitive effects, and modesty increased abuse potential. Psychopharmacology, 232, 871-883.

Ross, F. B., \& Smith, M. T. (1997). The intrinsic antinociceptive effects of oxycodone appear to be k-opioid receptor mediated. Pain, 73, 151-157.

Samer, C. F., Daali, Y., Wagner, M., Hopfgartner, G., Rebsamen , M. C., Rossier, M. F., et al. (2010). The effects of CYP2D6 and CYP3A activities on the pharmacokinetics of immediate release oxycodone. British Journal of Pharmacology, 160, 907-918.

Schoedel, K. A., \& Sellers, E. M. (2008). Assessing abuse liability during drug development: changing standards and expectations. Clinical Pharmacology and Therapeutics, 83, 622626.

Schoedel, K. A., McMorn, S., Chakraborty, B., Potts, S. L., Zerbe, K., \& Sellers, E. M. (2011). Positive and negative subjective effects of extended-release oxymorphone versus controlled-release oxycodone in recreational opioid users. Journal of Opioid Management, 7, 179-192.

Seehan, V. D. (1998). The Mini-International Neuropsychiatric Interview (M.I.N.I): the development and validation of a structured diagnostic interview for DSM-IV and ICD-10. Journal of Clinical Psychiatry, 59(Suppl. 20), 22-23.

Sellers, E. M., Perrino, P. J., Colucci, S. V., \& Harris, S. C. (2013). Attractiveness of reformulated OxyContin ${ }^{\circledR}$ tablets: assessing comparative preferences and tampering potential. Journal of Psychopharmacology, 27, 808-816. 
Setnik, B., Roland, C. L., Cleveland, J. M., \& Webster, L. (2011). The abuse potential of Remoxy, an extended-release formulation of oxycodone compared with immediate- and extended. Pain Medicine, 12, 618-637.

Shram, M. J., Sathyan, G., Khanna, S., Tudor, J. C., Nath, R., Thipphawong, J., et al. (2010). Evaluation of the abuse potential of extended release hydromorphone versus immediate release hydromorphone. Journal of Clinical Psychopharmacology, 30, 25-33.

Shram, M., Colucci, S., harris, S., Perrino, P., Levy-Cooperman, N., Schoedel, K., et al. (2014). Pharmacokinetic-pharmacodynamic (PK/PD) analyses in the assessment of abusedeterrent opioid formulations (ADFs). College on Problems of Drug Dependence. San Juan: Altreos Research Partners.

Sloan, P. A., \& Babul, N. (2006). Extended-release opioids for the management of chonic nonmalignant pain. Expert Opinion on Drug Delivery, 3, 489-497.

Staahl, C., Upton, R., Foster, D. J., Christrup, L. L., Kristensen, K., Hansen, S. H., et al. (2008). Pharmacokinetic-pharmacodynamic modeling of morphine and oxycodone concentrations and analgesic effect in a multimodal experimental pain model. Journal of Clinical Pharmacology, 48, 619-631.

Stoops, W. W., Lile, J. A., Fillmore, M. T., Glaser, P. E., \& Rush, C. R. (2005). Reinforcing effects of methylphenidate: influence of dose and behavioral demands following drug administration. Pharmacology, 177, 349-355.

Stoops, W. W., Hatton, K. W., Lofwall, M. R., Nuzzo, P. A., \& Walsh, S. L. (2010). Intravenous oxycodone, hydrocodone, and morphine in recreational opioid users: abuse potential and relative potencies. Psychopharmacology, 212, 193-203.

Trescot, A. M., Datta, S., Lee, M., \& Hansen, H. (2008). Opioid pharmacology. Pain Physician, 11, S133-S153.

U.S. Food and Drug Administration. (2011). Approval package for: Oxecta. FDA, Center for Drug Evaluation and Research.

Vanyukov, M. M., Tarter, R. E., Kirillova, G. P., Kirischi, L., Reynolds, M. D., Kreek, M. J., et al. (2012). Common liability to addiction and "gateway hypothesis": theoretical, empiritcal and evolutionary perspective. Drug and Alcohol Dependence, 123(Suppl. 1), S3-S17.

Volkow, N. D., \& Baler, R. D. (2014). Addiction science: uncovering neurobiological complexity. Neuropharmacology, 76, 235-249. 
Volkow, N. D., \& Fowler, J. S. (2000). Addiction, a disease of compulsion and drive: involvement of the orbitofrontal cortex. Cerebral Cortex, 10, 318-325.

Volkow, N. D., Fowler, J. S., Wang, G.-J., \& Swanson, J. M. (2004). Dopamine in drug abuse and addiction: results from imaging studies and treatment implications. Molecular Psychiatry, 9, 557-569.

Volkow, N. D., \& Li, N. (2005). The neuroscience of addiction. Nature Neuroscience, 8, 14291430.

Wakefield, J. C. (2015). DSM-5 substance use disorder: how conceptual missteps weakened the foundations of the addictive disorders field. Acta Pyschiatrica Scandinavica, 1-8.

Walsh, S. L., Nuzzo, P. A., Lofwall, M. R., \& Holtman, J. R. (2008). The relative abuse liability of oral oxycodone, hydrocodone and hydromophone assessed in prescriptionopioid abusers. Drug and Alcohol Dependence, 98, 191-202.

Wasan, A. D., Butler, S. F., Budman, S. H., Fernandez, K., Weiss, R., Greenfield, S., et al. (2009). Does report of craving opioid medication predict aberrant drug behavior among chronic pain patients? Clincal Journal of Pain , 25, 193-198.

Webster, L. R. (2009). The question of opioid euphoria. Drug Discovery and Development.

Webster, L. R., Bath, B., Medve, R. A., Marmon, T., \& Stoddard, G. J. (2012). Randomized, double-blind, placebo-controlled study of the abuse potential of different formulations of oral oxycodone. Pain Medicine, 13, 790-801.

West, B. T., Welch, K. B., \& Galecki, A. T. (2014). Linear Mixed Models: A Practical Guide Using Statistical Software. Ann Arbor: CRC Press.

White, A. G., LeCates, J., BimBaum, H. G., Cheng, W., Roland, C. L., \& Mardekian, J. (2015). Positive subjective measures in abuse liability studies and real-world nonmedical use: potential impact of abuse-deterrent opioids on rates of nonmedical use and associated healthcare costs. Journal of Opioid Management, 11, 199-210.

Wilsey, B. L., Fishman, S., Li, C., Storment, J., \& Albanese, A. (2009). Markers of abuse liability of short- vs long-acting opioids in chronic pain patients: A randomized crossover trial. Pharmacology, Biochemistry and Behavior , 94, 98-107.

Wise, R. A., \& Koob, G. F. (2014). The development and maintenance of drug addiction. Neuropsychopharmacology, 39, 254-262. 
Wilsey, B. L., Fishman, S., Li, C., Storment, J., \& Albanese, A. (2009). Markers of abuse liability of short- vs long-acting opioids in chronic pain patients: a randomized cross-over trial. Pharmacology, Biochemistry and Behavior, 94, 98-107.

Wise, R. A., \& Koob, G. F. (2014). The development and maintenance of drug addiction. Neuropsychopharmacology, 39, 254-262.

Yee, D. A., Best, B. M., Atayee, R. S., \& Pesee, A. J. (2012). Observations on the urine metabolic ratio of oxymorphone to oxycodone inpain patients. Journal of Analgesia and Toxicology, 36, 232-238.

Young, A. M., Havens, J. R., \& Leukefeld, C. G. (2011). Route of administration for illicit prescription opioids: a comparison of rural and urban drug users. Harm Reduction Journal, 7, 1-7.

Young-McCaughan, S., \& Miaskowski, C. (2001). Measurement of opioid-induced sedation. Pain Management Nursing, 2, 132-149. 


\title{
$\underline{\text { Appendices }}$
}

\section{APPENDIX I}

\author{
Approval letter from CAMH REB
}

\author{
33 Russell Street \\ Toronto, Ontario \\ Canada MSS 251 \\ Tel: 416535.8501 \\ 33, rue Russell \\ Toronto (Ontario) \\ Canada MSS 251 \\ Tel z 416334,8501 \\ mww.cant.ca
}

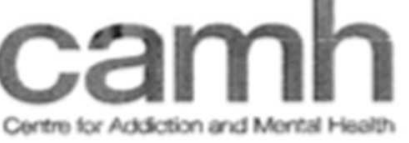

\section{PROTOCOL REFERENCE \#043/2013}

January 2, 2014

Dr. Beth Sproule, PharmD

Clinical Research Department

Centre for Addiction and Mental Health

33 Russell Strect, RS-1112

TORONTO ON MSS 2SI

Dear Dr. Sproule:

Re: Approval for research protocol w043/2013 entitled "Abuse I.iability of Controlled-Release Oxycedone Formulations" by Sproule B, Brands B, Furlan A, Smith A

We are writing to advise you that the Centre for Addietion and Mental Health Rescarch Ethics Board (CAMH RFB) has granted approval to the above-named rescarch study for a peried of one year from the date of this letter'. IF TIIE STUDY IS IXPECTED TO CONTINUR BEYOND THE RXPIRY DATE, YOU ARE RESPONSIBL.A FOR ENSURING TIE STUDY RECETVES RE-APPROVAL BY SUBMTTING THB CAMH REB "ANNUAL RENEWAL, OF ETHCS APPROVAL"

FORM ON OR BEFORE December 1.2014. Should the study be completed prior to the annual reacwal date, please subenit a "Final Report". The level of continuing review for this study is Level 2 ."

Your revised "consent form" (Version 5 - December 30, 2013); "protocol" (Version 3 - December 12, 2013) received December 30, 2013 and "advertisement" (Version date: March 1, 2013) received Abgust 17, 2013 have becn approved. Copies of consent and advertisement are attached. Subjects should receive a copy of their consent form.

Please contact Anita. Dubey, Manager, Researeh Communications at ext. 4932 prior to using any advertisemeat.

During the course of the rescarch, any significent deviations from the approved protocol (that is, any deviation which would lead to an increase in risk or a decrease in benefit to human subjects) and/or any unanticipated developments within the research should be brought to the attention of the Research Fthics Office.

Best wishes for the successful completion of your project,

$$
\text { Suman } \longrightarrow: 1 \ldots
$$

Susan Pilon, MHSc

Manager, Rescarch Ethics Office, CAMH

SP/ep

Encls

ce: Anita Dubey

Josie Chundamala

' CAMH Investigators are reminded that should they lave CAMH, they aro ropuired to inform the Rescarch Bthies Bound of the atatus of any eo-goine rosearch. If a stedty is to be closed or transforned to anseber facility, the REB must be informod and any adventivements must be discoetinoed

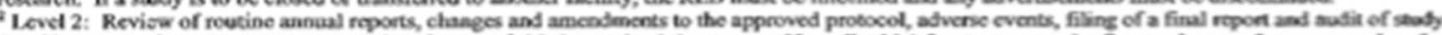
files/documcreatioe. Please retain a printed cepy of this letter (and decuments if applicable) for your recerds. Quete above refereace nember for amendments. 


\section{APPENDIX II}

\section{No Objection Letter from Health Canada}

\section{$12 / 13 / 2013 \quad 14: 57 \quad 6139529656$ \\ D.7. Heaith Sante \\ Canada Canada}

TPD-OCT

Sth Floor, Holland Cross, Tower B Address Locator \# $3105 \mathrm{~A}$ OTTAWA, Ontario K1A OK9

Dr. Andrew Smith c/o Beth Sproule, PharmD, Clinician Scientist (Pharmacy) Centre for Addiction and Mental Health 33 Russell Stroet

TORONTO, Ontario MSS 2S1

(416) 535-8501 Ext. 6501

No Objection Letter RE: Protocol \# 043-2013 (Version 2, dated 2013.09.23)

Dear Ms. Sproule:

I am pleased to inform you that the information and material to support your Clinical Trial Application for OXXCODONE, control number 169883, received on November 13, 2013, have beer reviewed and we have no objection to your proposed study. I would remind you of the necessity of complying with the Food and Drug Regulations, Division 5, in the sale of this product for clinical testing. In addition, the regulations impose record keeping responsibilities on those conducting elinieal trials. You are also reminded that all clinical trials should be conducted in compliance with the Therapeutic Products Directorate's Guideline for Good Clinical Practice.

Please note that Health Canada has implemented electronic reporting of adverse drug reactions and is currently in pilots with some sponsors. Those sponsors who have an established electronic connection with Canada Vigilance Production stream should submit their reports using the distribution nules provided to them by Health Canada, and reporting to multiple directorates is no longer required. For the sponsors who have not yet established this connection, they should continue submitting their reports to the applicable directorate by fax or by courier. The following website provides further clarification on Health Canada's adverse drug reactions reporting requirements for clinical trials: http://www.hc-sc.ge.ca/dhp-mps/alt_formats/pdf/prodpharma/applic-demande/guide-ld/ich/efficac/e2a_pr e_notice_avis-eng.pdf

Consistent with Health Canada's Notice - Registration and Disclosure of Clinical Trial Information of November 30, 2007, sponsors are encouraged to register their clinical trials within 21 days of the trial's onset, using a publiely available registry that conforms with intermational standards for registries such as: Clinicaltrials.gov (www.clinicaltrials.gov); Current Controlled Trials (www.controlled-trials.com).

Should you have any questions concerning this letter, please contact the Office of Clinical Trials (613) 941-2132.

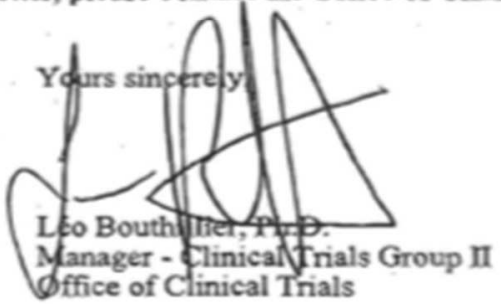

LB/en Canadä

\section{APPENDIX III}




\section{Appendix III}

Participant Telephone Pre-Screening Form

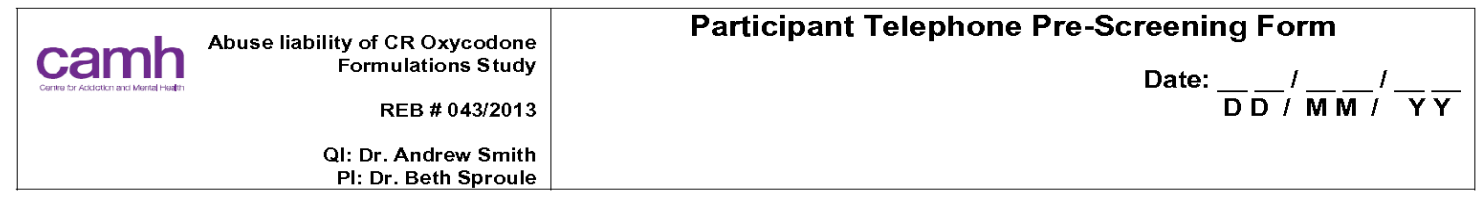

\begin{tabular}{|c|c|c|}
\hline \multicolumn{3}{|l|}{ Screening ID Number } \\
\hline \multicolumn{3}{|l|}{ Date Called (MM/DD/YYYY) } \\
\hline Call Back Required? & $\begin{array}{l}\text { Yes } \\
\text { If yes, date of call back } \\
\text { (MM/DD/YYYY) } \\
\text { 1) } \\
\text { 2) } \\
\text { 3) }\end{array}$ & No $\square$ \\
\hline $\begin{array}{l}\text { Can Leave Message for Call Back? } \\
\text { N/A }\end{array}$ & Yes $\square$ & No $\square$ \\
\hline $\begin{array}{l}\text { Good Time for Call Back? } \\
\text { N/A } \\
\text { Telephone Screening Completed? }\end{array}$ & $\begin{array}{l}\text { Yes } \\
\text { If no, reason why telept }\end{array}$ & No $\square$ \\
\hline \multicolumn{3}{|l|}{$\begin{array}{l}\text { Date Telephone Screening } \\
\text { Completed (MM/DD/YYYY) } \\
\text { N/A } \square\end{array}$} \\
\hline \multicolumn{3}{|l|}{ Telephone Script Read Yes $\square$} \\
\hline \multicolumn{3}{|l|}{ Where saw ad: } \\
\hline \multicolumn{3}{|l|}{ Eligibility Questions } \\
\hline \multicolumn{3}{|l|}{ Age: } \\
\hline \multicolumn{3}{|c|}{ Number of times opioids used in the past 12 months: } \\
\hline \multicolumn{3}{|c|}{ Number of times opioids used in the past 90 days: } \\
\hline \multicolumn{2}{|c|}{ Taking chronic pain medication regularly: } & No $\square$ \\
\hline \multicolumn{3}{|c|}{ Current usage of other recreational drugs: $\quad$ Yes $\square$} \\
\hline
\end{tabular}




\begin{tabular}{|r|r|}
\hline Formulations Study & Participant Telephone Pre-Screening Form \\
REB \# 043/2013 & $\begin{array}{r}\text { Abuse liability of CR Oxycodone } \\
\text { QI: Dr. Andrew Smith } \\
\text { PI: Dr. Beth Sproule }\end{array}$
\end{tabular}

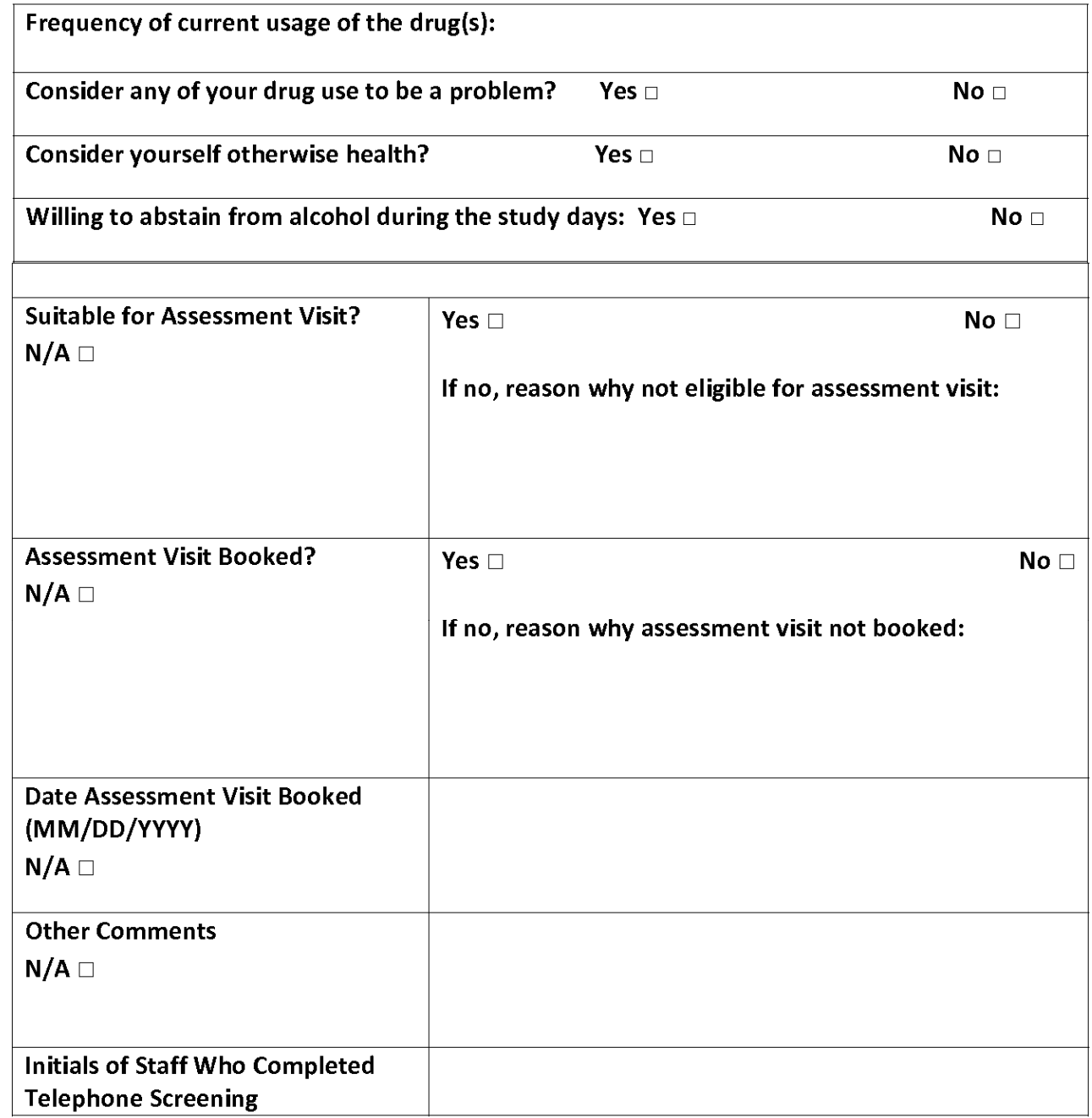




\title{
APPENDIX IV
}

\author{
Participant Information and Informed Consent Form
}

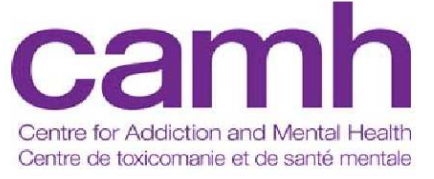

\section{Participant Information and Informed Consent}

May 5, 2014

Study Name: Abuse Liability of Controlled-Release Oxycodone Formulations

Principal Investigator: Beth Sproule, RPh, BScPhm, PharmD

Qualified Investigator: Andrew Smith, MDCM

Co-Investigators: Keyghobad Farid Araki, MD

Andrea Furlan, PhD, MD

Graduate Student:

Bijan Rafat, BSc

This study will take place at the Centre for Addiction and Mental Health 33 Russell Street site under the supervision of Dr. B. Sproule and Dr. A. Smith. This project involves experimental research and is part of the MSc graduate program of Bijan Rafat, under the supervision of Dr. B. Sproule. There will be 12 people taking part in this study.

Please take the time to read this information sheet carefully and ask any questions that you may have before deciding whether you wish to participate in this study.

You have been asked to participate because you have indicated you use opioid products recreationally, but not regularly.

\section{Study Medications}

During the course of this study you will be asked to take a single dose of study medication for 3 study days. The 3 study medications will consist of 2 different pharmaceutical formulations of controlled-release oxycodone and 1 placebo. A placebo is an inactive substance that is made to look like the other medications. The medications will look identical, and you will not know which drug you are taking on which day.

Page 1 of 7

Subject Initials

ICF Version 7, May 5, 2014 


\section{Purpose of the Study}

The purpose of the study is to determine the immediate effects of controlled-release formulations of oxycodone.

\section{Procedures}

If you agree to participate, you will first undergo an assessment to be sure you are eligible for the study and to collect general information about you. This will include questions about:

- demographics (e.g., your age, education, occupation)

- your past and present drug use

- psychiatric symptoms and history

- medical history

Also, a urine sample (for a drug screen) will be collected and a blood sample will be taken for medical screening, including a pregnancy test for women. The assessment will take approximately 2-3 hours. Once the results of the testing are available, you will be contacted to confirm eligibility and to schedule the first study day. Participating women must agree to use a medically acceptable form of birth control throughout the study.

The study itself will involve three (3) study days.

- For all of the study days, you will be asked to arrive at $\mathrm{CAMH}$ in the morning and stay for approximately 9 hours. All study days will be the same, except for the type of study medication administered.

- The study days will be a minimum of 2 days and a maximum of 21 days apart and will be scheduled according to your availability. This would mean that if your

Page 2 of 7

Subject Initials

ICF Version 7, May 5, 2014 
study day is scheduled on the $1^{\text {st }}$ of the month the next study day will be on any day from the $3^{\text {rd }}$ to $21^{\text {st }}$.of the same month.

- You will be required to miss your breakfast and to abstain from nicotine (smoking), caffeine and alcohol for 12 hours before the study session and for the 9 hour study day. Sources of caffeine include: tea, most non-clear sodas and energy drinks. If you have any questions regarding a specific beverage or food, please ask study personnel. At the start of each study day you will be asked to blow into a breathalyzer to confirm no recent alcohol consumption.

- When you arrive for the study day you will also be asked to give a urine sample for drug testing.

- You will take one dose of study medication approximately $1 / 2$ hour after arrival.

- You will be asked to complete some questionnaires and tasks on 11 occasions throughout the day: once prior to drug administration and at 1 hour post-dose, then every half-hour for 4 hours, then at 6 hours and 8 hours after taking the dose.

- A snack and lunch will be provided.

The activities and tasks during the 11 testing cycles include:

1. Vital Signs measurement. We will record your vital signs (such as breathing and heart rate) at each cycle.

2. Measurement of drug effects. A number of questions will be asked about how you are feeling to estimate the drug effects of the study medication.

(time $=5$ minutes).

3. Measurement of mood. A number of questions will be asked about how you are feeling, to estimate your current mood (time $=5$ minutes).

Page 3 of 7 
4. Measurement of hand-eye coordination. A task that requires you to substitute a number for a symbol in a pattern on the computer.

5. Measurement of the size of your pupils.

Blood samples will be taken at each of these time points as well up to 6 hours after the dose, in order to measure the drug concentrations in blood. At the start of the day an intravenous catheter will we be inserted into a vein in your arm. This will be used throughout the day to draw the blood samples without needing to poke you each time. A total of approximately $110 \mathrm{mls}$ (about 7 tablespoons) will be taken in total. One more testing cycle (without the blood draw) will be conducted at 8 hours.

After completing the final testing cycle you will have finished the study day. You will be sent home via a taxi provided by us and advised to remain at home that evening to allow the medication to fully wear off.

\section{Risks and Discomforts}

You will be required to stop smoking starting 12 hours before each study day. This may cause you some discomfort. The main physical risk would be associated with the blood draws, although this is a safe procedure, slight bruising, pain or inflammation is possible. The study medications are generally well tolerated. The most significant risk with oxycodone medication is slowed breathing if too much is taken. You will be monitored throughout the study day to ensure you are tolerating the drug. Other possible sideeffects include: itchy skin, dizziness, sleepiness, and stomach upset. Any side-effects from the single doses of medication are expected to be temporary. Study staff will help manage these side-effects as needed. You will be made aware of any new information 
that may impact your willingness to continue participating in a timely manner. Although very unlikely, if you experience a medical emergency during the course of the study, pleases contact emergency services at 911 .

Please note, because the drug may cause drowsiness, dizziness or light-headedness, it may impair your mental and/or physical ability to perform potentially hazardous tasks (e.g., driving, operating machinery). As a reminder, driving under the influence is a criminal offence and if you are caught you may be prosecuted to the full extent of the law.

\section{Benefits}

There are no direct benefits to you for participating in this study.

\section{Compensation}

In consideration of your participation you will receive $\$ 300$ for completing 3 study days at the end of your participation in the study. If you leave the study early, your compensation will be adjusted according to the number of study days completed.

\section{Voluntary Participation}

Your participation in this study is completely voluntary and you can withdraw from the study at any time and for any reason. If you decide not to participate or you decide to withdraw from the study you will not be penalized and this will not affect your current or any future care at the Centre for Addiction and Mental Health in any way. The investigators may end your involvement in the study at any time. This could be due to medical reasons or for not following study procedures.

Page 5 of 7 


\section{Confidentiality}

Your identity will be kept strictly confidential to the full extent provided by the law. All information collected during the course of this study will be kept secure and confidential and will only be made available to the researchers in this study. The data will be identified by your initials and a code number only, and not by your name. Published reports and presentations at scientific meetings will refer to only a code number or grouped data, and not a name or initial.

This study is under the authority of Health Canada because it involves evaluating a drug in a non-treatment experimental manner. Your records may therefore be assessed by the Health Canada Therapeutic Products Programme. In addition, as part of continuing review of the research, your study records may be assessed on behalf of the Research Ethics Board. A person from the research ethics team may contact you (if your contact information is available) to ask you questions about the research study and your consent to participate. The person assessing your file or contacting you must maintain your confidentiality to the extent permitted by law. Finally, as part of the Research Services Quality Assurance Program, this study may be monitored and/or audited by a member of the Quality Assurance Team. Your research records and CAMH records may be reviewed during which confidentiality will be maintained as per $\mathrm{CAMH}$ policies and to the extent permitted by law.

A description of this clinical trial will be available on http://ClinicalTrials.gov. This Web site will not include information that can identify you. At most, the Web site will include a summary of the results. You can search this website at any time.

Page 6 of 7

Subject Initials

ICF Version 7, May 5, 2014 


\section{Informed Consent}

I, have read (or had read to me) the information sheet for the study "Abuse Liability of Controlled-Release Oxycodone Formulations". The purpose of this research, the procedures and the risks associated with it have been fully explained to me. I have had the opportunity to ask questions and my questions have been answered to my satisfaction. I understand that I am able to withdraw from this study at any time and for any reason. I understand that my withdrawal from this study would in no way affect any current or future treatment at the CAMH. I voluntarily consent to participate in this research study.

I have been given a copy of this informed consent and information sheet to keep for my own records. If I have any further questions I understand that I can contact the Principal Investigator Dr. B. Sproule at (416) 535-8501 ex. 36501 or the Graduate Student, Bijan Rafat at (416) 535-8501 ex. 34448. If I have any questions or concerns of a medical nature related to the study, I may contact Dr. Andrew Smith at (416) 535-8501 ex. 36019. If I have any questions regarding my rights as a subject in this research, I may contact Dr. Padraig Darby at (416) 535-8501 ex. 6876.

Printed Name of Subject

Printed Name of Person Who Conducted Informed Consent Discussion
Signature of Subject

Date
Signature of Person Who Conducted Informed

Consent Discussion
Date 


\section{APPENDIX V}

\section{Assessment Day Form}

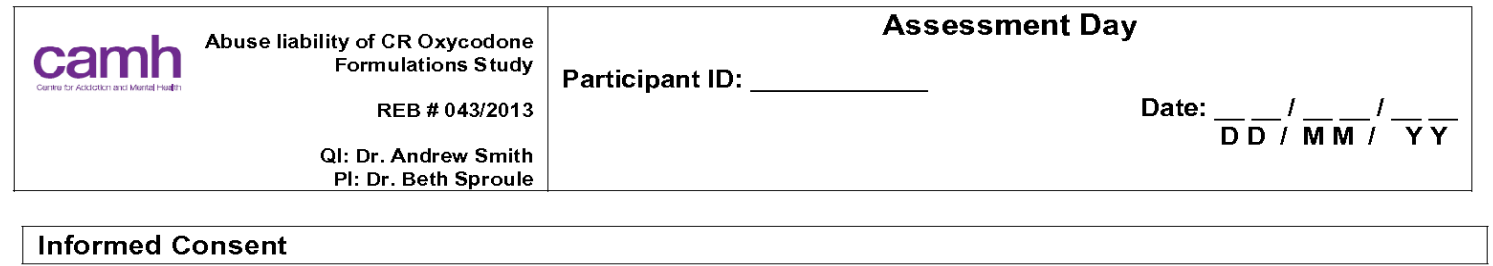

Consent Version \#/ Date: I

Consent signed and dated by research participant prior to any study related procedures: YES $\square \quad$ NO $\square$

Date/time signed:

Was a copy of the consent given to the research participant?

YES $\square \quad$ NO $\square$

Did the Research Participant demonstrate comprehension of consent form contents? YES $\square \quad$ NO $\square$

Comments:

Consent obtained by:

Print name 


\begin{tabular}{|c|c|c|c|}
\hline & Abuse liability of $C R$ Oxycodone & \multicolumn{2}{|c|}{ Assessment Day } \\
\hline & $\begin{array}{r}\text { REB \# 043/2013 } \\
\text { QI: Dr. Andrew Smith } \\
\text { PI: Dr. Beth Sproule }\end{array}$ & 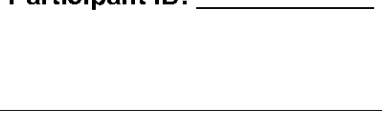 & Date: $\overline{\mathrm{D}} \overline{\mathrm{D}}^{\prime} \overline{\mathrm{M}}^{\prime} \overline{\mathrm{M}}^{\prime} \overline{\mathrm{Y}} \overline{\mathrm{Y}}$ \\
\hline
\end{tabular}

\section{Demographics}

Age: years

Gender:

$1 . \quad$ Male

2. Female

3.

Marital status:

1. Single

2. Married/Common law

3. Separated/Divorced

4. Widowed

5. $ـ$ Other (please specify):

Highest level of education completed:

1. None

2. Elementary school

3. High school

4. Technical/college/undergraduate education

5. __ Graduate/professional education or higher

Employment status:

1. Full time

2. Part time

3. Self-employed

4. Homemaker

5. $\longrightarrow$ Student

6. Retired

7. Not employed

8. —_ Other (please specify): 


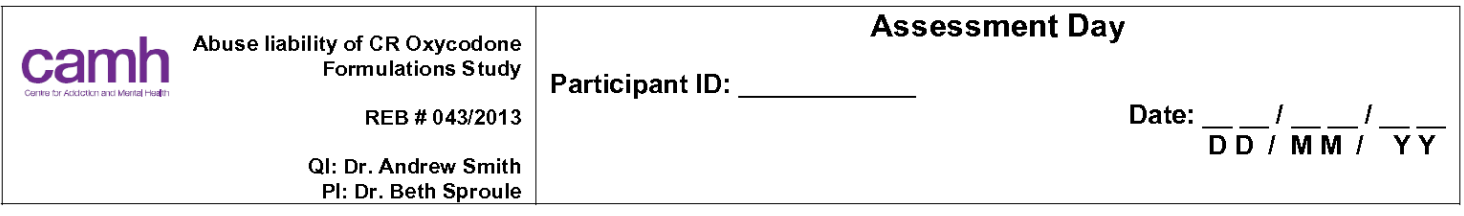

\section{Opiate Use Assessment}

Have you used opioids recreationally at least 5 times in the past year?

1.

2 .

Have you used opioids recreationally at least once in the past 90 days?

1.

2 .

When was the last time you used opioids? (Month, Year)

How often do you usually use opioids?
a)__ daily
b) 3-6 $\times$ per week
c) 1-2 $x$ per week
d) $1-2 \times$ per month
e) $\_$once per month

On the days that you use opioids, how much do you usually take?

Opioid:

Opioid:

Opioid:
Amount:

Amount:

Amount:
(\# mg, \# tablets)

(\# mg, \# tablets)

(\# mg, \# tablets)

Total mg:

What opioids have you used recreationally? Check all that apply.
a) oxycodone
b) __ hydromorphone
c) codeine
d) fentanyl
e) morphine
f) other:

Of these opioids, do you have a preference for one of them?

What methods of administration have you used? Check all that apply.
a) __ swallowed tablet
b) _ crushed and swallowed
c) crushed and snorted
d) crushed, mixed and injected
e) _ IV product injected
f) other:

Of these methods, which method of administration do you prefer? 


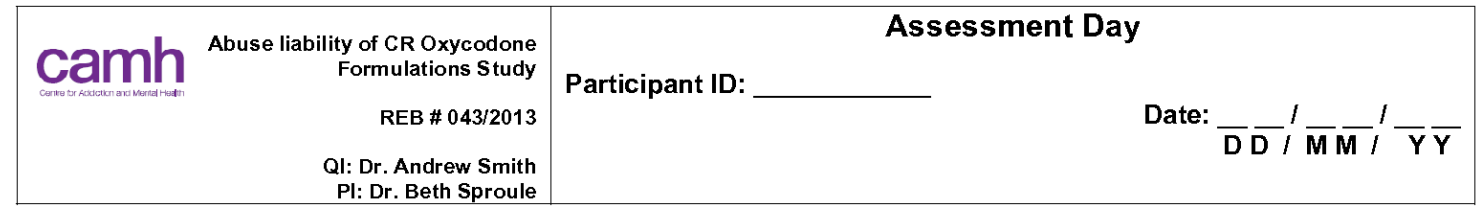

At what age did you first take an opioid for recreational use?

What is the maximum amount of an opioid you have taken on one occasion?

Opioid:

Amount

(\# mg, \# tablets) Total mg:

When was that?: (month/year)

Have you ever used opioids more frequently than you do now?

1. _ yes

2. no

If yes, how long ago? (months, years)

If yes, what is the maximum frequency you have ever used opioids?
a) daily
b) 3-6 $\mathrm{3}$ per week
c) 1-2 $\times$ per week
d) 1-2 x per month
e) $<$ once per month

\section{Other Substance Use}

\begin{tabular}{|l|l|l|l|l|l|l|}
\hline Substance & $\begin{array}{c}\text { Ever } \\
\text { Used? }\end{array}$ & $\begin{array}{c}\text { Current } \\
\text { Use? }\end{array}$ & $\begin{array}{c}\text { Amounts/ } \\
\text { Frequency }\end{array}$ & $\begin{array}{c}\text { Date/Time } \\
\text { Last Use }\end{array}$ & $\begin{array}{c}\text { Problem } \\
\text { Per Client }\end{array}$ & Comments \\
\hline Nicotine & & & & & & \\
\hline Alcohol & & & & & & \\
\hline Cannabis & & & & & & \\
\hline Cocaine & & & & & & \\
\hline Amphetamines & & & & & & \\
\hline Methylphenidate & & & & & & \\
\hline Sedatives & & & & & & \\
\hline Hallucinogens & & & & & & \\
\hline Inhalants & & & & & & \\
\hline Other: & & & & & & \\
\hline
\end{tabular}

Willing to abstain from alcohol and other substances for 12 hours before and during study days? $\square$ Yes $\square$ No 


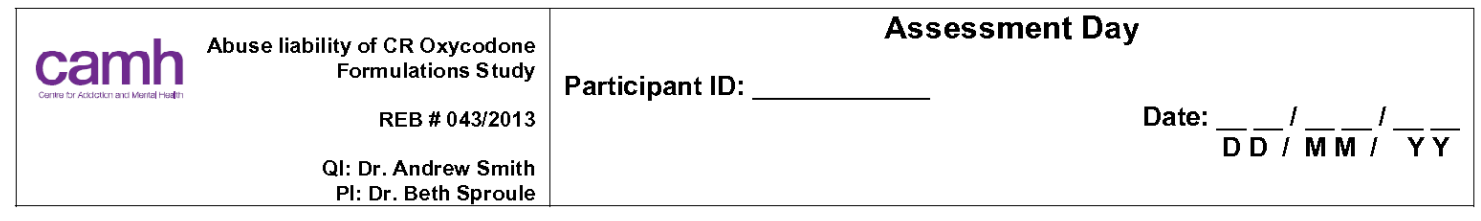

Health Conditions
Current $\square$ none
Past Major $\square$ none
a.
b.
c.
d.
e.
a.
b.
c.
d.
e.

\section{Allergies}

\section{No Known Allergies $\square$}

Medications Other

a.

b.

c.

b.

Current Medications

Regular $\square$ none
\begin{tabular}{|l|l|l|l|}
\hline & Drug & Dose \& Frequency & Last Dose \\
\hline a & & & \\
\hline b & & & \\
\hline c & & & \\
\hline d & & & \\
\hline e & & & \\
\hline
\end{tabular}

PRN $\square$ none
\begin{tabular}{|l|l|l|l|}
\hline & Drug & Dose \& Frequency & Last Dose \\
\hline a & & & \\
\hline b & & & \\
\hline c & & & \\
\hline d & & & \\
\hline e & & & \\
\hline
\end{tabular}

\section{MINI}

MINI completed $\square \quad$ No current or past Axis I psychiatric illness (except nicotine dependence) $\square$ MINI conducted by: 


\begin{tabular}{|r|r|}
\hline Formulations Study & Participant ID: \\
REB \# 043/2013 & Assessment Day \\
QI: Dr. Andrew Smith \\
PI: Dr. Beth Sproule
\end{tabular}

\section{Vitals}

$\mathrm{BP} \_\quad 1 \quad \mathrm{~mm} / \mathrm{hg}$ Temperature

(C) Pulse

beats/min Resp/min

\begin{tabular}{|c|c|c|c|c|}
\hline \multicolumn{5}{|l|}{ Review of Systems } \\
\hline & Normal & Abnormal & N/A & Details \\
\hline General & $\square$ & $\square$ & $\square$ & \\
\hline Head \& Neck & $\square$ & $\square$ & $\square$ & \\
\hline $\begin{array}{l}\text { Cardiovascular (MI, Hypertension, } \\
\text { PVD) }\end{array}$ & $\square$ & $\square$ & $\square$ & \\
\hline $\begin{array}{l}\text { Respiratory (COPD, Lung Cancer, } \\
\text { Emphysema) }\end{array}$ & $\square$ & $\square$ & $\square$ & \\
\hline Gastrointestinal (Ulcer, Acid Reflux) & $\square$ & $\square$ & $\square$ & \\
\hline Neurological (Seizures, Strokes) & $\square$ & $\square$ & $\square$ & \\
\hline Oncological & $\square$ & $\square$ & $\square$ & \\
\hline Kidney (Renal Failure) & $\square$ & $\square$ & $\square$ & \\
\hline $\begin{array}{l}\text { Hepatic (Cirrhosis, Hepatitis, } \\
\text { Gallbladder) }\end{array}$ & $\square$ & $\square$ & $\square$ & \\
\hline Musculoskeletal & $\square$ & $\square$ & $\square$ & \\
\hline Dermatological & $\square$ & $\square$ & $\square$ & \\
\hline Other & $\square$ & $\square$ & $\square$ & \\
\hline Comments & & & & \\
\hline
\end{tabular}

Birth Control (women only)

Not Applicable (male) $\square$

Are you pregnant, looking to become pregnant, or breastfeeding?

O No O Yes

Are you willing to use birth control or abstain from sexual relations for the duration of the study?

O No O Yes

Method of birth control willing to use during the study: 


\begin{tabular}{|r|r|}
\hline Formulations Study & Participant ID: \\
REB \# 043/2013 & Assessment Day \\
QI: Dr. Andrew Smith \\
PI: Dr. Beth Sproule
\end{tabular}

Sample Collection

Urine $\square$ Time:

Blood $\square$ Time:

Time Assessment Day Finished:

Physician:

Print name

$\overline{\text { Signature }} \overline{\text { Date }}$

Research Personnel:

Print name

Signature

Date 


\section{APPENDIX VI}

\section{Study Day Form}

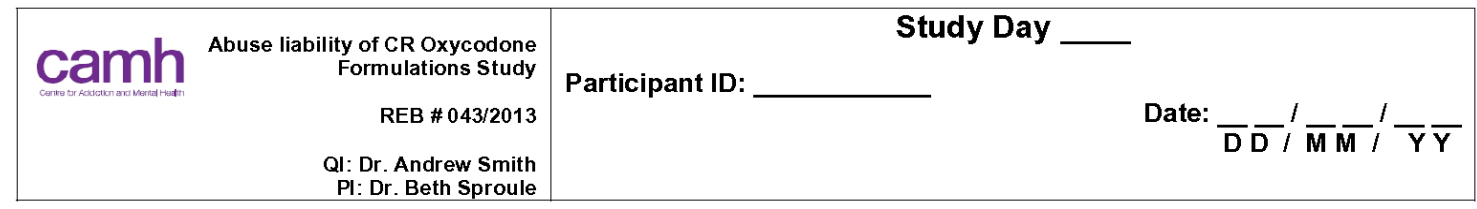

\#

Time Subject Arrived:

\begin{tabular}{|c|c|c|c|}
\hline Test & Time & Result & Comment \\
\hline Breathalyzer result & $: \quad$ ) & & \\
\hline Urine toxicology test & $(\quad: \quad)$ & $\begin{array}{l}\text { Negative } \square \\
\text { Positive } \square\end{array}$ & \\
\hline $\begin{array}{l}\text { Abstained from nicotine, alcohol } \\
\text { and caffeine in the last } 12 \text { hours }\end{array}$ & & $\begin{array}{l}\text { Yes } \square \\
\text { No } \square\end{array}$ & \\
\hline Fasted in the last 8 hours & & $\begin{array}{l}\text { Yes } \square \\
\text { No } \square\end{array}$ & \\
\hline
\end{tabular}

Adverse Event Log Reviewed: Yes $\square \quad$ Not Applicable

Baseline Cycle 1

Blood Draw Obtained: $\square$ Time: $\quad$ : $\quad$ ) +20 minutes $=$

Vital Signs Time: $(\quad: \quad)$

\begin{tabular}{|l|l|l|}
\hline & Result & Comment \\
\hline Blood pressure & & \\
\hline Temperature (Celsius) & & \\
\hline Pulse & & \\
\hline Respiratory rate & & \\
\hline Oxygen saturation & & \\
\hline
\end{tabular}

Subjective Assessment by Nurse: Time: ( : ) Initials:

\begin{tabular}{|l|l|}
\hline Assessment & Comment \\
\hline Sedation & \\
\hline $\begin{array}{l}\text { Other Adverse } \\
\text { Events / } \\
\text { Observations }\end{array}$ & \\
\hline
\end{tabular}




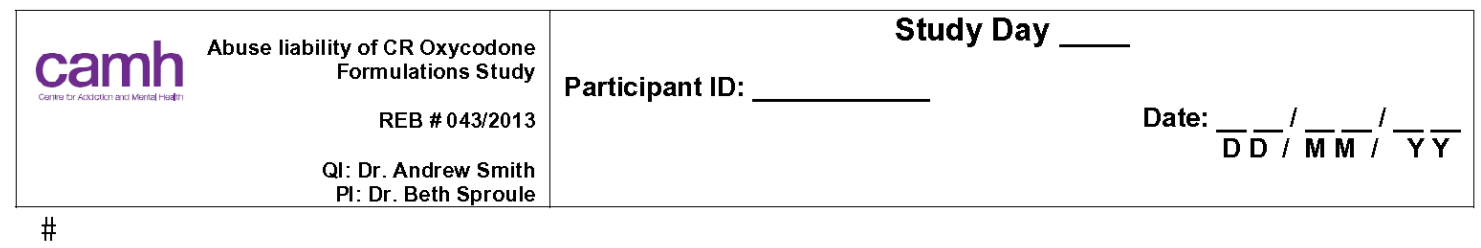

Computerized Tests: Time Started: ( : )

\begin{tabular}{|l|c|l|}
\hline Test & Completed & \\
\hline VAS & $\square$ & \\
\hline DSST & $\square$ & \\
\hline POMS & $\square$ & \\
\hline ARCI & $\square$ & \\
\hline
\end{tabular}

\begin{tabular}{|l|c|c|c|}
\hline & Time & Result & Comment \\
\hline Pupillometer $\square$ & $(1:) \quad$ & & \\
\hline
\end{tabular}

Blood Sample Centrifuged x 10 minutes: $\square$ Start Time: ( : ) Refrigerated:

Study Drug Administration: $\square$ Time: ( : ) Next Blood Draw + 1 hour: ( : )

Affix Rx Label 


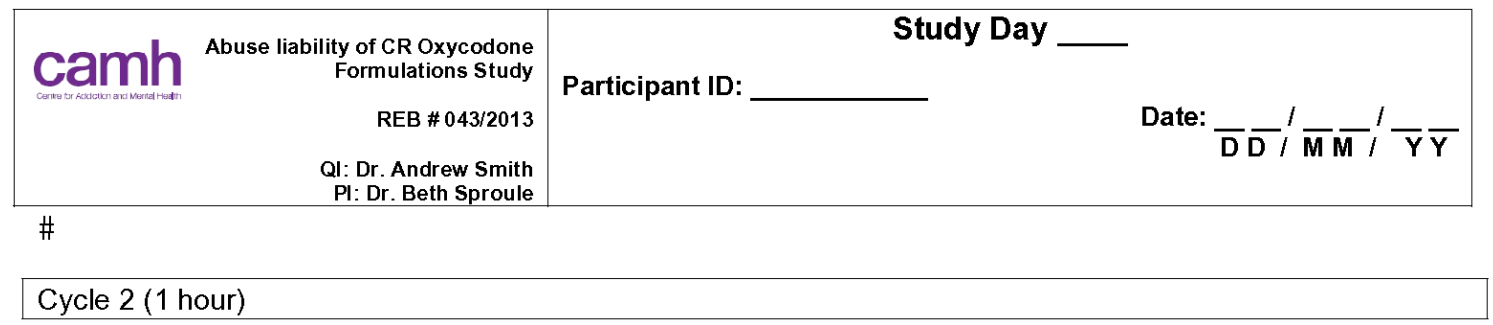

Blood Draw Obtained:

Target Time: ( : ) Actual Time: $(: \quad)+20$ minutes $=$

Vital Signs Time: $(\quad: \quad)$

\begin{tabular}{|l|l|l|}
\hline & Result & Comment \\
\hline Blood pressure & & \\
\hline Temperature (Celsius) & & \\
\hline Pulse & & \\
\hline Respiratory rate & & \\
\hline Oxygen saturation & & \\
\hline
\end{tabular}

Subjective Assessment by Nurse Time: ( : ) Initials:

\begin{tabular}{|l|l|}
\hline Assessment & Comment \\
\hline Sedation & \\
\hline $\begin{array}{l}\text { Other Adverse } \\
\text { Events / } \\
\text { Observations }\end{array}$ & \\
\hline
\end{tabular}

Computerized Tests: Time Started: ( : )

\begin{tabular}{|l|c|l|}
\hline Test & Completed & Comments \\
\hline VAS & $\square$ & \\
\hline DSST & $\square$ & \\
\hline POMS & $\square$ & \\
\hline ARCI & $\square$ & \\
\hline
\end{tabular}

\begin{tabular}{|l|c|c|c|}
\hline & Time & Result & Comment \\
\hline Pupillometer $\square$ & $(\quad: \quad)$ & & \\
\hline
\end{tabular}

Blood Sample Centrifuged x 10 minutes: $\square$ Start Time: ( $\quad$ ） Refrigerated:

Abuse Liability of CR Oxycodone Formulations Data Collection Form Study Days 2-4 Version 1

Page 3 of 16 


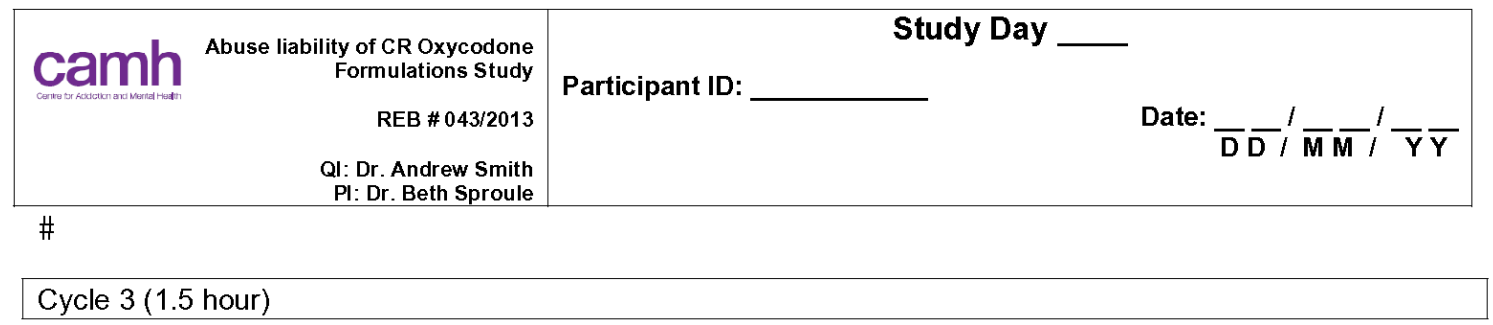

Blood Draw Obtained:

Target Time: ( : ) Actual Time: $(: \quad)+20$ minutes $=$

Vital Signs Time: $(\quad: \quad)$

\begin{tabular}{|l|l|l|}
\hline & Result & Comment \\
\hline Blood pressure & & \\
\hline Temperature (Celsius) & & \\
\hline Pulse & & \\
\hline Respiratory rate & & \\
\hline Oxygen saturation & & \\
\hline
\end{tabular}

Subjective Assessment by Nurse Time: ( : ) Initials:

\begin{tabular}{|l|l|}
\hline Assessment & Comment \\
\hline Sedation & \\
\hline $\begin{array}{l}\text { Other Adverse } \\
\text { Events / } \\
\text { Observations }\end{array}$ & \\
\hline
\end{tabular}

Computerized Tests: Time Started: ( : )

\begin{tabular}{|l|c|l|}
\hline Test & Completed & Comments \\
\hline VAS & $\square$ & \\
\hline DSST & $\square$ & \\
\hline POMS & $\square$ & \\
\hline ARCI & $\square$ & \\
\hline
\end{tabular}

\begin{tabular}{|l|c|c|c|}
\hline & Time & Result & Comment \\
\hline Pupillometer $\square$ & $(\quad: \quad)$ & & \\
\hline
\end{tabular}

Blood Sample Centrifuged x 10 minutes: $\square$ Start Time: ( $\quad$ ） Refrigerated:

Abuse Liability of CR Oxycodone Formulations Data Collection Form Study Days 2-4 Version 1

Page 4 of 16 


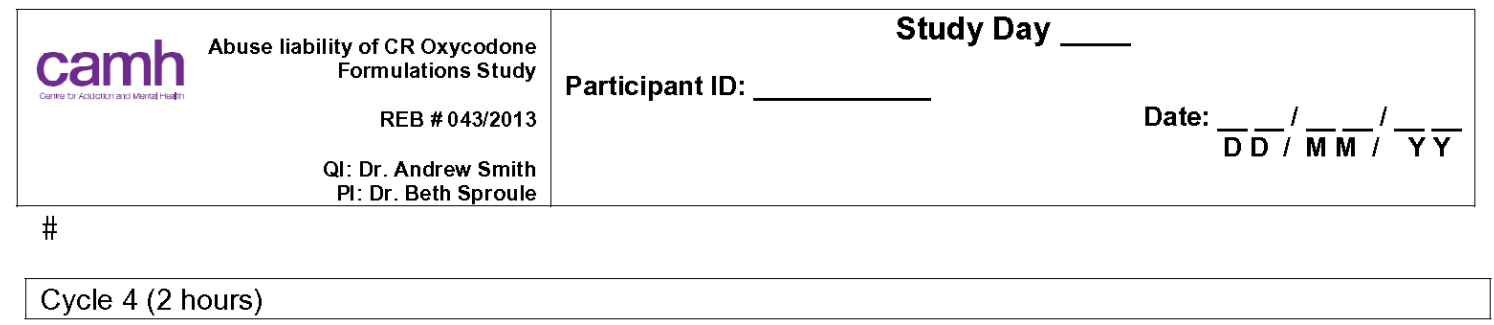

Blood Draw Obtained:

Target Time: ( : ) Actual Time: $(: \quad)+20$ minutes $=$

Vital Signs Time: $(\quad: \quad)$

\begin{tabular}{|l|l|l|}
\hline & Result & Comment \\
\hline Blood pressure & & \\
\hline Temperature (Celsius) & & \\
\hline Pulse & & \\
\hline Respiratory rate & & \\
\hline Oxygen saturation & & \\
\hline
\end{tabular}

Subjective Assessment by Nurse Time: ( : ) Initials:

\begin{tabular}{|l|l|}
\hline Assessment & Comment \\
\hline Sedation & \\
\hline $\begin{array}{l}\text { Other Adverse } \\
\text { Events / } \\
\text { Observations }\end{array}$ & \\
\hline
\end{tabular}

Computerized Tests: Time Started: ( : )

\begin{tabular}{|l|c|l|}
\hline Test & Completed & Comments \\
\hline VAS & $\square$ & \\
\hline DSST & $\square$ & \\
\hline POMS & $\square$ & \\
\hline ARCI & $\square$ & \\
\hline
\end{tabular}

\begin{tabular}{|l|c|c|c|}
\hline & Time & Result & Comment \\
\hline Pupillometer $\square$ & $(\quad: \quad)$ & & \\
\hline
\end{tabular}

Blood Sample Centrifuged x 10 minutes: $\square$ Start Time: ( $\quad$ ） Refrigerated:

Abuse Liability of CR Oxycodone Formulations Data Collection Form Study Days 2-4 Version 1

Page 5 of 16 


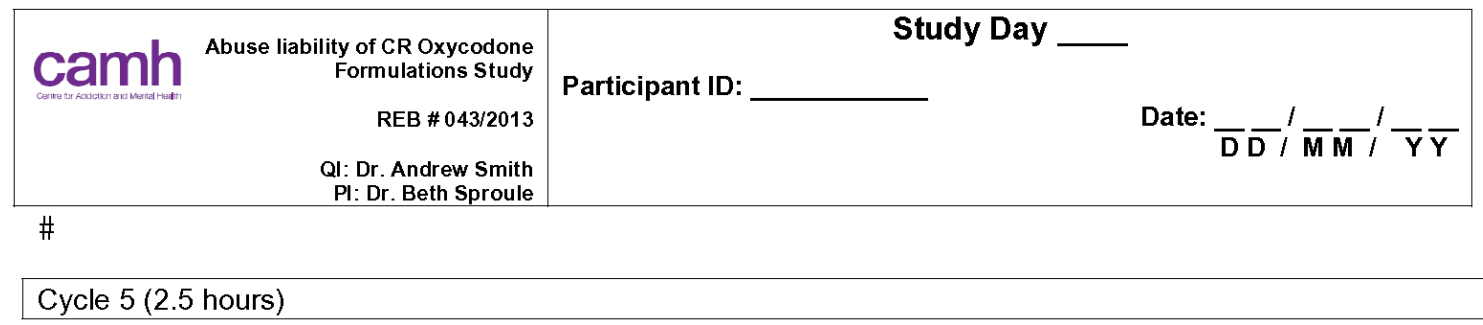

Blood Draw Obtained:

Target Time: ( : ) Actual Time: $(: \quad)+20$ minutes $=$

Vital Signs Time: $(:$ : $)$

\begin{tabular}{|l|l|l|}
\hline & Result & Comment \\
\hline Blood pressure & & \\
\hline Temperature (Celsius) & & \\
\hline Pulse & & \\
\hline Respiratory rate & & \\
\hline Oxygen saturation & & \\
\hline
\end{tabular}

Subjective Assessment by Nurse Time: ( : ) Initials:

\begin{tabular}{|l|l|}
\hline Assessment & Comment \\
\hline Sedation & \\
\hline $\begin{array}{l}\text { Other Adverse } \\
\text { Events / } \\
\text { Observations }\end{array}$ & \\
\hline
\end{tabular}

Computerized Tests: Time Started: ( : )

\begin{tabular}{|l|c|l|}
\hline Test & Completed & Comments \\
\hline VAS & $\square$ & \\
\hline DSST & $\square$ & \\
\hline POMS & $\square$ & \\
\hline ARCI & $\square$ & \\
\hline
\end{tabular}

\begin{tabular}{|l|c|c|c|}
\hline & Time & Result & Comment \\
\hline Pupillometer $\square$ & $(\quad: \quad)$ & & \\
\hline
\end{tabular}

Blood Sample Centrifuged x 10 minutes: $\square$ Start Time: ( $\quad$ ） Refrigerated:

Abuse Liability of CR Oxycodone Formulations Data Collection Form Study Days 2-4 Version 1

Page 6 of 16 


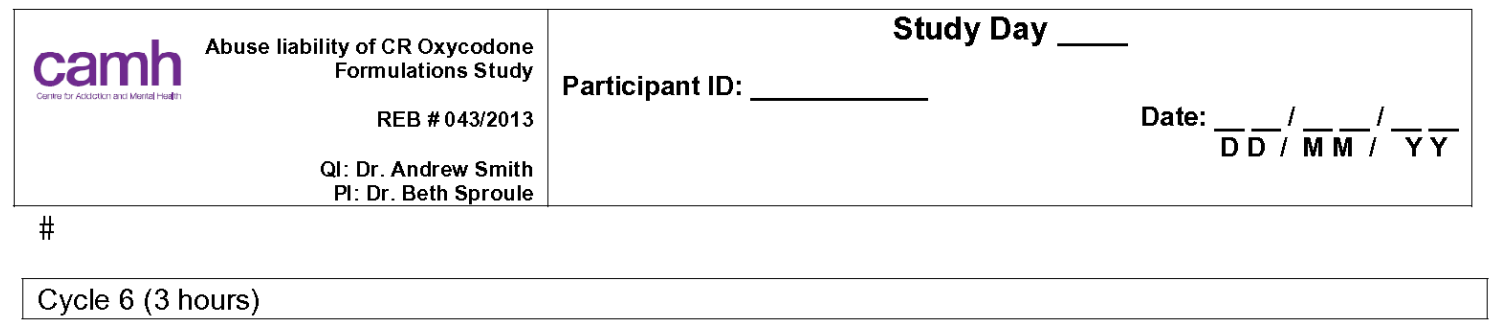

Blood Draw Obtained:

Target Time: ( : ) Actual Time: $(:)+20$ minutes $=$

Vital Signs Time: $(\quad: \quad)$

\begin{tabular}{|l|l|l|}
\hline & Result & Comment \\
\hline Blood pressure & & \\
\hline Temperature (Celsius) & & \\
\hline Pulse & & \\
\hline Respiratory rate & & \\
\hline Oxygen saturation & & \\
\hline
\end{tabular}

Subjective Assessment by Nurse Time: ( : ) Initials:

\begin{tabular}{|l|l|}
\hline Assessment & Comment \\
\hline Sedation & \\
\hline $\begin{array}{l}\text { Other Adverse } \\
\text { Events / } \\
\text { Observations }\end{array}$ & \\
\hline
\end{tabular}

Computerized Tests: Time Started: ( : )

\begin{tabular}{|l|c|l|}
\hline Test & Completed & Comments \\
\hline VAS & $\square$ & \\
\hline DSST & $\square$ & \\
\hline POMS & $\square$ & \\
\hline ARCI & $\square$ & \\
\hline
\end{tabular}

\begin{tabular}{|l|c|c|c|}
\hline & Time & Result & Comment \\
\hline Pupillometer $\square$ & $(\quad: \quad)$ & & \\
\hline
\end{tabular}

Blood Sample Centrifuged x 10 minutes: $\square$ Start Time: ( $\quad$ ） Refrigerated:

Abuse Liability of CR Oxycodone Formulations Data Collection Form Study Days 2-4 Version 1

Page 7 of 16 


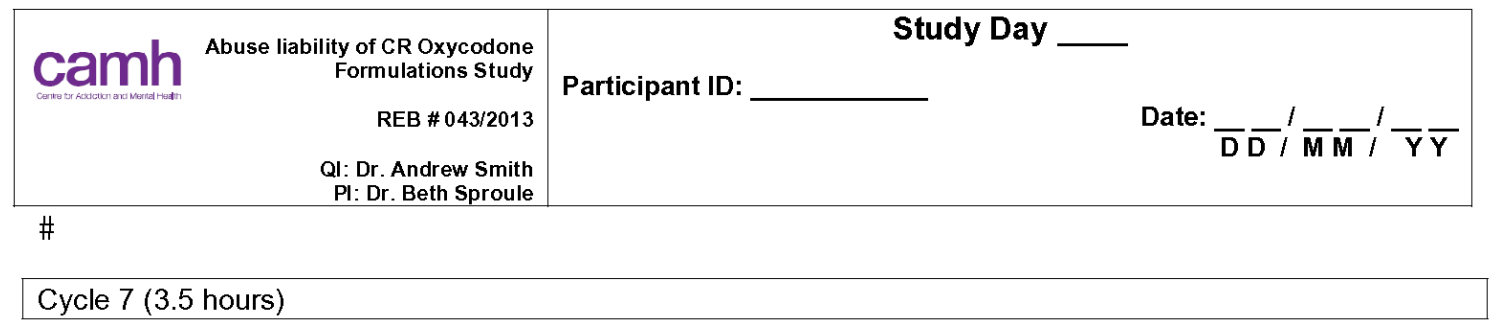

Blood Draw Obtained:

Target Time: ( : ) Actual Time: $(: \quad)+20$ minutes $=$

Vital Signs Time: $(\quad: \quad)$

\begin{tabular}{|l|l|l|}
\hline & Result & Comment \\
\hline Blood pressure & & \\
\hline Temperature (Celsius) & & \\
\hline Pulse & & \\
\hline Respiratory rate & & \\
\hline Oxygen saturation & & \\
\hline
\end{tabular}

Subjective Assessment by Nurse Time: ( : ) Initials:

\begin{tabular}{|l|l|}
\hline Assessment & Comment \\
\hline Sedation & \\
\hline $\begin{array}{l}\text { Other Adverse } \\
\text { Events / } \\
\text { Observations }\end{array}$ & \\
\hline
\end{tabular}

Computerized Tests: Time Started: ( : )

\begin{tabular}{|l|c|l|}
\hline Test & Completed & Comments \\
\hline VAS & $\square$ & \\
\hline DSST & $\square$ & \\
\hline POMS & $\square$ & \\
\hline ARCI & $\square$ & \\
\hline
\end{tabular}

\begin{tabular}{|l|c|c|c|}
\hline & Time & Result & Comment \\
\hline Pupillometer $\square$ & $(\quad: \quad)$ & & \\
\hline
\end{tabular}

Blood Sample Centrifuged x 10 minutes: $\square$ Start Time: ( $\quad$ ） Refrigerated:

Abuse Liability of CR Oxycodone Formulations Data Collection Form Study Days 2-4 Version 1

Page 8 of 16 


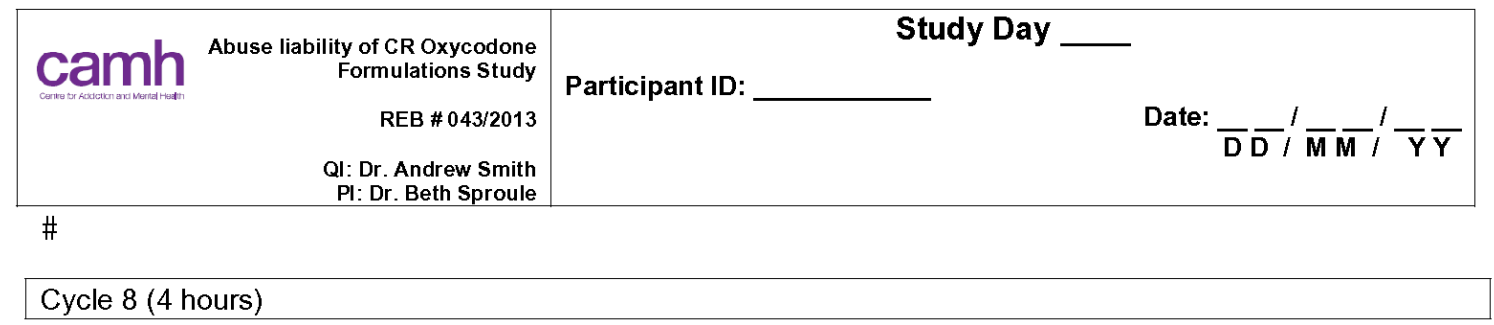

Blood Draw Obtained:

Target Time: ( : ) Actual Time: $(:)+20$ minutes $=$

Vital Signs Time: $(\quad: \quad)$

\begin{tabular}{|l|l|l|}
\hline & Result & Comment \\
\hline Blood pressure & & \\
\hline Temperature (Celsius) & & \\
\hline Pulse & & \\
\hline Respiratory rate & & \\
\hline Oxygen saturation & & \\
\hline
\end{tabular}

Subjective Assessment by Nurse Time: ( : ) Initials:

\begin{tabular}{|l|l|}
\hline Assessment & Comment \\
\hline Sedation & \\
\hline $\begin{array}{l}\text { Other Adverse } \\
\text { Events / } \\
\text { Observations }\end{array}$ & \\
\hline
\end{tabular}

Computerized Tests: Time Started: ( : )

\begin{tabular}{|l|c|l|}
\hline Test & Completed & Comments \\
\hline VAS & $\square$ & \\
\hline DSST & $\square$ & \\
\hline POMS & $\square$ & \\
\hline ARCI & $\square$ & \\
\hline
\end{tabular}

\begin{tabular}{|l|c|c|c|}
\hline & Time & Result & Comment \\
\hline Pupillometer $\square$ & $(\quad: \quad)$ & & \\
\hline
\end{tabular}

Blood Sample Centrifuged x 10 minutes: $\square$ Start Time: ( $\quad$ ） Refrigerated:

Abuse Liability of CR Oxycodone Formulations Data Collection Form Study Days 2-4 Version 1

Page 9 of 16 


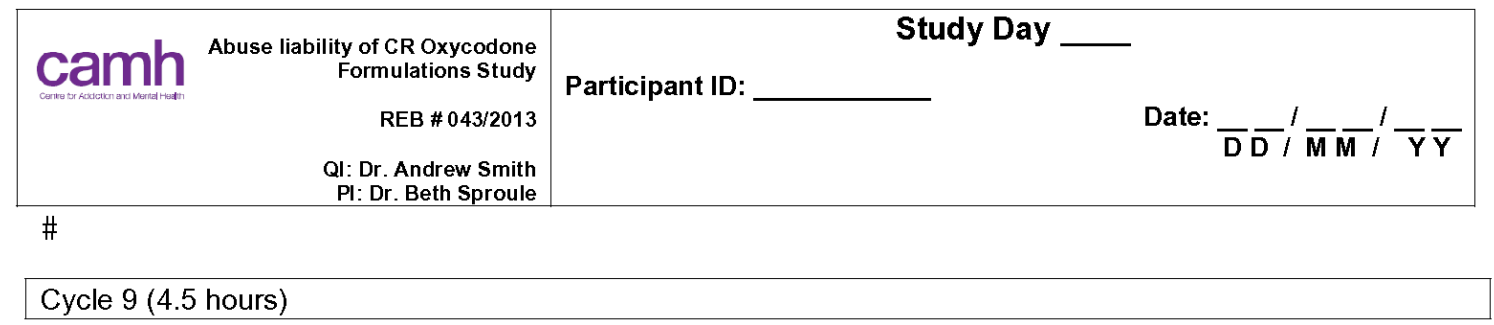

Blood Draw Obtained:

Target Time: ( : ) Actual Time: $(: \quad)+20$ minutes $=$

Vital Signs Time: $(\quad: \quad)$

\begin{tabular}{|l|l|l|}
\hline & Result & Comment \\
\hline Blood pressure & & \\
\hline Temperature (Celsius) & & \\
\hline Pulse & & \\
\hline Respiratory rate & & \\
\hline Oxygen saturation & & \\
\hline
\end{tabular}

Subjective Assessment by Nurse Time: ( : ) Initials:

\begin{tabular}{|l|l|}
\hline Assessment & Comment \\
\hline Sedation & \\
\hline $\begin{array}{l}\text { Other Adverse } \\
\text { Events / } \\
\text { Observations }\end{array}$ & \\
\hline
\end{tabular}

Computerized Tests: Time Started: ( : )

\begin{tabular}{|l|c|l|}
\hline Test & Completed & Comments \\
\hline VAS & $\square$ & \\
\hline DSST & $\square$ & \\
\hline POMS & $\square$ & \\
\hline ARCI & $\square$ & \\
\hline
\end{tabular}

\begin{tabular}{|l|c|c|c|}
\hline & Time & Result & Comment \\
\hline Pupillometer $\square$ & $(\quad: \quad)$ & & \\
\hline
\end{tabular}

Blood Sample Centrifuged x 10 minutes: $\square$ Start Time: ( $\quad$ ） Refrigerated: \begin{tabular}{ll}
\hline Abuse Liability of CR Oxycodone Formulations & Page 10 of 16 \\
Data Collection Form Study Days 2-4 Version 1 &
\end{tabular} 


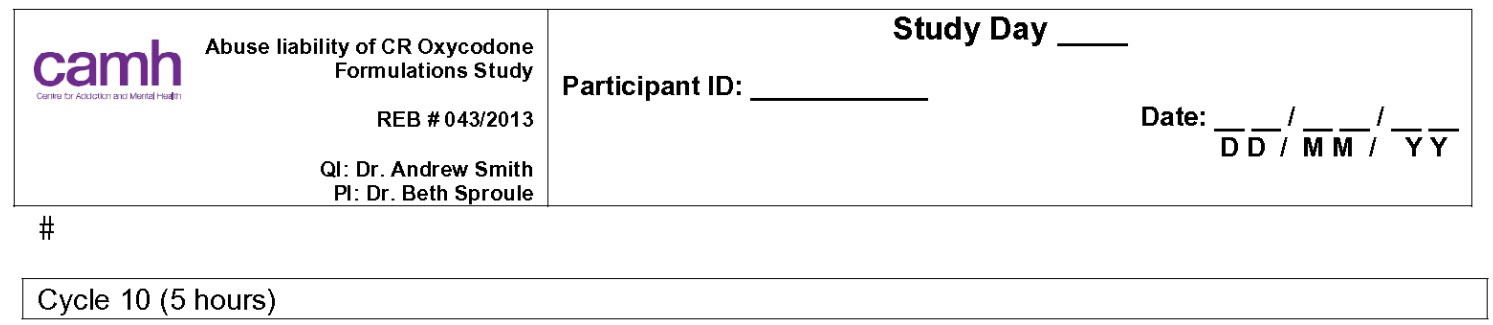

Blood Draw Obtained:

Target Time: ( : ) Actual Time: $(: \quad)+20$ minutes $=$

Vital Signs Time: $(\quad: \quad)$

\begin{tabular}{|l|l|l|}
\hline & Result & Comment \\
\hline Blood pressure & & \\
\hline Temperature (Celsius) & & \\
\hline Pulse & & \\
\hline Respiratory rate & & \\
\hline Oxygen saturation & & \\
\hline
\end{tabular}

Subjective Assessment by Nurse Time: ( : ) Initials:

\begin{tabular}{|l|l|}
\hline Assessment & Comment \\
\hline Sedation & \\
\hline $\begin{array}{l}\text { Other Adverse } \\
\text { Events / } \\
\text { Observations }\end{array}$ & \\
\hline
\end{tabular}

Computerized Tests: Time Started: ( : )

\begin{tabular}{|l|c|l|}
\hline Test & Completed & Comments \\
\hline VAS & $\square$ & \\
\hline DSST & $\square$ & \\
\hline POMS & $\square$ & \\
\hline ARCI & $\square$ & \\
\hline
\end{tabular}

\begin{tabular}{|l|c|c|c|}
\hline & Time & Result & Comment \\
\hline Pupillometer $\square$ & $(\quad: \quad)$ & & \\
\hline
\end{tabular}

Blood Sample Centrifuged x 10 minutes: $\square$ Start Time: ( $\quad$ ） Refrigerated:

\begin{tabular}{ll}
\hline Abuse Liability of CR Oxycodone Formulations & Page 11 of 16 \\
Data Collection Form Study Days 2-4 Version 1 &
\end{tabular} 


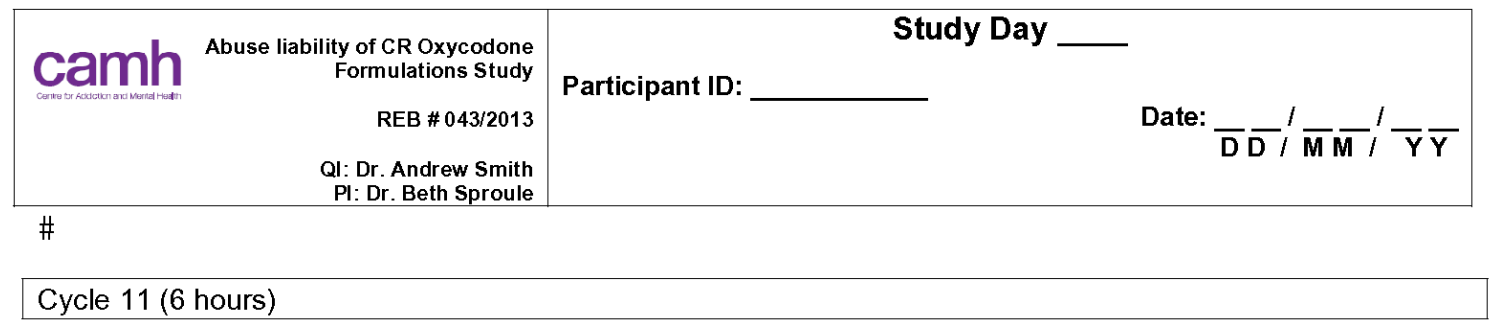

Blood Draw Obtained:

Target Time: ( : ) Actual Time: $(: \quad)+20$ minutes $=$

Vital Signs Time: $(\quad: \quad)$

\begin{tabular}{|l|l|l|}
\hline & Result & Comment \\
\hline Blood pressure & & \\
\hline Temperature (Celsius) & & \\
\hline Pulse & & \\
\hline Respiratory rate & & \\
\hline Oxygen saturation & & \\
\hline
\end{tabular}

Subjective Assessment by Nurse Time: ( : ) Initials:

\begin{tabular}{|l|l|}
\hline Assessment & Comment \\
\hline Sedation & \\
\hline $\begin{array}{l}\text { Other Adverse } \\
\text { Events / } \\
\text { Observations }\end{array}$ & \\
\hline
\end{tabular}

Computerized Tests: Time Started: ( : )

\begin{tabular}{|l|c|l|}
\hline Test & Completed & Comments \\
\hline VAS & $\square$ & \\
\hline DSST & $\square$ & \\
\hline POMS & $\square$ & \\
\hline ARCI & $\square$ & \\
\hline
\end{tabular}

\begin{tabular}{|l|c|c|c|}
\hline & Time & Result & Comment \\
\hline Pupillometer $\square$ & $(\quad: \quad)$ & & \\
\hline
\end{tabular}

Blood Sample Centrifuged x 10 minutes: $\square$ Start Time: ( $\quad$ ） Refrigerated: \begin{tabular}{ll}
\hline Abuse Liability of CR Oxycodone Formulations & Page 12 of 16 \\
Data Collection Form Study Days 2-4 Version 1 &
\end{tabular} 


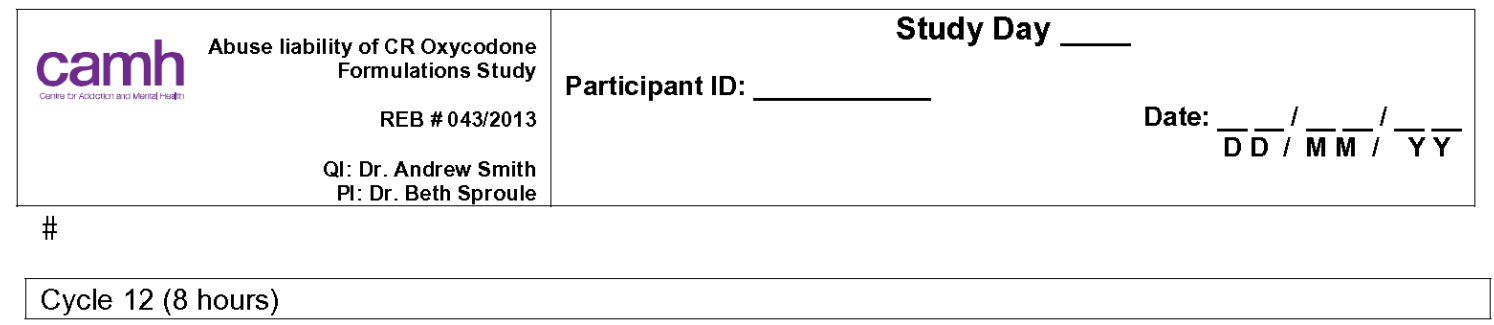

\begin{tabular}{|c|c|c|}
\hline & & \\
\hline & Result & comment \\
\hline \multicolumn{3}{|l|}{ Blood pressure } \\
\hline \multicolumn{3}{|c|}{ Temperature (Celsius) } \\
\hline \multicolumn{3}{|l|}{ Pulse } \\
\hline \multicolumn{3}{|l|}{ Respiratory rate } \\
\hline Oxygen saturation & & \\
\hline
\end{tabular}

Subjective Assessment by Nurse Time: ( : ) Initials:

\begin{tabular}{|l|l|}
\hline Assessment & Comment \\
\hline Sedation & \\
\hline $\begin{array}{l}\text { Other Adverse } \\
\text { Events / } \\
\text { Observations }\end{array}$ & \\
& \\
\hline
\end{tabular}

Computerized Tests: Time Started: ( : )

\begin{tabular}{|l|c|l|}
\hline Test & Completed & Comments \\
\hline VAS & $\square$ & \\
\hline DSST & $\square$ & \\
\hline POMS & $\square$ & \\
\hline ARCI & $\square$ & \\
\hline
\end{tabular}

\begin{tabular}{|l|c|c|c|}
\hline & Time & Result & Comment \\
\hline Pupillometer $\square$ & $\left(\begin{array}{l} \\
\end{array}\right.$ & & \\
\hline
\end{tabular}




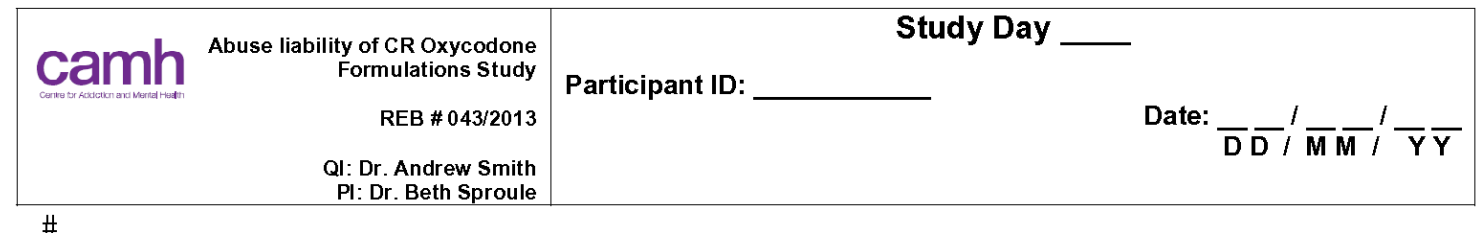

\#

Food/Beverage Consumption Throughout Study Day

\begin{tabular}{|c|c|c|c|}
\hline \multicolumn{2}{|c|}{ Time } & Description & Comments \\
\hline( & ) & & \\
\hline( & ) & & \\
\hline( & ) & & \\
\hline( & ) & & \\
\hline( & ) & & \\
\hline ( & ) & & \\
\hline
\end{tabular}

Adverse Event Log Completed

Yes

Not Applicable 


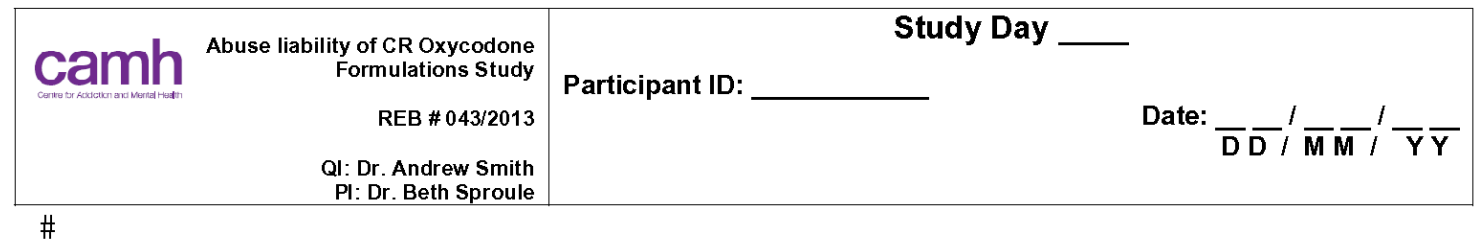

Final Assessment by Nurse

\begin{tabular}{l} 
Is the subject in a suitable condition to go home? $\square$ YES $\square$ NO \\
If not explain: \\
\hline Advised him/her to stay at home tonight $\square$ \\
The taxi is provided \\
The time he or she leaves: ( $\quad$ Taxi chit \# \\
Time : ( $\quad$ Initials:
\end{tabular}

General Comments/Observations from Day:

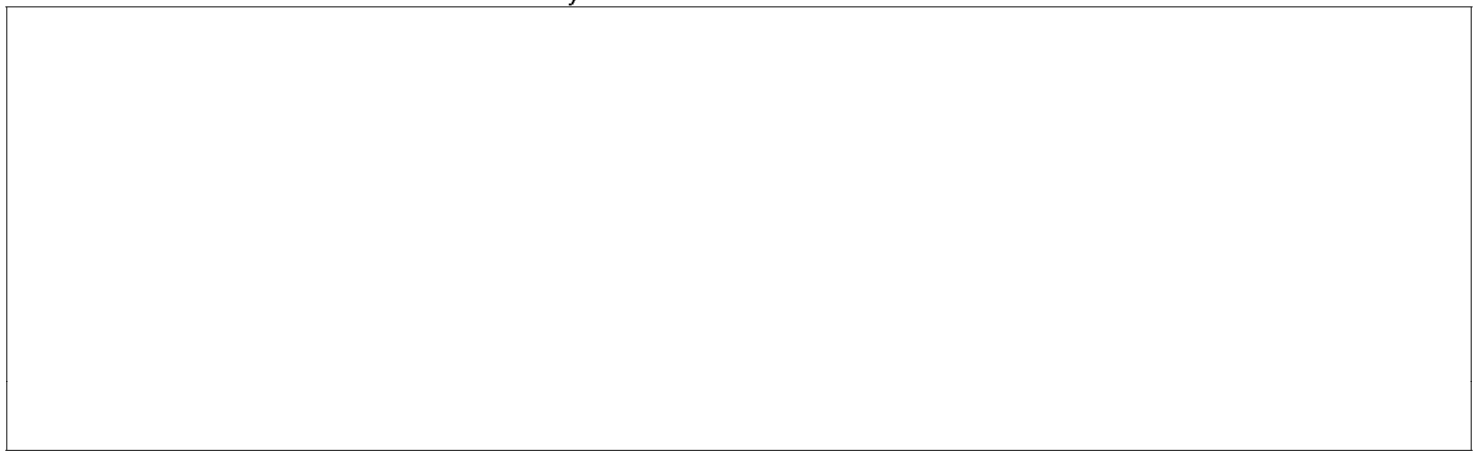

Study Day Sign Off

Nurse:

$\begin{array}{lll}\text { Signature } & & 1 \\ \text { Name } & 1\end{array}$

Abuse Liability of CR Oxycodone Formulations Data Collection Form Study Days 2-4 Version 1

Page 15 of 16 


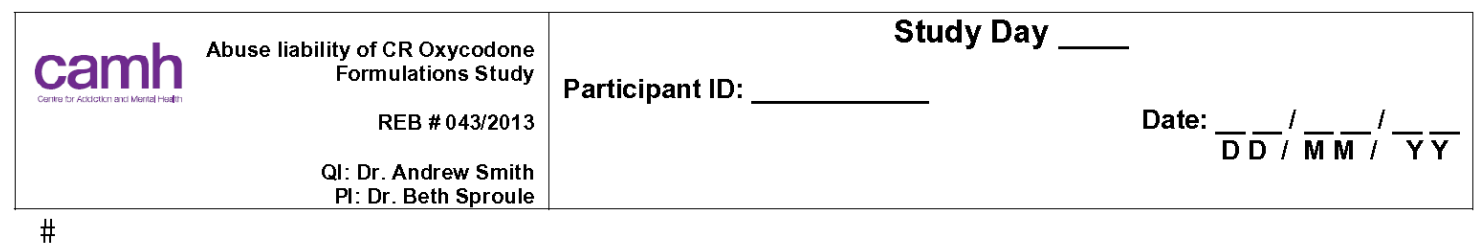

\begin{tabular}{|l|l|l|}
\hline Test & $\begin{array}{l}\text { Tick if the results attached to this form, } \\
\text { otherwise explain. }\end{array}$ & Initials \\
\hline ARCI (printouts attached) & $\square$ & \\
\hline POMS (printouts attached) & $\square$ & \\
\hline DSST (printouts attached) & $\square$ & \\
\hline VAS (printouts attached) & $\square$ & \\
\hline $\begin{array}{l}\text { Pupillometer results (printout } \\
\text { attached) }\end{array}$ & $\square$ & \\
\hline
\end{tabular}

Blood samples transported to freezer: Time: ( : )

Refrigerator Temperature:

Freezer Temperature:

\begin{tabular}{|l|l|}
\hline Cycle 1 $\square$ & Cycle 7 $\square$ \\
\hline Cycle 2 $\square$ & Cycle 8 $\square$ \\
\hline Cycle 3 $\square$ & Cycle 9 $\square$ \\
\hline Cycle 4 $\square$ & Cycle 10 $\square$ \\
\hline Cycle 5 $\square$ & Cycle 11 $\square$ \\
\hline Cycle 6 $\square$ & \\
\hline
\end{tabular}

General Comments/Observations from Day:

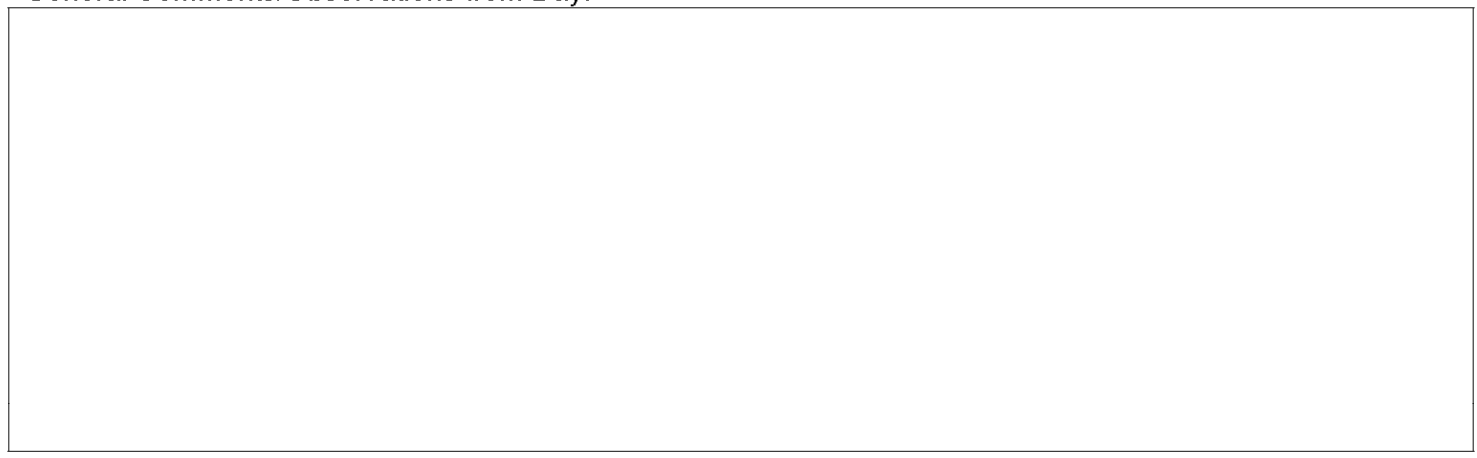

Study Day Sign Off

Study Assistant:

$\begin{array}{lll}\text { Signature } & & \frac{1}{(\mathrm{dd} / \mathrm{mm} / \mathrm{yy})}\end{array}$

